\title{
Die Wattenmeer-Lebensgemeinschaften im Königshafen von Sylt.
}

\author{
Von ERich WoHLENBerg.
}

Preuß. Marschenbauamt, Forschungs-Abt. Husum und Büsum, vorher Biolog. Anstalt auf Helgoland. (Aus der Biologischen Anstalt auf Helgoland und deren Zweiglaboratorium List auf Sylt.)

(Mit 67 Abbildungen im Text.)

\section{Inhalt.}

A. Einf ührung

Seite

I. Die Aufgabe

II. Die morphologische Gliederung

1. Die Lage zum Meer

2. Die Priele

3. Die Wattflächen

III. Zum erdgeschichtlichen Werdegang

B. Der Wasserhaushalt des Königshafens

I. Die hydrographischen Untersuchungsmethoden . . . . . . . 8

II. Das Wasser im Königshafen

1. Das Wasser im Hauptpriel

2. Das Wasser über den Wattflächen $\quad \cdot 9$

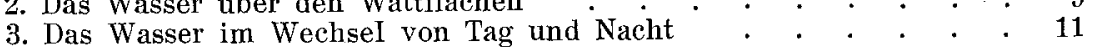

C. Die Sedimente des Königshafens

I. Die sedimentanalytische Untersuchungsmethode . . . . . . 12

II. Aufbau und Verteilung der Sedimente

1. Die Sedimente der Wattflächen

2. Die Sedimente der Prielufer und Prielböden . . . . . . . 16

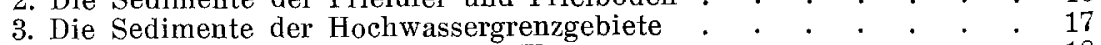

III. Das in den Sedimenten enthaltene Wasser . . . . . . . . 18

D. Der Kleine Hafen

I. Die Gliederung . • . . . . . . . . . . . . 20

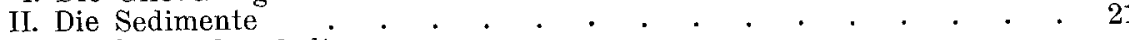

III. Der Wasserhaushalt

1. Das Wasser bei Niedrigwasser . . . . . . . . . . 22

2. Das Wasser bei Hochwasser . . . . . . . . . . . 23

E. Die Lebensgemeinschaften des Königshafens

I. Die biologische Untersuchungsmethode . . . . . . . . 23

II. Biota (= Fauna und Flora)

1. Liste der gefundenen Tierarten . . . . . . . . . . 24

2. Liste der gefundenen Pflanzenarten . . • . . . . . . 28

III. Die Standorte und ihre Besiedelung

2. Die Tonnenlegerbucht

a) Die Lage und die gestaltenden Kräfte . . . . . . . . . $\quad . \quad 29$

b) Die allgemeine Besiedelung . . . . . . . . . . . 30

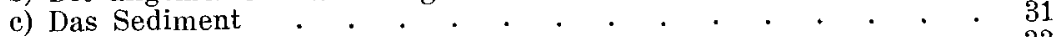

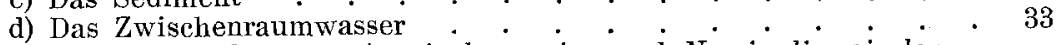

e) Die Wohndichte von Arenicola marina und Nereis diversicolor 34

$\begin{array}{llllllllllll}\text { aa) In der Tonnenlegerbucht } & \cdot & \cdot & \cdot & \cdot & \cdot & \cdot & \cdot & \cdot & \cdot & \cdot & 34 \\ \text { bb) Auf dem Mövenber } r \text { Watt } & . & . & \cdot & \cdot & \cdot & \cdot & \cdot & \cdot & \cdot & \cdot & 35\end{array}$

3. Das Uthörner Außenwatt

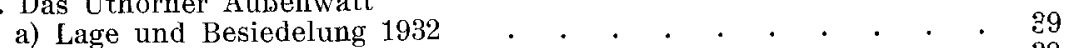

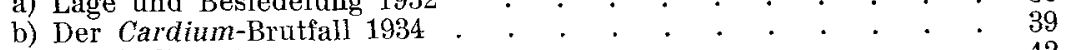

c) Das Sediment . . . . . . . . . . . . . . . . . 42

4. Das Gröning-Wat

a) Vergleich der Besiedelung zwischen 1932 und 1934 . . . . 43 


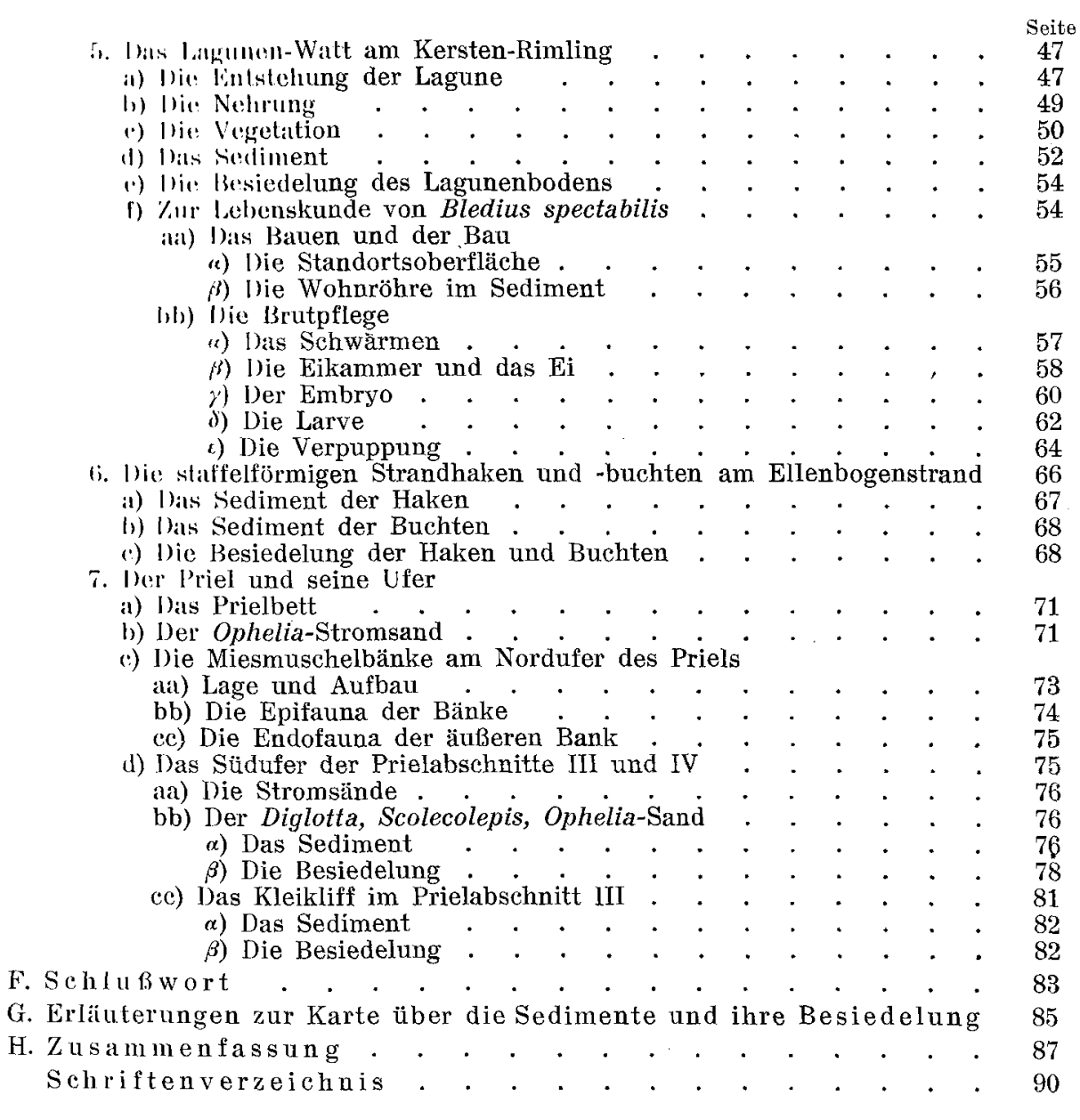

\section{A. Einführung.}

\section{Die Aufgabe.}

Im Juli 1932 wurde mir von Herrn Prof. Dr. Hagmeier, dem jetzigen Direktor der Staatl. Biologischen Anstalt auf Helgoland, die Aufgabe gestellt, die Tierwelt des Königshafens von Sylt in ihren Beziehungen zum sie umgebenden Lebensraum zu untersuchen. Der einzuschlagende Weg, nämlich die Anwendung ökologischer Untersuchungsmethoden, war mit dieser Zielsetzung von vornherein festgelegt.

Ausgerüstet mit Ratschlägen und Hinweisen von Herrn Prof. Dr. Mielck, dem derzeitigen, leider so früh verstorbenen Direktor der Anstalt, und Herrn Prof. Dr. HAgmeier siedelte ich Mitte Juli 1932 nach List auf Sylt über und bezog dort das Zweiglaboratorium der Biologischen Anstalt.

Die eigentliche Geländearbeit im Watt verteilte sich auf je drei Sommermonate der beiden Jahre 1932 und 1933. Gelegentliche Kurzbesuche auf der Insel in den Jahren 1934 bis 1936 wurden für die Nachprüfung einiger Fragen ausgenutzt.

Während mir im ersten Jahre die Arbeiten in List durch eine Unterhaltsbeihilfe aus der Friedrich Heincke-Stiftung der Biologischen Anstalt erleichtert wurden, verdanke ich für das zweite Jahr (Mai bis Juli 1933) der Notgemeinschaft der Deutschen Wissenschaft (jetzt Deutsche Forschungsgemeinschaft) eine Unterstützung zur Durchführung der Untersuchungen. Diese Beihilfen und nicht zuletzt die günstige Lage des Sylter Laboratoriums haben wesentlich zum Gelingen der Arbeiten beigetragen. Auch die Hilfsbereitschaft der Helgoländer Kollegen und der Deutschen Seewarte in Hamburg haben manche Widerstände leichter überwinden helfen. Während mir Herr Dr. MEunIer, Helgoland, bei der Bestimmung der Polychaeten mit Rat und Tat zur Seite stand, bin ich für die Bestimmung der Käfer 
Herrn Konservator L. Benick, Lübeck, und Herrn Prof. Dr. v. Lengerken, Berlin, und für Namhaftmachung der Blaualgen Herrn Prof. Dr. L. GeITLER, Wien, Dank schuldig.

Der Wasserbauamtsvorstand Husum gestattete mir jederzeit Zutritt zu den Aufzeichnungen des Lister selbstschreibenden Pegels.

Schließlich danke ich außer den soeben angeführten Personen und Behörden den Offizieren der Marine-Nachrichten-Station List und den Leitern der Deutschen Verkehrsfliegerschule List für ihr verständnisvolles Entgegenkommen bei der Untersuchung des zur Standortverwaltung gehörenden Wattgebietes und endlich den Herren DetLef DethLefs und Peter Diedrichsen in List für Auskünfte über die jüngere Vergangenheit des Untersuchungsgebietes, wobei es sich zur Hauptsache um mündliche Ueberlieferungen handelte.

Das ökologische Arbeitsziel - die Aufdeckung der Beziehungen der im Watt lebenden Tiere zum sie umgebenden Lebensraum - brachte es mit sich, daß eine Beschränkung der Arbeitsmethoden auf rein biologische nicht ausreichte, sondern daß außerdem chemische und physikalische Untersuchungen in engster Verbindung mit den biologischen notwendig waren. Darüberhinaus ist die Kenntnis vom Werdegang der von den verschiedenen Tieren bewohnten Standorte für das Verständnis des ganzen Lebensraumes von nicht nur ebenbürtiger, sondern eher größerer Bedeutung Die geschichtliche Betrachtung selbst kleinster Biotope schafft eine wesentliche Vertiefung unserer Kenntnisse von den Beziehungen zwischen Tier und Lebensraum. Sie ist d e r Faktor, den Friederichs (18a, S. 109) als bedeutsam für die biocönotische Erforschung eines Gebietes bezeichnet und den ThienEmann in der biocönotischen Forschung entbehrt, wenn er sagt, daß der Biologe auch Physiograph sein müsse (81, S. 215). Der Umstand, daß mir für die Durchführung der zahlreichen biologischen, chemischen und physikalischen Analysen keine Hilfskraft, weder im Gelände noch in den Laboratorien List und Helgoland zur Verfügung stand, hatte zwar den Vorteil, daß sämtliche Untersuchungen eng miteinander verbunden von einer Hand ausgeführt wurden und eine Trennung durch etwaige Abgabe von Untersuchungsmaterial an nicht im Gelände befindliche Dritte vermieden wurde, legte mir aber andrerseits hinsichtlich der endgültigen Lösung verschiedener biologischer Fragen eine Beschränkung auf.

Infolge meiner Berufung als biologischer Sachbearbeiter für die Landgewinnung an die neugegründeten Forschungsstellen der Westküste Schleswig-Holsteins war es mir wegen Arbeitsüberlastung bisher nicht möglich, die Ergebnisse meiner Felduntersuchungen eher dem Druck zu übergeben. Um die Veröffentlichung jedoch nicht weiter hinauszuschieben - seit meiner Geländearbeit im Königshafen sind nunmehr drei Jahre verflossen - habe ich mich trotz einiger noch nicht klargestellter, biologischer Probleme entschlossen, die im Herbst 1935 fertiggestellte Handschrift der Oeffentlichkeit zu übergeben.

Ich war von Anfang bis zu Ende meiner Untersuchungen bemüht, den Königshaf̉en als Ganzes, als einheitlichen Lebensraum innerhalb unseres deutschen Wattenmeeres zu erfassen. Bei Abschluß meiner Geländearbeiten wurde mir klar, daß die vorgenommenen Untersuchungen die Mannigfaltigkeit der im Königshafen vorliegenden biologischen und ökologischen Probleme noch nicht erschöpfend behandeln konnten. Dieses Geständnis und die nun folgenden Darlegungen mögen erweisen, daß das Königshafenwatt ein geradezu ideales Untersuchungsgebiet für ökologische Fragestellungen ist, und daß wir zusammen mit den bisherigen Arbeiten über die Tierwelt des Wattenmeeres (Wesenberg-Lund, Mortensen, Orton, Hagmeier, Kändler, Stephen, Wohlenberg, Thamdrup) noch am Anfang einer Untersuchungsrichtung stehen, die nicht allein für die Meeresökologie, sondern für die ökologische Forschungsrichtung überhaupt, einmal grundsätzliche Bedeutung erlangen dürfte.

\section{Die morphologische Gliederung.}

1. Die Lage zum Meer.

Der Königshafen ist in den letzten Jahren mehrfach Gegenstand wissenschaftlicher Erörterungen gewesen, so daß ich mich bezüglich der geographischen Lage auf diese Arbeiten, worunter besonders die Darstellungen NIENBuRG's (53) und Kolumbes $(36,37) \mathrm{zu}$ nennen sind, beziehen kann. Ich beschränke mich daher auf die Anführung der wichtigsten topographischen Punkte und lege besonderen Wert auf die Herausstellung jener Eigenschaften, die das Königshafenwatt eindeutig als einen vom Watt der Festlandsküste unterschiedlichen Typus erkennen lassen.

Sondern wir aus der der Küste vorgelagerten Wattenzone die Flußmündungen als ausgesprochene Brackwasserbereiche und die größeren Buchten der ostfriesischen Küste 
ab, so kann gesagt werden, daß der größte Teil des Wattenmeeres, nach Westen hin offen liegt. Die Flut dringt, nachdem sie durch den äußeren Kranz der Sände und Inseln in ihrer abtragenden Kraft geschwächt worden ist, in breiter Front von den Haupttiefs her über die weiten Wattflächen gegen die Küste vor. Für ihren Wasser- und Sinkstoffhaushalt ist außer der nach Westen offenen Lage vor allem die Beständigkeit der Westwinde bestimmend. In den Königshafen dagegen kann das aufkommende Wasser nur von Osten her eintreten, da die Bucht im Süden, Westen und Norden von den hohen Dünen des Listlandes bezw. des Ellenbogens eingeschlossen ist. Dadurch ist sie auch gegen alle aus diesen Richtungen wehenden Winde geschützt.

Es ist unschwer einzusehen, daB mit dieser vom offenen Meer abgewendeten Lage ein Sonderfall geschaffen ist, der das Gebiet aus dem alltäglichen Bilde der unserer Küste vorgelagerten Watten heraushebt. Manche seiner Eigenheiten in hydrographischer, geologischer und vor allem biologischer Beziehung sind dieser besonderen Lage und der damit verbundenen Morphologie zuzuschreiben.

2. Die Priele.

Südlich der Ellenbogenspitze mündet mit breitem und flachem Bett der Hauptpriel in das nordöstlich vorbeistreichende Lister Tief ein. Bei Flut schickt das Lister Tief einen kleinen Teil der von ihm geführten Wassermassen durch diesen Priel in die Bucht hinein. Während die Prielmündung eine flache Senke ist, erreicht das Prielbett weiter innen mit kerbtalartigen Einschnitten verhältnismäßig ansehnliche Tiefen (bei $\mathrm{H} \mathrm{W}$ fast 4,00 m). So besonders in den Prielabschnitten IV, IIl und II (Abb. 1). Im Abschnitt I wird das Bett wieder flacher, bis es im Prielbecken unterhalb des Grönings bei Niedrigwasser nur noch bis zu $30 \mathrm{~cm}$ Wasser führt. Nachdem bei steigendem Wasser das Prielbett aufgefüllt ist, werden die nördlich, westlich und südlich gelegenen Wattflächen ihrem für Wattverhältnisse nicht immer geringen Gefälle entsprechend ganz allmählich bestaut. In ähnlicher Weise erfolgt der Abfluß mit einsetzender Ebbe. Die außer dem Hauptpriel noch vorhandenen beiden Nebenpriele, wovon der eine als flache Senke südlich von Uthörn herumstreicht, der andere den sogenannten Kleinen Hafen ent- und bewässert und seinen Weg um die Spitze der Lister Odde (vergl. Karte Abb. 1) herumnimmt, haben für die im Tidewechsel vor sich gehende Auf- und Abfüllung der Bucht nur eine nebengeordnete Bedeutung. Für die Höhenund BewässerungsverhäItnisse um Uthörn ist die Beobachtung interessant, daß nach dem ersten Steigdrittel der Flutstrom südwestlich um Uthörn vorbeistreicht und nordwärts die Verbindung mit dem Hauptpriel herstellt. Mit diesem Vorgang ist das Watt um Uthörn allseitig vom Wasser umgeben, bis endlich bei Hochwasser nur noch Uthörn selber als schmale weiße Sichel über das Wasser emporragt. (Ueber die Beziehungen Uthörns zum ganzen Gebiet vergl. Abschnitt A. III.)

\section{Die Wattflächen.}

In diesem Abschnitt will ich nur die Unterteilung nach topographischen Gesichtspunkten anhand der Karte (Abb. 1) vornehmen. Ihre Besiedelung durch Organismen und der Aufbau ihrer Sedimente folgt weiter unten. Aus der Karte Abb. 1 entnehmen wir, daß das Uthörner- und das Odde-Watt die östlichen Grenzgebiete des Königshafens bilden. Die gestrichelt angedeutete mittlere Niedrigwasserlinie ist nicht allein eine hydrographische, sondern auch eine ausgeprägte biologische Grenze zum östlich von Sylt gelegenen offenen Wattenmeer. Oestlich dieser Linie bildet nämlich das Gebiet der Seegraswiesen (Zostera marina L., vergl. NienBurg (53) und WohlenBerg (90) den Uebergang zur Lister Austernbank "Ellenbogen", die einen Teil des Hanges zum Lister Tief einnimmt. Im Abschnitt E, III 1, sind Angaben über die unterschiedliche Besiedelung oberhalb und unterhalb dieser Linie zu finden.

Das Uthörner Watt zerfällt in einen äußeren, östlich von der Sandinsel gelegenen Teil und einen inneren, westlich von ihr umschlossenen. Das Uthörner Außenwatt liegt am tiefsten von allen Abschnitten der Bucht und hat daher die längste Ueberflutungsdauer. Das Uthörner Binnenwatt liegt etwas höher. Es liegt zwischen Uthörn und dem Prielabschnitt III und ist in morphologischer, geologischer und biologischer Beziehung eines der interessantesten Teilgebiete (vergl. E, III, 7)

Auch das Odde-Watt, womit ich das östlich der Lister Odde und nördlich des Lister Hakens gelegene Watt bezeichne, liegt ziemlich tief. Es ist hinsichtlich seines Sedimentes ein sehr wechselvoll aufgebautes Gebiet und fast überall schlecht zu begehen. 
Das Mövenberg-Watt umfaßt die größte zusammenhängende Fläche und weist nur wenig Gefälle auf. Diese Eigenschaft und auch die ziemlich gleichförmige Besiedelung hat es mit dem gegenüberliegenden Westfeuer-Watt gemeinsam. Beide gehen nach Norden bezw. nach Süden allmählich in den westwärts immer seichter werdenden Prielabschnitt I über.

Ganz im Westen liegt zwischen ihnen das Gröning-Watt, das einerseits vom Gröning selber und andererseits vom Prielbecken und den beiden Fucus-Inseln darin begrenzt wird. Das Gröning-Watt steht dem Odde-Watt an "Verkehrsfeindlichkeit" nicht viel

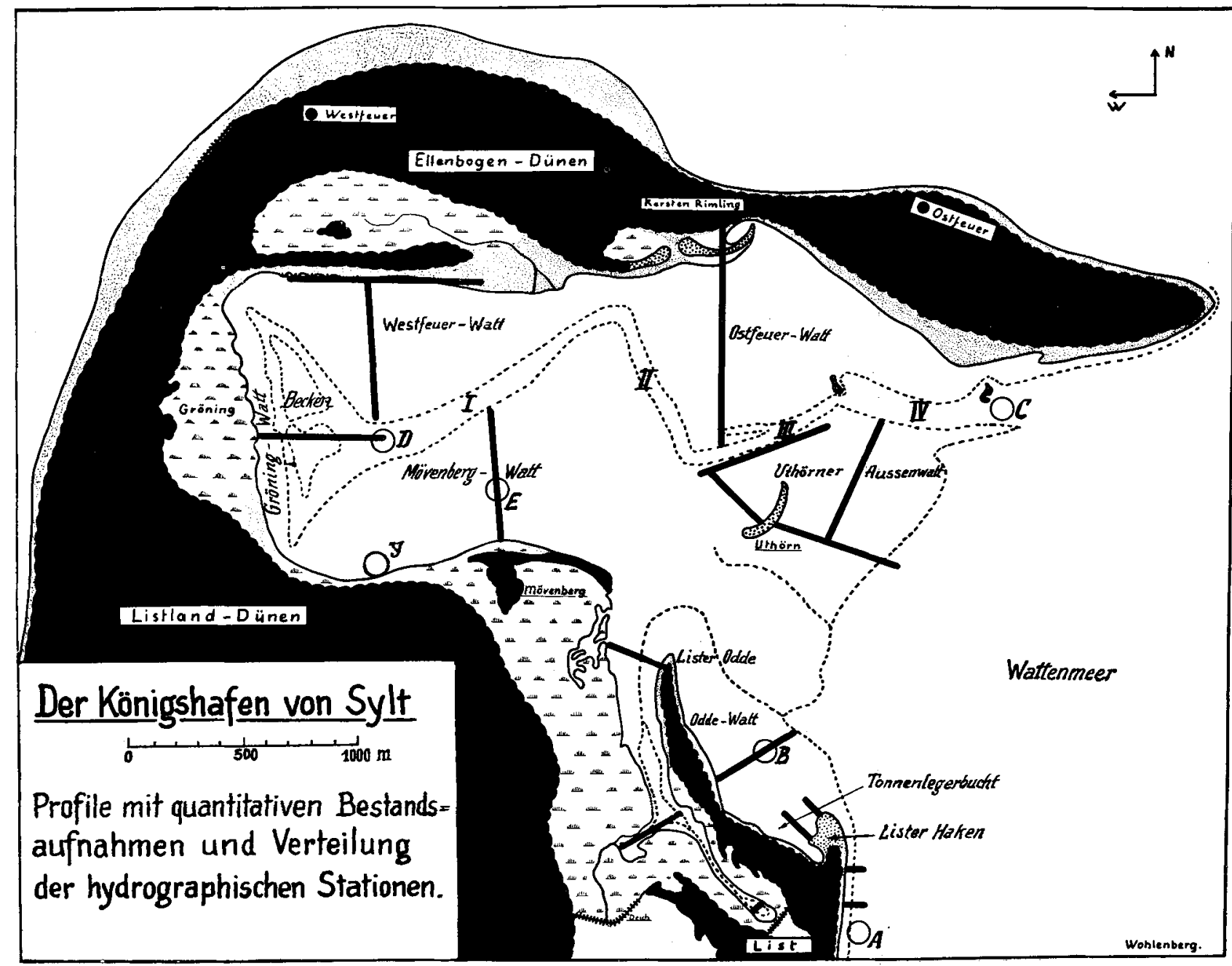

Abb. 1.

nach. Es hat außerdem von allen Teilgebieten das stärkste Gefälle, d. h. die Entfernung zwischen der Hoch- nnd Niedrigwasserlinie ist nur klein.

Eine bewegtere morphologische und biologische Gliederung zeigt das an Fläche recht beträchtliche Ostfeuerwatt. Im Westen und Süden wird es von den Prielabschnitten II bis IV und im Norden vom Kersten Rimling des Ellenbogens umschlossen. Die Gliederung des oberen Teiles wird in dem Absatz über das Lagunen-Watt eingehender besprochen (vergl. E, III, 5). Wichtige morphologische und biologische Bestandteile sind die beiden Miesmuschelbänke am Nordufer des Priels.

Schließlich sei noch der sogenannte Kleine Hafen als Einheit erwähnt. Seine Grenzen sind die Lister Odde im Osten einerseits und die Andelwiesen südlich vom Mövenberg andererseits (vergl. Abschnitt D). 


\section{Zum erdgeschichtlichen Werdegang.}

Der Werdegang des Königshafens und die Beziehungen dieses Namens zu der heute so benannten Bucht sind seit DANKWERTH durch die Jahrhunderte hindurch immer wieder Gegenstand wissenschaftlicher und volkstümlicher Erörterungen gewesen. Die Ergebnisse aller Arbeiten haben jedoch nicht ausgereicht, die mit dem Namen Königshafen verbundenen Fragen restlos zu klären. 1932 hat Kolumbe (37) mit Erfolg den Versuch unternommen, mit Hilfe der morphologischen Arbeitshypothese neues Licht auf die Entstehung der Bucht zu werfen. Ich will im Rahmen dieser Arbeit nicht im Einzelnen auf das Für und Wider der bisherigen Abhandlungen eingehen (ob Königshafen diesseits oder jenseits des Ellenbogen, ob 1644 Kriegsschauplatz oder nicht u. a.). Neue, überraschende Funde im inneren Königshafen veranlassen mich jedoch, nicht zuletzt um hiermit Anregungen für eine vorzunehmende geologische Untersuchung zu geben, aus der umfangreichen Literatur zwei oft wiederkehrende Aussagen diesem neuen Fund gegenüberzustellen. Bei ihnen handelt es sich

1. um die (übrigens durch keine exakte wissenschaftliche Untersuchung begründete) Behauptung, der Königshafen sei immer so flach wie heute gewesen (36, 37, $53 \mathrm{u}$. a.),

2. um die häufig wiederkehrende Bemerkung, daß die Bucht durch den von Westen anwehenden Flugsand immer weiter versandet $\left.{ }^{1}\right)(36,53,24)$.

Unter den neueren Arbeiten steht MAGER (45) mit seiner Ansicht, daß die jetzt mit Königshafen bezeichnete Bucht im Mittelalter eine bedeutende Tiefe gehabt habe, ziemlich allein.

Die für die ökologischen Untersuchungen notwendigen Begehungen kreuz und quer über alle Wattflächen führten mich an einem heißen, windstillen Sommertag um die Niedrigwasserzeit auch an den Hauptpriel. Das Wasser war ruhig und so klar, daß ich fast auf den Grund des Prieles sehen konnte. In der Außenkurve (Südufer) des Prielabschnittes III entdeckte ich einen mauerartig steilen Abfall zum Prielbett. Beim Waten und Tauchen wurde festgestellt, daß das den Priel einsäumende, reine Sandwatt etwa $50 \mathrm{~cm}$ unterhalb der MNW-Linie in deutlich ausgebildeten Terrassen zur Prielsohle abfiel. Das von den Terrassen und der Prielsohle (etwa 2,00 m unter MNW) geförderte Material schien zu meiner größten Ueberraschung ziemlich reiner Ton zu sein! Ich benutzte den nächsten Sturm aụs Ost, um bei NW in der Nähe des Prielabfalls ein Profil zu graben. Dabei konnte einwandfrei eine Wechsellagerung von zuerst weniger dicken, dann mächtigeren Tonschichten mit ziemlich dünnen Sandschichten festgestellt werden. An einem anderen Ostwindtag wurde die Grabung an einer anderen Stelle des Prielabschnittes III wiederholt. Sie ergab dasselbe Bild (vergl. Korngrößenanalyse Tabelle Nr. 9). Die Klei-Lagen machten keinen jungen Eindruck. Sie waren fest, sehr widerstandsfähig und einheitlich im Aufbau.

Auf eine genaue Untersuchung der Schichtenfolge im Einzelnen mußte ich mangels eines Bohrgerätes verzichten. Aus demselben Grund konnte die Feststellung der horizontalen Ausdehnung dieser feinstkörnigen Ablagerungen nicht gemacht werden. Ich begnügte mich mit dem $60 \mathrm{~cm}$ tiefen, mit dem Spaten gegrabenen Schürfloch und den Proben aus dem Prielkliff. Wieviele Jahre die Entstehung dieser Ablagerungen zurückliegt, kann ich nicht sagen. Seegrasreste konnten nachgewiesen werden, außerdem Austern- und Miesmuschelschalen.

Mit dem Nachweis dieser Ablagerungen dürfte erwiesen sein, daß zumindest der zum Prielabschnitt III gehörige Teil des Königshafens nicht immer so flach, wie er heute vor uns liegt, gewesen sein kann. Damit wäre Aussage 1 (siehe oben) erstmalig - wenn auch bisher nur für einen Teil des Gebietes - widerlegt. Der näheren Untersuchung durch den Geologen mögen weitere Angaben vorbehalten bleiben, darunter auch der Nachweis einer Aufeinanderfolge verschiedenartiger Sedimentationsperioden. Auf die Zeitabschnitte mit vorwiegend tonigen Ablagerungen wird in der jüngeren Vergangenheit eine Periode mit grobsandigen Ablagerungen gefolgt sein. Auf diese jüngere Periode gehen

1) Flor, M. R., Nachrichten von der Insel Sylt. 1758. Thottske Saml. 4, Nr. 1817. Kgl. Bibl. Kopenhagen.

BOYSEN, JENS, Beschreibung der Insel Sylt in geographischer, statistischer u. historischer Rücksicht. Schleswig 1928.

OrdemanN, W., Beiträge zur morphologischen Entwicklungsgeschichte der deutschen Nordseeküste mit besonderer Berücksichtigung der dünentragenden Inseln. Mittln, d. geogr. Ges., Jena. 1912 .

alle drei zitiert nach MAGER (45). 
die heute im Königshafen vorliegenden sandigen Oberflächensedimente zurück. Sie beherrschen das heutige Bild und führen uns damit auf die oben herausgestellte Aussage 2 über die Bedeutung des Flugsandes für die Tiefenverhältnisse der Bucht zurück.

In Anlehnung an FloHr (vergl. S. 6) und ReINkE (59) schreibe auch ich den allgemein sandigen Charakter des Königshafenwatts dem Flugsand zu. Daneben der Zufuhr bezw. Sonderung durch Strömungen und Wellenschlag. Es will mir jedoch nicht einleuchten, daß die einzeln fliegenden Sandkörnchen, wie man sie heute noch an stürmischen Tagen in die Bucht hinein wehen sieht, die mächtigen Sandablagerungen hervorgebracht haben sollen. Vielmehr denke ich neben dem fliegenden zuerst an den wandernden Sand und möchte diesen Gedanken mit der Insel Uthörn in Verbindung bringen.

So haben mir alte Lister und ihre Nachkommen erzählt, was sie von dem Aussehen Uthörns während der letzten 80 Jahre wußten. Die Aussagen stimmen darin überein, daß die jetzige Sandinsel ehemals eine ausgesprochene Düne gewesen sei. Noch vor 30 Jahren waren die letzten Helm-Horste vorhanden. Heute ist Uthörn eine vollkommen vegetationslose schmale, sichelförmige Sandinsel, die in ihrer Morphologie nichts mehr aufweist, was an das Dünenstadium erinnern könnte. Nur einen indirekten biologischen Faktor kann ich zum Verständnis mit heranziehen und einen kartographischen Vergleich, der außerdem zeigt, daß die Entwicklung Uthörns bis zum heutigen Tage nicht abgeschlossen ist. Die Dünenvegetation Uthörns soll vor wenigen Jahrzehnten noch ein sicheres und sehr ergiebiges Brutgebiet für verschiedene Strand- und Seevögel gewesen sein. Auch ich konnte 1932 und 1933 eine Anzahl Gelege der Küsten- (oder auch der Fluß-)seeschwalbe feststellen, außerdem 1 Gelege des Austernfischers und 2 der Eiderente. In beiden Jahren wurden sämtliche Gelege durch Ueberflutung der Insel vernichtet. Für die Lister bedeutet dieses Schicksal der auf Uthörn nistenden Vögel nichts Absonderliches mehr. Es wiederholt sich in jedem Jahre. Vielleicht aber darf man in dem beharrlichen Festhalten der Tiere an Uthörn als Brutstätte eine überkommene Anhänglichkeit sehen derart, daß die Insel in früheren Jahren einmal eine für die Aufzucht der Jungen bessere und sichere Gelegenheit geboten hat.

Bei dem kartographischen Vergleich kann ich - so reizvoll die Abwicklung dieser Fragestellung auch ist - des Raummangels wegen nicht auf die alten Karten zurückgreifen. Ich beschränke mich auf das Einheitsblatt des Deutschen Reiches 1:100000 und auf die von NiENBURG veröffentlichte Karte, die offenbar auch auf das Einheitsblatt zurückgeht. Auf beiden Darstellungen ist Uthörn als 800 (!) m lange Insel zu sehen. Heute mißt die von mir abgeschrittene Sandsichel keine $300 \mathrm{~m}$ mehr. (Anm. Erst nach Abschluß meiner Geländearbeit kam die neue Karte 1:25000 mit den richtigen Größen der Insel heraus). Wir sehen also, was die Insel Uthörn in den letzten 50 Jahren an Größe eingebüßt hat, und es liegt eigentlich nichts vor, was an einer ebenfalls nicht unerheblichen Veränderung in weiteren 50 Jahren grundsätzliche Zweifel aufkommen ließe. Ich bin der Ansicht, daß in ähnlicher Weise wie sich der Mövenberg von dem in Luv befindlichen Dünenmassiv losgelöst hat und bis zur Festlegung allein weitergewandert ist (REINKE, 59), auch in Uthörn entweder die Reste einer weit nordwärts hineinreichenden "Odde", oder einer ostwärts in den Königshafen eingewanderten Düne zu sehen sind. Beide Formen können nach und nach vom Wasser abgebaut worden sein.

Ich sagte schon, daß Uthörn keinerlei Vegetation und keinerlei Zeichen einer Düne mehr trägt. Wind und Vegetation haben die Herrschaft über den Sand längst an das Wasser abgetreten. Uthörn liegt heute im Springtidenbereich. Vielleicht verdankt es sein Fortbestehen bis in unsere Tage einem mit seiner Lage verbundenen Formgesetz. Lösen wir die Insel aus der soeben geschilderten, auf ihre Geschichte ausgerichteten Blickrichtung heraus und betrachten sie lediglich als heutige Gegebenheit, so ist sie eine nackte Sandbank, die der Flutstrom täglich ein wenig verändert. Die von mir in den letzten 4 Jahren gemachten Beobachtungen ergeben, daß der Flutstrom, nachdem die Prielbetten aufgefüllt sind, über das Uthörner Außenwatt in breiter Front an Uthörn heran kommt und dann beiderseits zu Norden und Süden um die Insel herumstreicht. Bei diesem Vorgang verlagern sich beide Enden der Sichel je nach der Stärke der Strömung bezw. der anderen umlagernden Kräfte westwärts. Auf die Dauer gesehen beschränkt sich diese Verlagerung natürlich nicht nur auf die Enden, sondern die Insel als Ganzes legt alljährlich einen Weg nach Westen von etwa 3 bis $4 \mathrm{~m}$ zurück. Diese Zahl verdanke ich Herrn DethLEFS, der infolge der Wanderung der Insel seine Richtbake für die Austernbank "Ellenbogen" in jedem Frühjahr um etwa diesen Betrag nach Westen versetzen muß, wenn sie auf dem Sand verbleiben soll. 
Angesichts dieser Befunde ist die Herkunft des groben Sandes im Königshafen (vergl. Blockdiagramme) nicht mehr problematisch. Sie führen uns zu der Annahme, daß die seit dem Tage ihrer Einwanderung im Wirkungsbereich der Gezeiten befindliche Düne als Ausgangspunkt der neuen, nämlich der sandigen Sedimentationsperiode anzusehen ist. Bezüglich der schlickigen Beimengungen in den groben Oberflächenablagerungen schließe ich mich Nienburas Ansicht von der überragenden Bedeutung der autochthonen Sedimentation an (53). Infolge der üppigen Besiedelung des Wattgebietes durch Pflanzen und Tiere hält dieser Vorgang der Beimengung ständig an.

Durch den Nachweis des Klei-Kliffs im zentralen Hafen im Prielabschnitt III war die Hervorhebung der beiden Fragen, nach der früheren Tiefe einerseits und der fortschreitenden Versandung andererseits berechtigt. Es wäre jetzt Sache der Geologen, diese beiden versshiedenartigen Sedimentationsperioden gegeneinander abzugrenzen und ihre im Grundsätzlichen von einander abweichenden Bedingungen räumlich, zeitlich und gebietsmäßig festzulegen, damit die verschiedenen, mehrere Jahrhunderte überdauernden Meinungen über den Werdegang des Königshafens endlich auf eine sichere Grundlage bezogen werden können.

\section{B. Der Wasserhaushalt des Königshafens.}

\section{Die hydrographischen Untersuchungsmethoden.}

Der Wasserhaushalt des Königshafens wurde im Jahre 1933 in den Monaten Mai bis Juli untersucht. Bei den hydrographischen Untersuchungen handelt es sich um die Bestimmung des Salzgehaltes, des Sauerstoffs, des Schwefelwasserstoffs, der Wasserstoffionenkonzentration und der Temperatur. Alle im folgenden mitgeteilten Werte beziehen sich auf das Oberflächenwasser.

Während der Salzgehalt nach der in der Meereskunde üblichcn Methode der Mohrschen Chlortitrierung bestimmt wurde, erfolgte die Sauerstoffbestimmung nach der Winklerschen Methode, der Schwefelwasserstoff nach Drucker (Jodverbrauch), die Reaktion des Wassers mit Hilfe eines vorher im Helgoländer Laboratorium hergestellten Standardröhrensatzes nach Mc CLENDON (92) und die Temperäturen mit dem sogenannten Normalthermometer von Richter und Wiese. Die Temperatur und die Reaktion des Wassers wurden sogleich im Gelände an Ort und Stelle bestimmt. Die Bestimmung des Sa uerstoffund Schwefelwasserstoffgehaltes wurde nach Zusatz der erforderlichen Reagenzien im Gelände nach Rückehr von den Watten abends im Laboratorium durchgeführt.

Ich bemühte mich nicht, durch Ausnützung bestimmter Wetterlagen mehr oder weniger selten auftretende Höchst- oder Mindestwerte zu erhalten. Auch vermied ich, gefundene Einzelwerte, die zu verschiedenen Zeitpunkten gemessen wurden, willkürlich einander gegenüberzustellen. Der Untersuchungsgang wurde möglichst so eingerichtet, daß das Wasser an einer Station während des Ablaufs einer ganzen Flut- oder Ebbeperiode von Stunde zu Stunde auf die verschiedenen, mir wichtig erscheinenden Eigenschaften untersucht wurde. Die in einstündigen Zwischenräumen wiederholten Meßreihen zeigten die Zusammensetzung des Wassers also inbezug auf Salzgehalt, Sauerstoff, Schwefelwasserstoff, Wasserstoffzahl und Temperatur. Besonderen Wert legte ich auf die Innehaltung gleichzeitiger Untersuchung der verschiedenen Wassereigenschaften. Erst die Gleichzeitigkeit läßt die Wechselwirkungen mit der notwendigen Schärfe erkennen. Jeweils nach Erlangen des Hochwasser- oder Niedrigwasserstandes wurden die Serien der Meßreihen abgebrochen. Wenn es mir möglich war, fügte ich an die im inneren Königshafen abgeschlossene Meßreihe am selben Tage noch eine Paralleluntersuchung des Wassers aus dem Lister Tief von der Austernbrücke an. Mit der Gegenüberstellung der Werte aus dem Königshafen einerseits und der Lister Ley andrerseits kam der Einfluß der Wattflächen auf die ${ }^{\top}$ verschiedenen Wassereigenschaften deutlich zum Ausdruck.

\section{Das Wasser im Königshafen.}

1. Das Wasser im Haupt-Priel.

Da in jedem Falle sowohl für den Priel als auch für die Wattflächen das Lister Tief die Quelle der Versorgung war, führte ich als Grundlage für die eigentlichen Prielund Wattuntersuchungen einige Meßreihen am Kopf der Austernbrücke beim Dorfe List durch.

Die während einer vollen Ebbe- und Flutperiode am Brückenkopf gefundenen Werte sind in der Tabelle 1 wiedergegeben. Sie bestätigen zum Teil die früher von NiEnBURG 
durchgeführten Messungen (53). Um die Niedrigwasserzeit, die am 13. Juni unter Mittag lag, stiegen die Sauerstoffsättigung und die Wasserstoffzahl an. Die enge Beziehung zwischen ansteigender Sauerstoffsättigung einerseits und dem $\mathrm{pH}-$ Wert andrerseits kommt auf den Wattflächen noch besser zum Ausdruck (vergl. S. 10). Angesichts der riesigen vom Lister Tief hin- und herbewegten Wassermengen könnte der Temperaturanstieg kurz nach Niedrigwasser befremden. Er wird durch die Landnähe der Entnahmestelle (Brückenkopf) zu erklären sein. Die ansteigenden Sauerstoffwerte dürften in der erhöhten Assimilationstätigkeit des pflanzlichen Planktons ihre Ursache haben und das Verhalten der $\mathrm{pH}-$ Werte aus dem durch die Assimilation beeinflußten Karbonathaushalt des Wassers zu verstehen sein. Im allgemeinen sorgen die großen Wasserumsätze im Tief für gute Durchmischung, so daß die Wassereigenschaften von verhältnismäßig beständigem Charakter sind.

Im morphologischen Abschnitt (S. 4) habe ich bereits auf die Bedeutung des Hauptpriels für die Wasserversorgnng der Bucht hingewiesen. In den nebenstehenden Tabellen 2 und 3 sind die auf den Stationen C und D des Priels gefundenen hydrographischen Werte zusammengestellt. Die Station C liegt laut Abb. 1 in der Nähe der äußeren Miesmuschelbank über der Mitte des Prielbettes, das hier. bei Hochwasser etwa 3,5 $\mathrm{m}$ tief ist. Die während der Flutperiode am 24. Juni gemessenen Werte lassen eine ausgesprochene Gleichförmigkeit erkennen. Das ist bei der kerbtalartigen Form des Prielbettes und dem nicht geringen Wasserdurchlaß in der Zeiteinheit nicht weiter verwunderlich.

An der zweiten Prielstation D am Beckenausgang, Tabelle 3, sind die Werte dagegen nicht so gleichmäßig. Auch hier liegen die Meßreihen innerhalb einer Flutperiode. Während die Temperaturwerte mit steigendem Wasser fallen, die Salzgehaltswerte gleich bleiben, zeigen Sauerstoffsättigung und Wasserstoffzahl um die Niedrigwasserzeit die höheren Werte. Da in der Stationsnähe nur vereinzelte Seegrashorste stehen, dürfte der höhere Grad der Sättigung dem Wasser zuzuschreiben sein, das aus den benachbarten höher gelegenen Fucus- und Seegrasbeständen abfließt. Schwefelwasserstoff konnte nur in Spuren nachgewiesen werden. Durch das böige Wetter wurden geringe Umlagerungen der in der Ueberflutung begriffenen Wattflächen hervorgerufen, so daß hierauf der geringe Schwefelwasserstoffgehalt zurückgeführt werden kann. Wenn die Schwankungen im Prielbecken, also im inneren Königshafen auch nicht sehr erheblich sind, so zeigten die Meßreihen der Tabelle $3 \mathrm{im}$ Vergleich zur Tabelle 2 doch, daß das noch ständig wasserführende Prielbecken auf der Höhe Mövenberg/Westfeuer einem Wasserraum mit örtlich einschneidenden Verhältnissen angehören muß. Wie weit die Wattflächen den chemischen Wasserhaushalt bestimmen, kann im nächsten Abschnitt anhand der Tabellen 4 und 5 nachgewiesen werden.

\section{Das Wasser über den Wattfläehen.}

Da auch auf den Wattflächen die Meßreihen fortlaufend während einer Tide durchgeführt werden sollten, wurde das Boot bei Hochwasser an der vorher bei Niedrigwasser gekennzeichneten Station verankert und die verschiedenen Eigenschaften des Wassers vom Hochwasserscheitel an angefangen bis zum Niedrigwasser untersucht.

Von den beiden Stationen B und E liegt die erste auf dem Odde-Watt, die zweite nördlich vom Mövenberg. Das Odde-Watt liegt bedeutend tiefer als das Mövenberg-Watt. Während mein Boot vor dem Mövenberg schon zwei Stunden nach Hochwasser trocken lag, blieb es unter der Odde über eine volle Stunde länger flott. Das Trockenfallen während der Untersuchungszeit brachte es mit sich, daß das Schöpfen der Wasserproben im unteren Abschnitt der Ebbe mit Schwierigkeiten verbunden war. Ich begnügte mich alsdann mit dem in den seichten Rinnen abfließenden Wasser. Es handelt sich also in diesen Fällen um Wasser, dessen Einzugsgebiet etwas oberhalb der Stationen B und E lag. Bei der Entnahme dieser Proben war besondere Sorgfalt notwendig. Eine Beschädigung der Wattoberfläche (Oxydationsschicht) mußte wegen der flachliegenden Reduktionszone $\left(\mathrm{H}_{3} \mathrm{~S}\right)$ unbedingt vermieden werden. Tabelle 4 zeigt bereits recht eindringlich, von welchen Schwankungen das Odde-Watt, das an der untersuchten Stelle eine mäßige Vegetation von Fucus und Zostera angustifolia aufwies, im Laufe einer Ebbeperiode betroffen ist. Im Laufe der sechsstündigen Untersuchungsdauer steigt die Wassertemperatur um etwa 10 Grad an. Entsprechend den hohen Sättigungswerten für Sauerstoff $(129 \%)$ erreicht die Wasserstoffzahl bei Niedrigwasser 8,65. Obwohl im Stationsbereich die Reduktionszone nur von einer hauchdünnen Oxydationsschicht bedeckt war, konnte Schwefelwasserstoff nur einmal (5. Meßreihe, $15 \mathrm{Uhr} 30$ Minuten) in geringen Spuren nachgewiesen werden. Ob die Spuren von $\mathrm{H}_{2} \mathrm{~S}$ (in den Tabellen mit $\mathrm{Sp}$ bezeichnet) auf nicht wahrnehmbare Störungen in der 
Sedimentoberfläche bei der Probeentnahme zurückzuführen oder ob das Gas wirklich im Wasser gelöst vorhanden war, ist mit Sicherheit nicht zu sagen.

In noch stärkerem Maße traten laut Tab. 5 die hydrochemischen Veränderungen am 19. Juli auf dem Mövenberg-Watt auf. Die Sauerstoffsättigung steigt mit fallendem Wasser von $13 \mathrm{Uhr} 30$ bis $15 \mathrm{Uhr}$ von $147 \%$ auf $238 \%$. Erst am Spätnachmittag sinken die Sättigungswerte auf den Hochwasser-Ausgangswert zurück. Trotzdem beträgt um diese Zeit die Wasserstoffzahl noch 9,10. Es entzieht sich meiner Kenntnis, inwiefern ein Nachhinken der pH-Zahl durch den stark beeinflußten Karbonathaushalt bedingt ist. Die sehr hohen Sauerstoffwerte sind auf die im weiteren Bereich der Station E in üppiger Ausbildung vorhandenen Zostera nana- und angustifolia- sowie Fucus-Bestände zurückzuführen.

Tabelle 1.

\begin{tabular}{|c|c|c|c|c|c|c|c|}
\hline & $\begin{array}{l}\text { Station } \\
\text { Watum } \\
\text { atteru }\end{array}$ & & $\begin{array}{l}\text { Ister Tie } \\
\text { 3. Juni } \\
\text { nnig, w }\end{array}$ & $\begin{array}{l}\text { f, Auste } \\
1933 \\
\text { arm }\end{array}$ & nbrücl & & \\
\hline Entnahmestelle & Uhrzeit & Tide & Temp. ${ }^{\circ}$ & $\begin{array}{c}\text { Salzgeh. } \\
0 / 00 \\
\end{array}$ & $\begin{array}{r}\mathrm{O}_{2} \% \\
\text { Săttig. } \\
\end{array}$ & $\begin{array}{r}\mathrm{H}_{2} \mathrm{~S} \\
\mathrm{mg} / \mathrm{l}\end{array}$ & $\mathrm{pH}$ \\
\hline $\begin{array}{c}\text { Austernbrücke } \\
\text { ” } \\
” \\
" \\
"\end{array}$ & $\begin{array}{r}7^{00} \\
9^{00} \\
12^{00} \\
13^{00} \\
15^{00} \\
17^{00} \\
19^{00}\end{array}$ & $\begin{array}{l}\text { HW } \\
\text { fallend } \\
\text { NW } \\
\text { steigend } \\
\text { steigend } \\
\text { steigend } \\
\text { HW }\end{array}$ & $\begin{array}{l}17.72 \\
18.21 \\
19.45 \\
21.45 \\
21.28 \\
18.42 \\
17.50\end{array}$ & $\begin{array}{l}30.48 \\
30.48 \\
30.05 \\
30.52 \\
30.59 \\
30.61 \\
30.79\end{array}$ & $\begin{array}{r}93 \\
98 \\
108 \\
117 \\
116 \\
99 \\
113\end{array}$ & $\begin{array}{l}= \\
= \\
\bar{z} \\
=\end{array}$ & $\begin{array}{l}8.17 \\
8.17 \\
8.20 \\
8.25 \\
8.20 \\
8.17 \\
8.17\end{array}$ \\
\hline
\end{tabular}

Die Sauerstoffwerte wurden nach der Tabelle von Fox in H. W. HARveY (1928, Biological Chemistry and Physics of Sea Water) berechnet.

Tabelle 2.

Station $\quad \mathrm{C}$

Hauptpriel

vor der äußeren Miesmuschelbank

Datum 24. Juni 1933

Witterung sonnig, windig

\begin{tabular}{c|c|c|c|c|c|c|c}
\hline \hline Entnahmestelle & Uhrzeit & Tide & Temp. & $\begin{array}{c}\text { Salzgeh. } \\
\%\end{array}$ & $\begin{array}{c}\mathrm{O}_{\mathbf{2}} \% \\
\text { Sättig. }\end{array}$ & $\begin{array}{c}\mathrm{H}_{2} \mathrm{~S} \\
\mathbf{m g} / 1\end{array}$ & $\mathrm{pH}$ \\
\hline Prielmitte & $9^{15}$ & NW & 17.10 & 29.78 & 92 & - & 8.17 \\
$”$ & $10^{30}$ & steigend & $\mathbf{1 7 . 4 2}$ & 30.41 & 86 & - & 8.17 \\
$”$ & $11^{30}$ & steigend & 17.70 & 30.63 & 89 & - & 8.17 \\
$”$ & $13^{00}$ & steigend & 17.90 & 30.80 & 91 & - & 8.17 \\
& $14^{30}$ & HW & 17.85 & 30.79 & 96 & - & 8.17
\end{tabular}

Tabelle 3.

Station D

Prielbecken

Datum 26. Juni 1933

Witterung kühl, böig, Regen

\begin{tabular}{|c|c|c|c|c|c|c|c|}
\hline Entnahmestelle & Uhrzeit & Tide & Temp." & $\begin{array}{c}\text { Salzgeh. } \\
0 / 00\end{array}$ & $\begin{array}{l}\mathrm{O}_{2} \% \\
\text { Sättig. }\end{array}$ & $\begin{array}{l}\mathrm{H}_{2} \mathrm{~S} \\
\mathrm{mg} / 1\end{array}$ & $\mathrm{pH}$ \\
\hline $\begin{array}{c}\text { Beckenausgang } \\
” \\
” \\
"\end{array}$ & $\begin{array}{l}10^{45} \\
11^{45} \\
12^{45} \\
14^{00} \\
15^{30}\end{array}$ & $\begin{array}{l}\text { NW } \\
\text { steigend } \\
\text { steigend } \\
\text { steigend } \\
\text { HW }\end{array}$ & $\begin{array}{l}18.90 \\
18.70 \\
17.92 \\
17.65 \\
17.70\end{array}$ & $\begin{array}{l}30.57 \\
30.64 \\
30.77 \\
30.82 \\
30.77\end{array}$ & $\begin{array}{r}116 \\
116 \\
95 \\
95 \\
96\end{array}$ & $\begin{array}{c}0 \\
0 \\
\text { Sp. } \\
\text { Sp. } \\
0\end{array}$ & $\begin{array}{l}8.35 \\
8.30 \\
8.25 \\
8.17 \\
8.17\end{array}$ \\
\hline
\end{tabular}


Tabelle 4 .

\begin{tabular}{|c|c|c|c|c|c|c|c|}
\hline \multicolumn{2}{|c|}{$\begin{array}{l}\text { Datum } \\
\text { Witterung }\end{array}$} & \multicolumn{6}{|c|}{$\begin{array}{l}\text { B } \\
\text { Odde-Watt } \\
\text { Vegetation: Fucus und Zostera } \\
\text { 16. Juni 1933 } \\
\text { sonnig, warm }\end{array}$} \\
\hline Entnahmestelle & Uhrzeit & Tide & Temp. ${ }^{0}$ & $\underset{\% / 00}{\text { Salzgeh. }}$ & $\begin{array}{l}\mathrm{O}_{2} \% \\
\text { Sättig. }\end{array}$ & $\begin{array}{l}\mathrm{H}_{2} \mathrm{~S} \\
\mathrm{mg} / 1\end{array}$ & $\mathrm{pH}$ \\
\hline $\begin{array}{c}\text { Odde-Watt } \\
"\end{array}$ & $\begin{array}{r}9^{30} \\
11^{30}\end{array}$ & $\begin{array}{l}\text { HW } \\
\text { fallend }\end{array}$ & $\begin{array}{l}19.50 \\
21.02\end{array}$ & $\begin{array}{l}30.70 \\
30.73\end{array}$ & $\overline{110}$ & $\begin{array}{l}0 \\
0\end{array}$ & $\begin{array}{l}8.25 \\
8.30\end{array}$ \\
\hline$"$ & $12^{30}$ & $\begin{array}{l}\text { fallend } \\
(10 \mathrm{~cm})\end{array}$ & 24.80 & 30.84 & 129 & 0 & 8.30 \\
\hline$"$ & $14^{00}$ & fallend & 27.00 & 31.08 & 125 & 0 & 8.55 \\
\hline$"$ & $15^{30}$ & $\mathrm{NW}$ & $>27.00$ & 31.55 & 127 & Sp. & 8.65 \\
\hline Austernbrïcke & $16^{\mathbf{0 0}}$ & $\mathrm{NW}$ & 一 & 30.91 & 105 & 0 & - \\
\hline
\end{tabular}

Tabelle 5 .

Station

$\mathrm{E}$

Mövenberg-Watt

Zostera nana u. angustifolia u. Fucus

Datum 19. Juli 1933

Witterung sehr sonnig u. warm, so

\begin{tabular}{c|c|c|c|c|c|c|c|c}
\hline Entnahmestelle & Uhrzeit & Tide & Temp. & $\begin{array}{c}\text { Salzgeh. } \\
\% / 00\end{array}$ & $\begin{array}{c}\mathrm{O}_{2} \% \\
\text { Sättig. }\end{array}$ & $\begin{array}{c}\mathrm{H}_{2} \mathrm{~S} \\
\mathrm{mg} / \mathrm{I}\end{array}$ & $\mathrm{pH}$ \\
\hline Mövenberg-Watt & $13^{30}$ & $\mathrm{HW}$ & 20.95 & 31.36 & 147 & 0 & 8.45 \\
$"$ & $15^{60}$ & fallend & 25.20 & 31.46 & $>238$ & 0 & 8.75 \\
$"$ & $\mathbf{1 6}^{30}$ & fallend & 26.42 & 31.76 & $>235$ & 0 & 9.05 \\
$"$ & $\mathbf{1 7}^{30}$ & fallend & 26.40 & 32.01 & 169 & 0 & 9.05 \\
Austernbrücke & $\mathbf{1 8}^{30}$ & fallend & 24.90 & 32.35 & 140 & 0 & 9.10 \\
& $19^{30}$ & NW & 19.95 & 29.92 & 97 & Sp. & 8.20
\end{tabular}

Den Anstieg des Salzgehaltes möchte ich dem an dem Untersuchungstag mit starker Beständigkeit wehenden trockenen OSO-Wind zuschreiben. Daß der Anstieg des Salzgehaltes von $31,36 \%$ auf $32,35 \%$ und auch der Anstieg der übrigen Faktoren eine ausschließlich auf die Wattflächen beschränkte Erscheinung ist, ergibt die Gegenüberstellung der am Brückenkopf der Austernbrücke gefundenen Werte. Die Mindestunterschiede betrugen für die Temperatur $1 \mathrm{Grad}$, Salzgehalt $1,44 \%, \mathrm{O}_{2}-0.043 \%, \mathrm{pH} 0,25$, dagegen die Höchstunterschiede 6,47 Grad bezw. $2,43 \%$ bezw. $141 \%$ und 0,90 .

Daß im Wasser der Lister Ley Spuren von $\mathrm{H}_{2} \mathrm{~S}$ nachgewiesen werden konnten, wird aus dem durch den harten Südostwind hervorgerufenen Wellengang im östlichen Wattenmeer erklärlich. Das Wasser war vor der Brücke erheblich durch Sinkstoffe getrübt.

Es darf in diesem Zusammenhang darauf hingewiesen werden, daß der von NIENBURG in der Fucus-Zone nachgewiesene $\mathrm{H}_{2} \mathrm{~S}-\mathrm{Wert}$ von $3,81 \mathrm{mg} / \mathrm{l}(53)$ von $\mathrm{mir}$ an keiner Station bestimmt werden konnte.

\section{Das Wasser im Wechsel von Tag und Nacht.}

Stellen wir diesen Tageswerten die in der Nacht vom 6. auf den 7. August gemessenen Werte gegenüber, so rundet sich immer mehr das Bild von dem chemischen Haushalt des Königshafenwassers. Es ergibt sich, daß nicht allein die Gezeiten große Schwankungen hervorrufen, sondern auch die Tageszeiten.

Um 23 Uhr hatte das vom Mövenberg-Watt abfließende Wasser die auffallend niedrige Temperatur von nur 13 Grad und zeigte die erheblich untersättigten Sauerstoffwerte von 47 und $43 \%(2,5 \mathrm{ccm} / \mathrm{I})$. Auch die $\mathrm{pH}-$ Werte lagen mit 7,90 weit unter den normalen $(8,17)$. 
Die Spuren an II.gs dürften auf die in der Dunkelheit nicht mit der nötigen Zuverlässigkeit geschöpften Wasserproben zuriickzuführen sein.

Die Kontrollmessung an der Austernbrücke nachts um 1 Uhr 30 zeigte zwar ein wenig niedrigere Sauterstoffwerte als am Tage, sonst aber keine durch die Dunkelheit hervorgerufenen Veränderungen. In die Tabelle 6, die die Nachtwerte enthält, ist außerdem noch eine Mebreihe aus dem Kleinen Hafen hineingenommen. Ein Vergleich mit den Tagwerten dieses Gebietes, vergl. Tabelle 10, zeigt ebenfalls den bekannten Einfluf der Photosynthese auf die chemischen Eigenschaften des Wassers.

\section{Tabelle 6}

Station

e

Mövenberg-Watt u. Kl. Hafen

wie bei $\mathrm{E}$, Nachts

Datum

6./7. August 1933

Witterung

windstill

\begin{tabular}{|c|c|c|c|c|c|c|c|}
\hline Entnahmestelle & Uhrzeit & Tide & Temp. ${ }^{0}$ & $\begin{array}{c}\text { Salzgeh. } \\
\% / 00\end{array}$ & $\begin{array}{l}\mathrm{O}_{2} \% \\
\text { Sättig. }\end{array}$ & $\begin{array}{l}\mathrm{H}_{\mathrm{g}} \mathrm{S} \\
\mathrm{mg} ! \mathrm{l}\end{array}$ & $\mathrm{pH}$ \\
\hline Mövenberg-Watt & $23^{100}$ & NW & 13.00 & 31.98 & 47 & $S_{p}$. & 7.90 \\
\hline & $23^{00}$ & $m$ & 13.00 & 31.91 & 43 & $S_{1}$. & 7.90 \\
\hline $\begin{array}{l}\text { Kl. Hafen } \\
\text { äußeres Becken V }\end{array}$ & $1^{00}$ & $"$ & 14.50 & 32.56 & 32 & sp. & 8.25 \\
\hline Austernbrücke & $1^{30}$ & ” & 19.00 & 31.38 & 88 & Sp. & 8.17 \\
\hline$\eta$ & $1^{30}$ & $"$ & 19.00 & 31.40 & 88 & 0 & 8.17 \\
\hline
\end{tabular}

Die in der letzten Spalte der Tabelle 6 eingesetzten Wasserstoffzahlen sind bei künstlichem Licht bestimmt worden; sie sind also nur in Grenzen mit den Tageswerten vergleichbar.

Den stärksten Eindruck von den möglichen periodischen Veränderungen im Wasser der Gezeitenzone des Königshafens vermittelt die Gegenüberstellung der $\mathrm{O}_{2}$-Sättigungswerte der Tabellen 5 und 6 :

$$
\begin{aligned}
\text { Möve } \mathrm{nb} \text { erg-W a t } & \\
\text { Tageshöchstwert } & =238 \% \\
\text { Nachtmindestwert } & =43 \% \text {. }
\end{aligned}
$$

Hinzu kommen die nicht unerheblichen Schwankungen der 'T'emperatur. $\left.{ }^{1}\right)$

Auch NiCOL (51) findet Schwankungen zwischen $40 \%$ und $200 \% \mathrm{O}_{2}$-Sättigung.

Fassen wir das Wesentliche der Tabellen 1 bis 6 kurz zusammen, so ist hervorzuheben, daß es nicht besonders krasser klimatischer Sonderfälle bedarf, um große Unterschiede in den Wassereigenschaften nachweisen zu können. Schon der normale periodische Ablauf der Ueberflutung einerseits und der Belichtung andererseits hat zwangsläufïg einen erheblichen Wechsel im Gefolge. Der Wechsel und die Schwankungen sind es, die das Wesen des Wasserhaushaltes im Königshafen bestimmen. Alle Lebewesen dieses (iebietes sind den Schwankungen ausgesetzt und müssen befähigt sein, sich in den unbestiindigen Wasserhaushalt einzuordnen.

\section{Die Sedimente des Königshafens.}

\section{Die sedimentanalytische Untersuchungsmethode.}

Auch die Sedimentuntersuchungen wurden im Sommer 19333 im lister laboratorium durchgeführt. Im Rahmen meiner vorwiegend biologischen Intleisuchungen mußte ich mich auf zwei Hauptfragestellungen beschränken, nämlich erst'ns anu' diir' $\Lambda$ rt der Ver-

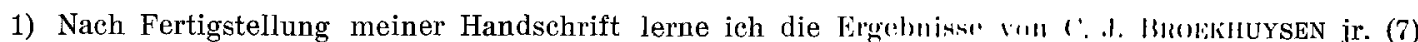

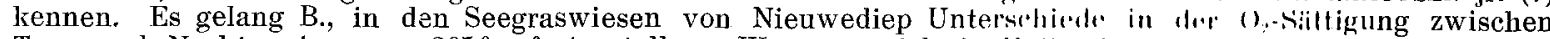

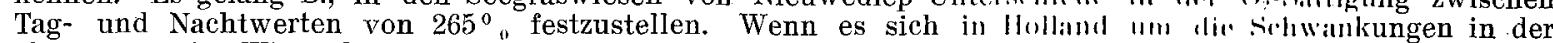
Zostera marina-Wiese handelt und bei uns in der Zone mit Zostera nam: um. liuru. Mytili, so sind die Schwankungen hier wie dort der Photosynthese zuzuschreiben.

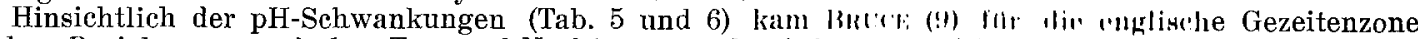

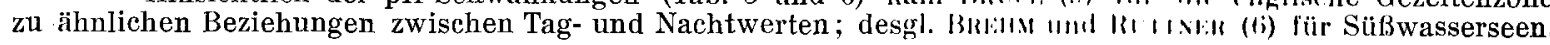


teilung der Sedimente im Königshafengebiet und zweitens auf die Frage nach den Beziehungen zwischen den verschiedenen Eigenschaften der Sedimente und der in ihnen lebenden Tiere und Pflanzen. Da Untersuchungen über den physikalischen und chemischen Haushalt der Königshafensedimente bisher nicht vorliegen, beschränkte ich meine Untersuchungen nicht auf die Korngrößenanalyse, sondern machte außerdem Wassergehaltsbestimmungen, in einzelnen Fällen Gefügemessungen sowie eine Anzahl Untersuchungen über die Chemie des Interstitialwassers. Dieses im Sediment enthaltene Wasser wurde gleichzeitig auf seinen Salz-Sauerstoff- und Schwefelwasserstoffgehalt, auf seine Temperatur und Wasserstoffzahl untersucht. Die Analyse umfaßte teils nur die von Tieren belebten Zonen, teils auch die tieferen Schichten.

Hinsichtlich der Korngrößenbeslimmung habe ich mich unter dem Zwange der Ansprüche, welche die gleichzeitige Erledigung der verschiedenen biologischen und chemischphysikalischen Untersuchungen an mich stellten, von der in der Geologie üblichen Schlämmanalyse freimachen müssen. Voruntersuchungen und Ueberlegungen überzeugten mich, daß eine sehr fein abgestufte Korngrößenbestimmung, wie sie der Geologe braucht, für die Kenntnis der biologischen Verhältnisse wohl im Bereich der HW-Grenze, tiefer jedoch nur in seltenen Fällen notwendig ist. Da die Sedimente im Königshafen in der Mehrzahl viel grobkörniger sind als die des Wattengebietes der Küste, habe ich mich mit der Siebung bis herunter zu $0,250 \mathrm{~mm}$ und mit der Schlämmung des Restes in der Claussenschen Schlämmröhre (GESSNER, 19) begnügt. Bezüglich der gröberen Korngrößengruppen schloß ich mich der von WeTzel (87) und Pratje (58) verwendeten Unterteilung an. In der Claussenschen Schlämmröhre ist bekanntlich nur die Schätzung der Mengen an Feinsand einerseits und Staub und Ton andererseits möglich. Die Anteile dieser Fraktionen sind für die Blockdarstellungen umgerechnet und mit dem bei dieser. Methode nicht zu umgehenden subjektiven Fehler behaftet.

Das Sieben der vorher getrockneten und gewogenen Proben erfolgte im nassen Zustande. Als Ersatz für die in List s. Zt. fehlende Wasserleitung wurden große Ballons mit Seewasser gefüllt, erhöht aufgestellt und das vorhandene Gefälle zum nassen Durchsieben der Proben benutzt. Als Siebsatz diente ein im Helgoländer Laboratorium angefertigter Satz aus Celloloid-Ringen mit zwischengelagerten Siebplatten aus Zink, die mit Bohrlöchern von 5,$00 ; 2,00 ; 1,00$ und $0,50 \mathrm{~mm}$ Durchmesser versehen waren. Für die Trennung der Gruppe unter $0,250 \mathrm{~mm}$ diente ein mit schweizer Seidengaze bespannter Messingring. Die nach dem Sieben getrockneten Korngrößengruppen blieben für die Wägung mit dem Salzfehler behaftet.

Für die Darstellung der Korngrößen wurde das schematische Blockdiagramm gewählt. Aus biologischen Gründen habe ich das Trockengewicht der einzelneu Gruppen nicht, wie üblich, auf das Gesamttrockengewicht der Probe, sondern auf das ursprüngliche Gesamtfeuchtgewicht, also auf den Normalzustand des frischen Sedimentes bezogen. Auf diese Weise tritt außer den auf Hundert bezogenen Korngrößenanteilen auch noch der absolute Wassergehalt mengenmäßig in Erscheinung. Die Untersuchungsergebnisse bestätigten meine Annahme, daß das Verhältnis zwischen den Raumanteilen des Wassers auf der einen Seite und der festen Bestandteile auf der anderen Seite oft von größerer Bedeutung ist, als die Unterteilung des Sedimentes in möglichst viele Korngrößengruppen.

\section{Aufbau und Verteilung der Sedimente.}

\section{Die Sedimente der Wattflächen.}

Mit der Beschreibung der über die verschiedenen Wattgebiete des Königshafens verteilten Sedimente greife ich auf die morphologischen Ausführungen (Abs. A. II, 3) zurück.

Die Ostgrenze des Untersuchungsgebietes bildet die NW-Linie. Oestlich dieser Grenze liegt der Zostera-marina-Gürtel, der in der Regel dauernd mit Wasser bedeckt ist. Es wurden jedoch besonders niedrige Wasserstände wahrgenommen, um durch qualitative Untersuchungen einen Einblick in ôen Aufbau und in die Besiedelung dieses Gebietes zu bekommen. Einen besonderen Anreiz dazu boten die Tagebuchaufzeichnungen Dr. KänDLERS, der gelegentlich seiner Austernuntersuchungen im Wattenmeer dieses für seine Untersuchungen nicht unwichtige Grenzgebiet ebenfalls bei ungewöhnlich niedrigem Niedrigwasser begangen und durch einige Stichproben auf die Besiedelung dieses nur selten der direkten Beobachtung zugänglichen Gebietes hingewiesen hat.

Das Sediment in diesem ganzen Gebiet von der Ellenbogenspitze bis zur Lister Austernbrücke ist feinsandig, arm an organischen Beimengungen und durchweg recht 
festgründig. In dem an sich nicht besonders ruhigem Außenbezirk wird der Sand durch das dichte Wurzelgeflecht der Zostera marina-Wiese festgehalten. (Nachträgl. Aenderungen durch die Seegraserkrankung vergl. WoHLEnBERG, 90). Die Zusammensetzung der Sedimente ist sehr einheitlich. Feinste Bestandteile sind lediglich in den Mulden mit Mya truncata und Amphitrite johnstoni, aber auch dann nur in Spuren enthalten.

Ich wende mich nunmehr dem eigentlichen Untersuchungsgebiet zu und unterteile das oberhalb der NW-Linie liegende Wattgebiet in 3 Abschnitte, in das Odde-Watt im Süden, in das Uthörner Außenwatt im Norden (bis an das Ufer des Hauptpriels) und in das zwischen dem kleinen Uthörner Nebenpriel und dem Odde-Watt liegenden Fucus Mytili-Watt.

Das Uthörner Außenwatt ist vom Prielufer bis zur Höhe von Uthörn ein vegetationsloses, stark bewegliches, reines Sandwatt. Die Reste einer früher einmal größer gewesenen Miesmuschelbank (nach Aussage von DETHLEFs) sind das einzig Beharrende in diesem Außenbezirk. Wie in der morphologischen Gliederung bereits angedeutet, setzt sich dieses Watt aus einem auffallend einheitlichen System von Strömungsbänken zusammen. Durch das bei NW zwischen den einzelnen Bänken stehenbleibende Wasser tritt die Gliederung trotz der nur schwach ausgebildeten Wölbung deutlich in Erscheinung. Die westliche Grenze des Uthörner Außenwatts bildet von der Nordspitze der Insel Uthörn bis an das Prielknie (III-IV, vergl. Abb. 1) den unbeständigsten Teil. Die Mehrzahl der auf NNW, SSO liegenden Strombänke haben - rein topographisch (nicht genetisch) gesehen - in dieser unbeständigen Westgrenze ihre Wurzel. Jede Tide hinterläßt hier in ausgesprochener Weise Spuren, die auf den umfangreichen Sandauf- und abbau schließen lassen. Dieser von dem Uthörner Nordzipfel bis an das Prielknie reichende Sandrücken fällt unvermittelt $30-50 \mathrm{~cm}$ tief auf das westlich daran anschließende Uthörner Binnenwatt ab. Das tritt besonders scharf durch die starken Farbgegensätze in Erscheinung: der nackte Sandrücken mit seiner Mannigfaltigkeit an Strömungs- und Brandungsformen hell und leuchtend auf der einen Seite und das dunkle, stets feuchte, vom grünen Zwergseegras bedeckte und in ruhiger Ebene daliegende Uthörner Binnenwatt auf der anderen Seite. Der Verlauf der bei steigendem und fallendem Wasser hier vorhandenen Strömungen läßt unschwer erkennen, daß hier bezüglich der Sedimentationsverhältnisse ein ausgesprochenes Störungsgebiet vorliegt. (Vergl. auch die Angaben im Abschnitt A, III über das Wandern der Insel). Für das Uthörner Außenwatt sind noch schlickige Beimengen in der unmittelbaren Nähe der Insel erwähnenswert. Das Vorhandensein von zahlreichen Klaffmuschelschalen in Lebendstellung beweist jedoch, daß dieser Schlick nichts mit dem heute hier herrschenden Sedimentationshaushalt zu tun hat, sondern einer Sedimentationsperiode mit anderen Bedingungen angehört (vergl. S. 7). Die Entwicklungstendenz kommt in der westwärts gerichteten Sandverfrachtung im Uthörner Außenbezirk zum Ausdruck.

Von anderer Beschaffenheit ist der südlich daran anschließende Teil des Außenbezirkes. Vom Südende Uthörns bis an das Odde-Watt ist das Gebiet mit einem einheitlichen Pelz von Fucus Mytili und zum Teil auch mit einem dichten Bestand an Zostera angustifolia bedeckt. Der Fucus ist hier stets mit der Miesmuschel versponnen (vergl. $\mathrm{Abb}$. 18). Infolge der ausgeprägten Weichgründigkeit ist dieses Watt sehr schlecht zu begehen, was durch die auch während der Niedrigwasserzeit hier vorhandene $15 \mathrm{~cm}$ hohe Wasserbedeckung noch verstärkt wird. Diese Besonderheiten lassen das Gebiet nur schwer in den üblichen Rahmen der Watteneinteilung eingliedern. Meinem Empfinden nach sollte der Begriff Watt für solche Standorte nicht verwendet werden. Das Substrat als solches ist treffender mit Mudd zu bezeichnen, da einerseits der Gehalt an in der Zersetzung begriffener organischer Substanz beträchtlich und andererseits der Wassergehalt noch so groß ist, daß die Ablagerung eigentlich erst auf dem Wege ist, ein Sediment zu werden.

Der einheitliche Fucus-Bestand wird nur unterbrochen durch das unregelmäßig verlaufende flache Bett der beiden Priele und geht weiter südwärts in einen ebenfalls einheitlichen Bestand von Zostera angustifolia über. Damit ist der Anschluß an das OddeWatt erreicht. Hier nehmen die Fucus-Bestände sehr schnell an Dichte ab. Der Zostera angustifolia-Rasen beschränkt sich mit größerer Annäherung an die Odde auf die tieferen feuchten Stellen und tritt das immer noch sehr weiche und schlickige Watt nahe der Odde an das Zwergseegras Zostera nana Roth. ab. Besonders hervorzuheben mit Bezug auf die Sedimentbildung sind noch die nicht mit Fucus Mytili versponnenen MytilusSiedlungen im unteren Teil des Odde-Watts. Die Muscheln liegen hier eng miteinander versponnen sehr nachgiebigen weichen Schlickpolstern auf, in die sie bis über die Hälfte eingebettet sind. Bis auf den der Odde unmittelbar benachbarten Streifen ist das gesamte Odde-Watt schwer zugänglich. In der nördlich von dem kleinen Lister Haken befindlichen 
Senke war es zum Beispiel nicht möglich, ohne weiteres eine Bestandsaufnahme durchzuführen. Ich bin in dieser Gegend unvermittelt bis an die Hüften in dem schwarzen Mudd eingesunken, was mich dazu zwang, mich im Boot an den zu untersuchenden Stellen trockenfallen zu lassen und die Zählungen und Beobachtungen vom Boot aus zu machen. Die mit großer Mühe durchgeführten Grabungen ergaben, daß das Sediment durch sehr umfangreiche Seegrasablagerungen mit wechselmäßjig beigemengten Sandmassen und vorwiegend muddähnlichem Schlamm den Charakter einer faulschlammähnlichen Ablagerung hat. Auch wenn die Oberfläche nicht gestört wurde, stiegen allerorts Gasblasen aus der Tiefe auf, und die weißlich gelben Schleier kündigten den bis zur Ausfällung des elementaren Schwefels gesteigerten Oxydationsvorgang an. Die Senke vor dem Haken und die weitere Umgebung, deren Sedimente nur graduell davon verschieden waren, machten die Arbeiten auf dem Odde-Watt nicht nur durch ihre Unzugänglichkeit wenig erfreulich, sondern vor allem auch durch die verpestete Luft. Selbst bei frischer Brise steigerte sich der $\mathrm{H}_{3} \mathrm{~S}-$ Gestank bis zur Unerträglichkeit (vergI. Abs. E, III, 2 c, d Abb. 4 und Tab. 13). Daß sich im Sediment Vorgänge abwickeln, die die Chemie des Standortes vollständig beherrschen und das Watt vor der Odde als ein besonderes kennzeichnen, ergibt sich aus der Tabelle 13 mit den hohen Schwefelwasserstoffwerten des Zwischenraumwassers.

Bei der Erörterung der Sedimente des Odde-Watts mag noch ein Profil erwähnt werden, das in nordöstlicher Richtung von der HW- bis zur NW-Grenze des Odde-Watts verläuft. Entlang dieses Profils entnahm ich in Abständen, deren Größe durch die Morphologie und Besiedelung gegeben war, Wattproben. Mit der Kurvendarstellung Abb. 2 beschränke ich mich auf die Wiedergabe der Korngrößengruppen von 4 Stationen, von denen Station a etwas unterhalb der MHWGrenze des Oddestrandes (Brandungszone) und Station IV etwas oberhalb der MNWLinie des Odde-Watts, die anderen beiden dazwischen liegen. Die Ziffern der Ordinate sind auf Hundert bezogene Werte und beziehen sich auf das Ausgangsfeuchtgewicht (Naturgewicht) der untersuchten Probe, das

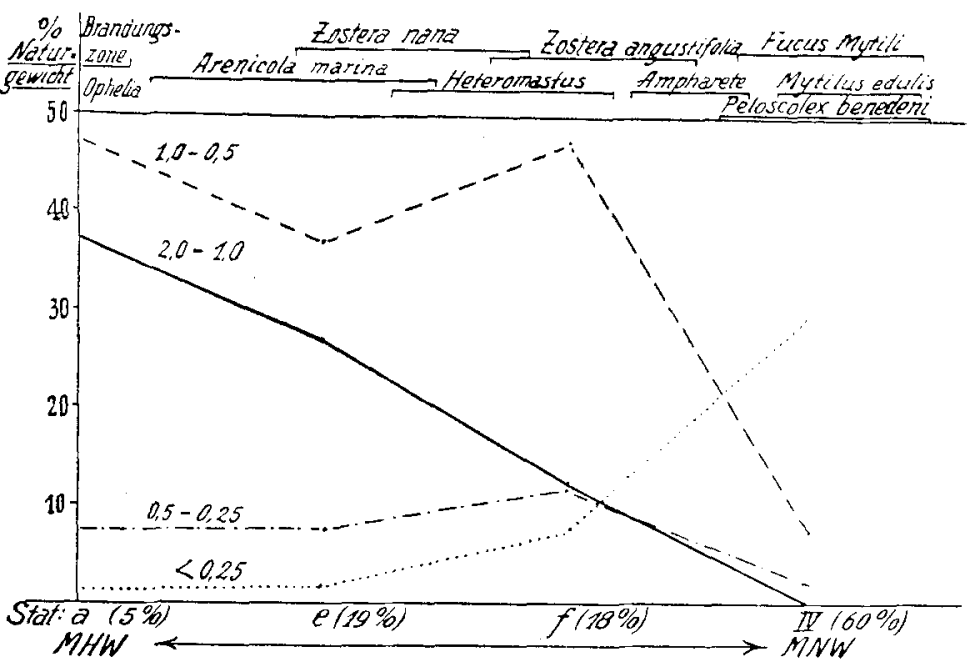

Abb. 2. Korngrößenverteilung und Besiedelung auf einem Schnitt quer über das Odde-Watt von der HW- bis zur NW-Grenze. gleich 100 gesetzt wurde. Auf der Abzisse sind die 4 Stationen entsprechend ihrer topographischen Anordnung im Gelände aufgetragen. Die eingeklammerten Zahlen hinter der Stationsbezeichnung geben den absoluten Wassergehalt der Sedimentprobe an. Die 4 Darstellungen der Abb. 2 vermitteln außer dem Bild von der quantitativen Zusammensetzung der untersuchten Proben vor allen Dingen eine Vorstellung von der Sedimentverteilung von der MHWLinie bis in den tieferen Bezirk des Odde-Watts. Besonders eindrucksvoll zeigen die beiden Strichkurven für die Gruppen 2,0 bis $1,0 \mathrm{~mm}$ und für weniger als $0,25 \mathrm{~mm}$ die gegensinnig verlaufende Verteilung entlang des Profils. Die Kurve für die Gruppe 0,5 bis $0,25 \mathrm{~mm}$ zeigt dagegen sehr ausgeglichene Werte. Diese Art der Verteilung hat für das Odde-Watt mit Ausnahme der Randgebiete ähnlich auch für das Gröning-Watt nahezu gesetzmäßigen Charakter.

Das Randgebiet wird am Südende der Odde von der sogenannten Tonnenlegerbucht gebildet. Die Tonnenlegerbucht ist gegen das offene Wattenmeer durch den Lister Haken geschützt. Sie ist eine flache Senke mit weichem, von schwarzem Mudd durchtränktem Sandwatt. Die innerste Bucht nimmt die riesigen Mengen an abgestorbenem Seegras auf, die vor dem Haken (Abb. 4) nicht zur Ablagerung gekommen sind. Unterhalb des Funkpeilturmes mündet ein Siel in die Bucht, wodurch der kleine Wasserraum der Bucht noch stärker der Verschmutzung preisgegeben ist. Dies ist die einzige Stelle im Untersuchungsgebiet, die durch menschliche Einflüsse verändert worden ist. 
Das nördliche Grenzgebiet des Odde-Watts ist das der Odde-Spitze vorgelagerte Sandgebiet. Es wird nach Norden und Nordosten von dem Bett des aus dem Kleinen Hafen kommenden Priels begrenzt. Der sandige Charakter und die Oberflächenformen weisen auf erhebliche Umlagerungen hin.

Die Sedimente des Mövenberg-Watts sind über große Flächen hin einheitlich sandig. Eine Ausnahme von dieser Regel macht das Uebergangsgebiet zum Uthörner Binnenwatt, das in schwach ausgeprägter Senke ein weichgründiges Sediment mit Zostera angustifolia und Fucus Mytili-Besiedelung aufweist und der höhere Teil des zwischen den beiden Prielabschnitten I und II gelegenen Fucus Mytili-Watts, der auch weichgründig ist. In der ganzen Breite vom Uthörner Binnenwatt bis an das Prielbecken vor dem Gröning ist das Mövenberg-Watt mit Zostera nana besiedelt. Infolge dieser einheitlichen Vegetationsdecke bleibt auch während der Ebbe etwas Wasser über dem Watt zurück, so daß mit kleinen örtlichen Ausnahmen das Sandwatt vor dem Mövenberg dauernd feuchtigkeitsge- bezw. übersättigt ist. Innerhalb der Zwergseegras-Formation vor dem Mövenberg fallen nackte Streifen auf, die sich durch eine leichte Wölbung von der Umgebung abheben (Blockdiagramm Abb. 10). Ich kann nicht sagen, ob diese Streifen wandernde Sandrücken darstellen (Abb. 8). Ihre besonders aufschlu(3reiche Biologie folgt in E. III, $2 \mathrm{e}$. Unterhalb der Bledius-Terrasse vor dem Gröning liegt ein sandiger Wattstreifen, der nach unten durch größere Schlickbeimengungen in ein ausgesprochenes Schlickwatt von mäßig fester Beschaffenheit übergeht. Je mehr man sich der Niedrigwassergrenze nähert, um so weichgründiger und wasserhaltiger werden die Ablagerungen, bis man endlich in der Fucus-Siedlung und vor allem auch in der nordwestlichen Ecke des Gröning-Watts das so schwer zugängliche Mudd-Watt antrifft.

Was bezüglich weiträumiger Einheitlichkeit vom Mövenberg-Watt gesagt wurde, gilt ähnlich vom gegenüberliegenden Westfeuer-Watt. Da auf diesem Watt die Zwergseegrasformation nicht so üppig ausgebildet ist wie auf der gegenüberliegenden Seite, bleibt hier während der Ebbe kein Wasser flächenhaft auf der Wattoberfläche zurück. Nur innerhalb der Fucus Mytili-Bestände wird etwas Wasser ähnlich wie auf dem MövenbergWatt zurückgehalten. An der Hochwassergrenze des Westfeuer-Watts kommt es zur Bildung von Strandhaken, deren Enden ostwärts gerichtet sind. Zum Strand hin schließen sie kleine Buchten ein. Während die Haken selbst aus reinem Sand aufgebaut sind, enthalten die Buchten schlickige Beimengungen. Das Sediment der Buchien ist deutlich geschichtet und nach oben hin durch den bereits häufiger erwähnten Cyanophyceenrasen abgeschlossen. Der Aufbau der Sedimente der staffelförmigen Strandhaken und der von ihnen umschlossenen Buchten ist aus den Blockdiagrammen (Abb. 54) und auf S. 67 zu ersehen.

Das Ostfeuerwatt ist zur Hälfte bewachsen. Von der inneren Miesmuschelbank (am Prielknie zwischen den Abschnitten III und IV) breitet sich Fucus Mytili in dichten, einheitlichen Beständen nord-nordwest- und nordostwärts aus. Das Watt ist trotz der üppigen Besiedelung mit Fucus unter einer dünnen Mudd-Schicht überall festgründig sandig. An die Fucusbestände schließt sich nach oben ein Streifen mit Zostera nana an und weiter zur HW-Grenze folgt ein nackter Streifen mit festem, hartem Sandwatt. Auch der untere Abschnitt zwischen dem Fucus und Prielabschnitt III ist festgründig. Vegetation fehlt hier vollständig. Das ganze Gebiet mit Ausnahme eines kleineren, dem Prielabschnitt II benachbarten Teiles zeigt alle Formen eines stark überströmten Sandwatts. Ein einheitliches System von Strömungsbänken streicht von Nordwesten nach Südosten. Auf dem in den Prielabschnitt III hineinragenden Sandhaken verlaufen sie in Nordsüdrichtung. Der dem Prielabschnitt II benachbarte Teil ist in ruhiger Lagerung. Hart am Prielhang liegt eine kleine Miesmuschelbank. Der nördliche Teil des Ostfeuer-Watts wird vom Lagunenbezirk eingenommen, auf den ich im Abschnitt E, III, 5 eingehen werde.

Es muß bei der Betrachtung des Ostfeuerwatts hervorgehoben werden, daß der weiträumige Fucus Mytili-Bestand auf NienBurgs Vegetationskarte vollkommen fehlt. Er spricht ausdrücklich davon, daß das nördlich vom Priel gelegene Watt vegetationslos sei (53). Heute liegt hier nördlich des Prielabschnitts III das größte zusammenhängende Fucus Mytili-Gebiet des Königshafens. Es muß also unter Zugrundelegung der Vegetationskarte von Nienburg angenommen werden, daß der Mytilus- und Fucus Mytili-Bestand des Ostfeuer-Watts erst im Laufe des verflossenen Jahrzehntes herangewachsen ist.

\section{Die Sedimente der Prielufer und Prielböden.}

So weit es mir möglich war, die Prielböden auf ihre Zusammensetzung zu untersuchen, zeigen alle mehr oder weniger stark gerippelten, sandigen Boden. Nur der Boden 
im Prielabschnitt III ist von fester, kleiartiger Beschaffenheit. Außer vielen Kleigeröllen liegt Muschelschill in größeren Mengen auf der Prielsohle. Austernschalen und Miesmuschelklappen dienen der Meerseite (Chorda Filum L.) als Verankerung in dem Prielbett. Die Korngrößenanteile des im Prielabschnitt III in verschiedenen Tiefen am Südufer anstehenden Kleis sind in der Tabelle 7 zusammengestellt. ${ }^{1}$ )

Die Fraktion E besteht zum größten Teil aus autochthonen Foraminiferen, und zwar $\mathrm{zu} 76,0 \%$ aus Polystomella striatopunctata, zu 15,3\% aus Rotalia Beccarii und zu 8,7\% aus Nonionina depressula. Die Zählung ergab ferner, daß in dem für die Analyse bereiteten Boden von $25 \mathrm{~g}$ Ausgangsgewicht etwa 10000 Foraminiferen enthalten waren. Wie weit die Foraminiferen heute noch an der Zusammensetzung der Königshafensedimente beteiligt sind, entzieht sich meiner Kenntnis. Neuere Beobachtungen im Wattenmeer der Westküste deuten darauf hin, daß die Wattqualitäten nicht zuletzt durch die Kleinlebewelt in entscheidender Weise beeinflußt werden, so daß u. a. auch diese Untersuchungen vom Laboratorium der Forschungsstellen Westküste her in Angriff genommen worden sind. Auch der Boden des Prielabschnittes IV ist mit Schill bedeckt, zum Teil auch mit kleineren Geschieben, wie man sie auch beim Aufgraben der Muschelbänke des Priels findet. Die Mündung des Hauptpriels ist dagegen wieder sandig.

Das Becken des großen Priels ist nicht, wie Nienburg (53) noch annahm, tief, sondern so flach, daß man bei Niedrigwasser bequem hindurchwaten kann. Der Boden ist an den unbewachsenen Stellen mit Rippeln bedeckt. Nur vereinzelt findet man kleine Horste von Zostera marina und an Fucus Mytili versponnene Mytilus-Klumpen, die wohl durch Strömung oder Seegang hierher verfrachtet worden sind. Die Gegensätze in der Zusammensetzung und vor allem in der Festigkeit der vom Seegras oder vom Fucus bedeckten Stellen ist im Prielbecken und im Abschnitt I außerordentlich groß. Von den unmittelbar benachbarten Siedlungen mit Zostera marina einerseits und mit Fucus Mytili andererseits ist der Zostera-Standort festgründig und sandig, der Fucus-Standort dagegen polsterförmig gewölbt, sehr weichgründig und wasserhaltig. Dabei sind beide nicht geringen Stromstärken ausgesetzt. Bei der Wölbung unter der Fucus Mytili-Siedelung handelt es sich um feinen, locker gelagerten Sand mit schlickigen Beimengungen.

Auch die Betten der beiden Nebenpriele zwischen Uthörn und der Oddespitze sind sandig. Ihre auffallende Weichgründigkeit täuscht meistens nachgiebiges Schlickwatt vor, aber es handelt sich um sehr locker gelagerte, triebsandähnliche Sedimente, die sich von den gewöhnlichen Triebsanden durch ein starkes Pigment $\left(\mathrm{FeS}_{2}\right)$ unterscheiden.

\section{Tabelle 7 .}

Korngrößenanteile des Kleis vom Hauptpriel.

$\begin{array}{cccc}\text { Gruppe } & \text { B } & 45.34 \% & \text { des Trockengewichtes } \\ " & \text { C } & 14.83 \% & " \\ " & \text { D } & 26.69 \% & " \\ " & \text { E } & 5.08 \% & " \\ " & \text { F } & 6.78 \% & " \\ " & \text { G } & 1.27 \% & "\end{array}$

Die Fraktionen $\mathrm{F}$ und $\mathrm{G}$ entstammen zur Hauptsache einer vom Klei eingeschlossenen Lage gröberen Sandes. (Korngrößensystem nach der Preuß. Geolog. Landesanstalt.)

\section{Die Sedimente der Hochwassergrenzgebiete.}

Von den Hochwassergrenzgebieten interessieren uns hier weniger die Brandungszonen (vergl. Odde-Watt, Abb. 2, Stat. a) als vor allem die mehr oder weniger regelmäßig überfluteten Flä chen. Die abwechselnd etwas oberhalb oder unterhalb der MHWLinie liegende Brandungszone mit Talitrus saltator ist nicht näher untersucht worden. Dagegen verdient ein Standort, der etwas unterhalb der MHW-Linie gelegen ist, besonderes Interesse, zumal er mir in ähnlich spezialisierter Ausbildung bisher im Wattenmeer der Küste nicht wieder, wohl aber auf anderen Nordseeinseln begegnet ist. Es sind die Bledius spectabilis-Standorte und die Bledius arenarius-Gebiete. Bledius arenarius var. subniger ist allerdings nicht an regelmäßige Ueberflutung gebunden. Die Standorte sind daher auch höher als die von Bledius spectabilis gelegen. Im Abschnitt über ihre Oekologie, E, III, 5 und 6, bin ich näher auf ihre Zusammensetzung eingegangen. Die beiden Blockdiagramme

1) Die Analyse wurde im Atterberg-Zylinder und im Schöne'schen Schlämmzylinder in freundlicher Weise von Herrn Dr. DITTMER im Laboratorium der Staatl. Forschungsstelle Westküste in Büsum ausgeführt. 
Abb. 26 und Abb. 54 (Mitte) lassen deutlich ein verwandtes Sediment erkennen. Von ausschlaggebender Bedeutung für die Entstehung und die Art des Aufbaus dieser Standorte scheint das Vorhandensein von Blaualgen zu sein, worunter besonders Microcoleus chthonoplastes an erster Stelle zu nennen ist. Eine umfassendere Untersuchung wurde an zwei Stellen durchgeführt, auf dem Lagunen-Watt (E. III, 5) am Kersten Rimling und auf den staffelförmigen Strandhaken beim Westfeuer-Watt (E. III, 6). Die andern drei Standorte liegen vor dem Gröning, gleich unterhalb der Andelwiese des Grönings, vor dem Mövenberg und im Kleinen Hafen am Odde-Ufer gegenüber und auf den beiden Inseln. Wie bereits aus der Darstellung NiEnburgs (53) hervorgeht, liegen vor dem Fuß des Mövenberges allmählich zusammenwachsende Andelpolster. Zwischen diesen und sogleich unterhalb dieser Verlandungszone folgt gewissermaßen als erstes Wattstadium eine tafelförmige Ebene. Das ist die Bledius-Terrasse. Ihr Sediment erhält durch den abschließenden Cyanophyceenrasen, durch vereinzelt stehende Queller und Suaeda-Pflanzen sowie durch die zahlreichen Krümelhäufchen in Form und Aufbau ein besonderes Gepräge.

Ganz entsprechend sind die übrigen Standorte zu kennzeichnen. Auch dem GröningWatt ist unterhalb der Andelwiese eine ebene Zone mit einem einheitlichen Blaualgenfilz und der charakteristischen Bledius-Besiedelung vorgelagert. Dasselbe trifft für den kleineren halbmondförmigen Standort im Kleinen Hafen zu. Alle Bledius-Standorte des Königshafens sind so einheitlich im Aussehen und Aufbau, in der Festigkeit, im Feuchtigkeitsgehalt und in der Schichtung, daß man bereits beim einfachen Hinüberschreiten den Eindruck gewinnt, daß es sich um stark spezialisierte Standorte handelt. Sowohl die sedimentanalytischen als auch die biologischen Untersuchungen haben es bestätigt (vergl. E, III, 5 und 6).

Fasse ich das über die Verteilung und den Aufbau der Sedimente im Königshafen Gesagte kurz zusammen, so lassen sich eine Reihe von Merkmalen herausstellen. Zunächst gibt es im Königshafen einige Standorte, deren Sedimente nicht unter den heute in ihrem Bereich herrschenden Ablagerungsbedingungen entstanden sein können. Es handelt sich einmal um das östlich unterhalb Uthörn freiwerdende Mya-Beet mit schlickigen Ablagerungen und zum andern um die Kleiablagerungen am Südufer des Prielabschnittes III. Beide Sedimente haben fossilen Charakter. Die heute vorliegenden Ablagerungsbedingungen stehen im Widerspruch zu ihrer Korngrößenzusammensetzung. Sodann sind die Watten ohne Vegetation solchen mit Pflanzenwuchs gegenüberzustellen. Der Pflanzenwuchs beeinflußt nicht nur die Oberfläche sondern auch die Struktur der Sedimente. Für die Fucus Mytili-Bestände sind zum Beispiel oberflächliche faulschlammähnliche, halbflüssige Ablagerungen mit großem Gehalt an organischer Substanz bezeichnend (Mudd-Watt). Dasselbe gilt für das mit Zostera angustifolia besiedelte Watt, während das Sediment der Zwergseegraswiese (Zostera nana) wohl locker gelagert und durchwurzelt, aber doch verhältnismäßig gut begehbar ist. Es ist ein Sandwatt, das neben einer starken Uebersättigung mit Wasser auch durch eine tief schwarzblaue Pigmentführung (Schwefeleisen) ausgezeichnet ist. Für alle diese bewachsenen Wattflächen gilt die Regel, daß auch während der Nichtüberflutung auf den Wattflächen eine mehr oder weniger starke Wasserschicht zurückbleibt.

Die vegetationslosen Wattgebiete sind aufzuteilen in solche mit formbeständiger Oberfläche, wozu die im ganzen Gebiet festen, unterhalb der MHW-Linie zonenartig ausgebildeten Sandwatten, sowie die fast unzugänglichen Schlickwatten vom Mudd-Typ zu zählen sind, und solche von unbeständiger Lagerung und Oberflächenentwicklung, wozu ich die Störungszonen sowie alle Gebiete, deren Struktur und Oberfläche durch Strömungen und Wellenschlag regelmäßig verändert werden, rechne.

$\mathrm{Zu}$ den bewachsenen Gebieten gehören auch die tischebenen, glatten Flächen der Bledius-Standorte, deren Sonderstellung bereits erwähnt wurde.

\section{Das in den Sedimenten enthaltene Wasser.}

Es ist naheliegend anzunehmen, daß die Eigenschaften des in den Sedimenten enthaltenen Wassers eine gewisse Bedeutung für die in ihnen lebenden Organismen haben. Es fragt sich nur, kommen die Tiere mit dem Zwischenraumwasser der Sedimente in Berührung oder stellen ihre Wohnröhren innerhalb des allgemeinen Lebensraumes Kleinräume mit besonderen Eigenschaften dar? Diese Fragen treten uns besonders bei den Tieren entgegen, die eine Dauerwohnröhre im Watt bewohnen.

Man kann z. B. leicht beobachten, daß der Sandpier Arenicola marina in einem Gang lebt, dessen Hohlraum gegen das umgebende $\mathrm{H}_{2} \mathrm{~S}$-haltige Sediment durch einen einheitlichen Oxydationsmantel "geschützt" ist. Man hat daraufhin von einer durch die 
Röhren erfolgende „Bewetterung“ gesprochen (KRJECI-GRAF, 37 a). Andererseits ist aber auf einem Arenicola-Watt täglich zu beobachten, daß der Wurm zeitweise auch lange Kotbänder von tiefschwarz-blauem Pigment, also Material mit reduzierenden Eigenschaften an die Oberfläche preßt, womit erwiesen ist, daß der Wurm sehr wohl mit dem $\mathrm{H}_{2}$ S-haltigen Sediment in Berührung kommt (vergl. auch RICHTER, 62). Nach eigenen Untersuchungen umgeht auch der Schlickkrebs Corophium volutator nicht die Ablagerungen mit reduzierenden Eigenschaften (WOHLENBERG, 88). Von den übrigen Borstenwürmern des Wattenmeeres ist noch Nereis diversicolor zu nennen, die sowohl mit dem oxydierten als auch mit dem reduzierten Teil des Sediments in unmittelbare Berührung kommt. Bei Nereis ist eine ausgesprochene Treue zur Wohnröhre vorhanden. Ich kann nicht die Ansicht Hecir's (25) von der dauernden Neuanlage von Gängen durch Nereis teilen. Die ausgeprägten Oxydationshöfe und ihre erhöhte Widerstandsfähigkeit gegen Abtragung sprechen dagegen. Anders ist es bei dem Capitelliden Heteromastus, ferner bei Scoloplos, Nephthys, Colobranchus und bei einigen Oligochaeten. Ihre unregelmäßigen Gänge hinterlassen keinerlei Spuren einer Oxydation geschweige den Eindruck einer Formbeständigkeit im Röhrenverlauf. Wir ersehen hieraus, daß ein nicht geringer Teil der das Watt bewohnenden Tiere direkt, z. T. dauernd mit den $\mathrm{H}_{2} \mathrm{~S}$-haltigen Sedimenten in Berührung kommt, offenbar ohne Schaden zu nehmen.

Bei dem Wunsch, die Verhältnisse in der Natur nicht verwickelter zu sehen als sie wirklich sind, habe ich mich daher mit der chemischen Analyse des Zwischenraumwassers als Ganzem begnügt. Es wurde auf folgende, einfache Weise gewonnen. Bei Niedrigwasser wurde auf dem betreffenden Standort eine möglichst enge und steilwandige Vertiefung gemacht. Die Tiefe der Entnahmestelle richtete sich danach, wie tief der jeweils vorliegende Wohnraum der Tiere hinabreichte, also in der Corophium-Zone $4 \mathrm{~cm}$, in der Arenicola-Nereis-Zone dagegen bis zu $40 \mathrm{~cm}$. Das aus den Wandungen der Vertiefung zusickernde Wasser wurde für die Analyse verwendet.

Bei der Durchführung dieser Untersuchung war mir klar, daß der Weg, das Zwischenraumwasser der Sedimente auf diese Art zu sammeln und nach Berührung mit der freien Atmosphäre zu analysieren, in quantitativ chemischer Hinsicht anfechtbar sei. Welche Fehler konnten sich nun schlimmsten Falls einschleichen? Im wesentlichen doch nur die, daß die Sauerstoffwerte infolge der Berührung des austretenden Wassers mit der Luft $\mathrm{zu}$ hoch und die Schwefelwasserstoffwerte durch denselben Umstand zu niedrig ausfallen würden. Diese Ungenauigkeiten meine ich bei der Untersuchung der vom Normalen so sehr abweichenden Verhältnisse ohne Bedenken mit in Kauf nehmen zu dürfen. Auf jeden Fall sind bei vorsichtiger Bewertung die gefundenen Sauerstoffwerte Höchstwerte und die Schwefelwasserstoffzahlen Mindestwerte.

In der folgenden Tabelle 8 sind von einer eben unterhalb der Hochwasserlinie liegenden Entnahmestelle von $5 \mathrm{~cm}$ Tiefe zwei Proben von Zwischenraumwasser untersucht. Der Grund für diese Analysen war die auffallende Verarmung dieser Gegend an Organismen. Außer einigen kümmerlichen Exemplaren von Nereis diversiolor wurden keine Tiere in diesem Sandwatt gefunden. Aus der Tabelle 8 geht nun deutlich hervor, daß der Salz-

Tabelle 8 .

Zwischenraumwasser.

Station Y, HW-Grenze westl. v. Mövenberg

$5 \mathrm{~cm}$ unter der Oberfläche

Datum 7. Aug. 1933

\begin{tabular}{|c|c|c|c|c|c|c|c|}
\hline Entnahmestelle & Uhrzeit & Tide & Temp. & $\underset{v / 00}{\text { Salzgeh. }}$ & $\begin{array}{l}\mathrm{O}_{2} \% / 0 \\
\text { Sättig. }\end{array}$ & $\begin{array}{r}\mathrm{H}_{2} \mathrm{~S} \\
\mathrm{mg} / 1\end{array}$ & $\mathrm{pH}$ \\
\hline $\left.\begin{array}{r}\text { HW-Grenze } \\
5 \mathrm{~cm} \text { tief }\end{array}\right\}$ & $\begin{array}{l}12^{00} \\
12^{\circ 0}\end{array}$ & $\begin{array}{l}\text { NW } \\
\text { NW }\end{array}$ & $\begin{array}{l}21.50 \\
21.50\end{array}$ & $\begin{array}{l}6.95 \\
6.91\end{array}$ & 47 & $\begin{array}{l}0 \\
0\end{array}$ & $\begin{array}{l}6.50 \\
6.75\end{array}$ \\
\hline
\end{tabular}

gehalt des Zwischenraumwassers außerordentlich gering war. Ich möchte annehmen, daß in dieser Gegend aus den darüber liegenden Dünen Grundwasser in das Watt tritt und die Herabsetzung des Salzgehaltes bewirkt hat (vergl. Nienburg, 53, Stocker, 77). Auffallend sind auch die niedrigen $\mathrm{pH}$-Werte. Sie sind mit $\mathrm{pH}=6,50$ die niedrigsten, die 
ich im Königshafenwatt nachweisen konnte. Auch die Sauerstoffsättigung ist mit $47 \%$ recht gering, so daß neben der ausgesprochenen Hartgründigkeit des Sedimentes diese vom Normalen abweichenden chemischen Faktoren die Ursache für die Verarmung bilden dürften.

Die Tabelle 9 enthält Werte aus einem $60 \mathrm{~cm}$ tiefen Sickerloch auf der äußeren Muschelbank am Priel. Die Entnahme wurde um die Niedrigwasserzeit ausgeführt, als der Wasserspiegel am Priel etwa $70 \mathrm{~cm}$ unterhalb der höchsten Stelle der Muschelbank lag. In dem zusickernden Wasser konnte kein Sauerstoff nachgewiesen werden, dagegen aber sehr hohe Schwefelwasserstoffwerte von über $11 \mathrm{mg}$ im Liter. Die gleichzeitig entnommenen Proben aus dem davorliegenden Prielbett beleuchten schlaglichtartig die schroffen Gegensätze innerhalb eng benachbarter Stellen im Gelände. Im übrigen weise ich auf die weiter unten zusammen mit biologischen Fragestellungen erörterten Tabellen 13 und 14 über die Zusammensetzung des Zwischenraumwassers anderer Sedimente hin.

Tabelle 9.

Zwischenraumwasser.

\begin{tabular}{|c|c|c|c|c|c|c|c|}
\hline & $\begin{array}{l}\text { Station } \\
\text { Datum } \\
\text { Witter }\end{array}$ & $\mathrm{ng}$ & $\begin{array}{l}\text {, Aeuß } \\
\text { n } 60 \mathrm{~cm} \\
\text { 4. Juli } \\
\text { onnig, }\end{array}$ & $\begin{array}{l}\text { Muse } \\
\text { Tiefe } \\
933 \\
\text { arm }\end{array}$ & helbant & & \\
\hline Entnahmestelle & Uhrzeit & Tide & Temp. ${ }^{0}$ & $\begin{array}{c}\text { Salzgeh. } \\
\% / 00\end{array}$ & $\begin{array}{c}\mathrm{O}_{2} \% \\
\text { Sättig. }\end{array}$ & $\begin{array}{l}\mathrm{H}_{2} \mathrm{~S} \\
\text { mg. } 1\end{array}$ & $\mathrm{pH}$ \\
\hline $\begin{array}{l}60 \mathrm{~cm} \text { unter der } \\
\text { Muschelschicht } \\
\text { Prielmitte }\end{array}$ & & $\begin{array}{c}\mathrm{NW} \\
\mathrm{NW} \\
\text { steigend }\end{array}$ & $\begin{array}{l}19.50 \\
19.50 \\
19.90\end{array}$ & $\begin{array}{l}30.44 \\
31.54\end{array}$ & $\begin{array}{c}0 \\
0 \\
131\end{array}$ & $\begin{array}{l}11.06 \\
11.00 \\
\text { Sp. }\end{array}$ & $\begin{array}{l}7.60 \\
7.50 \\
8.30\end{array}$ \\
\hline
\end{tabular}

\section{Der kleine Hafen.}

Der Einfachheit halber soll der Hydrographie des Kleinen Hafens eine kurze Beschreibung der Morphologie und der Sedimente vorangestellt werden.

Die Lage des Kleinen Hafens läßt von vornherein bei einem Vergleich mit dem eigentlichen Königshafen eine stärkere Abhängigkeit der Wassereigenschaften von der Umgebung erwarten. Wie weiter unten gezeigt werden wird, trifft diese Erwartung nur in eng begrenztem Maße zu.

\section{Die Gliederung.}

Wie aus der Abb. 1 und 3 hervorgeht, erstreckt sich der Schlauch mit einem beim Dorfe List blind endenden Becken (inneres Becken I) nordwärts zwischen der Dünenhalbinsel Lister Odde im Osten und den Andelwiesen südlich vom Mövenberg bis zum eigentlichen Königshafen. Etwa in der Mitte erweitert sich der Schlauch in westlicher Richtung zu einem weiteren Becken, dem Sielbecken. Die Fortsetzung des Sielbeckens bildet der Sielzug, ein Graben, der die nach Norden durch einen kleinen Deich abgeschlossenen Binnenländereien in den Kleinen Hafen entwässert. Dils sicillocken enthält die Entnahmestationen III und IV. Nach Osten wird das Sielbecken "lwas enger und tritt hier mit dem mittleren Becken des Schlauches in Verbindung. (1)is mittlere Becken mit der Entnahmestation II geht allmählich in das äubere Beckrn ïbur, dass mit seinem nördlichen Teile die eigentliche Mündung des Kleinen Hafens in don Kïnigslalfen einnimmt.

Bezüglich der Uferverhältnisse lassen sich zwei verschindr.mulige Ausbildungen unterscheiden, das Andelwiesenhochwasserkliff auf der Wostsill. uml das durchweg allmählich verlaufende mehr sandige Gleitufer (Brandungwanc) anf (w.. ()stseite, das zum größeren Teil von der Lister Odde eingenommen wircl. Nur dus imm.r. Becken und der

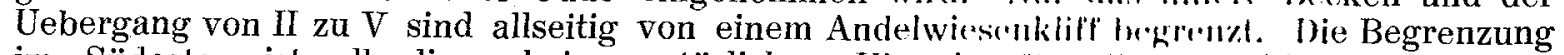

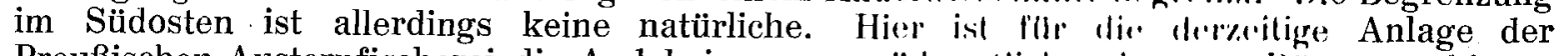

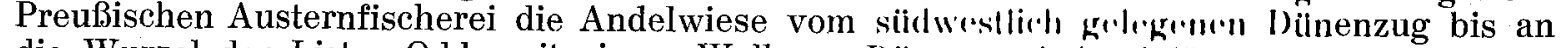
die Wurzel der Lister Odde mit einem Wall aus Dïn-nsinnd durrhliimmt worden. 
Zwischen diesen Ufern liegt das überall flache Bett des Kleinen Hafens. Bei normalem Hochwasser ist die Durchschnittstiefe etwa ein halber Meter. Das Bett des Prieles, der bei Flut und Ebbe die Wasserführung für den Kleinen Hafen übernimmt und in weitem Bogen um die Oddespitze herum in den Königshafen einläuft, ist etwas tiefer. Aus dieser durchschnittlichen Tiefe ergibt sich bereits, daß der Kleine Hafen nur im oberen Abschnitt der Tide überflutet wird. Die im äußeren Becken liegenden, kleinen Inseln und größeren Sandablagerungen am und im Prielbett auf der Höhe Oddespitze sorgen außerdem dafür, daß nicht alles bei Flut hineingeführte Wasser während derEbbe wieder ausströmt. Neben dem inneren Becken und dem Sielbecken ist es besonders das umfangreichere äußere Becken (Entnahmestation V, vergl. Abb. 3), das während der ganzen Ebbe, d. h. also praktisch dauernd, Wasser führt. Nur bei lang anhaltenden, trockenen Ostwindwetterlagen kommt es vor, daß das Wasser in diesen Abschnitten des Kleinen Hafens ganz verschwindet. Dann ist es aber nicht abgeflossen, sondern verdunstet.

Durch diese Tatsache auf der einen Seite und die normale stetige Wasserführung auf der anderen Seite weichen die hydrographischen Verhältnisse des kleinen Hafens von denen des Königshafens ab. Es ist aber nicht so sehr die Lage selbst, die diese Sonderstellung herbeiführt, als vielmehr die mangelhafte Entwässerung des Schlauches in den Königshafen.

Bevor ich auf die Eigenschaften des im Kleinen Hafen vorhandenen Wassers eingehe, beschreibe ich ganz kurz die hier vorhandenen Sedimente.

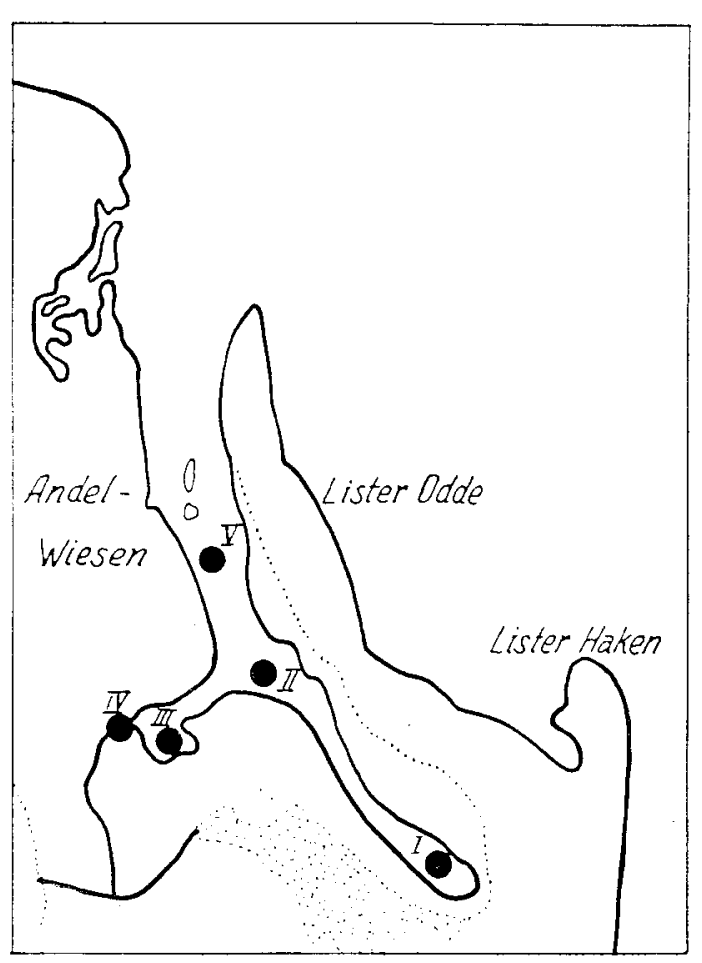

Abb. 3.

Die hydrographischen Stationen im Kleinen Hafen.

\section{Die Sedimente.}

Die Bezeichnungen, die wir zur Unterscheidung verschiedener Wattarten des allgemeinen Wattenmeeres verwenden, sind nicht geeignet, eine Vorstellung von der $\mathrm{Be}-$ schaffenheit der Sedimente im Kleinen Hafen zu vermitteln. Da nur der kleinere Teil bei Niedrigwasser zutagetritt, darf nur dieser mit Watt bezeichnet werden, der übrige Teil, den die Becken (vergl. Abb. 3) einnehmen, erhält zwar täglich zweimal neues Wasser um die Hochwasserzeit, gibt aber hiervon nur den Teil wieder während der Ebbe ab, der über die verschiedenen Barren den Weg in den Königshafen und damit in das Lister Tief findet. Der Rest verbleibt bis zur nächsten Ueberflutung im Becken, so daß dieses - dauernd von Wasser bedeckt - als ein Tide-Restbecken anzusehen ist.

Die einzelnen Abschnitte des Kleinen Hafens weisen sehr verschiedenartige Sedimente auf. Das innere Becken ist sehr weichgründig, der schlickige Sand locker gelagert und reich an Fäulnisprodukten. Gleich unter der Oberfläche ist der Boden von tief schwarzblauer Farbe. Es stehen vereinzelte Zostera-Horste in diesem flachen Becken.

Das mittlere Becken, von dem der größere Teil regelmäßig trockenfällt, ist festes, grobkörniges Sandwatt. In diesem Abschnitt liegt die seichteste Stelle, die die Schafe darum auch als Wechsel auf die Lister Odde benutzen.

Das Sielbecken führt dagegen während der Ebbe etwas Wasser. Das westliche Randgebiet ist in der Verlandung begriffen. Als eigenartige Verlandungsgesellschaft tritt hier das Schilf, Phragmites communis, zusammen mit dem Andel, Atropis maritima, und dem Queller, Salicornia herbacea, auf. Der Boden des Sielbeckens ist wie das innere Becken weichgründig und außerordentlich reich an faulenden Stoffen. Beim Hinüberschreiten dringen Fäulnisgase in schnell aufeinander folgenden Blasen an die Oberfläche.

Das mittlere Becken geht mit zunehmender Zostera-Vegetation nordwärts in das äußere Becken über. Dieses ist der größte, dauernd mit Wasser bedeckte Abschnitt des 
Kleinen Hafens. Die Ablagerungen sind hier außerordentlich locker gelagert und feinkörnig. Hier ist infolge der üppigen Vegetationsverhältnisse in stärkerem Maße von einer autochthonen Sedimentation zu sprechen. Das nördliche, äußere Drittel jedoch wird fester. Beim Uebergang in die Verlandungszone der westlich gelegenen Andelwiese beginnt ein ausgesprochenes Sandwatt mit üppigem Quellerbestand. In der Nähe der oben erwähnten kleinen Inseln ist Salicornia auf einem sehr nachgiebigen, ständig mit etwas Wasser bedeckten Sediment mit Zostera angustifolia vergesellschaftet. Das äußere Becken hat am

Tabelle 10.

$\begin{array}{ll}\text { Station } & \begin{array}{l}\text { Verschiedene } \\ \text { Kleiner Hafen } \\ \text { bei Niedrigwasser }\end{array} \\ \text { Datum } & \text { 3. Aug. 1933 } \\ \text { Witterung } & \text { warm }\end{array}$

\begin{tabular}{|c|c|c|c|c|c|c|c|}
\hline Entnahmestelle & Uhrzeit & Tide & Temp. ${ }^{0}$ & $\begin{array}{c}\text { Salzgeh. } \\
" / 00\end{array}$ & $\begin{array}{l}\mathrm{O}_{2}^{\circ} \% \\
\text { Sättig. }\end{array}$ & $\begin{array}{l}\mathrm{H}_{2} \mathrm{~S} \\
\mathrm{mg} / 1\end{array}$ & $\mathrm{pH}$ \\
\hline Inneres Becken I & $15^{00}$ & NW & 22.60 & 31.64 & 106 & Sp. & 8.50 \\
\hline Mittleres Becken II & & Stau & 23.70 & 31.38 & 107 & Sp. & 8.55 \\
\hline Sielbecken III & & Stau & 22.90 & 24.14 & 121 & Sp. & 8.30 \\
\hline Sielzug $\quad$ IV & & Stau & .22 .85 & 8.26 & 112 & 1.23 & 8.55 \\
\hline Aeußeres Becken $\mathrm{V}$ & & Stau & 22.00 & 31.56 & 142 & 0 & 8.70 \\
\hline Austernbrïleke & $16^{00}$ & Stau & 18.80 & 30.88 & 85 & Sp. & 8.20 \\
\hline
\end{tabular}

Tabelle 11.

$\begin{array}{ll}\text { Station } & \begin{array}{l}\text { Verschiedene } \\ \text { Kleiner Hafen } \\ \text { bei Hochwasser }\end{array} \\ \text { Datum } & \text { 8. Aug. 1933 } \\ \text { Witterung } & \text { windig, W. }\end{array}$

\begin{tabular}{|c|c|c|c|c|c|c|c|}
\hline Entnahmestelle & Uhrzeit & Tide & Temp. ${ }^{0}$ & $\begin{array}{c}\text { Salzgeh. } \\
\% / 00\end{array}$ & $\begin{array}{c}\mathrm{O}_{2} \% \\
\text { Sättig. }\end{array}$ & $\begin{array}{l}\mathrm{H}_{2} \mathrm{~S} \\
\mathrm{mg} / 1\end{array}$ & $\mathrm{pH}$ \\
\hline Inneres Becken I ! & $15^{00}$ & $\mathrm{HW}$ & 19.70 & 31.51 & 102 & 0 & 8.25 \\
\hline Mittleres Becken II & & Stau & 19.50 & 32.03 & 102 & 0 & 8.30 \\
\hline Sielbecken III & & Stau & 19.00 & 31.76 & 102 & 0 & 8.30 \\
\hline Vor dem Sielzug IV & & Stau & 19.65 & - & - & 一 & 8.30 \\
\hline Aeußeres Becken V & & Stau & 18.80 & 31.82 & 95 & 0 & 8.30 \\
\hline Austernbrücke & $16^{00}$ & Stau & 18.00 & 31.37 & 97 & 0 & 8.20 \\
\hline
\end{tabular}

Ufer der Lister Odde zwei bemerkenswerte Bildungen. Vor der Hochwasserlinie des Oddestrandes liegen zwei tischebene Terrassen, deren Oberfläche durch einen dichten Cyanophyceenrasen geschützt ist. Es sind Bledius-Standorte (vergl. S. 18 u. E. III, 5 u. 6).

Das Prielbett besteht in diesem äußeren Gebiet aus reinem Sand.

\section{Der Wasserhaushalt.}

Bei der Besprechung des Wasserhaushalts des Kleinen Hafens beschränke ich mich auf die Wiedergabe von zwei Tabellen, die die bei Niedrigwasser bezw. Hochwasser gemessenen Werte enthalten.

\section{Das Wasser bei Niedrigwasser.}

Nach den im vorhergehenden Abschnitt gemachten Ausführungen über die Morphologie, Vegetation und Sedimente sind normale hydrographische Verhältnisse nicht zu erwarten. In der Tabelle 10 sind die bei Niedrigwasser in den verschiedenen Abschnitten des Kleinen Hafens gemessenen Werte zusammengestellt. Der Abfluß aus dem Kleinen Hafen in der Zeit von 15 bis 16 Uhr, am 3. August, war gleich Null. 
Sehen wir vorerst vom Besonderen im Sielbecken ab, so fällt allgemein der hohe Sauerstoffwert $(142 \%)$ und die damit parallel laufende hohe pH-Zahl $(8,7)$ auf. Sie sind auf die Assimilationstätigkeit der dichten, dauernd überfluteten Seegrasbestände im äußeren Becken zurückzuführen.

Im Sielbecken (Entnahmestelle III) zeigt der verminderte Salzgehalt von 24,14\% deutlich den Einfluß des Sielzuges an. Eine Probe aus dem Graben innerhalb der Phragmites-Atropis-Salicornia-Bestände zeigt den nicht weiter überraschenden Wert von $8,36^{\circ} \%$. Trotz des kleinen Einzugsgebietes dieses Grabens muß ihm für den Wasserhaushalt um die Niedrigwasserzeit einige Bedeutung zugeschrieben werden.

Die in der letzten Spalte angeführte gleichzeitige Messung an der Austernbrücke zeigt in diesem Falle besonders deutlich den vergleichenden Wert einer solchen Kontrolle.

\section{Das Wasser bei Hochwasser.}

Die am 8. August bei Hochwasser gemessenen Werte sind bedeutend gleichförmiger (vergl. Tab. 11). Vom innersten Becken bis zum Mündungsgebiet liegt ein ziemlich einheitlioher Wasserraum vor. Die anschließend durchgeführte Kontrollmessung an der Austernbrücke läßt nur eine unwesentliche Temperatur- und Salzgehaltserhöhung während des Hochwassers im Kleinen Hafen erkennen. Im allgemeinen vermitteln die Werte die Vorstellung, daß die starken Schwankungen ausgesetzten Niedrigwasserwerte (Tab. 10) während der erneuten Ueberflutung ausgeglichen werden.

Die bisher für die Ostwindwetterlage gemachten Einschränkungen gelten natürlich auch für diesen Vergleich. Es war leider nicht möglich, in solchen Zeitabschnitten hydrographische Untersuchungen zu machen, wenn auch mehrfach festzustellen war, daß die Ueberflutung des Kleinen Hafens manchmal wochenlang ausblieb.

\section{E. Die Lebensgemeinschaften des Königshafens.}

\section{Die biologische Untersuchungsmethode.}

Die erste planmäßig durchgeführte biologische Bestandsaufnahme im Wattenmeer und eine systematische Liste über die im nordfriesischen Wattenmeer vorkommenden Tiere verdanken wir Hagmerer (21). Im Sommer 1932 führte ich die Bestandsaufnahme im Königshafen durch und wiederholte sie z. T. im nächsten Jahre, um sie bei gelegentlichen kurzen Aufenthalten im Jahre 1934 und 1936 zu ergänzen und nachzuprüfen. Wie aus der Geländeskizze Abb. 1 ersichtlich, legte ich durch die verschiedenen Wattgebiete des Königshafens Profile mit einer der Eigenart der einzelnen Teilgebiete Rechnung tragenden Anzahl von Stationen. Es stellte sich bald heraus, daß es wenig Zweck hatte, sich streng schematisch an die Profil-Linie zu halten. Dazu waren die Besiedelungsverhältnisse nicht gleichförmig genug. Unter Innehaltung der linienartigen Profile ging ich daher bald dazu über, das Stationsnetz darüber hinaus auch auf die abseits liegenden Standorte auszudehnen. Im Fortgang der Geländearbeit bestätigte sich immer von nenem, daß ein quantitativer Untersuchungsschnitt um so ergiebiger im ökologischen Ergebnis war, je sorgfältiger in dem betreffenden Gelände die qualitative Voruntersuchung durchgeführt worden war. Ich schob daher in regelmäßigen Abständen zwischen die Tage rein quantitativer Untersuchung einen Tag, der allein für die Beobachtung und für qualitative Analysen bestimmt war.

Die Bestandsaufnahmen wurden folgendermaßen durchgeführt. Das Zweiglaboratorium List der Biologischen Anstalt Helgoland bildete den Ausgangspunkt meiner Wattuntersuchungen. Die Biologische Anstalt stellte mir außer den im Lister Laboratorium vorhandenen Geräten ein kleines Ruderboot mit flachem Boden von etwa $2 \mathrm{~m}$ Länge und $1 \mathrm{~m}$ Breite, den „Steer“ zur Verfügung. Ein kleines Treibsegel erleichterte mir die langen Anfahrtswege in die Bucht hinein. Bei zu grober See ließ ich mich von DETHLEFs MotorAusternkutter an die Mündung des Hauptpriels schleppen.

Nachdem ich durch Vergleichbestimmungen die für verschiedenartige Siedlungen erforderliche Mindestgröße der Untersuchungsflächen herausgefunden hatte, wurden die quantitativen Bestandsaufnahmen abschnittweise durchgeführt. Das Hauptflächenmaß betrug $1 / 20 \mathrm{qm}$. Eine solche Probefläche wurde bis zu $30 \mathrm{~cm}$ Tiefe ausgehoben, der Sand bezw. Schlick in Zinkeimer gefüllt und durch den bekannten Helgoländer Siebsatz, der von der Biologischen Anstalt für die Ertragsschätzung des Meeresbodens verwendet wird, ge- 
siebt. Das kleinstmaschige Sieb (Krupp V 2 A-Gewebe) hatte die Maschenweite von $1 \mathrm{~mm}$. Die Bestandsaufnahme umfaßt also nur die Tiere, die noch von diesen Maschen zurückgehalten wurden. In bestimmten Sedimenten mit vorwiegend großen Besiedelungsdichten wurden klejne Probeflächen $(75 \mathrm{qcm})$ gewählt. 1933 verwendete ich noch ein Sieb von $1 / 2 \mathrm{~mm}$ Maschenweite. Hier machten sich jedoch die gröberen Sedimentteilchen recht störend bemerkbar.

Das Aussieben der Proben erfolgte an Ort und Stelle. Da die Untersuchungen bei trocken gefallenen Wattflächen durchgeführt wurden und der allein Wasser führende Priel oftmals weit entfernt war, grub ich an verschiedenen Stellen des Profils tiefe Löcher. Diese füllten sich allmählich mit Sickerwasser, so daß ich darin die Siebung vornehmen konnte. Die in den Sieben zurückgebliebenen Tiere wurden in $4 \%$ Formalinlösung konserviert, im Laboratorium in List und Helgoland bestimmt bezw. nachbestimmt und zum Teil gemessen und gewogen. Das Tagebuch enthielt außer den gefundenen Tieren Angaben über die Beschaffenheit des Standortes (Oberflächenformen, Vegetation, Festigkeit, Farbe, Schlick, Sand, Mächtigkeit der Oxydations- und Reduktionszonen, Geruch, Einschlüsse u. a.). An heißen und trockenen Tagen war das Aussuchen und Gewinnen der zarten Würmer sehr erschwert, weil sie sehr schnell an den Maschen antrockneten. Ein in der Nähe des Untersuchungsgeländes aufgestellter selbst verfertigter Windschirm erleichterte die Arbeit sowohl an den genannten heißen als auch an den kalten und windreichen Oktobertagen.

Nicht selten waren die organischen wie auch die anorganischen Siebrückstände so umfangreich, daß an ein quantitatives. Auslesen nicht zu denken war. Von solchen Standorten wurden die Gesamtproben ins Boot getragen und sorgfältig im Laboratorium untersucht.

Auch bei den faulschlammartigen Sedimentproben (Mudd-Watt) war das Aussieben nicht befriedigend. Mit diesen Proben setzte ich im Laboratorium Kulturen an, die mir nach einigen Tagen einen genauen Einblick in die Arten- und Individuendichte vermittelten. Gleichzeitig verdanke ich solchen Kulturen eine ganze Reihe von Anregungen bezüglich der Biologie verschiedener Wattiere (vergl. Abb. 60).

In der Regel wurde die Bestandsaufnahme bis zur erneuten Ueberflutung ausgedehnt. Ich ließ mich dann im bereitliegenden "Steer" vom aufkommenden Wasser bestauen und konnte über den flachen Bootsrand hinweg die Lebensäußerungen der im Watt lebenden Tiere im Augenblick der Ueberflutung beobachten.

Um auch einen Eindruck von der Zusammensetzung der größeren, beweglichen Tiere des Bodens im Untersuchungsgebiet zu bekommen, wurden gelegentlich Schleppzüge mit der eigens für das flache Wattenmeer in Helgoland konstruierten Hydroiden-Dretsche gemacht. Es handelte sich besonders darum, die Tiere zu erlangen, die sich bei Hochwasser im Randgebiet des Königshafens, also innerhalb der Zostera-marina-Bestände aufhalten. Da das Fischen mit dem vor dem Wind segelnden "Steer" zu ungleichmäßig war, mußte ich auf eine quantitative Auswertung dieser Dretschfänge verzichten.

Daß im Laboratorium eine Reihe verschiedener Watt-Aquarien für Sonderbeobachtungen aufgestellt war, bedarf keiner besonderen Erwähnung.

Das Wägen der Tiere erfolgte auf einer Hornschalenwage auf $1 / 100$ g genau, nachdem die konservierten Tiere vorher auf Fließpapier von der anhaftenden Feuchtigkeit befreit worden waren. Das Messen der Muscheln wurde bei schwacher Lupenvergrößerung über einem von unten beleuchteten Maßstab aus Glas mit Millimeterteilung vorgenommen.

\section{Biota ( = Fauna und Flora).}

1. Liste der gefundenen Tierarten.

In der folgenden Aufstellung sind die in und auf dem Watt des Königshafens lebend angetroffenen Tiere, soweit sie mit dem Sieb von $1 \mathrm{qmm}$ Maschenweite erbeutet werden konnten, zusammengestellt. Nicht einbezogen sind das Großplankton (Medusen, Mysideen usw.) und die Fische. Wegen der letzten verweise ich aluf die kürzlich veröffentlichte Liste (WOHLENBERG, 1935 S. 8-9).

W ürmer:

Lineus ruber Müll.

Amphiporus spec. beide Nemertinen wurden in größerer Anzahl und in starken Stücken besonders in der stark verschmutzten Tonnenlegerbucht gefunden, außerdem auf dem ganzen Odde-Watt und in der Zostera nana-Zone vor dem Gröning. 
Lepidonotus squamatus (L.).

Gattyana cirrosa (Pall.). Von diesen beiden Schuppenwürmern fand ich Gattyana nur nahe an der Niedrigwassergrenze auf gut durchfeuchteten und nie ganz trockenfallenden Watten. Lepidonotus war häufiger und auch in höher gelegenen Wattgebieten zu finden.

Eteone spec. Nicht selten auf allen mehr sandigen Watten.

Eulalia viridis (Müll.). In einem Stück in der Tonnenlegerbucht gefunden.

Phyllodoce maculata (L.). Selten in der Tonnenlegerbucht.

Nereis pelagica L. Nur in zwei Stücken in dem dauernd überfluteten Klei-Kliff des Prielabschnittes III nachgewiesen.

Nereis diversicolor Müll. Der Wattringelwurm ist dagegen sehr weit verbreitet, besonders im oberen Abschnitt der Gezeitenzone in vorwiegend schlickigen Sedimenten (vergl. Seite $30 \mathrm{u}$. ff.).

Nephthys Hombergii Aud. \& M. Edw. Fehlt an der Hochwassergrenze, dagegen häufiger in allen tiefer gelegenen, sandigen Sedimenten.

Scoloplos armiger (Müll.). Sehr häufig in allen ständig gut durchfeuchteten, dunkel pigmentierten Watten. Regelmäßig in dem schwefeleisen-haltigen Watt der Zostera nana-Zone zwischen den Rhizomen anzutreffen. Allgemein verbreitet.

Pygospio elegans Clapar. Wurde besonders zahlreich im oberen Abschnitt der Gezeitenzone im Corophium-Gürtel und darunter auf festgründigen Wattflächen gefunden. Die Wohn- und Brutröhren - oft rotbraun durch Eisenoxydhydrat - zeigten regelmäßig nahe unter der Oberfläche eine etwas dünnere, in spitzem Winkel abzweigende Nebenröhre. SöDERSTRöm (71) erwähnt in seiner ausführlichen Arbeit nicht solche Bildungen.

Polydora ligni Welster. Neu für die deutsche Bucht. Nur in dem ständig überfluteten Klei-Kliff im Prielabschnitt III (vergl. E, III, 7, d, ec) sehr dicht siedelnd.

Scolecolepis squamata Söderstr. = Nerine cirratulus (Delle Chiaje). In ausgesprochenen Sandwatten gefunden, die infolge starker Umlagerung durch Strömung und Wellenschlag keine faulenden organischen Reste enthalten und daher frei von Schwefeleisen sind, also vorwiegend im reinsandigen Brandungsgürtel und in den Stromsänden (vergl. E, III, 7, d, aa und bb).

Scolelepis foliosa Söderström = Nerine foliosa (Aud. \& M. Edw.). Sehr viel seltener als vorige.

Microspio wireni Augener. Nur im dauernd überfluteten tonigen Kliff des Prielabschnittes III angetroffen.

Colobranchus ciliatus Keferst. = Scolelepis ciliata (Keferst.). Neu für die de uts che Bucht. Zusammen mit Capitella und Peloscolex in dem halbflüssigen Mudd-Watt der Mytilus-Bänke und der Fucus-Zonen.

Magelona papillicornis Fr. Müll. Selten. Uthörner Außenwatt. Von Hagmeier (21, S. 17) einmal im Eidumtief festgestellt.

Ophelia cluthensis McGuire. Neu für die deutsche Bucht. Im Königshafen fast immer vergesellschaftet mit Scolecolepis squamata in besonders rein gewaschenen grobkörnigen Sanden (vergl. E, III, 7, b und d).

Heteromastus filiformis (Clapar.). Neu für die deutsche Bucht. Trotz allgemeiner Verbreitung auf den Watten der Westküste Schleswig-Holsteins zum ersten Mal für die Deutsche Bucht nachgewiesen. Auf dunkel pigmentierten schlickigen Sandwatten von lockerem Gefüge.

Capitella capitata (Fabr.). Oft zusammen mit Heteromastus, zahlreicher im Mudd-Watt mit den größten Schwefelwasserstoffwerten, hier zusammen mit Colobranchus und Peloscolex.

Arenicola marina (L.). Der Sandpier ist das verbreitetste Tier im Königshafen. Es lebt im gesamten Gezeitengürtel und auch darunter in dauernd überfluteten Sandgebieten. Die jungen Tiere siedeln im Königshafen für sich und bilden im oberen Abschnitt der Gezeitenzone auf festgelagerten Sandwatten einen breiten Gürtel. Dieser Gürtel - Arenicola-Brutwatt - wird in der Regel vom Corophium-Gürtel nach oben und von der Zostera nana-Wiese nach unten begrenzt (vergl. S. 45).

Ampharete grubei Malmgr. Nicht selten im Mudd-Sediment des Odde-Watts und vor dem Gröning. Hauptsächlich auf solchen Standorten, die von Zostera stenophylla (Kleiner Hafen) und Z. angustifolia (zwischen Odde-Spitze und der Insel Uthörn) bestanden und auch während der Ebbe mit etwas Wasser bedeckt sind. Auf der aus organischen Bestandteilen und feinstem Sediment zusammengesetzten 
Wohnröhre fand ich oft Diatomeen und Enteromorpha-Keimlinge, eine Erscheinung, die auf die von Nienburg (53) aufgeworfene Frage nach der Verankerung der Enteromorpha-Keimlinge auf den weichgründigen Schlammwatten Auskunft zu geben vermag.

Lanice conchilega Pall. Sehr häufig - bis zu 1500 Stck. auf den Quadratmeter! - innerhalb der Zostera marina-Wiese an der Niedrigwassergrenze. Im Königshafen fast stenotop mit $Z$. marina. Im übrigen Wattenmeer der Westküste dagegen nicht an Zosteren gebunden, aber dann in mehr lockeren Beständen als im Königshafen (Röhrenlänge bis zu $50 \mathrm{~cm}$ !).

Amphitrite johnstoni Malmgr. In großen Stücken im tieferen Teil der dauernd überfluteten Zostera marina-Wiese. Die dicken Wohnröhren aus sandigem Schlick innerhalb eines gleichmäßig feinkörnigen grauen Sandes überragen oft die Standortsoberfläche. Während des Trockenfallens (bei Sturm aus Ost) ließen die Tiere ihre rotbraunen Tentakelbüschel über die Röhrenmündung hängen.

Enchytraeus albidus Henle. Wurde im Königshafen lediglich im Sediment der Bledius spectabilis-Standorte gefunden (vergl. E, III, 5, e und f).

Clitellio arenarius (Müll.). Bevorzugt sandige, nicht schlickige Watten in der Nähe der Hochwasserlinie, kommt zusammen mit Scolecolepis und Ophelia vor, erträgt jedoch im Gegensatz $\mathrm{zu}$ diesen leichte Verunreinigungen durch $\mathrm{H}_{2} \mathrm{~S}$.

Peloscolex benedeni Udekem. Ist im Königshafen charakteristisch für das halbflüssige Mudd-Watt mit hohem Schwefelwasserstoffgehalt.

Muscheln:

Mytilus edulis L. Die Miesmuschel kommt in großen Beständen auf den Muschelbänken am Hauptpriel und auf dem Odde-Watt und in den Fucus-Zonen mit der Braunalge versponnen vor.

Volsella modiola (L.) = Modiola modiolus L. Die große Miesmuschel wurde in einem Stück im Hauptpriel (Prielabschnitt II) gefunden.

Ostrea edulis L. Bei Sturm aus Ost kann in seltenen Fällen das Wasser bei Hohlebbe so weit abfallen, daß unterhalb der Zostera marina-Wiesen vereinzelte Austern freikommen.

Macoma balthica (L.). Die Plattmuschel war stellenweise häufig auf locker gefügten, dunkel pigmentierten schlickigen Sandwatten. Auch im feinsten Mudd konnte zahlreiches Junggut nachgewiesen werden.

Tellina tenuis da Costa. Die dünnschalige Plattmuschel ist im Königshafen bezeichnend für die an der Niedrigwasserlinie liegenden vor der Brandung offenen Sandwatten, ohne organische Beimengungen. Sie war regelmäBig auf dem Uthörner Außenwatt und bei der ehemaligen Lister Austernbrücke zu finden.

Scrobicularia piperata (Gmelin) $=$ S. plana (da Costa). 1932 war die flache Pfeffermuschel im Gebiet sehr selten, 1934-36 dagegen sehr häufig in den weichgründigen schlickigen Sedimenten zwischen dem Mövenberg und dem Gröning sowie auf dem Odde-Watt.

Cardium edule L. Die Herzmuschel bevorzugt im Königshafen ausgesprochenes Sandwatt im Uthörner Außenbezirk. Auf dem Watt der Tonnenlegerbucht ist sie auch regelmäßig in dunkel pigmentierten, etwas schlickigeren Sedimenten zu finden.

Mya arenaria $\mathrm{L}$.

Mya truncata L. Während M. arenaria keine typische Verbreitungsweise aufweist, kommt $M$. truncata nur unter der Niedrigwasserlinie besonders gleich unterhalb der Zostera marina-Wiesen zusammen mit Amphitrite johnstoni vor.

Barnea candida (L.). Die weiße Bohrmuschel besiedelt das dauernd überflutete Kleikliff im Prielabschnitt III.

Schnecken:

Trachydermon cinereus (L.). Die Käferschnecke kam auf Miesmuschelbänken und in Fucuszonen auf dem Odde-Watt bei Uthörn vor. Sie hatte hier die hellbraune Farbe des Fucus angenommen.

Litorina litorea (L.). Die spitze Strandschnecke war allgemein verbreitet. Besonders wurden die Zostera-Wiesen von ihnen beweidet.

Litorina obtusata (L.).

Litorina saxatilis (Olivi) $=$ L. rudis (Mat.). Die stumpfe und die dunkle Strandschnecke konnten in der Fucus-Zone südlich von Uthörn gesammelt werden. 
Buccinum undatum L. Die Wellhornschnecke fand ich nach Stürmen auf der äußeren Miesmuschelbank.

Nassa reticulata (L.). Die Netzreusenschnecke beschränkte sich auf das von Zostera marina besiedelte Gebiet an und unter der Niedrigwasserlinie.

Hydrobia ulvae (Penn.) war im oberen Gezeitendrittel allgemein verbreitet. Die größte Siedelungsdichte fiel etwa mit der von Corophium zusammen, häufig aber auch im Zostera nana-Gebiet.

Polycera quadriliniata Müll. In der Zostera marina Wiese.

Limapontia capitata Müll. In der Salicornia-Zostera nana-Zone an der Mündung des Kleinen Hafens.

Krebse:

Idothea tricuspidata Desm. (= I. baltica Pall.). War zahlreich in den Z. marina-Beständen.

Iaera albifrons Leach. Gehört zur Epifauna der äußeren Miesmuschelbank.

Balanus balanoides L. Auf den Schalen jener Miesmuscheln, die nicht mit Fucus versponnen sind.

Talitrus saltator Mont. Der Sandspringer lebt an und oberhalb der Hochwasserlinie. Die Bevölkerungen konnten bei Wanderungen in die Dünen und bei solchen in die tiefer gelegenen Watten beobachtet werden, und zwar abends und nachts.

Gammarus locusta f. zaddachi (?) (=G. zaddachi Sexton). Zahlreich in den Fucus-Beständen.

Ericthonius difformis M. Edw. Zahlreich auf den Blattspreiten von Zostera marina in kleinen Wohnröhren aus Schleim und feinem Detritus.

Corophium volutator Pall. Im Königshafen durchweg auf eine gürtelartige Zone etwas unterhalb der Hochwasserlinie in sandigen und schlickigen Sedimenten beschränkt.

Crangon vulgaris Fabr. Bisweilen eingegraben gefunden.

Eupagurus bernhardus L. Kleine Stücke des Einsiedlerkrebses lebten in Litorina-Gehäusen in der Zostera marina-Wiese. Nach Stürmen wurden auch größere Stücke in Wellhorngehäusen gefunden.

Carcinus maenas L. Im ganzen Gebiet - mit Ausnahme der muddigen Ablagerungen eingegraben gefunden, jedoch vorwiegend junge Tiere.

Stachelhäuter:

Asterias rubens L. Zahlreich in kleineren Stücken innerhalb der Seegrasbestände an und unterhalb der Niedrigwasserlinie.

Psammechinus miliaris Gmelin. Der Strandigel kommt ebenfalls nur in der Seegraswiese und tiefer vor.

Insekten:

Archisotoma besselsi Pack. Neu für die deutsche Bucht. Sehr viele junge Tiere in einer verlassenen Wohnröhre von Bledius spectabilis und auch zusammen mit Corophium und Clitellio arenarius. ( $\mathrm{Im}$ übrigen Wattenmeer habe ich andere Arten gefunden.)

Chironomidae. Ephydrinae. Lispa caesia.

Die Chironomidenlarven fand ich nur im Kleinen Hafen dort, wo der Süßwassersielzug in den Kl. Hafen einmündet.

Die Hydrellia spec. (Ephidrinae) waren am Ellenbogenstrand mit Bledius arenarius und - spectabilis vergesellschaftet.

Lispa caesia kam in und unter dem Porenlufthorizont des Diglotta-Stromsandes (vergl. E, III, 7, d, bb) zur Entwicklung.

Cillenus lateralis Sam. Auf allen Bledius spectabilis-Standorten und auf dem DiglottaStromsand mitten im Königshafen (vergl. E, III, 5, e und 7, d, bb).

Dyschirius angustatus Ahr. Nur auf den Strandhaken am Ellenbogenstrand zusammen mit Bledius arenarius und Hydrellia spec.

Dischiriotrichus pubescens Payk. Zusammen mit Bledius spectabilis.

Heterocerus flexuosus Steph. Nur zusammen mit Bledius spectabilis.

Dyschirius spec. (wahrscheinlich nitidus Dej.?). Neben D. angustatus.

Bledius spectabilis Kr. Im Königshafen gebunden an geschichtete Sedimente, deren Oberfläche durch Cyanophyceenrasen hautartig nach oben abgeschlossen ist (vergl. E, III, 5 und 6). 
Bledius arenarius v. subniger Schneid. An und über der Hochwassergrenze auf den Hakensänden am Ellenbogen (E, III, 6).

Diglotta mersa Halid. Im Porenlufthorizont eines Stromsandes am Prielabschnitt III zusammen mit Cillenus, Lispa, Ophelia und Scolecolepis (vergl. E, III, 7, d, bb).

2. Die Liste der gefundenen Pflanzenarten.

Cyanophyceen. Von den Blaualgen wurden verschiedene Arten gefunden, von denen Microcoleus chthonoplastes für die Standortsbeschaffenheit die größte Bedeutung hat.

Diatomeen. Die Kieselalgen kamen in großer Artenzahl vor, und zwar einzeln und rasenbildend sowie vor dem Gröning in Schläuchen büschelförmig im sandig-schlickigen Sediment verankert.

Enteromorpha. In verschiedenen Arten.

Ulva Lactuca L. Auf Sandwatt an Steinen und Muschelschalen verankert.

Chaetomorpha linum (Müll.) Kütz. In langen aufgehaspelten Strängen auf dem tief gelegenen schlickigen Odde-Watt.

Elachista fucicola (Vell.) Aresch.

Chorda Filum (L.) Lamour. An Muschelschalen im Prielabschnitt III verankert.

Fucus vesiculosus L. An Steinen und Pfählen der Buhnen zusammen mit der nächstfolgenden Art.

F. Mytili Nienbg. Mit der Miesmuschel auf Muschelbänken auf schlickigem Watt und an Buhnenköpfen versponnen.

Polysiphonia violacea (Roth) Grev. Auf den Spitzen der mehrere Meter langen Chorda Filum im Prielabschnitt III.

Zostera marina L. An und unter der MNW-Linie.

Z. stenophylla. Im Tide-Restbecken des Kleinen Hafens.

$Z$. angustifolia. In der Gezeitenzone auf schlickigem weichem Boden.

$Z$. nana Roth. Im oberen Abschnitt der Gezeitenzone.

Salicornia herbacea L. In verschiedenen Formen auf den tischebenen Bledius spectabilisStandorten.

Suaeda maritima (L.) Dum. .Desgl.

Spergularia salina Presl. Desgl.

Statice Limonium L.

Phragmites communis Trin. In der Verlandungszone des Kleinen Hafens.

Puccinellia maritima Parl. = Atropis maritima Grisebach. Auf den tischebenen Bledius spectabilis-Standorten.

Agropyrum junceum P. B.

\section{Die Standorte und ihre Besiedelung.}

Um die in der Natur vorhandene enge Verflechtung verschiedenartiger Faktoren möglichst auch in der Darstellung zu wahren, habe ich die physikalischen und chemischen Einzel-Untersuchungen in enger Verbindung mit den biologischen durchzuführen versucht und sie nicht in den allgemeinen Abschnitten über die Sedimente und den Wasserhaushalt für sich getrennt wiedergegeben.

Bevor ich auf die einzelnen Standorte der Gezeitenzone eingehe, möchte ich die ökologische Grenzziehung durch die MNW-Linie und ihre Besiedelung anhand der Tagebuchaufzeichnungen besprechen.

1. Die MNW-Linie im Osten als ökologische Grenze.

Ich sagte bereits, daß die Niedrigwasserlinie nicht allein eine hydrologische, sondern auch eine ausgesprochene ökologische Grenze sei.

Da das untere Grenzgebiet selten trocken fällt, habe ich hier keine quantitativen Bestandsaufnahmen durchführen können. Aber meine Tagebuchaufzeichnungen über die qualitative Zusammensetzung genügen bereits, die Grenzziehung zu rechtfertigen.

An und eben unterhalb der MNW-Linie leben folgende Tiere: Mya truncata, Nassa reticulata, Litorina litorea, Litorina obtusata, Lacuna divaricata, Polycera quadrilineata, Gattyana cirrosa, Amphitrite johnstoni, Lanice conchilega, Ericthonius difformis, Eupagurus bernhardus, Idothea tricuspidata, Asterias rubens, Psammechinus miliaris. 
Diese Liste stimmt gut mit den 1927 von HAGMEIER und KäNDLER (21) gemachten Angaben über die Besiedelung dieser Gegend überein. Von diesen 14 Arten wurden $11 \mathrm{nicht}$ oberhalb der MNW-Linie gefunden. Für viele Arten ist die Seegraswiese, die ja gerade diesen Grenzstreifen einnimmt (jedenfalls 1932, spätere Befunde über die Erkrankung vergl. WoHlenberg, 90, S. 8-14), ein ausschlaggebender Standortsfaktor. Darum muß auch ihr neben dem Ueberflutungsfaktor die Hauptbedeutung für die Art der Besiedelung zugeschrieben werden. Die Grenzziehung könnte unschwer noch ïberzeugender gestaltet werden, wenn die gesamte Hydrobiose und alle festsitzenden und freilebenden Kleinorganismen mit aufgeführt würden. Bezüglich der hier lebenden Fische vergl. 90, S. 8-9.

\section{Die Tonnenlegerbucht.}

a) Die Lage und die gestaltenden Kräfte.

Das Watt der Tonnenlegerbucht gehört zum südöstlichen Randgebiet des Königshafens. Es wird im Westen durch die Lister Odde (Abb. 1 und 4), im Osten durch den sogenannten Lister Haken (nach Kolumbe, 37, die jüngste Strandbildung im Lister Bezirk) begrenzt. Nach Norden bezw. Nordwesten ist die Bucht offen. Eine flache Niederung, die an der Ent- und Bewässerung des Odde-Watts beteiligt ist, bildet die Grenze zum eigentlichen Odde-Watt. Der Lister Haken ist abgesehen von der am Ellenbogen gebildeten Nehrung die einzige Stelle, wo z. Zt. ein größerer Gebietszuwachs festzustellen ist. Dieser Gebietszuwachs erfolgt jedoch in ganz besonderer, nicht alltäglicher Weise.

Von Süden her kommen durch Küstenversetzung (37) unentwegt Sandmengen, von Norden her dagegen nach meinen Beobachtungen umfangreiche Mengen organischer Rohstoffe. Der von Süden heranwandernde Sand lagert sich am Ende des Hakens ab, oder wird vom Strom, der auf das Odde-Watt

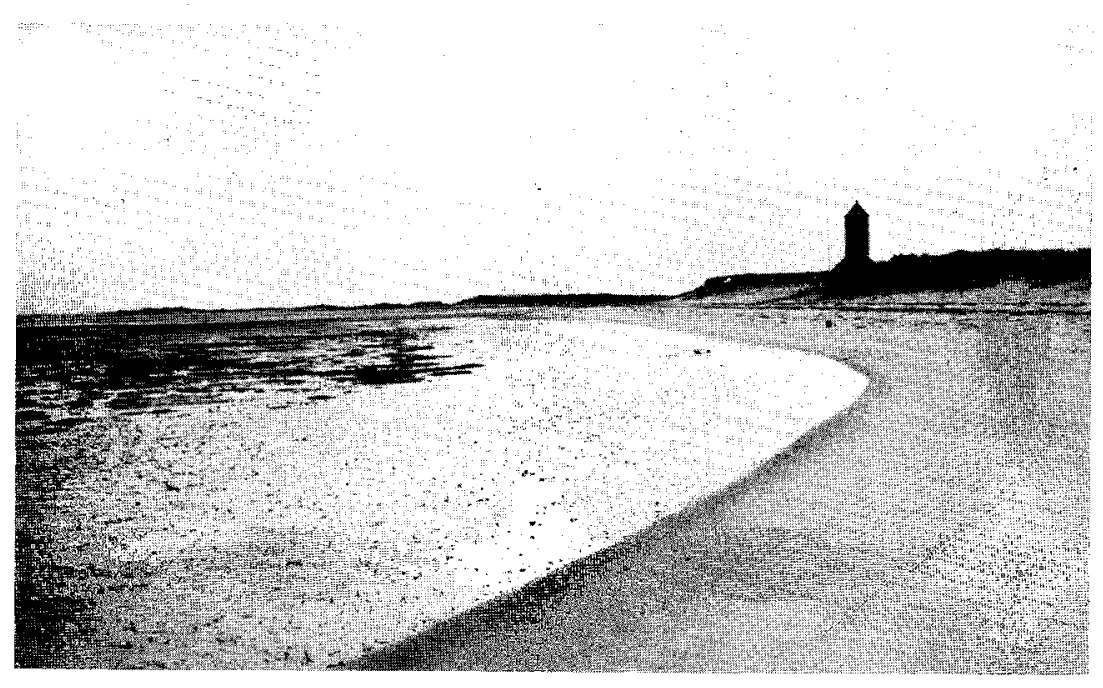

Abb. 4. Das dem südljchen Teil der Lister Odde (rechts) und dem Lister Haken (links hinten) vorgelagerte Watt der Tonnenlegerbucht. zudrängt, um die Hakenspitze herumgetragen. Hier kommt er streifenförmig zur Ablagerung und wandert nach und nach, wie ich durch Messung feststellen konnte, in schwachgewölbten Rücken auf die Hochwasserlinie des Hakens zu. So schiebt sich der Haken allmählich weiter nördlich vor. Bei diesem Zuwachsmaterial handelt es sich um ausgewaschenen Quarzsand. Der von Norden kommende Anteil des im Werden begriffenen Sediments ist in derselben ausgesprochenen Weise allein organischer, wie der von Süden kommende allein anorganischer Herkunft ist. Der innerste Teil der Bucht, auf den sich die unten erörterten Sedimentanalysen und die Bestandsliste nicht beziehen, ist zeitweise vollkommen angefüllt mit mehrere hundert Quadratmeter umfassenden und bis $\mathrm{zu} 60 \mathrm{~cm}$ mächtigen Ablagerungen von abgestoßenen Seegrasblättern (vergl. WohlenberG, 90, Abb. 7). Diese gewaltigen Mengen entstammen den Vegetationsgebieten des Königshafens, dem unmittelbar benachbarten Odde-Watt und z. T. wohl auch dem östlich gelegenen Wattenmeer. Auf dem Wege in die innerste Bucht oder auch in den Spülsaumbereich des Hochwassers bleiben größere zusammenhängende "Inseln" fladenförmig auf dem der innersten Bucht vorgelagerten Watt liegen. Je nach den in der darauffolgenden Zeit vorherrschenden Wind- und Wasserverhältnissen werden die Ablagerungen als Ganzes oder aufgelöst weitergetragen oder aber verbleiben als zusammenhängende Flade auf dem Watt. Es ist wiederum eine Frage der Wetterlage, wie bald und wie stark die Seegrasablagerung von 
Süden her übersandet und damit schichtartig dem Sediment einverleibt wird. Dabei ist es bei diesen Erörterungen gleichgültig, ob der Sand in der oben beschriebenen Weise durch das Wasser oder durch starke südliche Winde vom hochwasserfreien Haken selber herübergetragen wird. Das Besondere an dieser Sedimentbildung ist der voneinander völlig getrennt erfolgende Materialtransport und "die Form der konzentriertesten Ablagerung organischer Stoffe, wie ich sie ähnlich im Watt am Hindenburgdamm nachweisen konnte (90, S. 15 u. 16). Im allgemeinen aber hat ja die organische Komponente im Watt der Festlandskïste die Struktur feinster in Zersetzung und Auflösung begriffener Reste von Pflanzen und Tieren, die durchweg mit der anorganischen gut durchmischt werden. Diese Sedimentationsverhältnisse der Tonnenlegerbucht vermitteln somit eine Vorstellung von den Kräften, die für die besondere Beschaffenheit der hier vorhandenen Sedimente verantwortlich zu machen sind.

\section{b) Die allgemeine Besiedelung.}

Arenicola marina ist das am weitesten verbreitete Tier im Königshafen. Bei den ersten orientierenden Exkursionen erschien die Besiedelung durch Arenicola so gleichförmig, daß von vornherein wenig Aussichten vorhanden waren, über frühere Feststellungen hinaus irgendwelche Nachweise über die Ansprüche dieses T'ieres an den Standort machen zu können. Auch das Watt der Lister Tonnenlegerbucht machte zuerst den Eindruck eines durchaus gleichförmig besiedelten Gebietes. Die Begehung zeigte jedoch, daß hier das Sediment Eigenheiten aufwies, die so ausgeprägt an anderen Stellen des Königshafens nicht vorkamen. Während die oberen Zonen noch f'est und von heller Farbe waren, nahm die Dunkelfärbung der Oberfläche an Intensität zu, je mehr ich mich dem tiefsten Teil der nördlich gelegenen Niederung näherte. Auch die Tiefgründigkeit nahm in so starkem Maße zu, daß Teile der Niederung vollständig unzugänglich und nur vom Boot aus zu untersuchen waren. Nach der Verteilung der mehr oder weniger dicht liegenden Häufchen schien es sich um ein ganz gewöhnliches Arenicola-Watt zu handeln. Eine genaue Bestandsaufnahme der in diesem Watt lebenden Endobiose ergab jedoch ein anderes, und zwar ein auffällig sprunghaftes Bild in der Artenverteilung sowohl als auch in der Wohndichte. Aus diesem Grunde wurde das Watt der Tonnenlegerbucht trotz der kleinen Flächenausdehnung mit einer größeren Anzahl von Stationen belegt, als es im übrigen Gebiet sonst möglich war. Es ist selbstverständlich, daß alle auf quantitativer Grundlage untersuchten Bodenproben durch eine noch größßere Zahl von qualitativen oder orientierenden Nachforschungen ergänzt und unterstüt $\%$ t wurden.

Aus der folgenden Bestandsliste (Tab. 12) geht klar hervor, daß der Borstenwurm Nereis diversicolor für das Watt der Tonnenlegerbucht das Charaktertier darstellt. Die Stückzahl für ${ }^{1 / 20} \mathbf{m}^{2}$ ist recht hoch (Max. 51). Die Größe der Würmer war schwankend

Tabelle 12.

Bestandsliste über die unter $1 / 20 \mathrm{~m}^{2}$ Wattfläche lebenden Tiere. Tonnenlegerbucht, August 1932.

\begin{tabular}{|c|c|c|c|c|c|c|c|c|c|c|c|c|c|c|c|c|c|c|c|c|}
\hline \multirow{2}{*}{ Art: } & Profil: & III & III & III & IV & III & III & III & III & III & III & III & III & III & III & IV & IV & III & III & III \\
\hline & Station: & $7 \mathrm{a}$ & $6 \mathbf{a}$ & $5 a$ & 3 & $5 \mathrm{~b}$ & $5 \mathrm{c}$ & $4 \mathrm{a}$ & $4 \mathrm{~b}$ & $3 a$ & $3 \mathrm{~b}$ & $3 \mathrm{c}$ & $2 \mathrm{a}$ & $2 \mathrm{~b}$ & $2 \mathrm{c}$ & 1 & $2 b$ & $1 a$ & $1 \mathrm{~b}$ & $1 \mathrm{c}$ \\
\hline \multicolumn{2}{|c|}{ Macoma balthica } & - & - & - & 3 & 1 & - & - & - & - & 2 & - & 4 & 1 & 10 & - & $\ldots$ & 2 & 13 & 13 \\
\hline \multicolumn{2}{|c|}{ Cardium edule } & - & 一 & 2 & - & 2 & - & 一 & - & - & 一 & 1 & 2 & 2 & 1 & 2 & - & 1 & 5 & 4 \\
\hline \multicolumn{2}{|c|}{ Litorina litorea } & - & - & - & 3 & - & - & - & - & 一 & - & 一 & - & - & - & 二 & & 1 & 1 & 1 \\
\hline \multicolumn{2}{|c|}{ Nereis diversicolor } & 4 & 20 & 6 & 5 & 46 & 32 & 33 & 29 & 51 & 38 & 21 & 19 & 34 & 22 & 31 & $: 35$ & 25 & 20 & 19 \\
\hline \multicolumn{2}{|c|}{ Arenicola marina } & - & - & 3 & 2 & - & - & - & - & 5 & 16 & 14 & 19 & 15 & 31 & $\ldots-$ & & 9 & 23 & 19 \\
\hline \multicolumn{2}{|c|}{ Scoloplos armiger } & - & - & - & 2 & - & - & - & $=$ & 3 & - & 1 & 1 & 1 & - & -- & & - & - & - \\
\hline \multicolumn{2}{|c|}{ Pygospio elegäns } & 一 & 3 & 1 & - & 一 & 9 & 一 & 4 & $\longrightarrow$ & 一 & 1 & - & - & $-\cdots$ & 一 & - & - & - & - \\
\hline \multicolumn{2}{|c|}{ Eteone spec. } & - & - & 1 & 一 & 1 & 一 & - & - & 1 & 3 & 一 & - & 1 & 1 & -- & - & - & 一 & - \\
\hline \multicolumn{2}{|c|}{ Capitella capitata } & - & 1 & - & 8 & 一 & - & 1 & - & 6 & 9 & 11 & 16 & 12 & 16 & 8 & 5 & 12 & - & 9 \\
\hline \multicolumn{2}{|c|}{ Heteromastus filiformis } & - & 一 & - & 4 & 一 & 一 & - & - & 5 & 1 & 3 & 1 & 1 & 10 & ?) & 4 & 1 & 5 & 10 \\
\hline \multicolumn{2}{|c|}{ Clitellio arenarius } & 一 & 3 & 1 & - & - & 1 & 一 & - & 一 & - & - & - & - & $\cdots$ & $\ldots$ & - & - & - & - \\
\hline \multicolumn{2}{|c|}{ Lineus ruber } & - & - & - & 一 & 一 & - & 1 & - & 一 & 一 & - & - & - & - & & $\ldots$ & - & - & 一 \\
\hline \multicolumn{2}{|c|}{ Corophium volutator } & - & 20 & 13 & 一 & 24 & 17 & - & 一 & - & 一 & 一 & - & $\ldots$ & - & - & - & - & - & 一 \\
\hline \multicolumn{2}{|c|}{ Crangon vulgaris } & 一 & - & 一 & - & - & 一 & - & 一 & -- & - & - & $\ldots$ & 一 & & $\cdots$ & - & - & 2 & - \\
\hline \multicolumn{2}{|c|}{ Carcinus maenas } & - & 一 & 一 & 3 & 3 & 一 & - & 1 & - & - & 一 & - & - & 1 & - & - & 2 & - & 1 \\
\hline
\end{tabular}


und uneinheitlich. Neben kleinen Tieren von $3 \mathrm{~cm}$ Länge kamen solche von $7-8 \mathrm{~cm}$ vor. Arenicola marina kommt auch in hoher Zahl vor (Max. 31 für ${ }^{1 / 20} \mathbf{m}^{2}$ ). Im Gegensatz zur Besiedelung durch Nereis ist diejenige durch Arenicola ausgesprochen sprunghaft. Die Nähe der MHW-Grenze wird gemieden (vergl. unterste Reihe der Tabelle), aber auch tiefer gelegene Stellen sind ohne Uebergang vollkommen frei von Arenicola.

Ueber die Verteilung der übrigen Glieder der Endobiose soll anhand der Liste nur gesagt werden, daß Scoloplos armiger in der Tonnenbucht nicht wahllos, sondern fast immer zusammen mit Arenicola vorkommt. Aehnliches scheint für Macoma balthica und Cardium edule zu gelten. Dagegen machen die Capitelliden, Capitella capitata und Heteromastus filiformis ${ }^{1}$ ) die Sprünge von Arenicola nicht mit. Die für sie gefundene Wohndichte ist verhältnismäßig gleichmäßig am ganzen Profil bis auf den wandernden Sandrücken, der eine ausgeprägte Lücke erkennen läßt. Die streifenförmige Corophium-Siedlung kommt in der Liste deutlich zum Ausdruck. Sie liegt zwischen 20 und $40 \mathrm{~cm}$ unter MHW

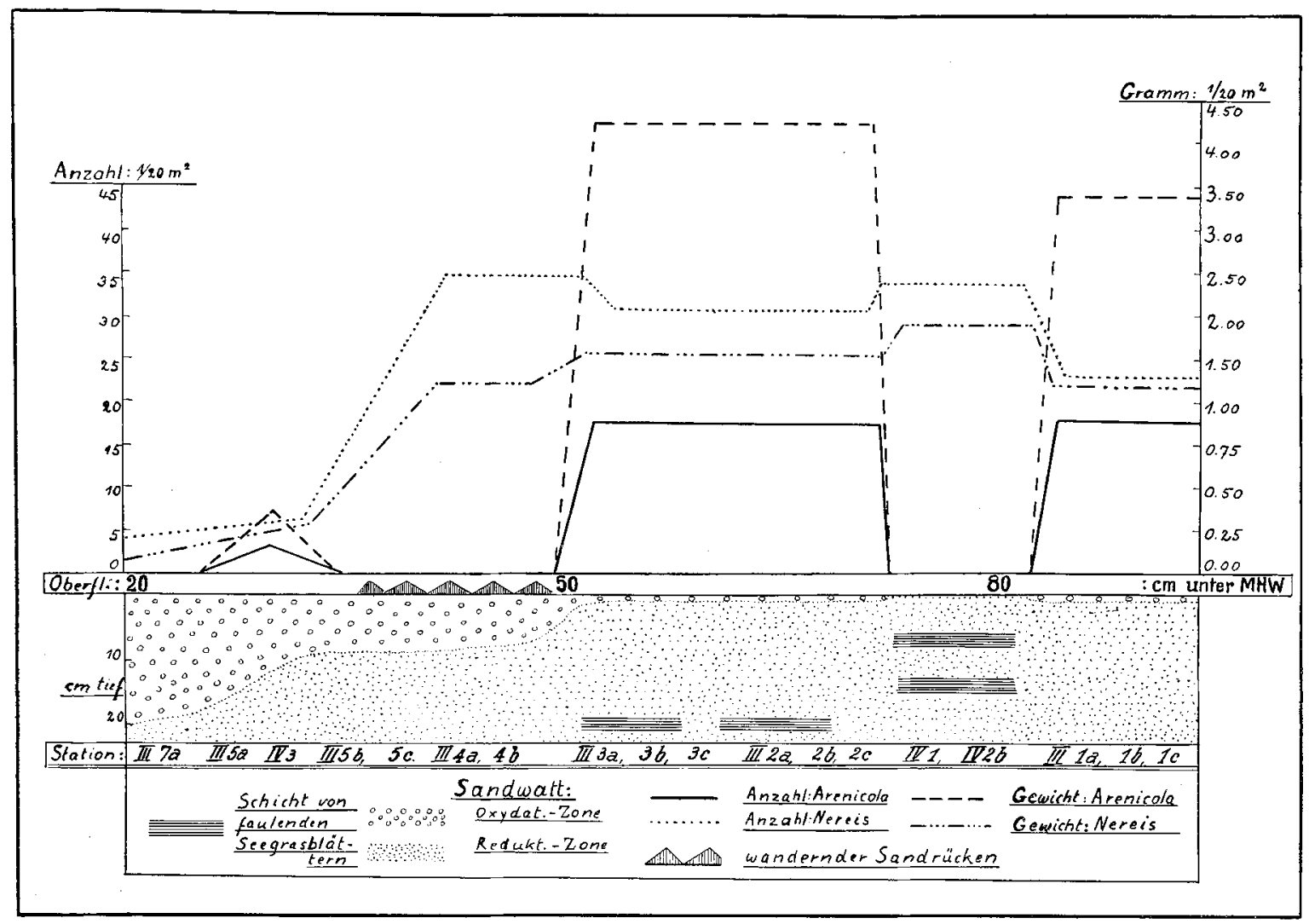

Abb. 5. Wohndichte und Gewichtsverhältnisse zwischen Arenicola marina und Nereis diversicolor und die Struktur der Sedimente in der Tonnenlegerbucht.

und bricht nach oben und unten ziemlich unvermittelt ab. Außer Corophium leben Clitellio arenarius und Pygospio elegans in dieser Zone.

In welchem Maße die Verteilung dieser Glieder der Endobiose der Tonnenlegerbucht auch für den übrigen Königshafen zutrifft, soll weiter unten untersucht werden. Vorerst ist das sprunghafte Verhalten in der Siedlungsweise von Arenicola aufzuklären und zunächst das Sediment selber zu untersuchen.

\section{c) Das Sediment.}

Wie schon in den allgemeinen Bemerkungen über die Tonnenlegerbucht gesagt wurde, fällt die verschiedene Färbung der Wattoberfläche längs eines Schnittes von der Hochwassergrenze bis zum tiefsten Teil der Niederung auf. Im oberen Teil ist die grau-

1) Dieser Capitellide konnte zum ersten Mal für die Deutsche Bucht nachgewiesen werden, obwohl er in manchen Gegenden des Wattenmeeres häufiger ist als Arenicola marina, ja, zu den häufigsten Tieren zählt. 
braune Oberfläche durch helle, gelbe Zonen (auf die HW-Linie zuwandernder Sand) unterbrochen, im unteren Teil ist sie dunkelgrau bis blauschwarz. Während die Oxydationsschicht im oberen Teil bis zu $20 \mathrm{~cm}$ mächtig ist, tritt die Reduktionszone im unteren Teil des Gebietes nahe an die Oberfläche und nimmt an einigen Stellen, wo ständig Gas aus dem Sediment austritt, die Oberfläche selbst ein. Elementarer Schwefel ist an solchen Stellen nicht selten an der Oberfläche zu beobachten.

Der innere Aufbau des Sediments ist in dem unteren Teil der Abb. 5 schematisch dargestellt. Die Oxydationsschicht nìmmt mit der Entfernung von der HW-Grenze ab. Bei den Stationen III 4 und 5 liegt ein wandernder Sandrücken; dessen Oberfläche Rippelmarken trägt, also bei jeder Ueberflutung mehr oder weniger stark umgelagert wird. Während nach dem Abfließen des Wassers bei Ebbe das Watt oberhalb wie unterhalb des Sandstreifens auch oberflächlich wasserge bezw. übersättigt bleibt, verliert der Sandrụ̣cken sehr bald das Wasser. Wegen der Unzugänglichkeit des tiefer gelegenen Watts ließ ich mein Ruderboot an den zu untersuchenden Stellen trockenfallen. Mit einem Peilstock wurden Ablagerungen aus feinstem, weichem Mudd von $120 \mathrm{~cm}$ Mächtigkeit festgestellt. Auch obne daß ich das Sediment in seiner Lagerung storte, war die Luft in diesem Teil des Königshafens selbst bei frischen Winden durch Fäulnisgase maßvoll ausgedrückt - verdorben. Das Ausstoßen von Gas durch das muddige Sediment

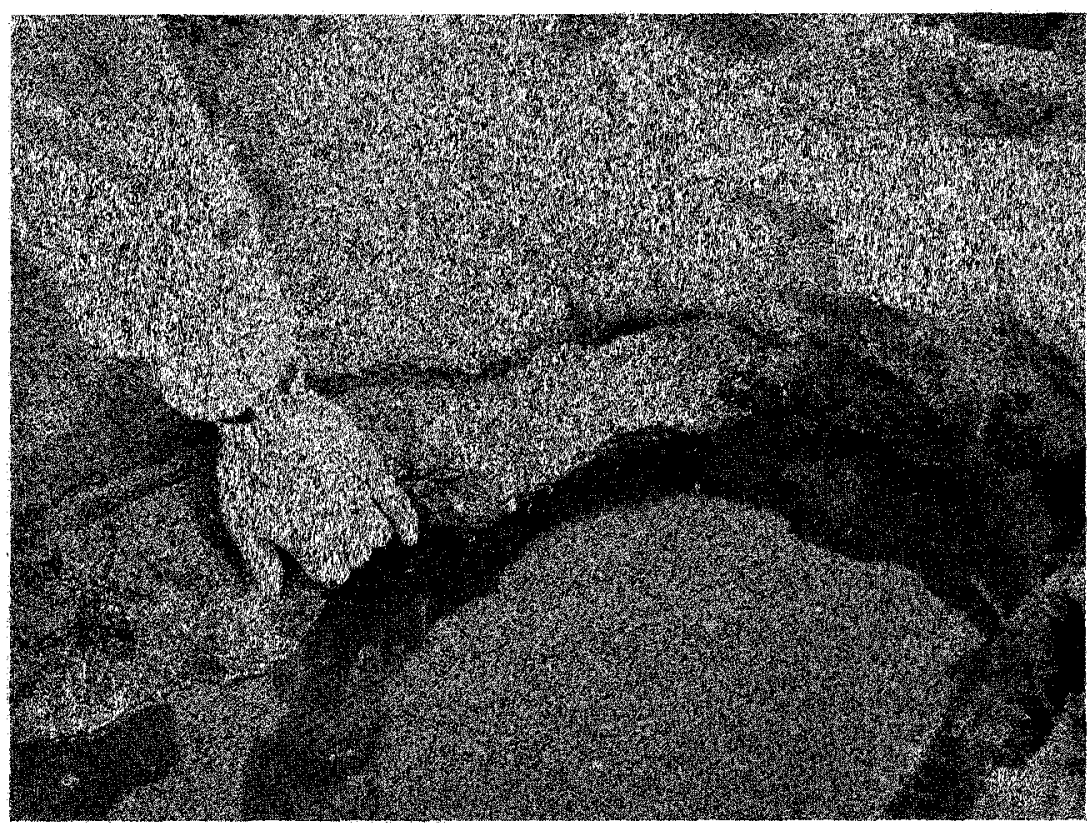

Abb. 6. Profil im Arenicota freien Watt der Tonnenlegerbucht. Meine Hand hält den $4 \mathrm{~cm}$ mâchtigen Horizont aus faulenden Seegrasb]ättern, der dureh Bespinlen der Profilwand freigelegt wurde. hindurch war oft zu beobachten und lieb charakteristische Spuren zurück. Da das vom freien Wattenmeerkommende, diesen Standort überffutende Wasser, bereits als vollkommen einwandfrei nachgewiesen werden konnte (vergl. S. 9), waren die Ursachen für die überaus intensiven Eisensulfid-undGasbildungen im Sediment selber zu suchen. Bei der Durchführung der Bestandsaufnahme ergaben sich beim Aussieben des Sediments stellenweise Schwierigkeiten, da der Siebrest den Siebboden in dicker Schicht bedeckte und das Aussuchen der Tiere verhinderte. Der Siebrest bestand aus Blättern von Zostera marina L., Zostera nana Roth. und Zostera augustifolia Hornem. Vereinzelt kamen auch Fucus-Reste vor. Zostera-Rhizome wurden nicht gefunden. Alle Teile waren in Fäulnis begritfen. Um mich über den Aufbau des Sediments genau zu unterrichten, wurden Profile abgebaut. Da das Sickerwasser das eben freigelegte Profil schnell wieder verdeckte, schachtete ich eine zweite Vertiefung aus, schöpfte diese mehrere Male leer und leitete schlieblich das blauschwarze Sickerwasser der Profilgrube in die zweite hinein. Die Profile (vergl. Abb. 6) stimmten darin überein, daß in verschiedenen Tiefen, zum Teil in Abstânden übereinander gelagert, mehr oder weniger dicke Schichten von faulenden Seegrusblattern eingebettet waren. Wie auch aus der Aufnahme ersichtlich, handelte es sich wicht tum gelegentlich eingestreute Blätter, sondern um mehrere Zentimeter mächtige, zzin zusammenhaltende Schichten von 3-10 $\mathrm{gm}$ Ausdehnung. Die auf Abb. 6 sichtbare Scegrasschicht lag etwa $8 \mathrm{~cm}$ unter der Wattoberfläche. Darunter befanden sich in verschiedenen Abständen noch weitere Lagen, die aber durch das schnell zufliebende sikkerwasser, für das die Zostera-Schichten gewissermaßen die Träger waren, in ahnlicher Weise wie die Tonschichten des Festlandes das Grundwasser tragen, noch vor der Aufnabme wieder verdeckt wurden. 
In diesen mächtigen Fäulnisherden ist also die Ursache für die starke Sulfid- und Gasbildung zu sehen.

Die hier durch Beobachtung gewonnene Kenntnis vom Aufbau des Sediments sei durch einige Korngrößenbestimmungen ergänzt und bestätigt. Zugleich soll vom methodischen Gesichtspunkt aus gezeigt werden, in welchem Umfang Korngrößenanalyse und -darstellung in der Lage sind, das für den Lebensraum Wesentliche und Entscheidende wiederzugeben.

Ich wende mich den nebenstehenden 4Blockdarstellungen(To. b-e) gleichzeitig zu. To. b-d sind Analysen von Proben aus dem Arenicola-freien Watt mit Zostera-Schichten (Abb. 5, Stat. IV, 1, 2b), To. e unmittelbar daneben (Abb. 5, Stat, III, $2 \mathrm{~b}-\mathrm{c}$ ), wo Arenicola in erheblicher Zahl vorhanden ist. Eine Probeanalyse ergab, daß die Werte für einen einheitlichen Kern von der Oberfläche bis unter die Zostera-Schicht hinab den wesentlichen Aufbau des Sediments überhaupt nicht erkennen ließen. Aus diesem Grunde unterteilte ich einen zusammenhängenden Kern von $12 \mathrm{em}$ Länge in 3 Abschnitte und nahm die Analyse jeweils für sich vor. Darstellung To. $b$ gibt die Oberschicht wieder, To. c den mittleren Abschnitt mit der Zostera-Ablagerung und To, d die Unterschicht. Der Vergleich der c-Werte mit den benachbarten zeigt einen auffallenden Unterschied nur im

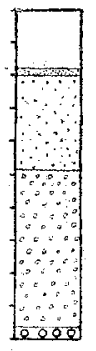

To. e

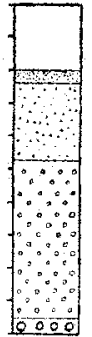

To. 6

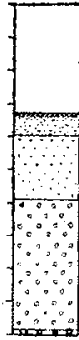

To. 6

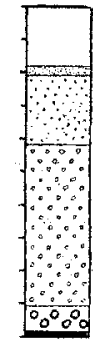

To. d

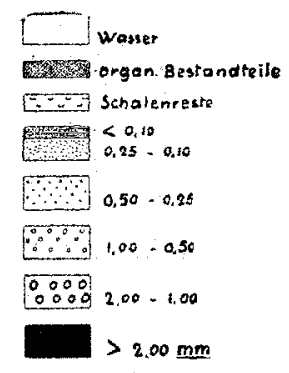

Abb. 7.

Diagramm To. e. Sandwatt der Tonnenlegerbucht, August 1932. Einheitliche Probe von 0 bis $12 \mathrm{~cm}$ Tiefe in der Arenicola/Nereis-Siedlung.

Diagramm To.b-d. Sedimente der Tonnenleger. bucht. In der Arenicola-freien Zone übereinanderiliegende Schichten.

Sedimentprohe e besteht zur Hauptsache aus dem faulenden Zostera-Horizont.

b liegt über diese Schicht, d darunter.

Ganzrechts Erklärungfür sämtliche Blockdiagramme.

(Die an der linken Seite der Diagramme befindliche Teilung umfaßt für jeden Teilstrich $10^{\circ} \%$ und bezieht sich auf das naturfeuchte Gesamtgewicht der dargestellten Sedimentprobe.) Wassergehalt. Der bei c zurDarstellung gekommene, um mehr als $50 \%$ höhere Wassergehalt geht nicht etwa auf ein größeres Porenvolumen des Sandes zurück, sondern vor allem auf den hohen Wassergehalt der organischen Substanz, der Zostera-Schicht, die in getrocknetem Zustand gewichtsmäBig von ganz untergeordneter Bedeutung ist und darum im Block c rechnerisch so klein wurde, daß sie nur angedeutet werden konnte. Die nebenher durchgeführte Volumenbestimmung der naturfeuchten Masse ergab bereits bessere Werte:

Blockdarstellung To. e (sieben oben) weicht, obwohl es den ganzen Kern von $12 \mathrm{~cm}$ Länge umfaßt, nur unwesentlich von $b$ ab. Diese Gegenüberstellung mag einstweilen genügen, um zu zeigen, welch geringen diagnostischen Wert eine Korngrößenanalyse unter gewissen Umständen haben kann.

\section{d) Das Zwischenraumwasser.}

Vom ökologischen Gesichtspunkt aus gesehen ist das im Sediment enthaltene Wasser, (=Zwischenraumwasser), seine physikalische und chemische Beschaffenheit, von Bedeutung. Für die ökologische Untersuchung gehört es züm Sediment schlechthin.

Es wurden in verschiedenen Zonen und Tiefen Untersuchungen auf Temperatur, Salz-, Sauerstoff- und Schwefelwasserstoffgehalt sowie pH-Bestimmungen durchgefübrt, um den Einfluß der Zostera-Schicht auf das Zwischenraumwasser klarzustellen. Die Tabelle 13 enthält Werte von Proben, die längs des besprochenen Schnittes vom Watt der Tonnenlegerbucht entnommen wurden. Sie zeigt, daß im Sickerwasser der Corophium-Zone Sauerstoff und Schwefelwasserstoff nur in Spuren nachzuweisen waren. Im Watt mit Arenicola und Nereis war kein Sauerstoff unten im Sickerwasser vorhanden. Der $\mathrm{H}_{2} \mathrm{~S}$-Gehalt nahm erheblich $\mathrm{zu}$, um schließlich in der Arenicola-freien Zone mit der Zostera-Schicht auf $8 \mathrm{mg}$ (!) für 1 Liter anzusteigen. Alle $\mathrm{pH}$-Werte lagen mit $\mathrm{pH} 7.50$ weit unter dem für normales Seewasser üblichen Wert (8.17). Eine weitere Tabelle 14 zeigt die Abnahme der pH-Werte mit zunehmender Tiefe. Die Entfernung vom gewöhnlichen Wert, der im Oberflächenwasser zwischen den Rippeln noch mit pH 8.20 nachzuweisen war, kommt hinreichend zum Ausdruck. 
Die Analysen ergeben also, daß durch das eingelagerte, in Zersetzung begriffene Seegras und andere organische Reste das im Sediment enthaltene Wasser in stärkstem Maße verändert wird. Die gefundenen Werte weichen so stark von den normalen ab, daß man geneigt sein könnte, ihnen einen entscheidenden Einfluß auf die Besiedelung des Standortes, so z. B. auf das Ausbleiben von Arenicola zuzuschreiben. Das liegt besonders nahe bei einem Vergleich mit den von HECHT (25) durch Laboratoriumsversuche über die Widerstandsfähigkeit der beiden Wurmer Arenicola marina und Nereis diversicolor gegen Schwefelwasserstoffanreicherung bezw. Sauerstoffverminderung gewonnenen Ergebnissen. HECHT konnte durch Aquariumsversuche nachweisen, daB Arenicola nicht mehr zu leben vermochte, wenn der $\mathrm{H}_{2} \mathrm{~S}$-Gehalt auf $8,45 \mathrm{mg}$ im Liter gestiegen war. Zufällig liegt mein maximaler $\mathrm{H}_{2} \mathrm{~S}$-Wert ungefähr in der gleichen Höhe. Arenicola fehlt in diesem Sediment, während Nereis in unverminderter Zahl vorhanden ist. Allein der Versuch, die Laboratoriumsergebnisse HECHT's mit den von mir auf freiem Watt gewonnenen zu vergleichen, muß an der grundsätzlichen Verschiedenheit der äußeren Verhältnisse seheitern:

Tabelle 13.

Chemische Beschaffenheit des Zwisehenraumwassers in Watt der Tonnenlegerbucht am 1. 8. 1933 mittags bei NW und Sonnenschein.

\begin{tabular}{|c|c|c|c|c|c|}
\hline Siedlung & Temp. & Salzgeh. & $\mathrm{O}_{2} \mathrm{cem} / 1$ & $\begin{array}{l}\mathrm{H}_{2} \mathrm{~S} \\
\mathrm{mag} l\end{array}$ & $\mathrm{pH}$ \\
\hline $\begin{array}{l}\text { Corophium } \\
\text { Arenicola Nereis } \\
\text { Arenicola/Nereis mit verstreuten } \\
\text { faulenden Zostera-Blattern }\end{array}$ & $\begin{array}{l}19.30 \\
19.70 \\
19.70\end{array}$ & $\begin{array}{l}31.94 \\
31.35 \\
31.36\end{array}$ & $\begin{array}{l}0.12 \\
0.00 \\
0.00\end{array}$ & $\begin{array}{l}1.88 \\
2.91 \\
2.93\end{array}$ & $\begin{array}{l}7.95 \\
7.85 \\
7.85\end{array}$ \\
\hline $\begin{array}{l}\text { Nereis o h n e Arenicola m it } \\
\text { faulender Zostera-Schicht }\end{array}$ & 19.10 & 31.76 & $\begin{array}{c}0.00 \\
0\end{array}$ & 8.03 & 7.50 \\
\hline
\end{tabular}

Das Verhalten der pH-Werte im Zwischenraumwasser der Arenicola-Nereis-Siedlung der Tonnenlegerbueht ain 2. 8. 1933 bei NW.

\begin{tabular}{|c|c|c|c|c|c|}
\hline \multicolumn{2}{|c|}{ Siedlung } & & wasser aus & $\begin{array}{l}\text { Tiefe } \\
\text { in em }\end{array}$ & $\mathrm{pH}$ \\
\hline \multicolumn{2}{|c|}{ Arenicola/Nereis } & \multirow{3}{*}{\multicolumn{2}{|c|}{$\begin{array}{l}\text { Obertlachenwasser in Rippeln } \\
\text { graublau gefärbtem Sand } \\
\text { schwarz gefärbtem Sand }\end{array}$}} & \multirow{6}{*}{$\begin{array}{r}0 \\
2 \\
5 \\
10 \\
20 \\
40\end{array}$} & \multirow{6}{*}{$\begin{array}{l}8.20 \\
8.00 \\
7.90 \\
7.90 \\
7.70 \\
7.70\end{array}$} \\
\hline 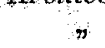 & \% & & & & \\
\hline$n$ & $\pi$ & & & & \\
\hline si & " & $\%$ & & & \\
\hline$n$ & " & $\%$ & " mit Zostera-Sehicht & & \\
\hline , & $"$ & $n$ & $\%$ & & \\
\hline
\end{tabular}

HEснт's $\mathrm{H}_{2} \mathrm{~S}$-Werte beziehen sich nicht auf das im Sediment befindliche Wasser, sondern auf das 40 Tage (1) lang nicht erneuerte, darüberstehende Atemwasser der Tiere, das mit jedem Tag einen höheren Gehalt an $\mathrm{H}_{2} \mathrm{~S}$ anzeigte. Das Watt der Tonnenlegerbucht da gegen wird täglich zweimal mit gut durchlüftetem Wasser überflutet, so daß den Tieren für mehrere Stunden des Tages $\mathrm{O}_{2}$-reiches Atemwasser zur Verfügung steht. Der von mir im freien Watt nachgewiesene Wert von $8,03 \mathrm{mg} \mathrm{H_{2 } \mathrm { S }}$ in 1 Liter Siekerwasser wird also auf Grund der täglich zweimal wiederkehrenden, günstigen hydrographischen Bedingungen von atmungs-physiologischen Gesiehtspunkten her eine ganz andere Bewertang erfahren müssen als die Ergebuisse des eingeengten Aquarium-Versuches. Dh ałe Biologie von Arenicola marina durchaus noch nicht so weit geklärt ist, wie man nach den Darlegungen HecrT'S (25) und KREJCr-GRAF (37 a) annehmen könnte, muf die Bedeutung der Wohnröhre für die $\mathrm{O}_{2}$-Versorgung der Tiere bis zum Vorliegen neuer Ergebnisse uber ihre Lebensweise im Sediment dahingestellt bleiben.

e) Die Wohndichte von Arenicola marina und Nerers diversicolor:

aa) In der Tonnenlegerbucht.

Die bisherigen Ergebnisse veranlaßten mich, möglichst durk Untersuchangen im freien Watt die Faktoren festzustellen, welche die Verbreitung won Arenicola marina 
einschränken. In den Jahren 1933 und 1934 konnten die 1932 aufgedeckten Beziehungen durch mehrfache Bestandskontrollen bestätigt bezw: erweitert werden. Das 1932 angetroffene Bild der Besiedelung (Tabelle 12) war also kein einmaliges und zufälliges. Die abschließende Betrachtung der Bestandsliste, Tabelle 12, und des Verteilungsdiagramms, Abb. 6, vermittelt einen Einblick in die Beziehung zwischen der Sprunghaftigkeit der Besiedelung durch Arenicola und dem jeweils zugehörigen Sediment. Die Linien stellen Mittelwerte dar.

$\mathrm{Ob}$ das Fehlen von Arenicola auf dem wandernden Sandrücken (Stat. III $5 \mathrm{~b}-\mathrm{c}$, III $4 a-b)$ auf die unruhige Sedimentoberfläche ${ }^{1}$ ) oder etwa auf die Wasseruntersättigung der oberen Schichten während der Ebbe zurückzuführen ist, geht aus den Untersuchungen in der. Tonnenlegerbucht nicht eindeutig hervor. Das unvermittelte Ansteigen "in der Besiedelungsdichte von Nereis zeigt um so eindringlicher, daß für Nereis offenbar kein hemmender Faktor vorliegt. Beim Wiedereinsetzen der Besiedelung durch Arenicola (Stat. III $2 a-c, 3 a-c, A b b .5)$ fällt auf, daß die Anzahl Nereis pro Flächeneinheit sogleich abnimmt, andererseits aber sogleich wieder ansteigt, sobald Arenicola nicht mehr im Sediment anzutreffen ist. (Stat. IV 1, 2 b und III $1 \mathrm{a}-\mathrm{c}$ ). Mit anderen Worten, es hat den Anschein, als ob beide Arten - Nereis und Arenicola - in der Tonnenlegerbucht zusammen über eine bestimmte: Siedelungsdichte nicht hinausgehen und ihre jeweilige Bevölkerungsziffer gewissermaßen aufeinander abstimmen. Es wird schwer sein, diesen Nachweis zu führen. Träfe die eben ausgesprochene, nur durch das Zahlenverhältnis gestützte Annahme zu, so könnte man ohne Uebertreibung von einem sich selbst regulierenden Gleichgewicht zwischen diesen beiden Arten innerhalb der Endobiose im Watt der Tonnenlegerbucht sprechen. Vorläufig jedoch reicht das Untersuchungsmaterial nicht aus, um diese grundsätzliche, biocönotische Fragestellung mit exakten Unterlagen zu beantworten.

Die auf dem unteren Teil des Verteilungsdiagramms schematisch dargestellte Struktur des Sediments zeigt weiter an, daß Arenicola nur dann fehlt, wenn die faulende Zostera-Schicht nicht tiefer als $10-12 \mathrm{~cm}$ unter der Oberfläche liegt. Das konnte bei IV 1 und $2 \mathrm{~b}$ und an vielen anderen Stellen der Bucht nachgewiesen werden. Die tiefer liegenden Schichten bei. III $2 a-c$ und III $3 a-c$ hatten gar keinen Einflub mehr auf die Besiedelungsidichte. Beim Betrachten dieser Tatsache liegt der Gedanke nahe, daß die flach liegenden. Schichten von ernährungstechnischer Bedeutung sein könnten, derart daß der Wurm die dichte Schicht nicht zu durchbohren vermag, oder daß das Seegras gerade in de m Bereich der Wohnröhre liegt, wo in irgendeiner Weise die Aufnahme von Sediment erschwert oder verhindert wird.

Als Ursache für das sprunghafte Ausbleiben von Arenicola bei Stat. IV 1 und $2 \mathrm{~b}$ wären somit zwei Faktoren ermittelt, 1) ein chemischer: $\mathrm{H}_{2} \mathrm{~S}-\mathrm{V}$ ergiftung (vergl. S. 34, Tab. 13) und 2) ein struktureller: Hindernis beim Röhrenbau bezw. bei der Ernährung durch Sedimentaufnahme. Nach den zuletzt gemachten Darlegungen neige ich dazu, den zweiten Faktor fast ausschließlich verantwortlich zu machen. Der erhöhte $\mathrm{H}_{2} \mathrm{~S}$-Gehalt im Sediment scheint bei den sonst günstigen Wasserverhältnissen für die Fernhaltung von Arenicola von untergeordneter Bedeutung zu sein.

\section{bb) Auf dem Mövenberg-Watt.}

Die in der Tonnenlegerbucht aufgegriffene Frage über das Verhältnis der Wohndichte zur Beschaffenheit des Sediments wurde an anderen Stellen des Königshafens weiter verfolgt. Auf den ebenen Sandwattflächen vor dem Mövenberg war eine merkwürdige Oberflächenentwicklung ausgebildet. Viele tausend Quadratmeter wiesen auf eine überaus dichte Besiedelung mit jungen Arenicola hin. Mitten in diese durch die Kothäufchen charakterisierten. Flächen waren allseitig scharf begrenzte Felder von größerer Längsausdehnung ausgespart. Sie trugen keinerlei Spuren einer Arenicola-Besiedelung und machten den Eindruck, als wenn sie sich in kaum wahrnehmbarer Wölbung eine Kleinigkeit über das umliegende Watt erhoben. Von solchen Flächen waren mehrere in verschiedenen Abständen hintereinander und nebeneinander angeordnet. (Vergl. Abb. 8.) Die vorgenommene Bestandsaufnahme bestätigte die durch die Oberflächenstruktur aufgedrängte Vermutung und zeigte, daß hier ein Besiedelungsbild von verhältnismäßig großer Einfachheit vorlag. Dieser Standort schien daher besonders geeignet zu sein, einen weiteren Baustein für die merkwürdigerweise immer noch sehr lückenhafte Oekologie des Sandwurms zu liefern. In dem umstehenden Verteilungsdiagramm (Abb. 9) habe ich

1) "sand of shifting charakter" nach AsHworTH (2) und "so ist der Sand für den Wurm zu beweglich" nach MEYN (47, S. 670). 
mich auf die Darstellung der Siedelungsdichten von Arenicola und Nereis beschränkt. Auf die anderen Glieder der Endobiose komme ich im Text zurück. Die sich auf die Anzahl Arenicola für ${ }^{1 / 20} \mathrm{~m}^{2}$ beziehende ausgezogene Linie (es sind wie bisher Mittelwerte

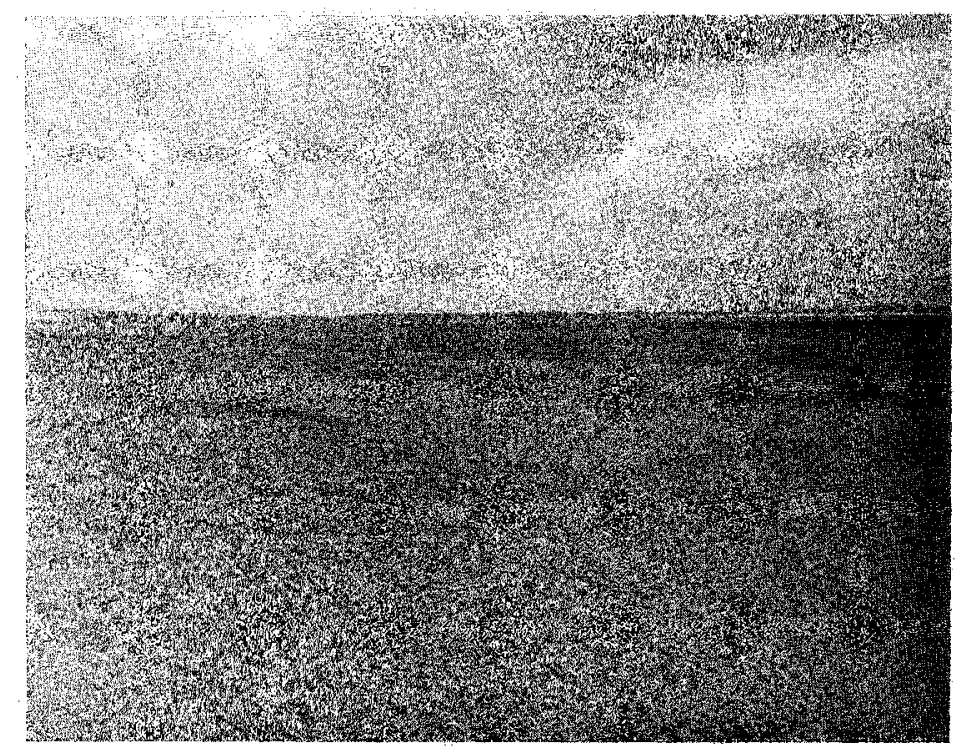

Abb. 8. Die Arenicola-freien Sandwattzonen vor dem Möwenberg. Die glatt aussehenden Zonen zeigen dentlich die scharfen Grenzen in der Arenicola-Besiedelung. dargestellt) zeigt abermals das sprunghafte Ausbleiben und Wiedereinsetzen der ArenicolaBesiedelung. Nereis (punktierte Linie) hingegen bleibt von diesem Aufundnieder offenbar vollkommen unberührt. Das Ausklingen der Besiedelungsdichte beider Tiere nach rechts ist auf die hier beginnende dichte Zostera-nana-Wiese (vergl. WOHLENBERG (90, Abb. 2) zurückzuführen.

Als Nächstliegendes hảbe ich versucht, die Ursachen für das auffällige siedlungsbild im Sediment selber zu suchen. Die Reduktionszone lag am ganzen Profil mehrere Zentimeter unter der Oberfläche, was auf die gute Durchlüftung bezw. Durchwässerung der oberen Schichten hinwies. Seegrashorizonte, etwa wie im Watt der Tonnenlegerbucht, waren in keiner Tiefenlage zu finden,

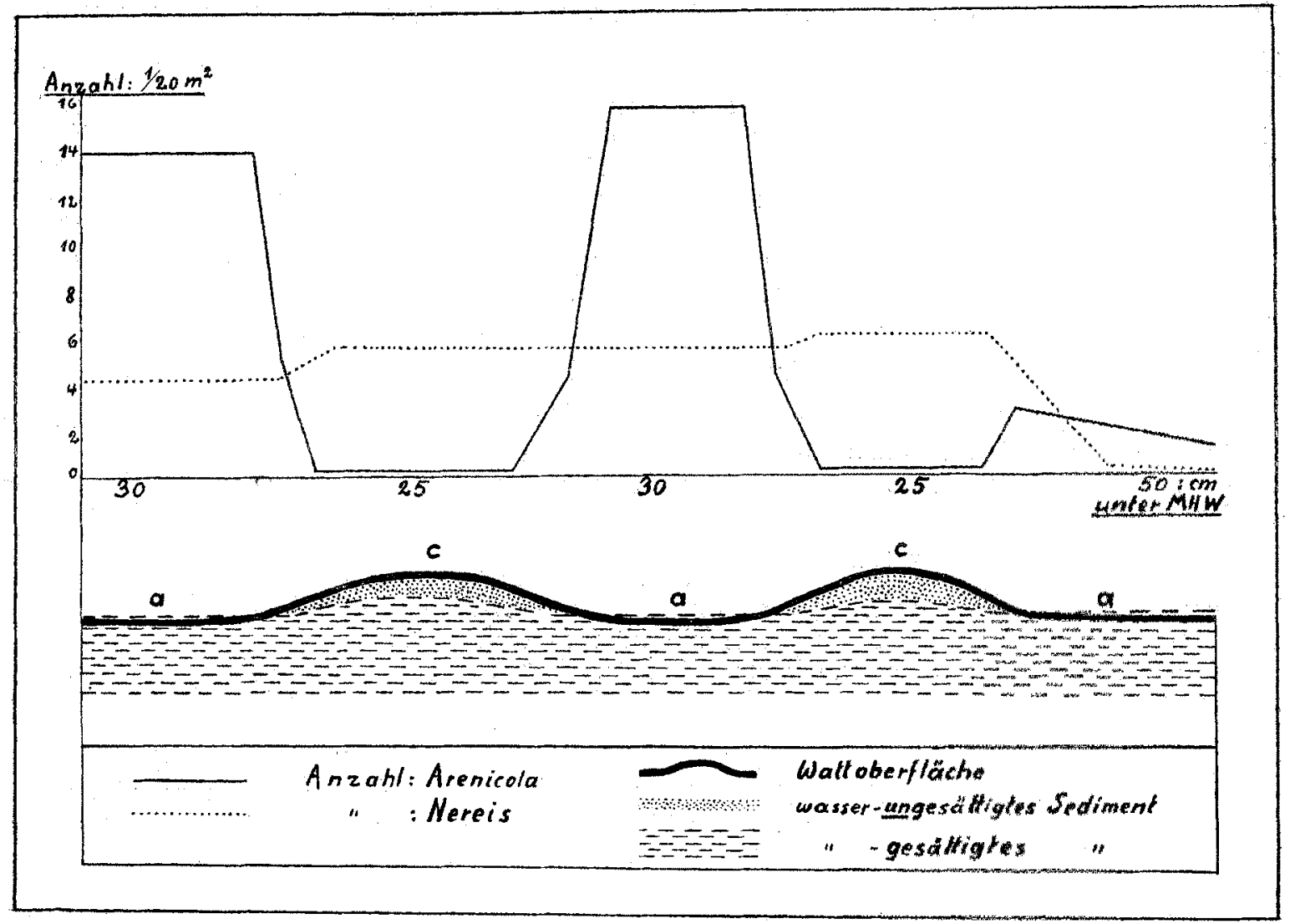

Abb. 9. Wohndichte von Arenicola marina und Nereis diversicolor aut deru Mbvenberg-Watt. 
auch keine Anhäufungen von Schill, Steinchen oder verkitteten Bodenteilchen. Es mußten also andere Ursachen vorliegen. Ich schritt daher zur Korngrößenuntersuchung.

Blockdiagramm Mö. a (Abb; 10) stellt die Zusammensetzung des Sediments aus der Zone mit, Mö. c aus der Zone o h n e Arenicola dar. Die Gleichartigkeit beider Proben überrascht. Ganz geringe Unterschiede sind zwar bemerkbar, nämlich der um $2,3 \%$ höhere Wassergehalt bei a und der um $4,2 \%$ höhere Gehalt an Körnern unter $250 \mu$ bei c, aber darüber hinaus war nichts erkennbar, was einen Einfluß auf die Verteilung von Arenicola vermuten ließ. Schließlich lenkten mich die am freien Standort fortgesetzten Beobachtungen auf eine ganz einfache Untersuchung der Oberfläche des Sediments hin. Ich stellte die Höhenlage des im Sediment enthaltenden Wassers, gewissermaßen den "Grundwasserspiegel" fest. Längs eines Schnittes von etwa $30 \mathrm{~m}$ Länge wurden mit einem Glasröhrchen $6 \mathrm{~cm}$ lange Sedimentkerne ausgestochen. Nach einigen Minuten hatte sich in dem gebohrten Loch das Wasser auf eine Höhe eingestellt, die der im Sediment vorhandenen entsprach. An den Standorten $\mathrm{m}$ it Arenicola (a, Abb. 9) stand das Wasser durchweg an bezw. $1-2 \mathrm{~cm}$ ü ber der Sedimentoberfläche, bei allen mit $c$ bezeichneten Stellen (f re i von Arenicola) dagegen stets $2-5 \mathrm{~cm}$ unter der Oberfläche. Bei a war die oberste Lage der Sedimente auch während der Nichtüberflutung also stets über- bezw. gesättigt, bei c jedoch stets untersättigt. Die Untersättigung der Oberfäche scheint demmach das Ausbleiben von Arenicola infolge ernährungstechnischer Schwierigkeiten verursacht zu haben. ${ }^{1}$ )

Da die untersuchten Flächen keine Anzeichen einer starken Úmlagerung aufwiesen, blieb zur Erklärung der Besiedelungsdiehte außer des soeben besprochenen Sättigungsgrades der Oberfläche noch der biocönotische Faktor, nämlich der Einfluß der übrigen Glieder der Endobiose aufzuklären. Sie setzt sich folgendermaben zusammen: Lineus ruber,

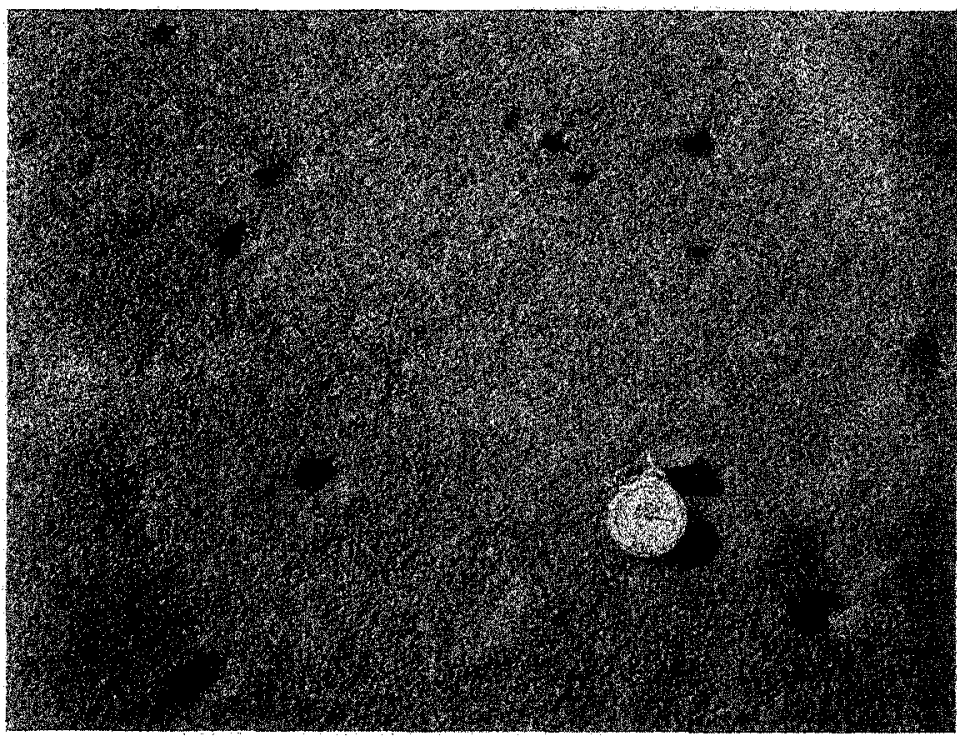

Abb. 11. Die Arenicola-freien Sandwattzonen vor dem Mövenberg haben eine dichte Corophium- und Nereis diversicolor-Besiedelung. Die auf der Abbildung lederartig genarbt aussehende Oberflache geht anf Corophium volutator zurück. Die muldenartigen Vertiefungen sind wahrscheinlich "Fanggruben" (?) von Nereis diversicolor. Eteone spec. Nereis diversicolor, Scoloplos armiger, Heteromastus filiformis, Capitella capitata, Arenicola marina, Corophium volutator, Macoma balthica, Cardium edule, Mya arenaria. Außer den bereits besprochenen und dargestellten Besiedelungsverhältnissen von Nereis und Arenicola (Abb. 5) lassen lediglich Scoloplos armiger und Corophium volutator eine verschiedenartige Verteilung erkennen. Scoloplos fehlt (zusammen mit Arenicola, vergl. Tonnenlegerbucht, Tab.12) auf allen c-Standorten.Corophium kommt in beiden Sedimenten vor, allein die Besiedlungsdichte beträgt im c-Sediment ein Mehrfaches von der im a-Sediment. Bereits die Oberfläche der c-Standorte weist auf die dichte Besiedelung durch Corophium hin. Abb.11

1) Aehnliches konnte THAMDRUP (79), auf dessen zeitlich parallel gelegenen, inzwischen veröffentlichten Untersuchungen über die Ho-Bucht im Einzelnen des abgeschlossenen Manuskriptes wegen nicht eingegangen werden kann, nachweisen. Allerdings wirkt in der Ho-Bucht die Trockenlage erst bei einer Tiefe von $25(!) \mathrm{cm}$ begrenzend. 
gibt einen Eindruck davon, wie die Oberfläche durch die früher von mir beschriebenen Röhrenmündungen durch die Tätigkeit des Schlickkrebses beim Einsammeln der Nahrung gestaltet wird (88). Die im Bild erkennbaren Mulden überraschen zunächst, da sie auf den ersten Blick an Arenicola-Trichter erinnern. Die Bestandsaufnahme hatte aber das vollständige Fehlen von Arenicola ergeben. Es zeigte sich bald, daß sich die Vertiefungen in mehreren Gängen, die einwandfrei Nereis zuerteilt werden konnten, nach unten fortsetzten. Die Ausbildung der von schlickigen Standorten bekannten Spuren (Abb. 12) war allerdings im oberen Mövenbergwatt nicht anzutreffen. Es liegt nahe, diese besondere Oberflächengestaltung durch Nereis diversicolor als eine vorwiegend durch die Eigenschaften des Standortes (sandig, wasseruntersäftigt) bedingte anzusehen. Ob die Mulden als "Fanggruben" (Ansammlung von Detritus, Tierleichen usw.) angesehen werden dürfen, muB eingehenden Untersuchungen über Ernährung und Lebensweise von Nereis diversicolor auf verschiedenartigen Watten vorbehalten bleiben. Nach dieser kurzen Besprechung einer bisher unbekannten, durch Nereis diversicolor verursachten Oberflächenform muß zugegeben werden, daß die Erörterungen über die etwaige Bedeutung der übrigen Glieder der Endobiose des Mövenbergwatts nicht das zutage gefördert haben, wodurch die sprunghafte Besiedelung durch Arenicola hätte aufgehellt, geschweige erklärt werden können. Hierbei muß allerdings ein für die Erforschung biocönotscher Zusammenhänge grundsätzlich wichtiger Hinweis gemacht werden, nämlich der, daß der historische Faktor gebührend in die Fragestellung aufgenommen wird.

Die im Vorangegangenen dargelegten Untersuchungen wurden zu einem Zeitpunkt ausgeführt, als das Watt der Umgebung mit Würmern besiedelt war, die zwar jung und

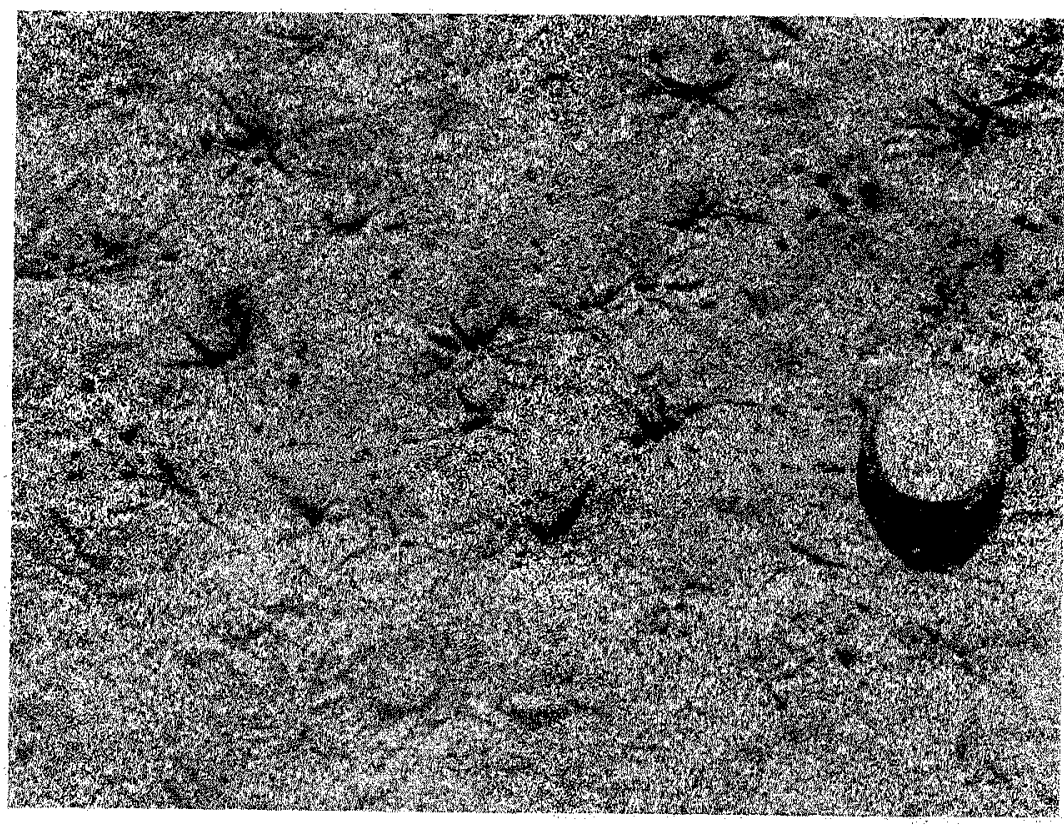

Abb. 12. Jagd- und FreBspuren von Nereis diversicolor auf ganz weichem Schlickwat. in der Entwicklung begriffen aber doch schon $4 \mathrm{~cm}$ lang waren. Da bei der sonst gleichförmigen Verbreitung von Arenicola angenommen werden muß, daß zur Zeit der erstmaligen $\mathrm{Be}$ siedelung durch bodenreife Wuirmer eine Auswahl des Standortes in solch ausgesprochener Form, wie das Besiedelungsbild heute zeigt, nicht der Fall gewesen sein wird, besteht die Möglichkeit, dab bereits die ersten bodenreifen Siedlex den Bedingungen des Standortes erlegen waren. Was dafür im einzelnen die Ursache gewesen sein mag, entzieht sich meiner Kenntnis. Es könnto für die jungenTin in erhöhtem Make einerseits die bei

Nichtüberflutong untersättigte Oberfläche des Sediments, andererseits aber auch der biotische Faktor der Ernährungsverhältnisse aller anderen Glieder der Endobiose ausschlaggebend gewesen sein. Es ist nicht ausgeschlossen, daß z. B. die bodenreifen Arenicola den Mitbewohnern zum Opfer gefallen sind. Daß der entscheidende Zeitpunkt fur die Festlegung des heute nachgewiesenen Besiedelungsbildes (Abb. 9) mit grofer Wahrscbeinlichkeit, die Zeit des Befalls gewesen sein dürte, deutet ein einfacher Versuch an, don ich an Ort und Stelle auf dem Mövenberg-Watt ausführte. Auf einem der untersuchton Sandrücken ohne Arenicola wurde eine etwa $1 \mathrm{qm}$ große Fläche gekennzeichnet und aut die Oberfläche des Sediments sechs Arenicola von etwa $4-5 \mathrm{~cm}$ Länge gelegt. Alle Mingrabungsversuche der Tiere scheiterten. Darauf machte ich eine kleine Vertiefung bis zum "Grundwasser“bereich, legte je einen Wurm hinein und deckte sie mit etwas Sand zu. Die Kontrolle in den nächstfolgenden Tagen zeigte, daß alle 6 Tiere lebten und die Kothatufohen auf dem 
sonst glatten Sandrücken in der bekannten Weise aus der Tiefe nach oben preßten. Das war im Juli. Im September ließen die Ausscheidungen an der Oberfläche noch auf 5 Tiere schließen, und im Dezember waren keine Ausscheidungen mehr zu finden. Diesem vereinzelten Umsiedelungsversuch kann natürlich nur orientierender Wert beigemessen werden. Es genügt einstweilen die Bestätigung, daß die Wasseruntersättigung der oberen Lagen des Sediments bereits für größere Individuen eine Schranke bildet und damit dem Besiedelungsbild des Standortes für längere Zeit das Gepräge geben kann.

Aus diesen Darlegungen über die Ökologie von Arenicola marina auf zwei verschiedenen Standorten des Königshafens geht hervor, welche Schwierigkeiten der Erforschung selbst von Teilen einer Lebensgemeinschaft bereits auf kleinstem Raum entgegentreten. Die dargelegten Ergebnisse bilden erst einen Anfang in der Aufklärung der Beziehungen zwischen Arenicola und den verschiedenen von ihr besiedelten Standorten.

\section{Das Uthörner Auß̣enwatt.}

a) Lage und Besiedelung 1932.

Dieser Wattbezirk liegt - wie bereits die Bezeichnung andeutet - östlich von Uthörn als äußerstes, d. h. dem offenen Wattenmeer am nächsten gelegene Watt. In seinem nördlichen Teil, nur durch Strömungsbänke kaum wahrnehmbar gegliedert, leitet es fast tischeben ganz allmählich den Hang zum östlich gelegenen Lister Tief ein. Dieses Wattgebiet hat von allen anderen des Königshafens das geringste Gefälle zur Niedrigwasserlinie, was am besten während der Flut zum Ausdruck kommt. Schneller als in jedem andern Teil des Königshafens rückt hier das Wasser nach Einsetzen der Flut nach Westen vor, um in ganz kurzer Zeit die Insel Uthörn an deren Ostkante zu erreichen. Auf etwas höherer Lage liegen die Strombänke, die im nördlichen Teil des Uthörner Außenwatts an den Priel heranreichen. Die Niedrigwasserlinie im Osten bildet etwa die Grenze der jetzt abgestorbenen, 1932 aber noch sehr üppigen Zostera marina-Wiese (vergl. WoHLENBERG, 90). Unterhalb der früheren Seegraswiese nimmt das Gefälle zum Lister Tief bin in stärkerem Maße zu. Im Süden und Südosten wird das nackte Uthörner Außenwatt durch Fucus- und Zostera angustifolia-Wiesen (Fucus versponnen mit Mytilus) begrenzt. Watet man von der Odde-Spitze nach der Insel Uthörn, so fällt besonders der überaus starke Wechsel im Aufbau des Sediments auf. Der Weg durch die südöstlich von Uthörn gelegenen Fucus-Wiesen ist außerordentlich beschwerlich. Erst kurz vor Uthörn werden die weichen, zum Teil halbflüssigen Muddschichten durch unnaehgiebiges Sandwatt abgelöst, das an der Oberfläche hell und sandig und in der Tiefe mehr und weniger von Schillbeimengungen durchsetżt ist. Das Außenwatt ist in seiner ganzen Ausdehning von gleich fester, sandiger Beschaffenheit. Ostwärts von Uthörn mißt die Fläche etwa $500 \mathrm{~m}$ bis zur Niedrígwassergrenze. Ueberall bildet heller gelber Sand die Oberfläche. Nur in den unterèn Schichten wechselt das Bild. Wie schon im Abschnitt $\mathrm{C}$ dieser Abhandlung besprochen (vergl. S. 14), werden von Zeit zu Zeit eben unterhalb Uthörns tote Mya in situ freigespült. An diesen Stellen ist der Sand von blaugrauem Pigment und etwas bindig, während das Sediment nach Nordosten und Osten erst von 6-10 $\mathrm{cm}$ Tiefe an Pigment zunimmt, aber sandig bleibt. Diese geringen Unterschiede kommen bereits in der Zusammensetzung der im Sediment lebenden Tiere zum Ausdruck. Auf allen Stationen des von Uthörn ostwärts bis an die Niegrigwasserlinie gelegten Profils wurde sehr viel Schill im Sediment und regelmäBig eine lichte Besiedelung (20-30 auf einen Quadratmeter) von Arenicola marina angetroffen. Mit der gleichen Regelmäßigkeit, jedoch erst mit dem Beginn der pigmentführenden Sehichten auf halber Höbe des Profils einsetzend, war Scoloplos zu finden. Große Cardien wurden vereinzelt erbeutet, häufiger dagegen Nephthys Hombergit und stellenweise Pygospio. An sehr lagerungsunbeständigen, pigmentfreien Plätzen fand ich zahlreiche Tellina tenuis. So war das Besiedelungsbild vom Sommer 1932.

\section{b) Der Cardium-Brutfall von 1934.}

Bei einem flüchtigen Besuch meines Arbeitsgebietes im Juli 1934, also zwei Jahre später, fiel mir auf, daß das Watt östlich von Uthörn längst nicht mehr so hell aussah wie 1932. Das Außenwatt war soeben trockengefallen, als ein sehr auffälliges Geräusch mich aufhorchen ließ. Es erinnerte mich sogleich an das vom Watt bekannte Zerspringen von vielen kleinen Bläschen (WOHLENBERG, 88). Das leicht angedunkelte und schwach gerippelte Watt hatte beim genauen Betrachten eine sehr merkwürdige Oberflächenstruktur. 
Auf3er den weitläufig eingestrenten Kothäufchen vom Sandwurm zeigte die Oberfläche kleine, dicht bei dicht liegende Vertiefungen, die auch in der $A b b .13 \mathrm{zu}$ erkennen sind. Diesen kleinen Trichtern entwichen noch ziemlich lange nach dem Abflielien des Wassers kleine Bläschen, die an der Luft zersprangen. Infolge der überaus dichten Lage war das Geknister recht beachtlich. Zwischen den Strömungsrücken dieses Gebietes (vergl. S. 14) stand noch blankes Wasser. Hier bemerkte ich anstatt der Trichter (Abb. 13) tiefe, kreisrunde Krater. Es waren die geöflneten Siphonen von jungen Herzmuscheln, in die ich

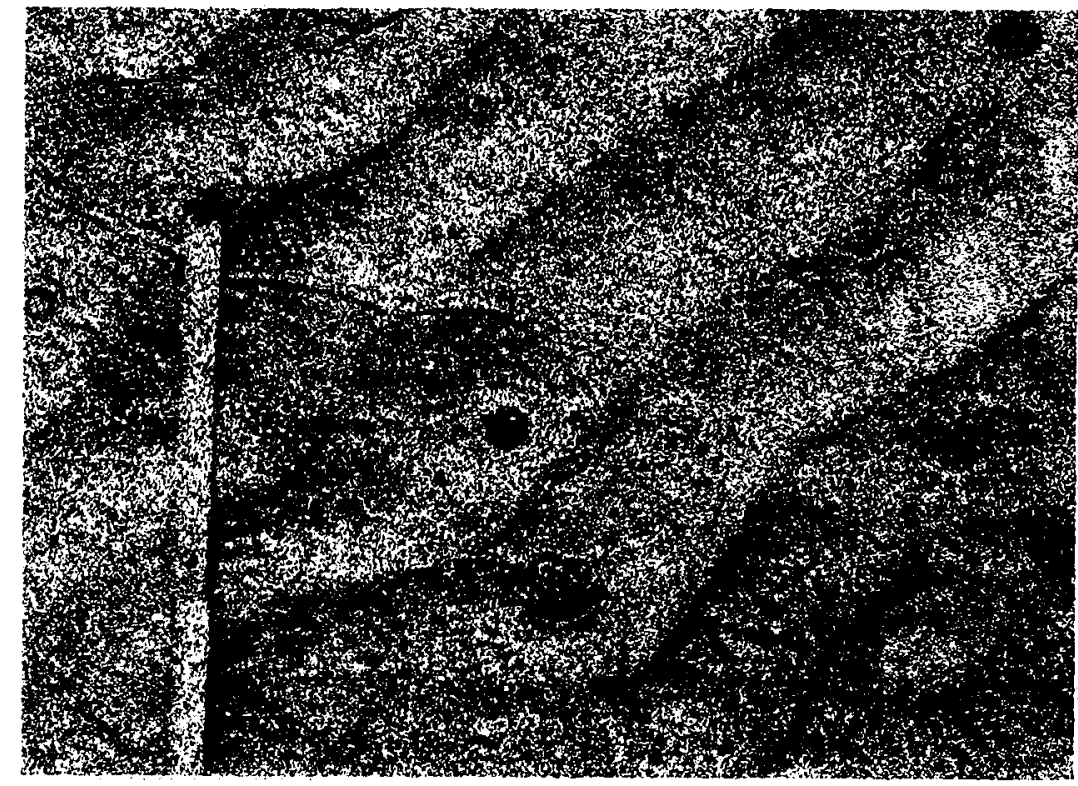

Abb. 13. Nahaufnahme von Stromsandrücken östlich von Uthörn. Unter jeder punktförmigen Vertiefung liegen die Siphonen vou Cardium edule. Die auf dem Bilde auffallende Crleichförmigkeit in der Besiedelungsdichte erstreckt sich über das ganze von der Brut befaltende Gebiet. IJie Forn der Kippeln und die schwache Besiedelung durch Arenicola marina weisen auf die Umlagerungsfähigkeit des Sedimentes hin. (Links Zentimetermafatab.)

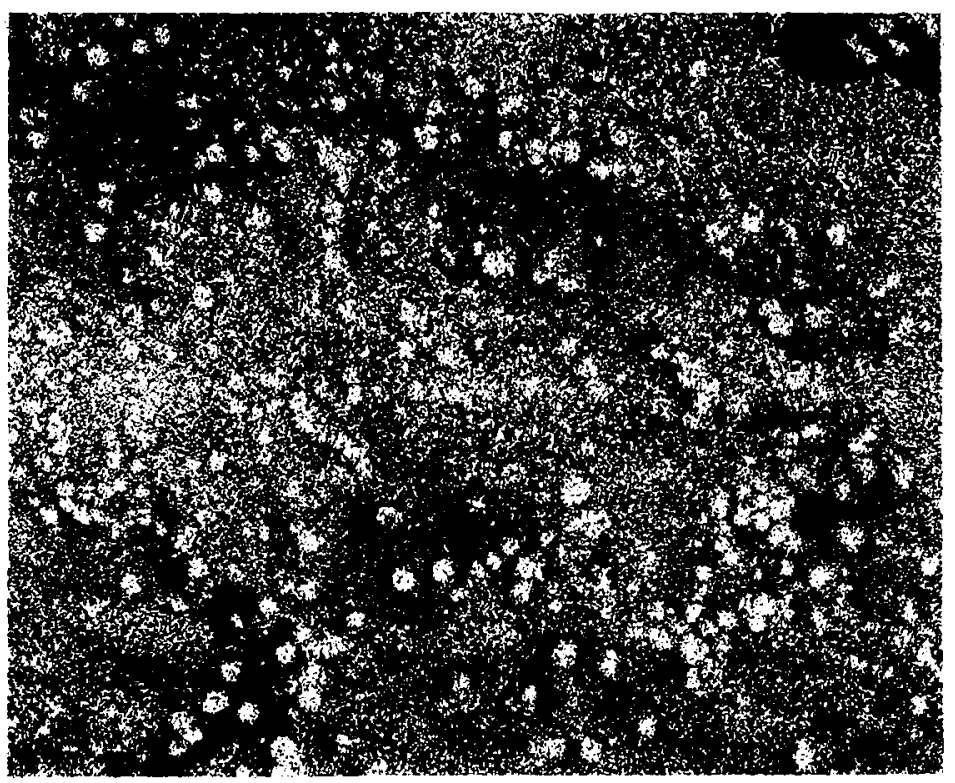

Abb. 1. Der zu oberst liegende Sand des Stromsandrückens wurde sorgfaltiu fortgeschwemmt. derart dath die lebenden Herımischein (Cardiut? edule) freigespült warden. Ein groler Teil der freigespültor Museheln kounte sich bis zur Aufnahme bereits wieder vergraben. hineinsah. So ergab denn:auch die Bestandsaufuahme, daß jeder Thichtor durch das beim Trockenfallen erfolgte Ginzichen des Siphos entatanden war. Unter jedem lrichler lag eine junge Herzmuschel, Cardium edule. Die Besiedelungsdichte übertraf jede Erwartung und Schätzung. Die aus einem Viertel Quadratmeter ausgesiebten Muscheln ergaben - laut Zählung in Laboratorium - die stattliche Zahl von 9865! Auf den Quadratmeter umgerechnet liegt somit eine Siedelungsdichte von nicht ganz 40000 Muschuin vor. AuBerdem entfielen auf denselben Quadratmeter 8 grobe Curdien, $24 \mathrm{Ma}$ coma bxlthica und 10 Tellina tonuis. Diese 40000 Muscheln stellten also fust ausschlieflich dio (1-Cruppe des Jahres 1934 dar. Ich schätze das Alter des Befalls aup $1-2$ Monate. Die linge der Sohulen betrug mit gribler Beständigkeit 4 bis $6 \mathrm{~mm}$. Individuen, die den Uebergang zu lon anfierdem grefumleren 8 gioforl) Candion von 23 30) num L. rünge hätten bilken kownen; waren nicht rothanden. Ein pasa rage darauf legte lek $\sin \mathbf{P}$ \%ofil mit einem arditur. Stationsnetz duroth das gefundene Oardim-Brutwatt. Der Befall bechü̈nkte sich Iuz armitichen auf Niesth : AuBenbezirk, dern vou den inveren 
Teilen des Königshafens hatte nur das dem Außenwatt benachbarte, westlich von Uthörn gelegene Watt einen unerheblichen Bestand an Junggut. Fast das ganze Außenwatt, besonders aber ONO von der Insel Uthörn, war mit einem Schlage zu einem Cardium-Watt allergrößten Ausmaßes geworden. Da dieser Standort eine seltene Gelegenheit bot, die Veränderungen der 0-Gruppe 1934 weiter zu verfolgen, wurde das am 3. August bestandsmäßig aufgenommene Profil durch Pfähle markiert und im darauf folgenden Winter, am 20. Dezember 1934, und schließlich im Mai 1936 abermals durch eine gleiche Anzahl Siebproben untersucht. In der folgenden Tabelle Nr. 15 sind die am 3. August, am 20. Dezember 1934 und am 17. Mai 1936 gefundenen Werte zusammengestellt. Die Länge der jungen Muscheln hat sich in beinahe 5 Monaten verdoppeln können. Vergleicht man diese Wachstumsverhältnisse mit denen anderer Gegenden, so kommt man entweder zu der Folgerung, daß der Standort im Uthörner Außenwatt übervölkert, d. h. die Nahrungskonkurrenz zu groß ist oder daß das den Standort täglich zweimal überflutende Wasser trotz genügender Ueberflutungsdauer arm an Nahrungsstoffen ist. Denn nach den Untersuchungen OkToN's (55) im Flußmündungsgebiet des Yealm-Flusses hat die 0-Gruppe des Jahres 1921 von Juni bis Juli bereits die Durchschnittslänge von $12 \mathrm{~mm}$ und am Ende des Jahres die stattliche Größe von max. $28 \mathrm{~mm}$ erreicht. Derselbe Verfasser gibt für 1918 als. Endwert $21 \mathrm{~mm}$ und für 1919 22-24 mm Länge an. Leider finden sich in den Arbeiten von ORTON keine Angaben über die jeweilige Bestandsdichte, mit der die betreffende 0-Gruppe aufgetreten ist, so daß unser Vergleich einseitig bleiben muß.

\section{Tabelle 15.}

Cardium edule-Brutfall auf dem Uthörner Außenwatt im Sommer 1934.

Besiedelungsdichte, Größen- und Gewichtsverhältnisse der Null-Gruppe 1934 in der Zeit vom August 1934 bis zum Mai 1936.

\begin{tabular}{|c|c|c|c|}
\hline & $\begin{array}{l}\text { August } \\
1934\end{array}$ & $\begin{array}{c}\text { Dezember } \\
1934\end{array}$ & $\begin{array}{c}\text { Maì } \\
1936\end{array}$ \\
\hline $\begin{array}{l}\text { Anzahl je } 1 \mathrm{gm} \\
\text { Gewicht je } 1 \mathrm{qm} \\
\text { Einzelgewicht (aus } 3000 \text { Stück) } \\
\text { Einzellänge (Mittelwert aus } 1200 \text { Mess.) }\end{array}$ & $\begin{array}{c}14000 \\
574 \mathrm{~g} \\
0,04 \mathrm{~g} \\
5,0 \mathrm{~mm}\end{array}$ & $\begin{array}{c}4300 \\
1290 \mathrm{~g} \\
0,31 \mathrm{~g} \\
10,2 \mathrm{~mm}\end{array}$ & $\begin{array}{c}800 \\
2500 \mathrm{~g} \\
3,42 \mathrm{~g} \\
22,3 \mathrm{~mm}\end{array}$ \\
\hline
\end{tabular}

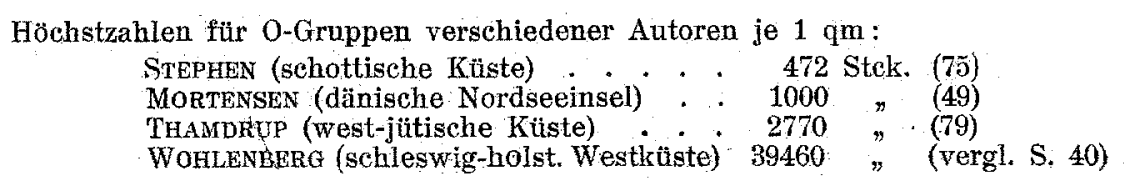

Aufschlußreicher sind die Vergleiche mit den von STEPHEN (75) ermittelten Werten. Nach Tabelle 1 bei STEPHEN auf S. 279 nimmt die Schalenlänge der 0-Gruppe 1930 vom 6. August bis zum 4. Oktober nur um den kleinen Betrag von $1,2 \mathrm{~mm}$ (von 3,1 auf $4,3 \mathrm{~mm})$ zu. Dieser für das schottische Watt bei Millport gefundene Wert bleibt im Gegensatz zu den Werten bei ORTON weit hinter den an sich schon geringen des Königshafens zurück, denn eine Zwischenanalyse, die ich ergänzend am 17. September durchführen konnte, ergab bereits eine durchschnittliche Schalenlänge von etwa $10 \mathrm{~mm}$, blieb somit also nur um einen Bruchteil hinter dem Durchnittswert vom Dezember zurück. Daraus kann man schlieBen, daB die Zuwachswerte von Oktober bis Dezember nur gering sein können. Allerdings ermittelt ORTON für den Oktobermonat noch $4 \mathrm{~mm}$, für November und Dezember 2 bezw. $1 \mathrm{~mm}$ Zuwachs in der Schalenlänge. (ORTON, $1926 \mathrm{~S}$. 275). In den zahlreichen Kurven über Gewichtszunahme und Verteilungsart von Cardium auf den westjütländischen Watten Dänemarks, die jüngst THAMdrup $(79, \mathrm{~S} .75, \mathrm{Abb} .24-27$ und S. $89, \mathrm{Abb}, 66$ bis 71) aufgestellt hat, finden wir leider nicht die Wachstumsverhältnisse einer Null-Gruppe dargestellt, sodaß diese nachbarlichen Watten nicht zum engeren Vergleich herangezegen werden können.

Günstiger werden die Vergleichsmöglichkeiten bei der Erörterung der von verschiedenen Autoren in verschiedenen Gebieten der Nordsee gefundenen Bestandsdichten. Allerdings schrumpfen sie bei der Beschränkung auf die Null-Gruppe, die hier allein zur Besprechung gestellt ist, leider auch sehr zusammen. Nach Tabelle 2 bei STEPHEN (76, S. 281) erreicht die Besiedelung durch die Null-Gruppe 1931 im Sommer den Höchstwert 
von 472 Muscheln je qm (STEPhen: 118 auf $1 / 4 \mathrm{qm}$ ). Bei Thambup (79, S. 88) wird als Höchstwert für die Null-Gruppe 2770 auf $1 \mathrm{qm}$ angegeben. Laut umstehender Tabelle beträgt der von mir ermittelte Durchschnittswert 14000 , d. i. nicht weniger als das Fünffache des THAMDRUP'sehen und das fast DreiBigfache des StePuEN'schen Null-GruppenWertes. Es ist demnach nicht übertrieben, wenn ich das Uthörner Außenwatt jedenfalls für den Sommer und - wie die Tabelle zeigt - auch für den Winter 1934/35 als das reichste bisher bekannt gewordene Cardium-Watt bezeichne. Das Unlersuchenswerte liegt nun ja nicht so sehr in der noch nie nachgewiesenen Besiedelungsdichte als vielmehr in dem glücklichen Umstand, auf einem leicht zugänglichen Watt in beschränkter Ausdehnung das Junggut etwa vom zweiten Lebensmonat an verfolgen zu können.

ES ist eine bekannte Tatsache, daf die Muschelbestände gegen den Winter hin abnehmen. Die Wiederholung der Bestindsaufnahmen auf demselben Profil nach viereinhalb Monaten ergab dann auch eine Abnahme um 9700 (von 14000 auf 4300 ) Muscheln für jeden Quadrafmeter, d. i, eine mitllere Einbuße von $69^{\circ}$, . Thamdrup's Null-Gruppe fällt 1934 vom Sommer bis zum Herbst um 2537. (von 2770 auf 233 ) Individuen für jeden Quadratmeter, was einen Verlust von $91 \%$ darstellt. Also auch in dieser Hinsicht liegt das Uthörner Außenwatt als Lebensraum offenbar günstiger als die bisher bekannt gewordenen Standorte.

Während die Gesamtbesiedelung auf einem Quadratmeter in Königshafen in der Zeit zwischen August und Dezember des Jahres 1934 und Mai 1936 von 14000 auf 4300 bezw. auf 800 Individuen fält, steigt dagegen das gesamte auf einen Quadratmeter bezogene Gewicht der Cardien von 574 auf 1290 und bis Mai 1036 auf 2500 Gramm. Während sich das für den Bestand eines Quadratmeters ermittelte Gesamtgewicht in der Zeit ron August bis Dezember 1934 îfolge des Bevölkerungsschwundes nur reichlich verdoppeln konute, erreichte das mittlere Dezember-Gewicht einer einzeln en Muschel nahezu das Achtfache ihres August-Gewichts. Die Zunahme (auf den ganzen Quadratmeter bezogen) um den fast 5 fachen Betrag an Gewicht spricht eigentlich nicht für Nahrungsknappheit oder Hungerzustände auf dem in so seltenem Mabe besiedeiten Sandwatt.

Auch scheint mir die nachgewiesene Dichteabnahme zum ersten Winter hin von nur $69 \%$ ein Zeichen dafür zu sein, daß das AuBenwatt trotz aller abweichenden Eigenschaften vom Cardium-Watt-Typus des Wattenmeeres nicht zu den ungünstigsten Standorten gezählt : werden darf.

\section{c) Das Sediment.}

Die Zusammensetzung des Sedimentes erseheint mir wichtig genug, um sie hier noch kurz anhand eines Diagramms zu bespreehen (Abb. 15). Fast $90^{\circ}$, des Gesanttrockengewichtes werden von den beiden Gruppen zwischen 0,25 und $1,00 \mathrm{~mm}$ gestellt. Größen unter $0,100 \mathrm{~mm}$ sind in so geringen Mengen vorhanden, daB sie im Diagramm nieht darstellbar sind. Der Wassergehalt der naturfeuchten' Proben liegt mit etwa $16 \%$ vom Gesamifeuchtgewicht etwas unter dem normalen Durchschnitt der Königshafensedimente ähilichen Aufbanes. Diese Zahienwerte und das Bild des Diagramms bekunden endeutig, daß das Uthörner AuBenwatt nicht altein ein ausgesproghenes Sandwatt ist, sondern daruber hinaus ein an Randfraktionen verarmtes Watt darstellt Es unterliegt einseitig angreifenden Kräften. Und trotzdem 14000 (nax. 39000 ) Muscheli anf einem Quadratmeter! Bei einex vergleichenden Bétrachtung der von anderen Autoren veröffentlichten Werte drängt sich der Eindruck auf, da 3 die KorngröBenzusammensetzung der Sedimente gar nicht so sehr von ausschlag-

Abb. 15 .

Uthorner Außenwatt (Cardium-Tellina tenuis). gebender Bedeutung zi sein braucht. THAMPROP's Höehstwerte 5410 Muscheln je an - beziehen sich auf den verhältnismäßig schliekrigsten Teil seiner sogenannten Buhnenlinie. HeCH und MATERN $(27, S, 366)$ gelangen im Rahnen ihrer ,bio-soziologischen Untersuehungen" in Watt bei Wangerooge sogar zu der GesetzmäBigkeit: ,je feinkörniger und wasserhaftiger (und damit auch weicher) das sediment" ist, um so stärker die Besiedelung" (durch Cardium). ${ }^{\text {) }}$

Da beide Arbeiten (79 und 27) darin äbereinstimmen, daß die Besiedelungsdichte um so größer, je feinkörniger das Sediment ist, liegt mit dem von mir untersuchten Uthörner

1) Leider enthalt diese Arbeit (27) anßer einer einfachen Zählung keme weiteren Angahen biologischer Art - Längeumaße, Anteile der Jatiresgruppen, Gewiehte a. a - so daß sie zur Erôrterung unserer NulGruppe nicht mit herangezogen werden kann. 
Außenwatt das äußerste Gegenteil in der Beziehung zur Korngrößenzusammensetzung vor. Auch Mortensen (49) berichtet von einer Besiedelungsdichte von 800-1000 Muscheln pro $1 \mathrm{~m}^{2}$ S a n d watt der dän. Insel Fanoe, und HaGmeier und Känler (21, S. 36) schreiben, daß Cardium im feinen, r ein e $\mathrm{n}$ Sand besonders zahlreich ist; eine entsprechende Angabe findet sich bei Nrcou(51). Aufgrund früherer Untersuchungen und zahlreicher weiterer Beobachtungen im Wattenmeer der schleswig-holsteinischen Westküste habe ich oft den Eindruck gehabt, als bestehe in unserem Wattenmeer durchweg die von HECHT und MATERN ausgesprochene Gesetzmäßigkeit. Aber mir begegneten so viele Ausnahmen und die in diesem Abschnitt geschilderten, mit quantitativem Zahlenmaterial belegten Verhältnisse im Königshafen raten zum mindesten zur Vorsicht und weisen darauf hin, daß die Beziehung zwischen Sediment und Cardium-Besiedelung noch einer sorgfältigen Untersuchung bedarf. Die Bestandsanalyssen im Königshafen vermögen jedenfalls eỉne biologische Gesetzmäßigkeit nicht nur nicht hinreichend zu unterbauen, sondern bekräftigen sogar das Gegenteil und bestätigen die zitierten Angaben (21, 49, 51).

Vom ökologischen Standpunkt möchte ich vom Uthörner Außenwatt nur sagen, daß der starke Befall durchaus kein Zufall zu sein braucht. Durch die Cardium-Besiedelung in den Jahren vorher, durch die allseitig offene Lage des Uthörner Außenwatts (vergl. Karte $\mathrm{Abb} .1$ ) und die damit verbundene Bewässerung sind die Voraussetzungen für den Befall mit Cardium-Junggut und durch die mögliche ausgedehnte Filtriertätigkeit auch die Voraussetzungen für eine ausreichende Ernäbrung gegeben. Die Ursache für die sehr geringe Besiedelungsdichte v o r dem Befall kann einerseits in den unbeständigen Lagerungsverhältnissen des Wohnsedimentes, andererseits in einer geringeren Bruterzeugung oder in einer ungünstigen Larven Ferfrachtung liegen. Bezüglich des Schicksals der Null-Gruppe 1934 mußte angenommen werden, daß sie außer durch tierische Feinde (Möven, Fische) auch durch Umlagerungen der oberen Sedimentschichten bald von ihrem hohen Winterbestand (4300 Muscheln im Dezember 1934) heruntergebracht sein würde. Die letzte Kontrolle im Mai 1936 (nur noch 800 Muscheln, vergl. Tab. 15) hat diese Vermutung bestätigt.

Da dem ungewöhnlich dichten Befall von 1934 im nächstfolgenden Jahre kein neuer Brutfall gefolgt ist, obwohl 1935 die großen Herzmuscheln in gleicher Zahl vorhanden waren, kann der Befall vom Sommer 1934 als ein direkt prüfbares Beispiel einer Fleckbildung, wie sie HAGMEIER von Spisula subtruncata nachweisen konnte (22a), angesehen werden.

Während ich sonst den Watt-Tieren sehr wohl eine große Bedeutung für die $\mathrm{Zu}$ sammensetzung des Sedimentes beimesse, so liegen die Verhältnisse beim Uthörner Außenwatt anders als im typischen Wattenmeer. Wohl ist die dunklere Farbe der Oberfläche, die mir im Sommer 1934 nach dem erfolgten Befall sogleich auffiel, auf die Stoffwechselprodukte der jungen Muscheln zurückzuführen, allein eine Umwandlung dieses reinen Sandwattes (vergl Abb. 15) in ein schlickiges Sandwatt dürfte selbst bei einer Besiedelung von 14000 Individuen auf den Quadratmeter nicht erreicht werden. Dafür ist der Lebensraum zu offen, zu sehr Außenbezirk, als dab das nur locker Geformte stets an Ort und Stelle zur Ablagerung kommen könnte. Flut- und Ebbstrom setzen täglich in breiter Front über dieses Gebiet hinweg, und was von ihnen nicht fortgeschafft wird, das entführen stürmische Einzelwetterlagen und lagern es an anderen, geeigneteren Orten ab.

Das gleichzeitige, nicht seltene Vorkommen von Tellina tenuis inmitten der Cardium-Brut gibt verschiedene Hinweise auf die Figenschaften des Standortes. Das Vorkommen beider Muscheln nebeneinander ist für das allgemeine Watt der Küste durchaus nicht die Regel. Tellina tenuis kommt im Königshafen lediglich auf dem Uthörner AuBenwalt und östlich vom Lister Haken an der MNW-Grenze im reinen Sandwatt vor. Sie kennzeichnet also ähnlich wie an der schottischen Küste (STEPHEN 75, 76) und an der dänischen (MoRTENsEN 49) die lagerungsunbeständigen A ußen bezirke. Daß sie dagegen im Königshafen etwa $25-30 \mathrm{~cm}$ über dem mittleren Niedrigwasserstand vorkommt, läßt sich nur durch den auch während der Nichtüberflutung vorhandenen wasserüber- bezw. gesättigten Zustand des Sedimentes erklären.

\section{Das Gröning-Watt.}

a) Vergleich zwischen der Besiedelung 1932 und 1934.

Die topographischen Verhältnisse des vor dem Gröning liegenden Wattgebietes sind bereits auf S. 5 besprochen worden. Die Besiedelungsbilder (Abb. 16) wurden 1932 und 
1934 durch quantitative Methoden ermittelt; allerdings veranschaulichen sie nur die Art der Besiedelung und sagen nichts über die mengenmäßige Beteiligung der verschiedenen Tiergruppen aus. Sie sollen einen Einblick geben in die von Jahr zu Jahr möglichen Verschiedenheiten in der Besiedelung eines bestimmten Wattgebiets. (Ueber die befristete Gültigkeit eines Besiedelungsbildes vergl. auch HAGMEIER und KäNDLER (21, S. 40). Es wurde bereits im einleitenden topographischen Abschnitt hervorgehoben, daß sich das GröningWatt von den anderen Abschnitten des Königshafens durch ein stärkeres Gefälle zur MNW-Linie unterscheidet. Diesem Umstand dürfen wir es wohl zuschreiben, daß die Besiedelung des Watts sowohl durch Tiere als auch durch Pflanzen eine deutliche Zonierung

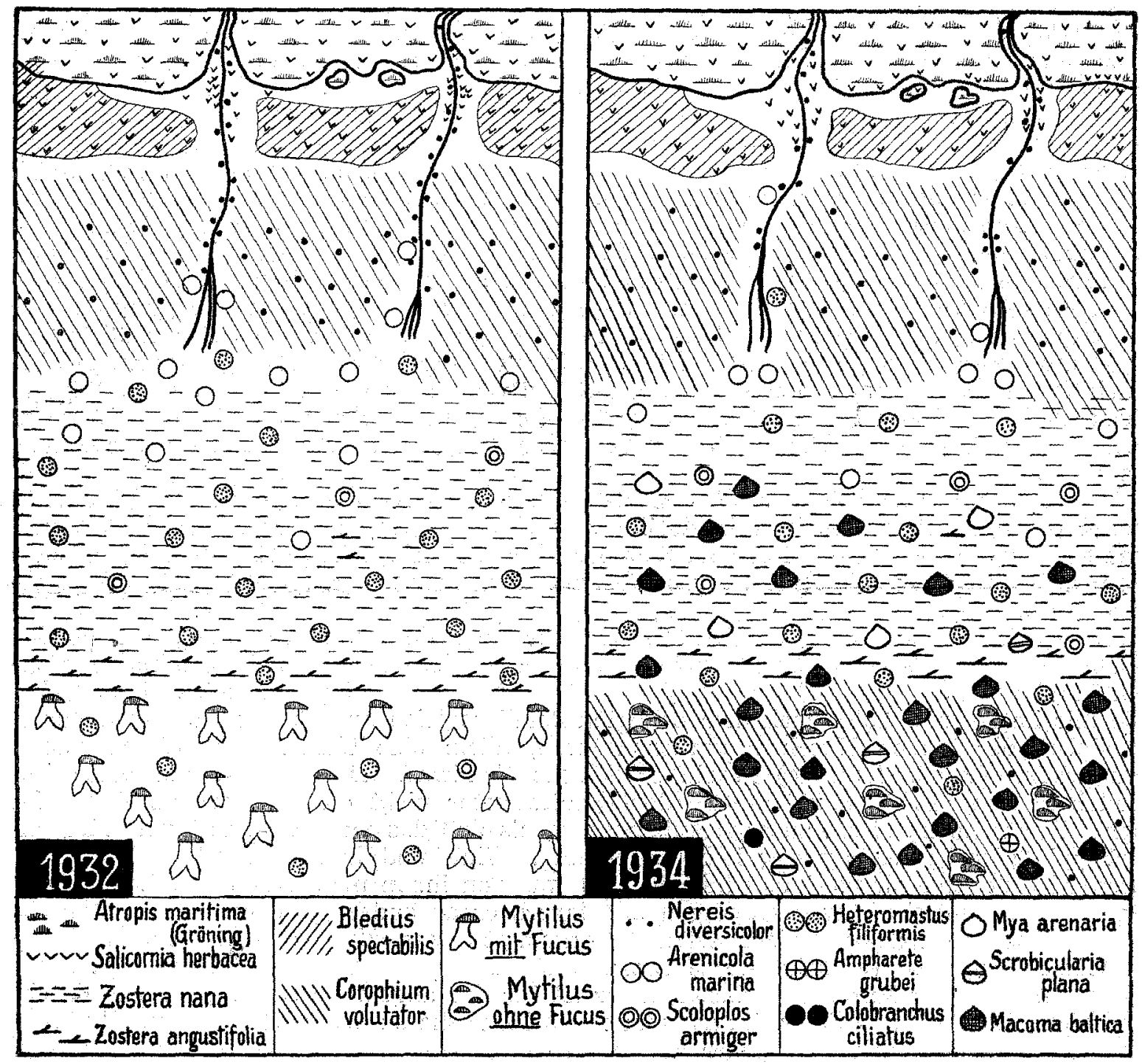

Abb. 16. Die gürtelförmige Besiedelung des Gröning-Watts in den Jahren 1982 und 1934.

erkennen läßt. Es lassen sich ohne Schwierigkeiten über das gesamte Gebiet vor dem Gröning vier verschiedene Besiedelungsarten festlegen. Sie treten auf einem West-Ost-Profil von der HW-Linie bis zar NW-Linie wie auf Abb. 16 dargestellt auf.

Unmittelbar vor der fast geschlossenen Andelwiese des Grönings erstreckt sich ein etwa $10 \mathrm{~m}$ breiter Gürtel, der sich sehr bald in der bereits besprochenen Weise (S. 18) als Bledius spectabilis-Standort zu erkennen gibt. Vereinzelt stehende, gespreizte Quellerpflanzen, näch erfolgter Ueberflutung der seifige Cyanophyceen-Rasen, auf der glatten Oberfläche die bekannten Krümelhäufichen des Kurzflüglers und sehlieflich das Verhalten des Sediments beim Hinüberschreiten sind verläßliche Anzeichen für die Art der $\mathrm{Be}$ - 
siedelung: nämlich mit dem Kurzflügler Bledius spectabilis zusammen mit den Raubkäfern Cillenus und Heterocerus (vergl. S. 69 und Tab. 16).

Ziemlich unvermittelt bricht der Blaualgenrasen nach Osten hin ab, gleichzeitig den Bledius-Standort begrenzend. Es folgt darauf eine vegetationslose Zone, deren Oberfläche aus der Nähe betrachtet zwei aufschlufreiche Merkmale trägt. Zunächst fallen kreisrunde Vertiefungen mil mehr oder weniger steiler Innenböschung auf. Es handelt sich um dieselben Gruben, die ich schon bei der Behandlung der Arenicola-freien Rücken vor dem Mövenberg erwähnt habe (Abb. 11). Auch hier vor dem Gröning sind diese Gruben dem Borstenwurm Nereis diversicolor zuzuschreiben. Außerdem ist die Oberfläche dieses gut entwässerten, sandigen Schlickwattes infolge der starken Besiedelung durch Corophium in der bekannten Weise (Trusheim, 83, WohLanberG, 88) genarbt. Beim Begehen dieses Wattstreifens fällt außerdem die geringe Nachgiebigkeit auf, was die im nebenstehenden Blockdiagramm, Abb. 17, links, dargestellte Verteilung der Korngrößen leicht erklärt. Bei dem für die Königshafensedimente verhältnismäßig beträchtlichen Anteil an Körnern unter $0,250 \mathrm{~mm}$ ist nämlich der geringere Wassergehalt von $20^{\circ !}$ bemerkenswert. Aus der Bestandsliste entnehmen wir, daß Anfang Oktober 1932 129 Corophium, Ende Juli 1934 dagegen 576 auf ${ }_{i 26}^{1}$ qm siedelten (vergl. Siedlungsschema Abb. 16).

Die nächstfolgende Zone ist ein Streifen, der nahezu vollständig mit Zostera nana bedeckt ist. Im Uebergangsgebiet vom Corophium- zum Seegrasgürtel tritt Arenicola marina stärker auf, um im tiefer gelegenen Teil der Zwergseegraswiese zahlenmäßig abzuklingen. Hier wie vor allem in großer Ausdehnung vor dem Mövenberg und auf dem Westfeuerwatt befindet sich ein Streifen, der nur mit jungen Arenicola besiedelt ist. Das Sediment zeichnet sich durch Festigkeit und Wasserarmut aus. Erst im weichgründigeren Zostera nana-Gürtel sind große dunkelfarbige Tiere zu finden. Die Verteilung ist so regelmäßig, daß man von einem Arenicola-,Junggut“-Watt sprechen kann. Seine obere Grenze innerhalb des Gezeitenberciches überschneidet die untere Grenze des CorophiumGürtels. In den Lücken zwischen den feinen Blattspreiten erkennt man die kleinen Perlhäufchen von Heteromastus filiformis. Er ist das Charaktertier dieses Abschnittes, wenu er auch nicht die Besiedelungsdichte von anderen mir bekannten Wattgebieten erreicht. Daß hier ein sehr schlickiges und infolge des dichten Bewuchses auch schlecht entwässertes Sedi-

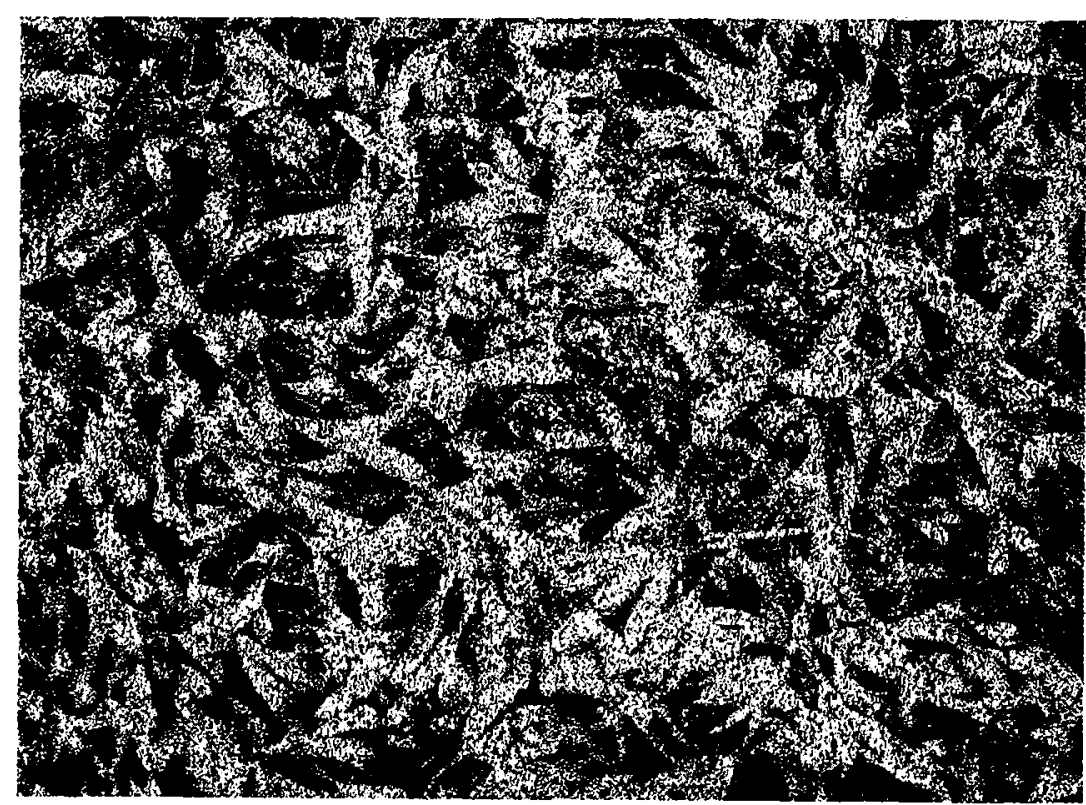

Abb. 18. Nabaufnahme aus der Fucus-Wiese zwischen Oddespitze und der Insel Uthörn. Der von NIENBura beschriebene Habitus ist gut erkennbar (53). Dieser Standort beherbergt außer den sichtbaren Litorina litorea die weniger zahlreich vorhandenen Litorina obtusata (1932). ment vorliegt, zeigt das Blockdiagramm (Abb. 17, rechts). Der Wassergehalt von $30 \%$ ist hoch.

Die Besiedelung dieser Zone war in den beiden Vergleichsjahren bis auf den Befall durch Macoma balthica im Jahre 1934 die gleiche. Während Macoma 1932 hier vollständig fehlte, zählte ich 1934277 Jungtiere auf $1 / 2, q m$. Diese Zahl steigt mit zunehmender Geländetiefe und Annäherung an die MNW-Linie auf $325 \mathrm{Mu}$ scheln auf :;:o qm an. Damit sind wir in die vierte Siedlung vor dem Gröning-Watt eingetreten. Es ist die Fucus Mytili-Siedlung.

Das Sediment dieser 1932 noch dicht vom Fucus bedeckten Zone, 
die über die MNW-Linie weit ins Prielbecken hineinreicht, ist noch einige Grade weicher und wasserhaltiger und auch tiefgründiger als im eben besprochenen Zwergseegrasstreifen. Teilweise ist ein Begehen sogar unmöglich. Als ich im Jahre 1932 meine ersten Analysen hier durchführte, war die Fucus-Zone so üppig und geschlossen ausgebildet, wie sie durch Nienburg bekannt geworden ist. (Vergl. Abb. 18.) Es drängte sich mir allerdings

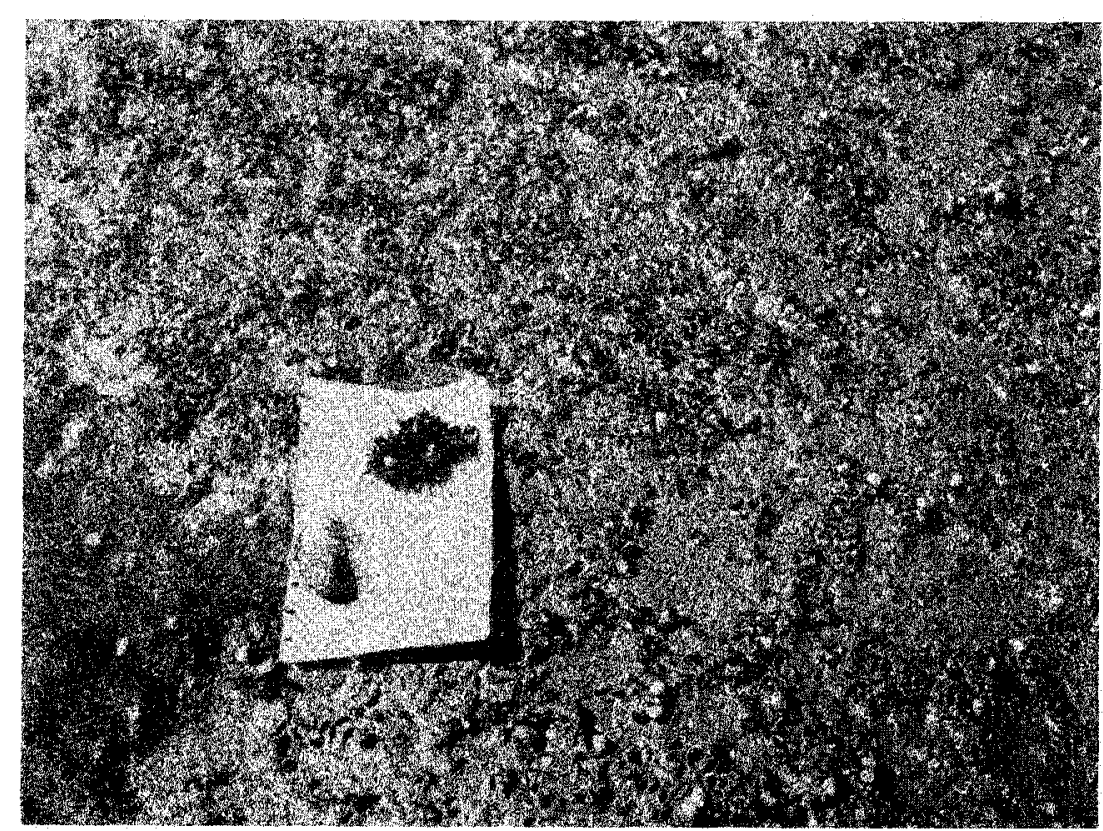

Abb. 19. Myfilus-Brut-Watt. Besiedelung eines ganz weichen Schlickwatts ohne Fucus vor der Odde. Die Miesmuschelbrut hat sich zu einem dichten Filz versponnen, wie das'stürk auf dem weißen Untergrund erkemnen läßt. Die darunterliegende Muschel als Maßstab (4 $\mathrm{cm}$ lang).

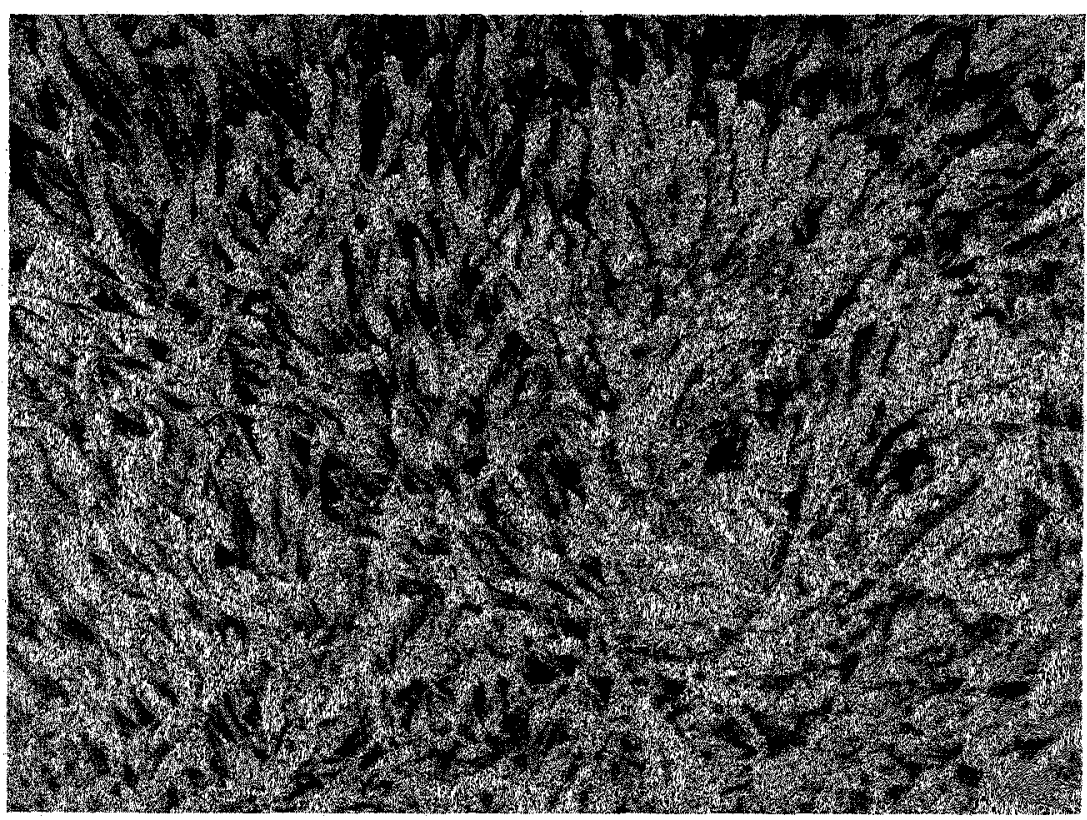

Abb 20. Ein mit Fucus bewachsener Buhnenkopf bei List. Die Untersontwo in der Thallusbildung zwischen dem an einem Buhxenpfahl nuit Haftscheibe wachsenden Fucus (rechte Bildhälfte) und dem mit Mytilus versponnenen Fucus (linke Bildhälfte) sind deutlich stightbar.
1932 schon der Verdacht auf, daß der Fucus hier nur noch ein Kümmerdasein führe. Die schon von NIENBURG beschriebene Brüchigkeit hatte einen sehr hohen Grad erreicht. Die neuen Sprosse maßen durchweg nur bis zu $5 \mathrm{~cm}$ Länge. Die Algen waren ziemlich regelmäßig mit den darunterliegenden Muscheln versponnen. Von der Wattoberfläche war infolge der dichten Bedeckung mit Fucus nichts zu erkennen. Ich verglich damals diesen Fucus mit Pflanzen, die, in gleicher Weise mit der Miesmuschel versponnen, an anderen Stellen des Königshafens wuchsen, so z. B. an den Muschelbänken des Hauptpriels (vergl. S. 73), an dén Buhnen (Abb. 20) und auf dem Wattrücken zwischen den beiden Prielabschnitten I und II. An diesen Plätzen war der Fucus nicht brüchig, sondern in seiner ganzen Länge elastisch und zum krassen Unterschied von den Standorten vor dem Grơnining, zwischen der Insel Uthörn und der OddeSpitze, wo ex die leuchtend gelb-braune Farbe hatte, immer von satter, dunkel-oliver Tonung. Nonbura hat diese Unterschiede im Königshafen nicht beschrieben. Wobl berichtet er in seinor letzten Arbeit (Nrengura 54, S. 35) vom Fehlen der "Brüchigkeit" in den Watten von Wyk and Amrum.

Als ich 1934 meine Bestaudsaufnahmen im 
selben Abschnitt wiederholte, hatte die Siedlung IV (Abb. 16) vor dem Gröning ein vollständig verändertes Aussehen. Es war nicht allein von einem geschlossenen Fucus-Bestand nicht mehr die Rede, sondern zwischen den zu Klumpen versponnenen Miesmuscheln, die locker über den ganzen Gürtel verstreut lagen, waren kaum noch Reste von Fucus vorhanden. Nur an zwei Stellen war noch brüchiger Fucus zu finden, aber auch hier war der Bestand derart gelichtet, daß die Wattoberfläche glatt und blank zutagelag. Die Muschelklumpen lagen frei und meistens ein wenig eingesunken auf dem wegen der Tiefgrïndigkeit kaum begehbaren Watt. In diesem Zusammenhang weise ich auf die Abb. 19 hin. Sie zeigt das Verhalten der Miesmuschelbrut auf einem ähnlich tiefgründigen weichen Schlick-Watt vor der Lister Odde. Die jungen Muscheln - etwa $1 \mathrm{~cm}$ lang - häben sich zu einer dichten filzartigen Matte versponnen und bedecken, wie aus der Aufnahme ersichtlich, dicht bei dicht die überaus weiche Wattoberfläche. Zur Erläuterung der Größenverhältnisse habe ich ein Stück dieses Filzes vom Schlick befreit und zusammen mit einer ausgewachsenen $4 \mathrm{~cm}$ langen Miesmuschel auf die weiße Unterlage gelegt. Alles nur irgendwie in Reichweite ihres Byssus Kommende haben die jungen Muscheln mit sich versponnen, wie z. B. Seegrasblätter und -wurzelstöcke, lebende und tote Strandschnecken (Litorina litorina), Schalen von Cardium und Macoma u. a. mehr. Auch sieht man deutlich auf dem Bild, daß der größte Teil der Muschelbrut bis zur Hälfte und auch tiefer in den weichen Schlick eingesunken ist.

Wenn ich heute auch noch nichts über die Lebensdauer dieser Brut, die sich ohne Fucus auf dem weichen Schlick behauptet, aussagen kann und auch der veränderte Befund unterm Gröning kein Dauerzustand zu sein braucht, so muB im Hinblick auf die von Ninnburg beschriebene "Lebensgemeinschaft ${ }^{\star}$ zwischen dem Fucus und der Miesmuschel doch auf die Möglichkeiten starker Veränderungen im Wattenmeer hingewiesen werden.

Wenden wir uns zum Schluß wieder der vergleichenden. Betrachtung der Besiedelung der Fucus-Zone von 1932 und $1934 \mathrm{zu}$, so fällt uns außer der bereits erwähnten Neubesiedelung durch Macoma diejenige von Scrobicularia plana und vor allem von Corophium volutator auf. Bezeichnenderweise tritt zusammen mit Corophium auch in dieser tiefliegenden Zone Nereis wieder auf. Ich möchte annehmen, daß die Neubesiedelung mit Tieren, von denen bei vollständiger Bedeckung des Standortes mit Fucus im Jahre 1932 kein einziges Tier nachgewiesen werden konnte, in direktem $\mathrm{Zu}$ sammenhang mit der Entfernung der dichten Fucus-Decke steht. Ich fand nicht weniger als 108 Corophien auf $1 / 20 \mathrm{qm}, 1932$ dagegen keine. Am Sediment selbst konnte ich äußerlich keine Veränderungen wahrnehmen.

Mit den beiden einander gegenübergestellten Besiedelungsbildern von 1932 und 1934 sollten Augenblicksbilder festgehalten werden. Sie vermitteln einen Einblick in die von Jahr zu Jahr auftretenden Schwankungen im Bestand sowohl als auch in die Veränderungen im Artbild.

\section{Das Lagunen-Watt am Kersten-Rimling.}

Das Lagunen-Watt gehört zum Ostfeuer-Watt und bildet hier einen Teil des Hochwassergrenzbezirkes.

Junge Dünengebiete und Strandbildungen sind bekannt dafür, daß ihre Morphologie ziemlich unmittelbar die in ihrem Bereich zuletzt wirksam gewesenen Kräfte abbildet. Dieser Tatsache kommt natürlich auch der Umstand zugute, daf in solchen Gegenden der Mensch eine untergeordnete oder auch gar keine Rolle spielt. Die Natur wirkt und waltet hier oft ohne Beschränkung in Stoff und Raum, so daß man - auch ohne Zeuge von den jüngsten Ereignissen gewesen zu sein - eine gute Vorstellung vom Werdegang der heute vorliegenden Form erhalten kann. So ist es am Südufer des Ellenbogen.

Die Lagune ist eine junge Bildung. Sie ist wie nur wenige andere Gebiete im Königshafen ein Standort, der in fast idealer Weise eine Einheit in Geschichte und Form und im Einklang damit einen in sich geschlossenen Lebensraum darstellt.

\section{a) Die Entstehung der Lagune.}

Als ich im Sommer 1932 die Untersuchungen aufnahm, suchte ich vergebens auf dem amtlichen Kartenmaterial nach dem Lagunenbezirk. Er wurde wie vorher der Lister Haken (vergl. S. 29) in einfacher Weise zur Gewinnung kartenmäßiger Unterlagen aufgemessen. 
Sehen wir uns zunächst die Lagune anhand der Abb. 21 als. Teilgebiet des Ellenbogenstrandes an, so fallen drei Bestandteile auf. 1. die Nehrung als langer halbmondförmig gebogener Sand, 2. die von der Nehrung umschlossene Lagune und 3. die außen am Fuf der Nehrung liegende Terrasse. Ein Rundblick von den umliegenden hoben Dünen des Ellenbogens vermittelt anhand der Geländeformen einen guten Einblick in die Entstehungsgeschichte der Lagune. Das Meßtischblatt, und ergänzend dazu meine Schwarzweißdarstellung (Abb. 1), lassen ohne Schwierigkeit erkensen. dab in Lauguenhezirk (Lagune, Haken und Terrasse) heute die Strandform im Werden begriffen ist, die $1000 \mathrm{~m}$ westlich davon, südlich vom Westfeuer, in etwas größerem Maßstab bereits vor Jahrzehnten (?) gereift und zum Abschlnß gekommen ist.

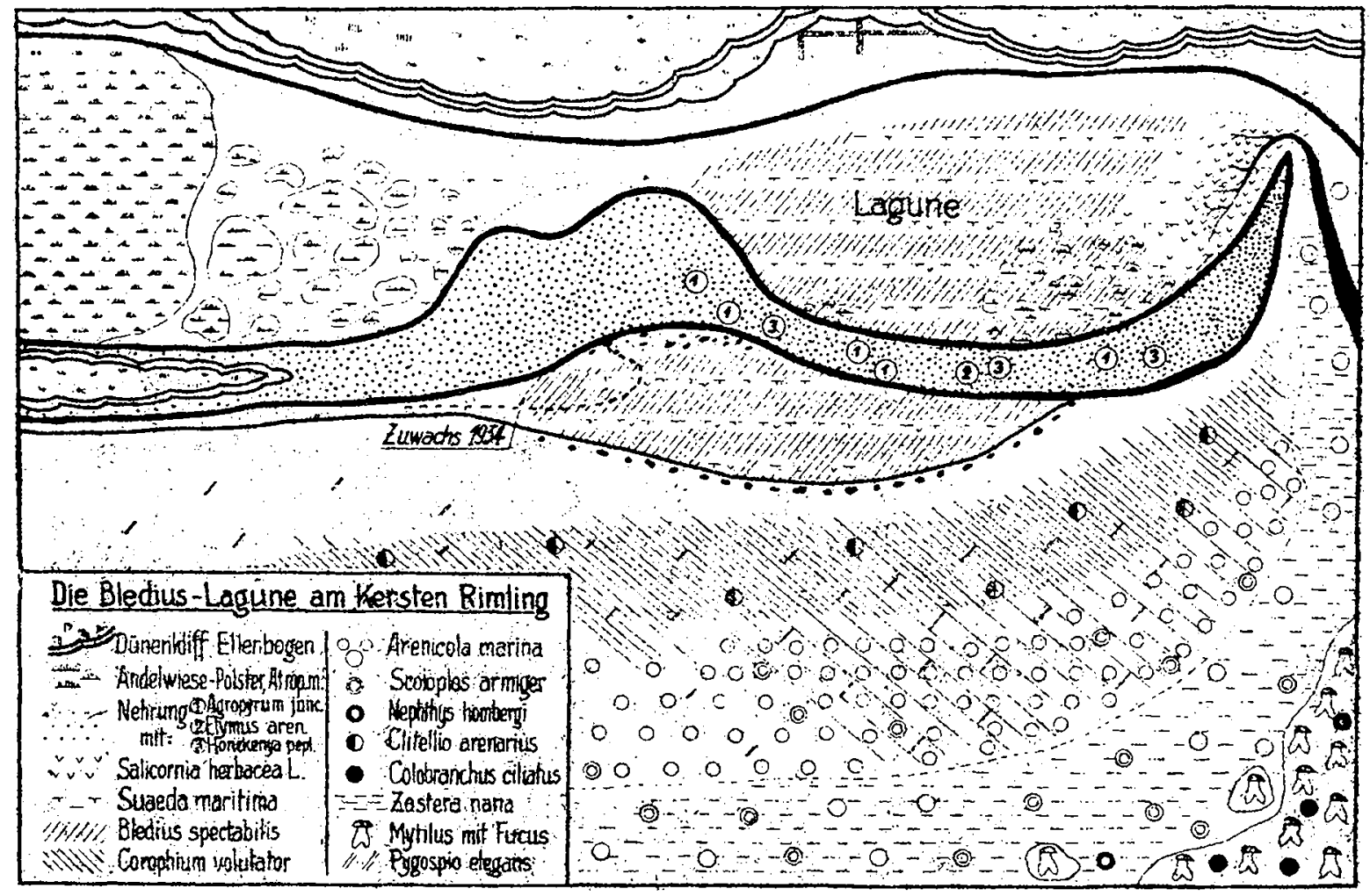

Abb. 21. Dei: Laqunen-Bezirk unterm Kersten Rimling am Ellenbogen.

Un einen Einblick in diese gesetzmäBjge Entwicklung zu erhalten, gehen wir am Ellenbogenstrand von der Lagune her wostwürts bis zur Höhe des Westfelers und überblicken vom $3 \mathrm{~m}$ hohen Dünenkliff am Königshafenufer nach Norden und Nordosten die Westfeuerniederung. Obwohl ihre Pflanzendecke keine reine Seemarschvegetation mehr darstellt, muß sie doch als eine im Schutz der allseitig umgebenden Dünen in jüngerer Zeit aufgewachsene Marseh angesehen werden.

In Norden und Westen durch 8 bis $12 \mathrm{~m}$ hohe Dünen gegen dạs Meer uhgegrenzt, ist im Süden in West-Ostrioltung eine Nelirung mit der Wurzel am Gö̈ning Lnde herangewachsen. Wie im Norden die hohen Dönen den EinfluB des offenen Meeres ausschalten, so dièse Netirung im Südèn den des Königshafens: Nur nach Südosten jkt tine halsförmige Verbindung mit dem Königshafen erhalten geblieben. Durch sie mündet eis kleiner Priel in den Königshafen, der innenthalb der Marschniederung die eharaktestistigchen Formen eines Vorlandpriels hat. Die unteren $200 \mathrm{~m}$ dieses Priels durchsotheniden eine stellenweise spärlich und unregelmäßig besiedelte (Agropyrum und Honckenią), in großen und ganzen aber nackte Strändaufschüttungszone, die durch Flugsand, durch Kiesel und Geschiebe je nach Wetterlage ihr wechselndes Aussehen erhält.

Der Aufwuchs der Westfeuerviederung dauert auch heukt nuh an. Starke beständige Winde haben daran den gröBten Anteil, in dom sie nirht getringe Sandmengen von den umgebenden Dünen in die Niederung hinoinwulun. Duell aueh das Wasser liefert von Zeit zu Zeit einen Beitrag. Bei Sturmfluten bildirt die halsförmige Oeffraing 
im Südosten ein breites Einfallstor für die Wassermassen, die der kleine Priel nicht mehr zu führen vermag. Die ganze Niederung, mit Ausnahme der höher gelegenen Restdünen, steht dann unter Wasser, das sich alsdann in dem denkbar günstigen Sedimentationsraum der mitgeführten Sinkstoffe entledigt. Wie sich der Verlandungsvorgang in der Westfeuerniederung im Einzelnen vollzogen hat, d. h. welche Bedeutung und welche Funktion ihre verschiedenen Randgebiete und welchen Anteil die nacheinander aufgetretenen Vegetations- und Faunenfolgen daran gehabt haben, mưß dahingestellt bleiben. Sie wurde hier nur erwähnt, um für die nunmehr zu behandelnde Lagune eine breitere, auf das Gesamtbild der landschaftsbildenden Kräfte zurückgehende Grundlage zu schaffen. Der Rückblick sollte zeigen, daß die Lagune nichts weiter darstellt als eine Teilentwicklungsstufe in der Gesamtmorphologie des Ellenbogens.

Diese in Bezug auf den Standort entwicklungsgeschichtlich gerichtete Betrachtung stelle ich der eigentlichen Untersuchung der Biocönose absichtlich voran. Gerade das Beispiel der Lagune, eines kleinen, in sich geschlossenen Lebensraumes, dürfte den Gedanken bekräftigen, daß die Erforschung einer Biocönose nicht mit der Aufstellung einer Liste über Artenbild und Wohndichte allein erschöpft ist. Wir müssen sehen, wie sich ein Biotop entwickelt hat und können dann die organische Einheit und das zwangsläufig mit ihr Verbundene besser verstehen. Der historische Faktor ist wichtig und für das Gesamtbild unentbehrlich.

Ein Blick auf die Karte (Abb. 1) zeigt, daß in der Entwieklung des Ellenbogens gerade im Gebiete des KerstenRimling noch nicht das letzte Wort gesprochen

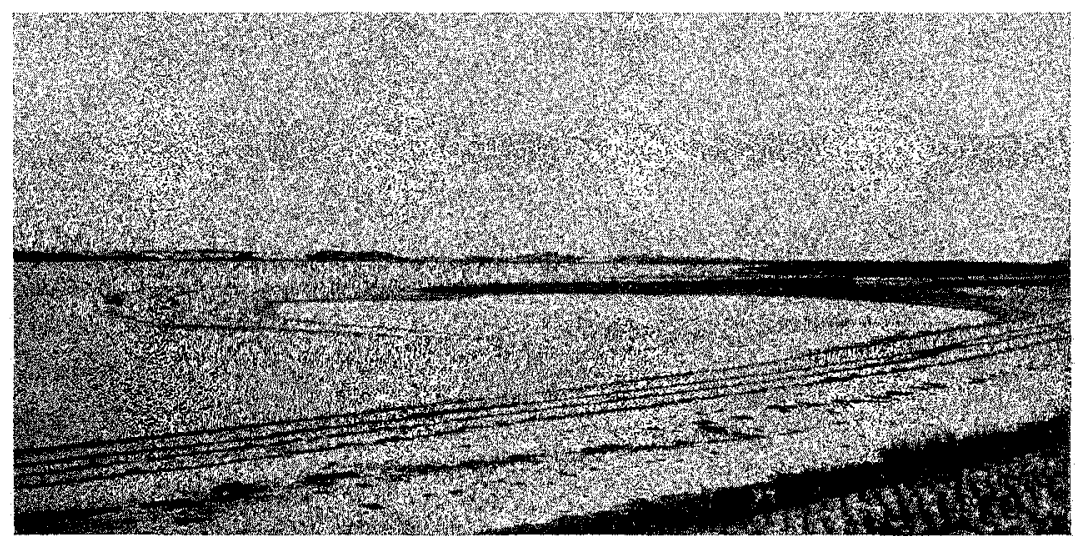

Abb. 22. Die Bledius-Microcoleus-Suaeda-Lagune am Kersten Rimling. Im Vordergrund die Spïlsäume am Ellenbogenstrand. Die von der Nehrung hakenförmig umsehlossene Lagune wird gerade überflutet. Im Hintergrund der Königshafen mit den hohen Dünen des Listlandes. ist. Die auffallende Einschnürung am Nordufer des Ellenbogens zwischen dem West- und dem Ostfeuer gibt auch dem Laien Anlaß zur Sorge um die Erhaltung des Ellenbogens als einheitlichen Wall gegen das nördlich hart vorbeiziehende Lister Tief. Das Nordufer büßt in immer wachsendem Maße dureh fortdauernde Abträge mehr und mehr vom Dünenkörper ein, während die Kliffbildung an der Südseite zur Ruhe gekommen ist und nunmehr neues Material mit dem in der Bildung begriffenen Sandhaken heranwandert. Ausgehend von einer größeren Dünenmasse, schiebt sich der nehrungsartige Haken ostwärts vor. Der erste Teil dieser Nehrung, der aus Ammophila-Dünen besteht, umschliebt eine Bucht, die - aus dem Zustand einer Lagune bereits herausgewachsen - z. T. eine junge Marschbildung (verkleinertes Abbild der Westfeuerniederung) darstellt. Der zweite Teil, die eigentliche Nehrung, schließst ein an der Hochwassergrenze gelcgenes Gebiet, das zum Teil noch Watt ist, in schmalem und langem, nach Süden konvex gekrümmtem Bogen ein (Abb. 21 und 22). Das allmählich sich verjüngende Ende des Hakens nähert sich dem Ellenbogenstrand bis auf eine schmale, wenig vertiefte Rinne. Diese Rinne ist der Priel, der den eingeschlossênen Teil - die Lagune - be- und entwässert (Abb. 21). Er hat nur im unteren Teil der Lagune und beim Umfließen der Hakenspitze ein eingeschnittenes Bett. Im Watt verflacht er sehr schnell und ist dort bald nicht mehr zu erkennen. Der Nehrung im Süden vorgelagert liegt die Terrasse, eine fast horizontale, glatte Ebene, die zum Watt mit einem scharf ausgebildeten Kliff von $7 \mathrm{~cm}$ Höhe abbricht (Abb. 25). Das Vorhandensein der Nehrung ist von entscheidender Bedeutung für den ganzen Lebensraum.

b) Die Nehrung.

Von den drei Bestandteilen des Lagunenbezirks ist der Sandhaken naturgemäß der unbeständigste. Seine höchsten Stellen liegen bis $\mathrm{zu} 60 \mathrm{~cm}$ über dem Lagunenboden. 
Je nach der Wetterlage zeigt seine Oberfläche eine verschiedene Struktur. In Zeiten des Zuwachses liegen feiner Sand und stellenweise, nach hohen Wasserständen, Spülsäume auf dem Rücken. Dann aber kann alles Neuaufgelagerte durch einen Sturm wieder fortgeräumt werden, sodaß ein Pflaster von Steinen und Muschelschalen zurückbleibt. Trotz dieses Wechsels haben sich, wenn auch nur in kümmerlichen Formen, einige Strandpflanzen angesiedelt. Es waren Elymus arenarius, Agropyrum junceum und Honckenya

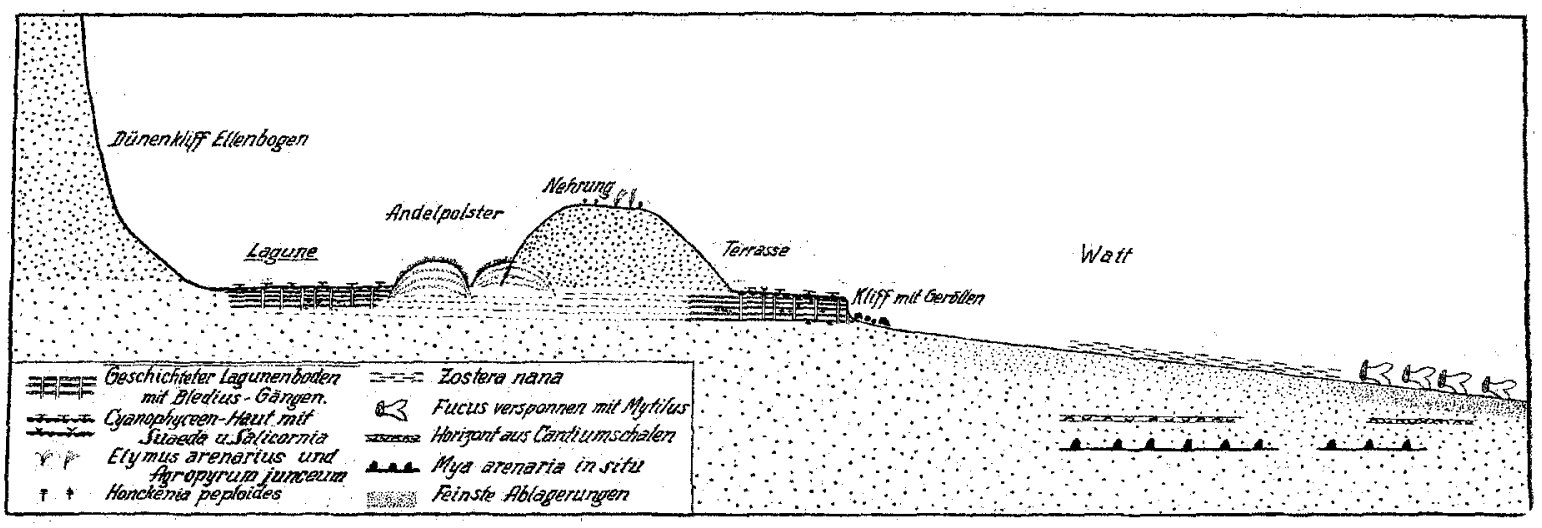

Abb. 23. Querschnitt durch den Lagunen-Bezirk am Kersten Rimling.

peploides (Abb. 21 und 23). Aber nicht nur die Oberfläche der Nehrurg ist Veränderungen unterworfen, sondern der ganze Haken ist in der Umlagerung, im Wandern begriffen, und zwar auf den Ellenbogenstrand zu. Die auf der Abb. 21 angedeutete eigenartige Verknüpfung am östlichen Ende mit dem ersten Teil läßt erkennen, daß der abgebildete Zustand kein dauernder ist. Ein Vergleich der Lage von 1932 mit der von 1934 bestätigt diese Vermutung. In diesem Zeitraum hatte sich das erste Drittel der Nehrung um 5 m dem Ellenbogenstrand genähert, so daß die Lagune also soviel an Breite eingebüßt hatte. Der nach dieser Verschiebung im Süden freigelegte Boden war mit größeren Kieselsteinen bedeckt, lag aber sonst mit der Terrasse in einer Ebene. Einen weiteren Nachweis über die Gesamtbewegung der Nehrung gab ihre Innenböschung, die gerade im Begriff war, die noch lebenden Pflanzen (Puccinellia maritima, in Polstern) zu verschütten (vergl. das schemat. Profil, Abb. 23).

c) Die Vegetation.

Da die Terrasse in allen wesentlichen Merkmalen bis auf ihre Lage zur Nehrung mit der Lagune äbereinstimmt, nämlich im folgenden:
1. Oberflächenausbildung
2. Besiedelung durch Pflanzen und Tiere und
3. durch gleiche Ablagerungen und gleichen Aufbau,

sei ihre Vegetation hier gemeinsam erörtert. Die Lagune ist ein in der Verlandung begriffenes Watt, dessen tiefer gelegener Abschnitt im Osten noch einen reinen Salicornia-Bestand trägt. Dieser Abschnitt wird regelmäßig überflutet. Nach dem nur unmerklich höher gelegenen Teil der Lagune zu bleibt Salicornia ganz aus. Statt dessen findet sich hier eine auffallend gleichmäßjige Besiedelung mit dicht an den Boden angedrückten und rötlich gefärbten Suaeda maritima (50-80 auf $1 \mathrm{qm}, \mathrm{Abb} 24)$. Sudeda besiedelt fast die ganzeLagune bei einem Deckungsgrad von etwa $30-50 \%$. Nur im zweiten Drittel der Nehrung ist der Lagunenboden mit einer größeren Gruppe von Andelpolstern (Abb. 21 und 23) bedeckt. Zum Teil liegen sie bereits, wie oben geschildert, unter der Nehrung begraben. Die von den Verlandungsgesellschaften im übrigen Wattenmeer bekannte innige Verzahnung mit Salicornia ist hier nicht erkennbar. Ueberhaupt scheint mit der Ausbildung des reinen Suaeda-Bestandes eine eigenartige Verlandungsfolge vorzuliegen. Auf der Terrasse wachsen vereinzelte Pflanzen von Suaeda und sehr spärlich eingestreute Salicornien. Als das wichtigste aber, das beiden Gebieten gemeinsam ist, muß der Cyanophyceen-Rasen (zur Hauptsache Microcoleus chtonoplastes) angesehen werden. Die Algen bedecken beide Ebenen ungeteilt mit einer zähen Haut. Das Bild, Abb. 25, erläutert besser als die Schilderung den Wert dieser Schicht für die 
Dauerhaftigkeit des Standortes. Bei regelmäßigen Tiden wird die abgebildete Randzone durch hin- und herrollende Steine und durch darüber hinbewegtes Treibsel beschädigt und durchlöchert. Der dahinter gelegene Teil ist glatt und eben. Der gräßere Teil der Lagune wird nicht so häufig überflutet wie die Terrasse. Jene liegt etwas höher, ihre Aufwuchsverhältnisse sind besser. Bleiben die Ueberflutung mit frischem Seewasser oder auch ergiebige Niederschläge in den heißen Sommermonaten längere Zeit aus, so reißt der CyanophyceenRasen infolge Schwundwirkungen auf. Die darauf einsetzende Felderung wird schließlich durch Aufwölben der Ränder noch verstärkt (vergl. NienburG, 53), so daf das darunter liegende Sediment ungeschützt daliegt. AuBer der geschilderten zerstörenden Wirkung durch anhaltende Trockenheit und bewegte Gerölle gefährdet noch ein dritter Faktor den Bestand des Cyanophyceen-Rasens. Das ist der Sandflug. Die erwähnte Abblasezone auf dem Rücken der Nehrung deutet bereits auf stärkere Sandwehungen hin. Durch Beobachtung konnte ich feststellen, daß die Algenhaut durch anhaltenden Sandflug an verschiedenen Stellen korrodiert und schließlich aufgearbeitet wurde. Mit welcher Schleifkraft der durchweg aus einer Richtung heranfliegende Sand selbst die höhere Vegetation der Lagune schädigt, zeigten die Andelpolster. An sämtlichen auf dem Lagunenboden freiliegenden Polstern war die Westsüdwestseite zerstört. Sie waren gewissermaßen nach Westen profilartig geöffnete Rasenhügel. Die Art derBeschädigungen der Epidermis der Blattspreiten lieb den flie-

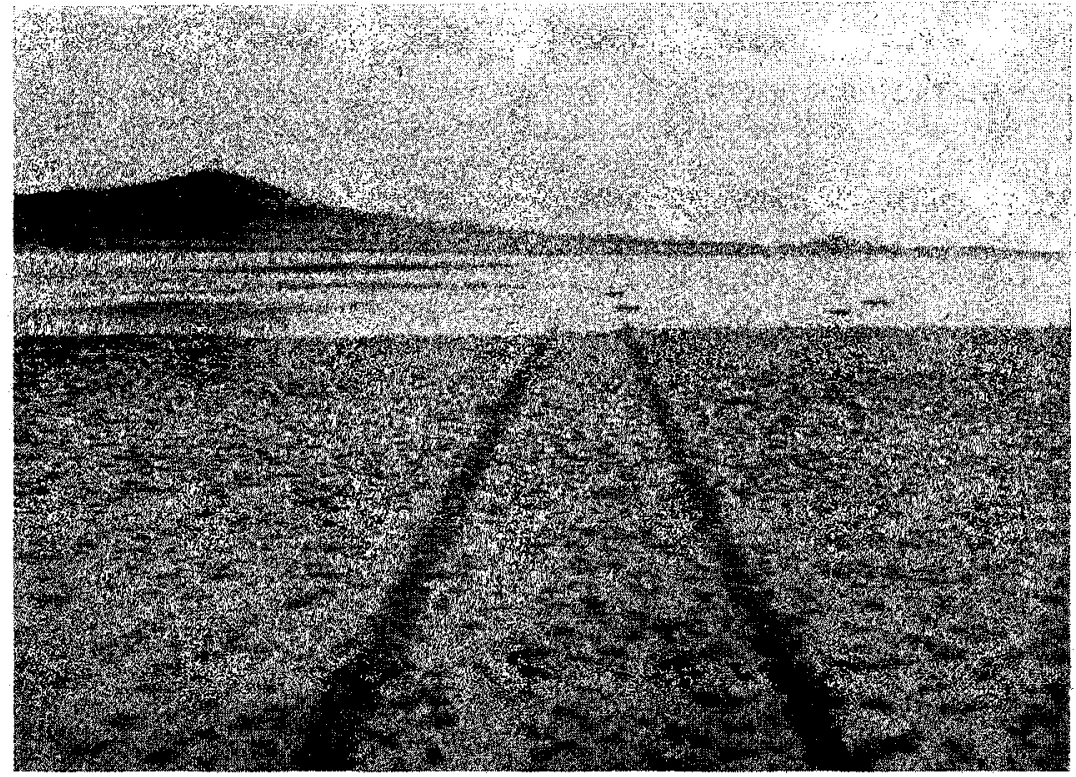

Abb, 24. Die Lagune am Kersten Rimling im Augenblick der Ueberfluting Im Vordergrund der gleichmâBig mit der niederliegenden Suaeda besiedelte Lagunenboden. In die Wagenspur habeh im Vorjahre Wind und Wasser Sand und Saaeda-Samen hineingetragen. Die Spur ist nicht mehr höhenmäßig, sondern lediglich noch durch die Vegetation erkennbar.

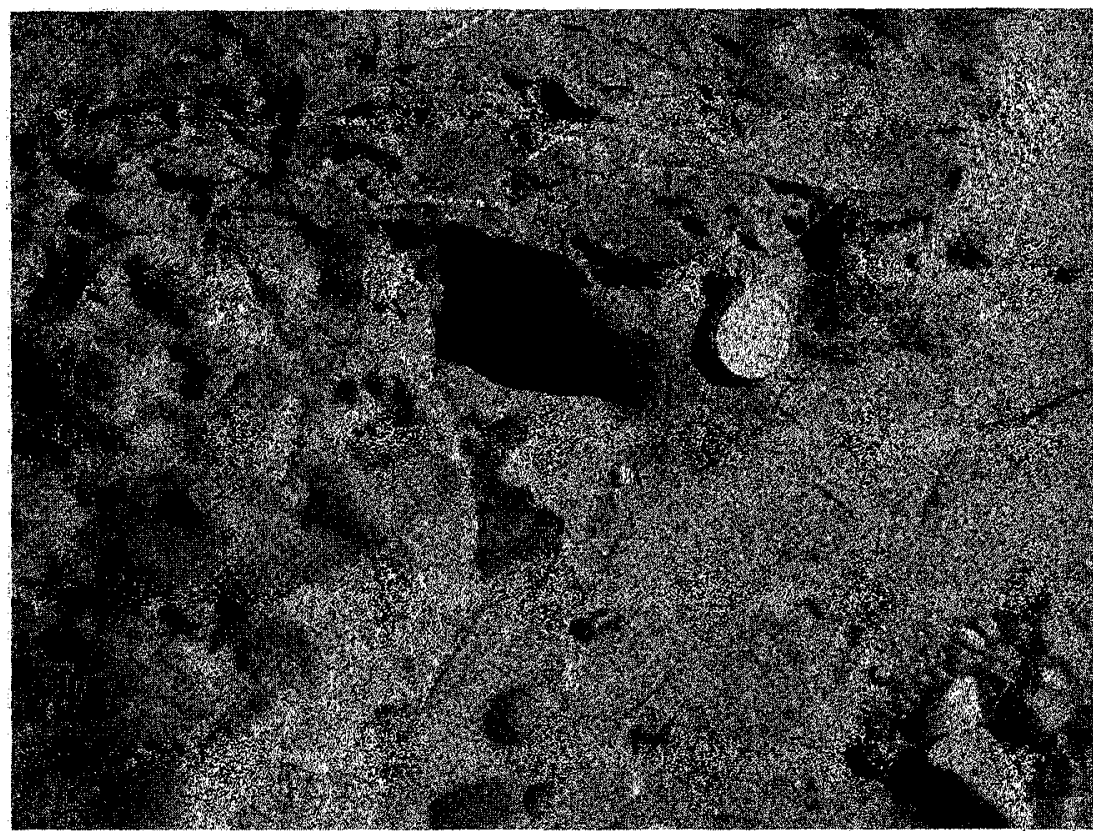

Abb. 25. Die kliffartig ausgebildete Randzone der Lagunen-Terrasse am Kersten Rimling zeigt im Vordergrund rechts die Geröllzone (kleines Geschiebe). Dann folgt naeh links das Kliff mit kleinsten Brandungserosionsformen und die in der Randzone etwas korrodierte, sonst einheitlich glatte Oberfläche der Terrasse. Die dunlien Flächen lassen die lederartige Cyanophycen-Haut erkennen. 
genden Sand als Urheber erkennen. Sie deutet auf die geringe Anpassungsfähigkeit des Andels an den Sandschliff hin. Auf der Terrasse fiel die starke Umkolkung der einzelnen Pflanzen (Salicornia wie auch Suaeda) auf.

\section{d) Das Sediment.}

Alle Ablagerungen der Lagune und der Terrasse sind geschichtet. Dies beruht einerseits auf der mehr oder weniger unregelmäßig erfolgenden Zufuhr neuer Ablagerungsstoffe, andrerseits aber auf dem biologischen Vorgang der Bindung. Die vom Wind (Flugsand) bezw. Wasser (Sinkstoff) abgelagerten Stoffe kommen auf dem CyanophyceenRasen zwischen den Pflanzen zur Ablagerung. Die Einverleibung dieser neu zugeführten Stoffe erfolgt auf biologische Weise, nämlich durch den Algenrasen. Wie durch Laboratoriumsversuche nachgewiesen werden konnte, ist er in ähnlicher Weise wie die Wattdiatomeen bestrebt, nach einer Ablagerung stets wieder die Oberfläche zu erlangen. Dadurch wird das erneute Forttragen bezw. Fortschwemmen der jungen Ablagerungen durch den Wind oder das Wasser verhindert. So wächst der Standort höher und höher.

In der geschilderten wechselseitigen Verknüpfung verschiedenartiger Vorgänge, den physikalischen (Zufuhr 1. durch Wind, 2. durch Wasser) einerseits und den biologischen (Bindung und Vermehrung der Zufuhren durch Algen) andererseits, liegt neben der Besiedelung das Besondere des Standortes. Die Korngröłenbestimmung von einem auf der Lagunenterrasse senkrecht entnommenen Kern von $10 \mathrm{~cm}$

Abb. 26. Tiefe und etwa $2 \mathrm{~cm}$ Breite ergab die auf

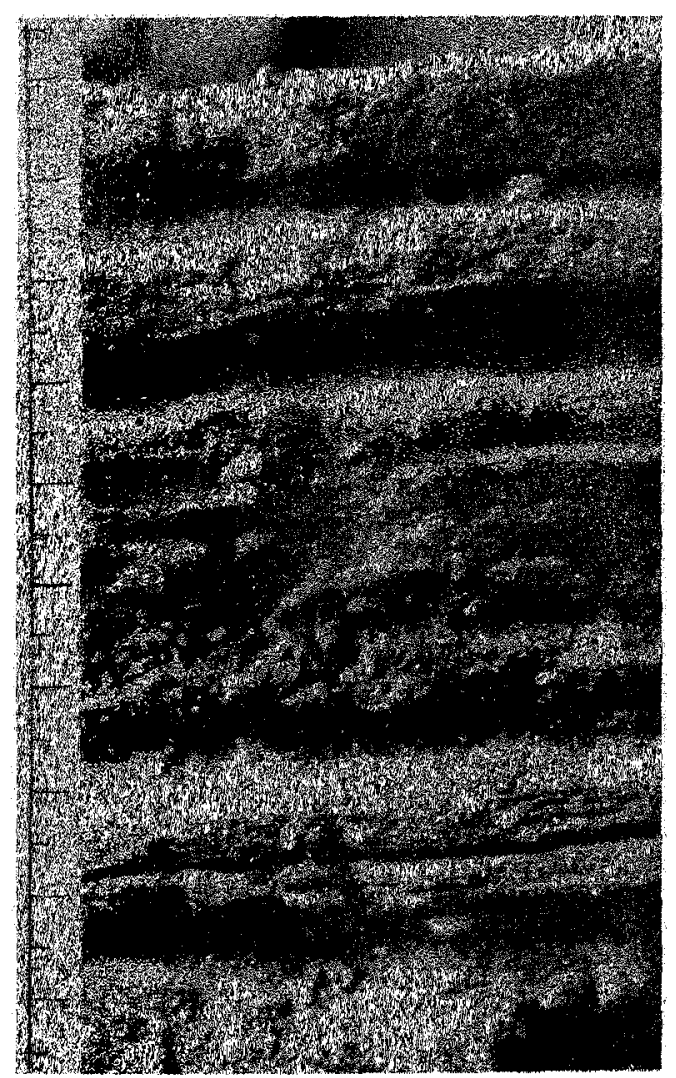

Abb. 27. Rrofil dureh den Lagunenboden am Kersten Rimling. Der senkrecht niedergeftahrte Sohnitf liakt durch kingtlieh hervorgerviene Erosion den geselrichteten Aufbau und das sehr ungleichformige Sediment von Schicht zu Schicht erkennen. Im unteren Teil des Profils sind Kiesschichten feinsten Schlickablagerungen benachbart.
Abb. 26 dargestellte Zusammensetzung. Wie im folgenden gezeigt werden wird, ist durch eine exakte mechanische Analyse keine befriedigende Vorstellung von der Eingenart der Ablagerung zu gewinnen. Die kritische Betrachtung des Blockdia gramms in $\mathrm{Abb} .26$ vermittelt höchstens zwei Hinweise, die in dem untersuchten Sediment ein besonderes vermuten lassen. Man gewinnt zunächst den Eindruck, als wären alle Korngrößengruppen in nur wenig voneinander abweichenden Mengenanteilen zugegen. Das ist für ein Wattenmeersediment auffallend. Der normale Aufbau ist meistens derart, dab zwei oder drei Korngrößengruppen in mengenmäßiger Beziehung weitaus den Vorrang haben und den Charakter der Ablagerung bestimmen.

Vergleichen wir das Diagramm, Abb. 26, mit den anderen in dieser Arbeit zur Darstellung gebrachten Sedimenten, so liegt die Vermutung, daß hier während des Aufwuchses ungleich gerichtete Kräfte am Werke gewesen sein müssen, nahe. Außer diesem an sich wünschenswerten Hinweis auf die Art der Kräfte vermag das Diagramm dann noch einen zweiten zu geben. Der im Vergleich mit anderen Proben hohe Gehalt an Korngröben unter $0,250 \mathrm{~mm}$, nämlich $12 \%$ des Gesamtgewichtes ist schlecht mit dem niedrigen Wassergehalt von $17 \%$ in Einklang zu bringen. Dieses Mißverhältnis weist auf eine für schlickige Wattsedimente mangelhafte Durchfeuchtung hin. Damit aber erschöpft sich der 
diagnostische Wert des Diagramms. Auch einer mit Hilfe komplizierter Schlämmgeräte oder anderer Zerteilungsmethoden gewonnenen, für die unteren Gruppen genaueren Analyse kann für das hier vorliegende Ziel der Untersuchung kein höherer Wert beigemessen werden. Der Charakter der Ablagerung würde auch durch sie nicht erfaßt und dargestellt werden können. Ich greife daher auf eine Form der qualitativen Analyse zurück, weil sie mir im vorliegenden Fall eine meinem gedrängten Arbeitsprogramm Rechnung tragende, einfache aber auch aufschlußreiche Antwort gegeben hat.

Abb. 27 zeigt den natürlichen, ungestörten Aufbau der Lagunen-Sedimente. Sie bestätigt die am Diagramm der Abb. 26 gezogene Folgerung, daß eine Ablagerung vorliegt, die sich von allen anderen Wattsedimenten unterscheidet. Das Sediment wurde nicht zerlegt, sondern im Profil "angesprochen". Nachdem die Korngrößenbestimmung nicht befriedigt hatte, wurde ein Block mit senkrechten Wänden aus dem Boden der Terrasse herausgeschnitten und eine Seite gleichmäbig mit einer breiten weichhaarigen Kalkquaste, die von Zeit zu Zeit in Wasser getaucht wurde, bepinselt. Nach kurzer Zeit wurde infolge des verschieden starken Widerstandes die im Bild erkennbare Schichtung herausmodelliert. In unverkenubarer Weise kommt der auf S. 52 erwähnte Wechsel in der Art der Materialzufuhr (Wind, Wasser) zum Ausdruck. Es leuchtet nunmehr auch ein, daß ein aus einer solchen Ablagerung für die mechanische Analyse herausgestochener Kern von zehn oder $15 \mathrm{~cm}$ Tiefe für das Wesentliche des Sediments ein nur ziemlich belangloses Bild geben kann. Die Abb. 27 gibt dagegen nicht nur eine Vorstellung von der Schichtung, sondern sie führt gleichzeitig denNachweis über den vollkommenen Wechsel in der Lagerung und Zusammensetzung der Schichten. Grobe Kiese liegen wahllos verstreut zwischen feinsten, schlickigen Ablagerungen oder sind diesen unmittelbar bankartig benachbart. Die mikroskopische Untersuchung ergab, daß an Diatomeen und Cyanophyceen arme und reiche Schichten miteinander abwechseln und durch umfangreichere sandige und kiesige Lagen voneinander getrennt sind.

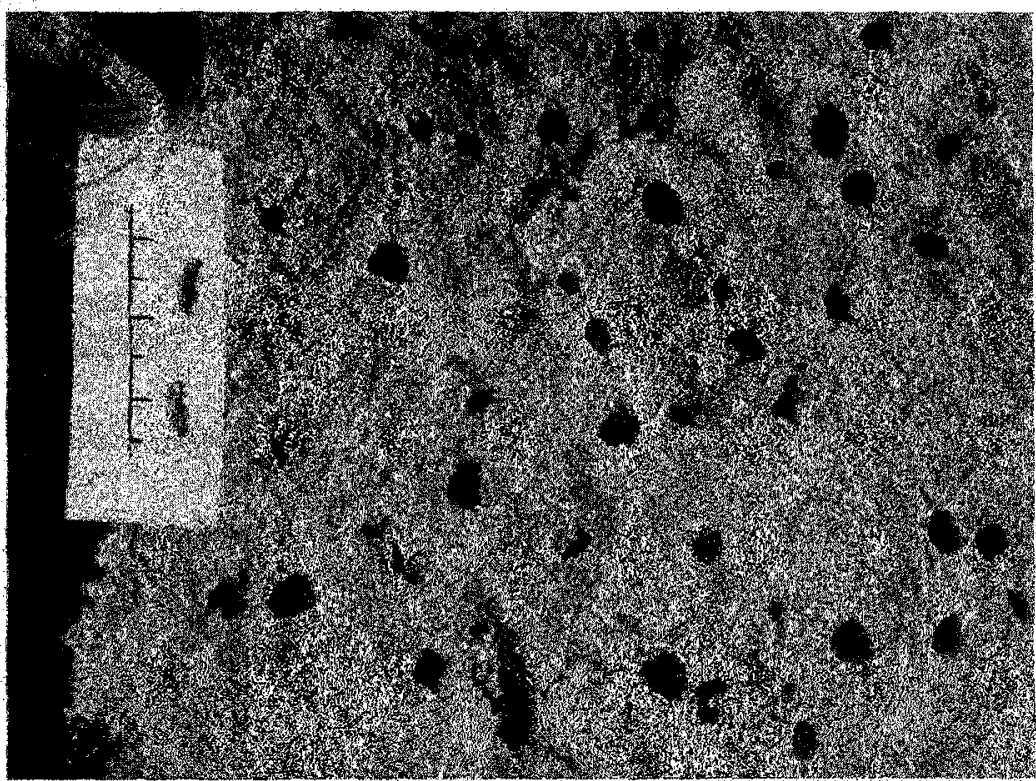

Abb. 28. Querbruch dureh das geschichtete Sediment der Kersten RimlingLagune am Ellenbogenstrand. Der Boden der Lagune und der der Nehrung vorgelagerten Terrasse (vergl, Zeichnung Abb. 21 u. 23) erhält-sein Gepräge durch die senkrechten Gänge von Bledius spectabilis. Links Zentimetermaßstab mit den Geschlechtstieren.

\section{Die armen Schichten sind}

begreiflicherweise die bei der künstlichen Aufbereitung zurüekspringenden Lagen. Es sind die schnell aufgewachsenen, nicht tonig gebundenen und weniger Widerstand bietenden Sandschichten. Lebende Diatomeen sind noch bis zu einer Tiefe von $3 \mathrm{~cm}$ zu finden. In den tiefer gelegenen Schichten sind die Diatomeen abgestorben aber noch sehr gut, zum Teil schichtweise, nachweisbar. Somit ist das ganze Profil im kleinen "stratigraphisch" auswertbar. Das Sediment stellt eine Summe von in unregelmäßigen Abständen und durch ungleiches Material verschütteten Algenhorizonten dar. (Vergl. auch schemat. Abb. 23 und 31.) Schon ein im Gelände mit der Hand gemachter Querbruch (also parallel zur Oberfläche) bestätigt es. Abb. 28 zeigt einen solchen Querbruch. So läßst sich das ganze Sediment in dicke und dünne Schichten zerlegen. Fast immer sind die auf diese Weise gewonnenen Bruchflächen schier und eben. Durch die inzwischen abgestorbene Algenhaut wurde die ehemalige Standortsoberfläche gut als Eläche konserviert.

Die auf der abgebildeten Schichtfläche erkennbaren Löcher sind die Querschnitte der senkrecht nach unten führenden Gänge des auf dem links angebrachten Maßstab sichtbaren Kurzflüglers Bledius spectabilis. 
e) Die Besiedelung des Lagunenbodens.

Die Lagune wird unregelmäßig, je nach Vorherrschen einer bestimmten Wetterlage, überflutet. Die Höhenlage bringt es mit sich, daß manchmal wochenlang keine Durchtränkung des Lagunensedimentes mit Meerwasser erfolgt, andrerseits aber tagelang nacheinander und mehrere Stunden ohne Unterbrechung (am 4. Sept. 1932 z. B. 8 Stunden!).

Als ich im August 1932 die Lagune zum ersten Mal betrat, war das Wasser gerade im Begriff, das Lagunenwatt zu überfluten (vergl. Abb. 22). Das Wasser stand an diesem Tag eineinhalb Stunden lang bis zu $25 \mathrm{~cm}$ über dem Lagunenboden. Wie eine schmale Sichel umschloß die Nehrung das gefüllte Lagunenbecken. Während der Ueberflutung wurde ich auf eine ununterbrochene Folge großer, dicht bei dicht aus dem Lagunenboden aufsteigender Luftblasen von etwa $1 \mathrm{~cm}$ Durchmesser aufmerksam, ohne dafi ich mir die Ursache dieser „brodelnden" Wasserfläche erklären konnte. Der in den darauffolgenden Tagen durchgeführten Vermessung folgte die morphologische und biologische Bestandsaufnahme. Sie ergab, daß Lagune und Terrasse fast ausschließlich von einem Staphyliniden, und zwar von Bledius spectabilis besiedelt waren.

Die größte Wohndichte auf der Lagune betrug 7 Imagines auf $1 / \% 0 \mathrm{qm}$. Die für die Terrasse ermittelten Werte lagen etwas höher, außerdem waren sie gleichmäßiger über größere Flächen verteilt. Dort betrug die Wohndichte 24 Individuen auf $1 / 20 \mathrm{qm}$. Darunter waren $90^{\star}$ (Aug. 1932). Außer Bledius waren stets eine Anzahl verschiedener Carabiden in den Proben vorhanden. Am häufigsten und regelmäßigsten war Cillenus lateralis mit Larven vertreten. In der gleichen Weise stetig, nur in geringerer Anzahl war Heterocerus flexuosus Steph. und in einem Falle Dichirotrichus pubescens Payk. zugegen. Heterocerus und Cillenus sind die beständigen Glieder der Bledius spectabilis-Gemeinschaft.

Während Bledius spectabilis und Heterocerus fast immer nur i m Boden gefunden wurden, sah ich Cillenus häufiger an der Oberfläche des Standortes herumlaufen. Regelmäßig war Cillenus nachts an der Oberfläche anzutreffen. Die Käfer suchten den Saum des letzten Hochwassers nach Beute ab. So fand ich am 5. August 1933 bei einer Nachtexkursion 17 Cillenus auf einem Fleck damit beschäftigt, einên angespülten Gobius aufzufressen. Es war im nu geschehen.

Außerdem gehört zu dieser engeren Gemeinschaft der Archioligochaet Enchytraeus albidus Henle. Im Grunde genommen ist $E$. von allen Mitgliedern der Gemeinschaft das einzige auch st andortstreue Glied, denn wenn im Herbst Bledius und Cillenus usw. ihre höher gelegenen Winterquartiere beziehen, bleibt $E$. im Sediment der Lagune zurück. Vorübergehend konnte der bis auf $E$. entblöBte Standort im Winter durch Talitrus saltator oder auch durch Corophium volutator neu besiedelt werden. Aber auch bereits im Sommer kann das Bild der Standortsbesiedelung recht bunt sein, wenn der Standort durch längere Ueberflutung gut durchfeuchtet ist. So fand ich im Juni 1983 am kleinen Hafen neben allen Entwicklungsstadien von Bledius spectabilis im selben Sediment

\section{Clitellio arenarius \\ Corophium volutator \\ Dipteren-Larven}

und in einer unbewohnten Bledius-Röhre eine große Anzahl von Blindspringern, Archisotoma besselsi. ${ }^{1}$ )

In der Literatur über Bledius finden sich zahlreiche Angaben über die Vergesellschaftung mit anderen Lebewesen, doch läßt keine von ihnen einen engeren Vergleich mit den Gliederu im Königshafen zu. So berichtet ScHönTE (66, S. 146) über das gemeinsame Vorkommen von Corophium und Bled. bicornis. Nach Nereshermer und WAgNER (50, S. 132) leben am Mellensee Bled. tricornis und die salzliebenden Arten Philontus salinus und Heterocerus obsoletus mit Bled. spectabilis zusammen. An Binnensalinen ist Bledius spectabilis nach $\delta$. SAINT-CLAIRE (65) einzig mit Dyschirius chalceus vergesellschaftet nnd schließlich berichtet SCHNEIDER (67) yon Borkum, daB Bledius spectabilis am weitesten gegen die See siedelt und mit Bled. bicornis zusammen auftritt. Von diesen Angaben lassen sich keine zwei miteinander zur Deckung bringen. Daraus mag hervorgehen, dab Bledius spectabilis wohl innerhalb eines Biotops in Bezug auf die mit ihm vergesellschafteten Tiere stenotop sein mag (Königshafen) aber durchaus nicht von Biotop zu Biotop verschiedener Landschaften.

\section{f) Zur Lebenskunde von Bledius spectabilis.}

Die hier folgenden Darlegungen gehen in erster Linie auf Untersuchungen und Beobachtungen am freien Standort in den Jahren 1932 und 1933 zurück. Sie wurden 1933

1) deren Bestimmung ich Herrn Prof. Dr. HANDSchrn, Basel verdanke. Mortensen (49) fand den Blindspringer Hyposastrura viatica Tullberg in Gemeinschaft mit Bledius. 
außerdem durch Untersuchungen im Laboratorium und durch gelegentliche Beobachtungen im übrigen nordfriesischen Wattenmeer und auf der ostfriesischen Insel Norderney ergänzt. . Im Rönigshafen wurden die Tiere auf dem Sommer-Standort zuerst in den ersten Apriltagen gesehen und die letzten im Herbst bis Mitte Oktober festgestellt.

aa) Das Bauen und der Bau von Bledius spectabilis.

a) Die Standortsoberfläche.

Betreten wir einen von $B$. spectabilis besiedelten Standort unmittelbar nach dem Abfließen des Wassers, dann leuchtet der sonst grau und glanzlos daliegende CyanophyceenRasen tief schwarzgrün und erscheint als vollkommen ebene Fläche. Verweilen wir hier eine längere Zeit, so sehen wir, wie ein Häufchen. Erde nach dem andern auf der glatten und schlüpfrigen Algenhaut entsteht. Aus der Nähe betrachtet ist zuerst nur eine Bewegung in der Algenhaut bemerkbar. Sie wird von unten her durchbohrt und darauf wird ein Sandkrümelchen durch die Oeffnung nach oben geschoben. In unregelmäßigen Abständen wiederholt sich dieser Vorgang des Heraustragens kleinster Sandmengen, bis ein Häufchen erkennbar wird. Jeder Zuwachs an Material ist mit einer leichten Erschütterung des ganzen Häufchens verbunden. Nach und nach erhält die Algenfläche ein Aussehen, wie es die Abb. 29 wiedergibt. Es sind die Auftragskrümelhäufchen von B. spectabilis. Die auf dem Watt und im Laboratorium am Aquarium wiederholten Beobachtungen bestätigen die oben beschriebene Art der Häufchenbildung. Es sind kleine, im Grundriß meist runde Erhebungen von toekerer . und krümeliger Struktur. Diese Merkmale sind so scharf ausgeprägt, daf es im gesamten Königshafengebiet ohne Schwierigkeit gelingt, das Verbreitungsgebiet von $B$. spectabilis gegen das der anderen Kurzflügler(Bled.arenarius), ohne daß eine Bestandsaufnahme nötig wäre, abzugrenzen.

Schon dieser Hinweis auf die Krämelstruktur der Häufchen und ihren allmählichen Werdegang veranlaßt mich, den für die Bledien schlechthin gemachten Vergleich mit dem Maulwurf (KRoGerus, 38, 39) auf die Grabetätigkeit von $B l . s p$. nicht anzuwenden. Im Aquarium konnte ich an einer zeitweilig verdunkelten. Auffenwand beobachten, wie der Röhrenbau und der Materialtransport vor sich gehen. Ein Glasgefäß $\beta$ wurde mit Sediment

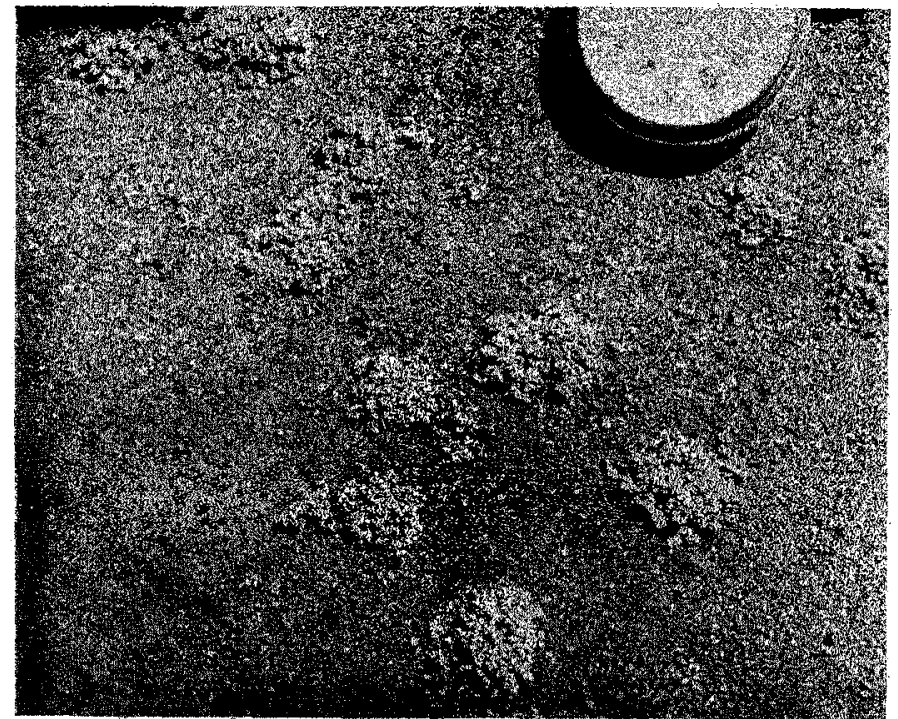

Abb. 29. Die Auftragskrümelhäufchen von Bledius spectabilis auf der Lagunen-Terrasse. Vom Mittelpunkt eines jeden Häufchens, unter dèr Algenhaut seitlich etwas verschoben, führt dieWohnröhre senkrecht in das Sediment hinein. Aufnahme kurz nach dem Trockenfallen des Standortes.

vom natürlichen Standort gefüllt und mit einer Anzahl von Geschlechtstieren von $B l$. $s p$. besetzt. Durch äuberst behende Bewegungen gelang es sämtlichen Tieren, sich in kurzer Zeit einzugraben. Jedes Tier grub zuerst eine Vertiefung, scheinbar ohne von der Tätigkeit des unmittelbar daneben arbeitenden Artgenossen Notiz zu nehmen. Die Tiere führten auf folgende Weise ihre Röhren abwärts. Ohne daß es mir - wohl wegen der Hurtigkeit in den Bewegungen - gelang, die Tätigkeit der mit Graborganen bewaffneten Vordertibien zu erkennen, nahmen die Tiere vom Boden oder von der Seitenwand der allmählich tiefer werdenden Röhre kleine Gruppen von Sandkörnchen oder auch einzelne größere und trugen sie - fest zwischen den Mandibeln gepackt - bis unter die Oberfläche. Hier wurden die dunklen Mandibeln beim Durchstoßen der Algenhaut für einen Augenblick sichtbar. Darauf wurde der bis an die Oberfläche getragene Sand durch eine durch Einbeugen und Vorstrecken des Kopfes hervorgebrachte Bewegung auf die freie Standortoberfläche befördert. Auf diese Weise sind die auf Abb. 29 sichtbaren Häufchen 
entstanden. Es liegt also ein anderer Werdegang vor als der vom Maulwurf oder auch von Talitrus bekannte Vorgang der Häufchenbildung. Denn auch die vom Sandhüpfer Talitrus saltator an die oberfläche gebrachten Sandhäufchen sind leicht von den beschriebenen zu unterscheiden. Jene werden tatsächlich auf die Oberfläche gew or f en und entbehren der krümeligen Struktur.

Die Frage nach der Art und Weise des Transportes führt auf die Zusammensetzung des Sedimentes. Aus Blockdiagramm, Abb. 26, ist zu ersehen, daß der tonige Anteil nicht gering ist. Daß auch die nach oben beförderten Sandmassen einen ebenfalls hohen Anteil der unteren Körnergruppen haben, versuchte ich nachzuweisen, indem ich eine Korngrößenbestimmung von Auftragshäufchen machte. Mit einem Rahmen wurden auf der Lagunenterrasse eine Fläche von $1 / 20$ qm gekennzeichnet und die im Laufe von 24 Stunden an die vorher gesäuberte Oberfläche gebrachten Krümelhäufchen (es waren 1.0) der Sieb- und Schlämmanalyse unterworfen. In Blockdiagramm, Abb. 30, ist der Anteil der

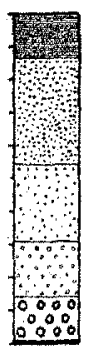

Abb. 30. Korngrö̧enanalyse von 10 Krümelhäufchen, die während 24 Stinden an die Oberfläche des Standortes befordert wurden. auffälligerweise nach jeder Richtung eine größere Ausdehnung als die geöffneten Mandibeln überhaupt zu umgreifen vermochten. Diese großen Körner werden mit Hilfe der tonigen Teilchen, womit sie verklebt waren, nach oben geschafft worden sein. Auf die freie Oberfläche gebracht, unterliegt das fenchttonige Bindemittel sogleich der Lufttrocknung, erhärtet und hindert die mit ihm verbundenen größeren Anteile am Zusammensacken. Damit ist die für Bledius spectabilis so überaus charakteristische Krümelstruktur, die mir an allen bekannt gewordenen Standorten der Nordseeküste immer wieder aufgefallen ist, aufgeklärt.

Das Graben und Aufwärtstragen erfolgt auch nachts. In der Nacht vom 5. auf den 6. August 1933 konnte ich draußen am freien Standort das Herauftragen im Schein der Taschenlampe beobachten. Die Lufttemperatur war auf $10,8^{\circ}$ und die Temperatur in $6 \mathrm{~cm}$ Tiefe tuf $12,0^{\circ}$ gesunken.

B) Die Wohntöhre im Sediment.

Von den am Aquarium gemachten Beobachtungen sind außier den im vorigen $\mathrm{Ab}$ schnitt bereits mitgeteilten noch folgende von Interesse. War der Bau einer Röhre bereits bis $\mathrm{zu}$ einer beträchtlichen Tiefe gediehen (über $10 \mathrm{~cm}$ ), so konnte in einem Fall beobachtet werden, daß für den Transport der Sandpartikelchen etwa auf halber Tiefe eine „Zwischenstation“ eingelegt wurde. Der Sand wurde nicht mehr in einem Zuge nach oben getragen, sondern erst einmal in die Mitte der Röhre gebracht. Erst als hier eine kleine Anhäufung sichtbar war, wurde der Sand nach oben weiterbefördert.

Beim Vertiefen ihrer Wohnröhren waren die in das Aquarium eingesetzten Käfer auf das sorgsamste bedacht, nicht in den Gang des Nachbarn hineinzustofen. Ein kleiner, eigens für diese Geschicklichkeitsprüfung angesetzter Versuch vermittelte eine eindrucksvolle Vorstellung von der Gewandtheit und Wachsamkeit der Käfer. Ein mit Sand gefülltes Glas erhielt eine übermäßige Besiedelung durch $B . s p$. Wie früher erwähnt, gräbt jedes Tier für sich allein. Die Zahl der grabenden Käfer war im vorliegenden Falle so gewählt, daß zwischen den anzufertigenden Wohnröhren nicht viel unberührter Baugrund mehr zur Verfügung sein konnte. Sobald nun ein Käfer beim Hinabführen seiner Röhre in die Nähe seines für ihn unsichtbaren ebenfalls grabenden Nachbarn kam, 
hielten der eine von ihnen oder auch beide plötzlich im Graben inne, um gleich darauf in mehr oder weniger grofer Eile von der nächst- und bestgelegenen Stelle Sand zu packen und unaufhaltsam an die "gefährdete" Röhrenwand zu tragen. Diese eilige Geschäftigkeit ließ sich zu einer unverkennbaren Nervosität steigern, wenn ein Carabide mit ins Glas gesetzt wurde.

In den meisten Fällen bildet die Wohnröhre von $B$. spectabilis einen senkrecht in die Tiefe geführten Schlauch von 5 bis $12 \mathrm{~cm}$ Länge. Der Durchmesser beträgt 3 bis $5 \mathrm{~mm}$ (Abb. 28). Die Wohnröhre des Geschlechtstieres gliedert sich nach der schematischen Zeichnung, Abb. 31, der Bedeutung nach in drei Teile, in den Hals-, Boden- und Mittelabschnitt. Wie auch aus der Abb. 31 hervorgeht, ist die Röhre nicht auf dem kürzesten Wege mit der Außenwelt verbunden. Etwa $10 \mathrm{~mm}$ unterhalb des Cyanophyceen-Rasens verjüngt sich die Röhre zum Halsabschnitt. Dieser macht in den meisten Fällen einen Bogen zur Seite und durchstößt die Algenhaut erst in 1 bis $2 \mathrm{~cm}$ Entfernung von der Achse der Hauptröhre. Während einer Westwindwetterlage (normale oder erhöhte Wasserstände) konnte ich regelmäßig beobachten, daß die Wohnröhre durch einen im Halsabschnitt befindlichen Pfropf aus lockerem Sand von der Außenwelt abgeschlossen war. Natürlich nur dann, wenn kein Sand an die Oberfläche getragen wurde.

Die Wand der Röhre erschien trotz des ungleichmäfigen Sedimentes eingeebnet und glatt. Im Mittelteil konnten Unebenheiten durch zwei Umstände entstehen. Entweder ragte ein großes, von den Tieren nicht wegzuschaffendes Sandkorn aus der Wand heraus oder aber die Verschlußspuren der seitwärts eingebauten Eikammern (vergl. Abb. 32-34) waren nicht wieder eingeebnet.

Der untere Teil der Wohnröhre, der Bodenabschnitt, ist allein zur Aufnahme der zahlreichen Kotwalzen bestimmt. Nur selten wurde beobachtet, daßs eine Kotwalze mit dem Sand nach oben befördert wurde. Unter größter

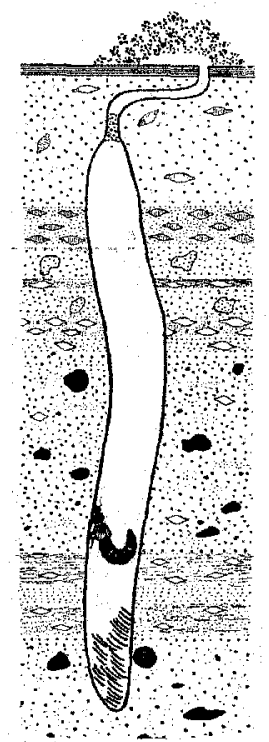

Abb. 31. Die Wohnröhre des Geschlechtstieres von Bledius spectabilis (schematisch). Das obere Ende der unverzweigten Röhre durchstößt entweder senkrecht von unten kommend direkt oder erst nach einer scharfen Wendung - parallel der Oberfläche laufend - den Cyanophyceenrasen der Standortsoberfläche. Ueber der Röhrenöffnung liegt der charakteristische Krümelhaufe. (Vergl. Abb. 29 und Text Seite 55.)

Raumausnutzung liegen die Walzen dicht neben und übereinander. Diese Art der Ablagerung kann nur durch den überaus wendigen Hinterleib möglich sein (vergl. auch Abb. 31 und 35). Hierin unterscheiden sich Imago und Larve erheblich voneinander.

bb) Die Brutpflege.

a) Das Schwärmen.

In der Literatur findet man mehrfach Hinweise, daf die Bledien $\mathrm{zu}$ bestimmten Tageszeiten ihre unterirdischen Wohnräume verlassen und umherfliegen. So erwähnt z. B. v. LENGERKEN (43, S. 74), daß die Imagines von B. spectabilis abends umherfliegen, WESENBERG-LUND (86) erwähnt das Umherfliegen von Bledius arenarius während der heißen Tageszeit, und Krogerus $(38,39)$ gibt allgemein für die Bledien an, daß sie abends nach Sonnenuntergang nahe beim Erdboden schwärmen. Nachdem ich mich lange, tags und nachts, im Königshafengebiet bemüht hatte, B. spectabilis außerhalb des Bodens zu beobachten, gelang es schließlich ein einziges Mal am 8. Juni 1933. Es war an einem heißen und schwälen Vor mittag mit stechendem Sonnenschein, als ich die Käfer beim Schwärmen antraf. In dichtem Schwarm über ihrem Standort hin- und herschwebend etwa in der Art, wie es die Bienen tun, gewannen sie keine größere Höhe als etwa $80 \mathrm{~cm}$ über dem Boden und hielten sich scheinbar durchaus innerhalb der Grenzen ihres Wohngebietes. Ueber dem angrenzenden Arenicola-Watt und der Zostera nana-Wiese waren keine fliegenden Käfer anzutreffen. Den Schwarm als Ganzes sah man natürlich nur, wenn man sich tief 
bückte und gegen den hellen Horizont blickte, Leider war kein Fangbeutel zur Hand, so daß ich die Beteiligung der beiden Geschlechter am Schwärmen nicht ermitteln konnte. $\mathrm{Zu}$ keinem andern Zeitpunkt habe ich sie wieder fliegend beobachten können.

\section{B) Die Eikammer und das Ei.}

Schon von Mitte Mai ab findet man beim Auseinanderbrechen von Bodenproben des Bledius spectabilis-Standortes regelmäßig von der Wohnröhre ausgehende, birnenförmige Erweiterungen. Form und Anordnung sind in den photographischen Abb. 32 und $33 \mathrm{zu}$ erkennen und in der $\mathrm{Abb} .34$ schematisch dargestellt. Wie die Abbildungen erkennen lassen, sind die kleinen Eikammern in dicht benachbarten Stockwerken übereinander und in bis zu 7 Radialebenen nebeneinander angeordnet. Jede Kammer ist ein allseitig geschlossener birnenförmiger Raum, dessen verjüngter Teil in die Wohn-

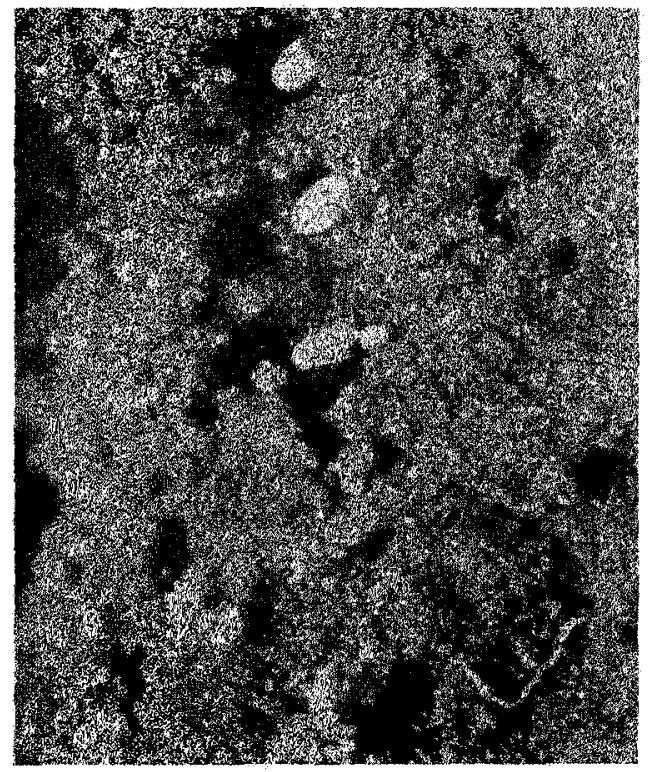

Abb. 32. Die in Stockwerken ubereinander angeordneten Eikanmern mit den an der oberen Kammerwandung angebrachten. Eiern von Bledius spectabilis. Vergr. 5-fach.

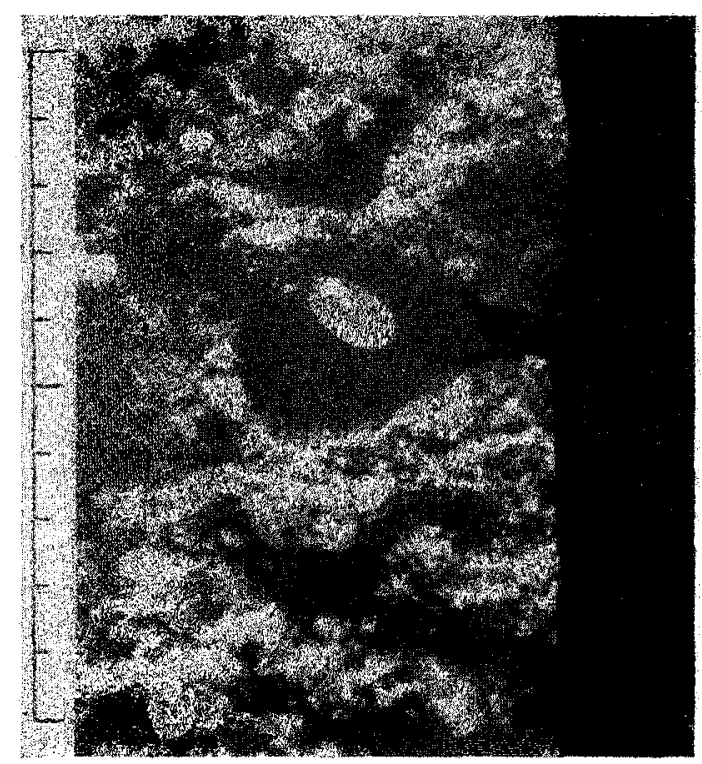

Abb. 33. Die einzelre Eikammer mit dem sehräg in die birnenförmige Kanmer hineinragenden $\mathrm{Ei}$. Der walzenförmige Eiträger ist erkeunbar.

(Die rech ts befindliche Hauptröhre wurde aus Gründen der Uebersichtlichkeit mit Tusche nachgezogen).

Vergr. 7-fach. Maßstab links in $\mathrm{mm}$.

röhre einmündet und nach der Eiablage mit einem Sandpfropf gegen diese abgeschlossen wird. Von der Wohnröhre her ist daher die Eikammer schwer festzustellen. Die Wandungen der Kammer sind ebenso wie die der Wohnröhre von allen Unebenheiten gesäubert und erscheinen geglättet. Von Kammer zu Kammer bestehen keine Verbindungen.

Wenn auch der Vorgang der Eiablage nicht direkt beobachtet werden konnte, möchte ich doch auf einige bauliche Einzelheiten eingehen, da sie Rückschlüsse auf die Brutpflege gestatten.

In jeder Kammer befindet sich ein einzelnes Ei. Abb. 33 läßt sowohl die Größe (vergl. Maßstab), die Form des Eies sowie auch seine Lage innerhalb der Kammer deutlich erkennen. Das zylindrisch-ovale $\mathrm{Ei}$ hat durehweg eine Länge von 1,3-1,4 mm und einen Durchmesser von etwa $0,6 \mathrm{~mm}$. Es ragt, wie die Abbildungen erkennen lassen, vom. Dach der Kammer frei in den Hohlraum hinein und zwar so, daß stets die Längsachse des Eies mit der Hauptrichtung der Wohnröhre nach oben einen spitzen Winkel bildet. Nach wiederholten Beobachtungen ist diese Ausrichtung der Eier eine stets wiederkehrende und gleichbleibende (Abb. 34); immer zeigt es vom oberen hinteren Teil der Kammer schräg nach unten auf die Wohnröhre des Geschlechtstieres. Wie ist nun diese systematische, fast mathematische Ausrichtung der Eier zu erklären? 
Die phot. Abb. 33 zeigt, daß das schräg nach unten zeigende Ei nicht direkt am Dach der Eikammer angebracht, sondern mit einem auf der Abbildung noch gerade sichtbaren walzenförmigen Gebilde verbunden ist. Das ist der Eiträger. Das eine Ende dieser bis $1,3 \mathrm{~mm}$ langen und $0,3 \mathrm{~mm}$ starken Walze ist mit dem Sediment selbst verbunden, das andere ragt frei schräg nach hinten in den Kammerraum. An der unteren, der Wohnröhre zugewendeten Seite des Trägers ist das $\mathrm{Ei}$, das sich an der Verbindungsstelle zu einer ganz schwach ansgebildeten, kaum wahrnehmbaren Grundplatte verbreitert, derart angeheftet, daß die Längsachse des Eies etwa einen rechten Winkel mit dem Träger bildet. Auf welche Weise der Träger am Dach der Kammer befestigt und wie das Ei mit dem Träger verbunden wurde, ließ 3 sich durch direkte Beobachtung noch nicht nachweisen. Die eingehende mikroskopische Untersuchung des Trägers bezüglich seiner Form, Oberfläche und stofflichen Zusammensetzung gibt jedoch einige aufschlußreiche Hinweise, die im folgenden kurz erörtert werden sollen.

Die glatte, walzenförmige Form des Trägers, der lückenlose, innere Aufbau und besonders die immer vorhandene kurzschenkelige Zuspitzung am freien Ende sowie das Fehlen jeglicher Eindrücke von Mundwerkzeugen in die fast glänzende Oberfläche des plastischen Materials sprechen wenig dafür, daß etwa die feinsten Teile des Wohnsedimentes von dem Tier zusammengetragen und von seinen Mundwerkzeugen oder Gliedmaßen zu einer solchen Walze geformt worden seien. Viel eher führt bereits die bloße Form der Walze zwingend zu der Vermutung, daß sie eine vom Darm geformte und ausgeschiedene Masse, nämlich eine Kotwalze darstellt. Die

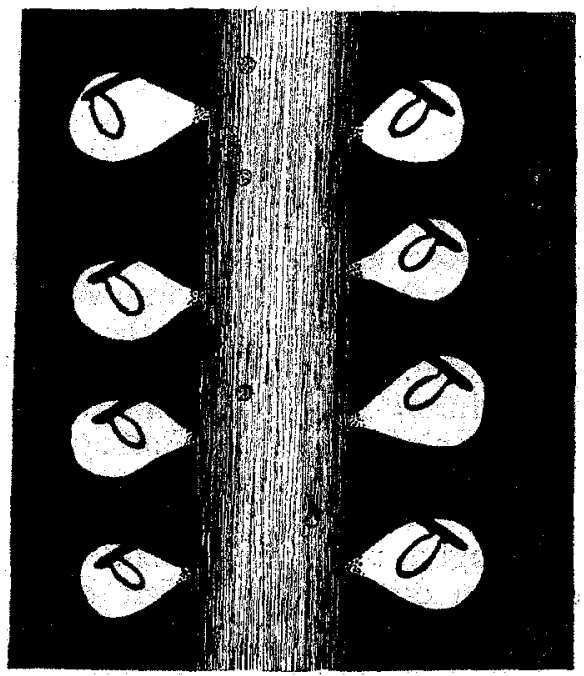

Abb. 34. Schematische Darstellung einer Radialebene mit der Anordnung der Ei-Kammern von Bledius spectabilis. Die Kammern sind in mehreren Stockwerken übereinander und Radialebenen nebeneinander angeordnet und nicht untereinander durch Gänge verbunden. Jede Kammer ist ein allseitig geschlossener, birnenförmiger Raum. Die einseitig verjüngte Kammer mündet in die Wohnröhre des Geschlechtstieres. Der Zugang dorthin ist bei belegter Kammer durch einen lockeren Sandpfrope ver schlossen. (Vergl. Text und Abb. 32 u. 33). mikroskopische Messung von gewöhnlichen Kotwalzen des Geschlechtstieres einerseits und von Eiträgern andrerseits ergab eine fast vollständige Uebereinstimmung. Auch aufbereitet ergaben beide ein auffallend übereinstimmendes Bild. Als gröbste Bestandteile waren einige Quarze von 50 bis $80 \mu$ im Durchmesser nachweisbar. An anorganischen Bestandteilen enthielten sie ebenfalls in gleicher Weise Diatomeen und Cyanophyceen, und zwar dieselben Formen, die auch an der Zusammensetzung der Algenhaut der Standortsoberfläche beteiligt waren. Mit der durch die mikroskopische Untersuchung begründeten Annahme, im Eiträger eine vom Darm (bezw. After) geformte Ausscheidung zu sehen, wird auch die kurzschenkelige Zuspitzung als eine vom After hervorgerufene Abschnürung des aus dem Darm herausgepreßten Kotbandes erklärlich.

Es bleiben nun noch die Fragen offen, wie kam

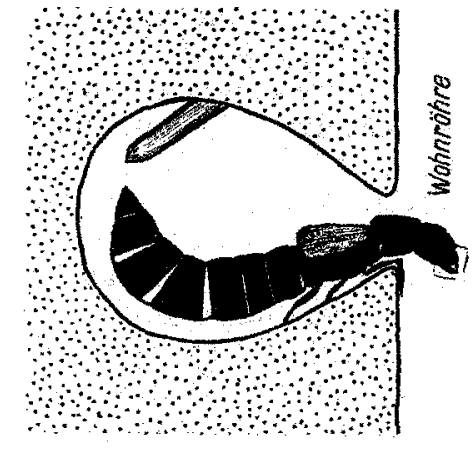

Abb: 35 . Vermutete Herkunft und Anbringung des Eiträgers am Dach der Eikammer. der Eiträger an das Dach und wie das Ei an den Träger der Eikammer, und zwar immer in derselben Weise?

Da die Träger in allen Fällen rund und glatt waren, vermute ich, daß der Käfer unter Anwendung seiner oben schon erwähnten Geschicklichkeit ohne Zuhilfenahme von Tibien und Mundwerkzeugen bei entsprechender Haltung seines wendigen Hinterleibes (etwa wie in der Abb. 35 schematisch angedeutet) den Eiträger durch begrenztes Entleeren seines Darmes an die obere Kammerwand geprebt hat. Ich erinnere bei dieser Vermutung an die saubere und geschickte Ablagerung der Kotwalzen am Grunde der Wohnröhre des Geschlechtstieres (S.57 u. Abb.31).

In ähnlicher Weise stelle ich mir die Anheftung des Ei es an den Träger vor, nämlich auf direktem Wege beim Entlassen aus dem Hinterleib. Ob die Eimembram 
im Augenblick des Auftreffens auf den Träger so beschaffen ist, daß die auf Abb. 37 angedeutete Anheftungsplatte entstehen kann, entzieht sich meiner Kenntnis. Beim Anheften des Eies wäre die Haltung des Hinterleibes natürlich gestreckter zu denken als in $\mathrm{Abb} .35$ dargestellt, so daß der Vorderkörper dabei weiter in die Wohnröhre hineinragt. Dies sind jedoch Vermutungen, deren Bestätigung bis zum Vorliegen neuer Beobachtungen offenbleiben muß.

\section{y) Der Embryo.}

In der Anbringung des Eies in der Eikammer glaube ich eine Anpassung an die Besonderheiten des Standortes sehen zu müssen. Es ist anzunehmen, daf selbst wenn die Wohnröhre voll Wasser laufen sollte, die von ihr abgeschlossenen Eikammern nicht unter Wasser gesetzt werden. Mit einer mehr oder weniger starken Durchfeuchtung des ganzen Sedimentes ist natürlich zu rechnen. Dieser wird das am Träger angebrachte Ei aber nur indirekt ausgesetzt sein, nämlich durch die Steigerung der Luftfeuchtigkeit sowohl, als auch durch Temperaturänderung. Nach meinen Versuchen im Brutschrank scheint aber der sich entwickelnde Embryo selbst gegen größere Schwankungen unempfindlich zu sein. Eine eingehende Untersuchung der Temperaturen im und über dem Standort ergab dann auch, daß selbst der engere Lebensraum des Käfers auch wur Brutzeit größeren Schwankungen unterworfen ist. Die Messungen wurden zu verschiedenen Tages- und Jahreszeiten durchgeführt. Ich beschränke mich auf die Wiedergabe einer einen vollen Tag umfassenden Meßreihe im Lagunenbezirk. Für die Dauer von 25 Stunden wurden

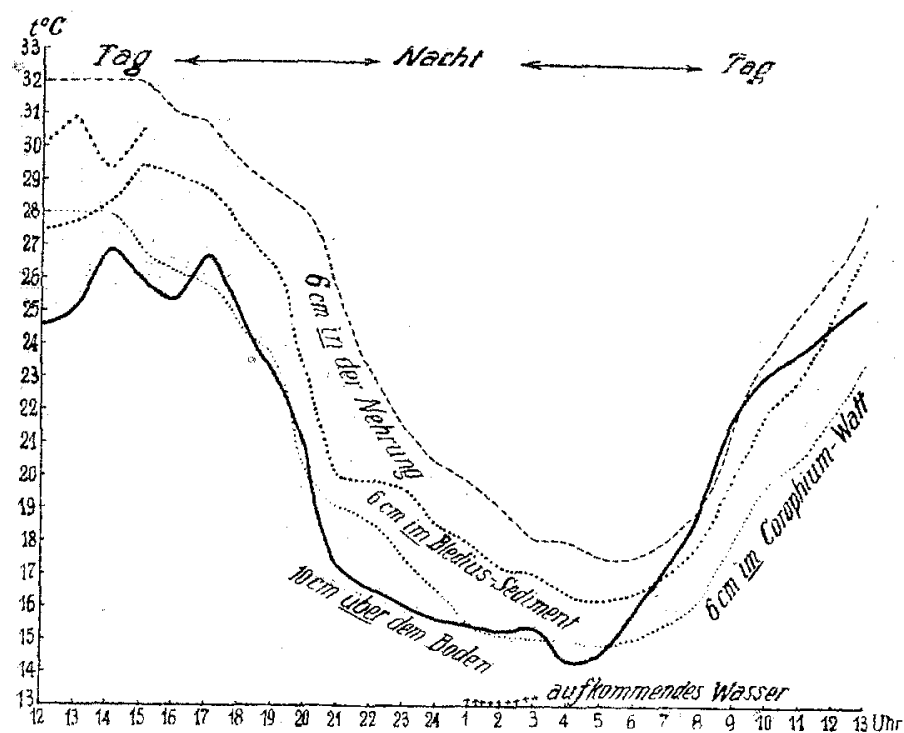

Abb. 36. Temperaturverlauf in und über dem Bledins spectabilisStandort der Lagunen-Terrasse einschließlich der Grenzbezirke: Nehrung, Corophium-Watt und aufkommendes Wasser, vom 6. VIl. 1933, 12 Uhr -7 . VIr. 1983, 13 Uhr. längs eines Schnittes in NordSüdrichtung über die Lagunenterrasse, Abb. 23, mit Hilfe von 9 Thermometern ununterbrochen Messungen über und in dem Boden, sowie in den unmittelbar benachbarten Grenzgebieten, dem Corophizm-Watt und dem Nehrungsrücken, durchgeführt. An zwei heißen Sommertagen, dem 6 . und 7. Juli 1933, also im Höhepunkt der. Brutzeit wurden sämtliche Thermometer $\mathrm{zu}$ jeder vollen Stunde von mittags 12 Uhr über Mitternacht bis zum nächsten Mittag 13 Uhr abgelesen. Thre örtliche Verteilung war folgende. Ein Richtersches Normalthermometer wurde unbeschattet $10 \mathrm{~cm}$ über dem Boden der Terrasse aufgehängt. Ein Max./Min. Thermometer wurde in den Boden der Terrasse $6 \mathrm{~cm}$ tief eingegraben, desgleichen 3 weitere Thermometer, deren Quecksilberkugel bis zur selben Tiefe, also mitten in den eigentlichen Brutbezirk, hinabreichten. Auf dem Nehrungsrücken wurden bis zur selben Tiefe zwei Thermometer eingesetzt und in dem mit Corophium besiedelten Wattgürtel (Abb. 21) ebenfalls eins $6 \mathrm{~cm}$ tief in das Sediment eingeführt und schließlich ein weiteres etwa $10 \mathrm{~cm}$ so über diesem Watt aufgehängt, daß die Quecksilberkugel um die Hochwasserzeit in das aufkommende Wasser eintauchte, sonst aber frei hing. Die abgelesenen Werte sind in der vorstehenden graphischen Darstellung wiedergegeben.

Das Kurvenbild (Abb. 36) entspricht nicht den Erwartungen. Die in Körngröße, Lagerung und Feuchtigkeitsgehalt recht unterschiedlichen Böden lassen im Temperaturverlauf keine auffallenden Abweichungen voneinander erkennen. Die Bodentemperaturen folgen alle ziemlich gleichläufig der Lufttemperatur, ganz gleich, ob es sich um Boden unter der Algenhaut handelt, um die grobsandige Nehrung oder schlieBlich um das wassergesättigte Sediment der Corophium-Zone. 
Stellt man die gemessenen höchsten Tagwerte den niedrigsten Nachtwerten gegenüber, so ergeben sich folgende Beziehungen:

\begin{tabular}{l|c|c|c}
\hline $\begin{array}{c}\text { Temp. Verlauf } \\
\text { gemessen : }\end{array}$ & $\begin{array}{c}\text { höchster } \\
\text { Tagwert }\end{array}$ & $\begin{array}{c}\text { niedrigster } \\
\text { Nachtwert }\end{array}$ & $\begin{array}{c}\text { Unter- } \\
\text { schiede }\end{array}$ \\
\hline 10 cm ü. d. Boden, Luft & 26,90 & 14,20 & 12,70 \\
im Wasser & 31,00 & 13,00 & 18,00 \\
Nehrung: 6 cm tief & 32,00 & 17,50 & 14,50 \\
Bledias-Sediment:6 cm tief & 29,50 & 16,20 & 13,30 \\
Corophimm-Watt: 6 cm tief & 28,00 & 14,80 & 13,20
\end{tabular}

Es ist bereits an anderer Stelle auf die großen Unterschiede zwischen Tages- und Nachttemperaturen im Wasser des Königshafen hingewiesen worden (vergl. Wasserhaushalt S. 11 u. 12, Tab. 5 u. 6). Doch scheint der von der Lagune im Corophium-Gürtel gemessene Unterschied von $18 \mathrm{Grad}$ das bisher Bekanntgewordene zu übertreffen. Der höchste Wert wurde mit $32 \mathrm{Grad} \mathrm{C}$ in den oberen Schichten des Sandhakens gemessen. Der hierfür ermittelte größte Unterschied beträgt 14,5 Grad. Zwischen diesen Grenzwerten liegen die Unterschiedswerte für das Bledius- und Corophium-Watt etwa mit 13,00 Grad. Beide Lebensräume erwärmen sich zeitweise ganz beträchtlich. Der von $B$. spectabilis besiedelte Boden zeigte 29,50 Grad, der von Corophium besiedelte 28,00 Grad. Diese Werte, in $6 \mathrm{~cm}$ Tiefe gemessen, lassen es nicht zu, von einem ausgeglichenen Verlauf der Wärme in den lebenswichtigen Schichten der beiden Standorte am Tage der Messung zu spreehen. In diesem Zusammenhang interessieren die von Krogerus ${ }^{1}$ ) (41, Diagr. Nr. 1, S. 144) in Kurven dargestellten Werte aus dem Triebsandgebiet (es ist Dünensand gemeint. Wir verstehen im Deutschen unter Triebsand etwas anderes). Einerseits zeigen seine Kurven, soweit sie über dem Standort gemessene Werte darstellen, ähnliche Tagesschwankungen wie meine, andrerseits aber nimmt die Kurve für $10 \mathrm{~cm}$ Tiefe und erst recht die für $40 \mathrm{~cm}$ einen sehr eindrucksvollen ausgeglichenen Verlauf. Aus dem Diagramm bei Krogreus geht leider nicht hervor, von welcher Struktur und sonstiger physikalischer Beschaffenheit der Sand war, für den die gemessenen Werte gelten. Der Unterschied zwischen unseren Kurvenbildern ist vorderhand nicht erklärlich, es sei denn dadurch, daß meine Messungen $4 \mathrm{~cm}$ flacher angesetzt wurden. Die für das Innere des Bledius spectabilis-Standortes erhaltenen Werte und Schwankungen müssen nicht nur von den Geschlechtstieren, sondern auch vom Embryo und von der nur schwach chitinisierten Larve ertragen werden können. Wir dürfen darin bereits einen hohen Grad der Anpassungsfähigkeit sehen und ordnen ökologisch gesehen - den Kurzflügler $B$. spectabilis nicht in die stenotherme sondern in die eurytherme Gruppe ein. DaB die Eurythermie wirklich vorhanden ist, konnte durch Brutversuche an Eiern im Wärmeschrank nachgewiesen werden.

Der eigentliche Grund für die Durchführung der Brutschrankversuche war allerdings ein anderer, nämlich die Lage des Embryos im Ei und den Schlüpfvorgang lkłarzustellen. Um diese Fragen beantworten zu können, verschaffte ich mir vom natürlichen Standort von Zeit zu Zeit eine Anzahl besetzter Eikammern und setzte sie, umgeben von einer feuchten Kammer, bei einer Temperatur von $30 \mathrm{Grad}$ in den Wärmeschrank. Ohne Schaden für das Leben des Embryos konnte ich die Temperatur auf $40^{\circ} \mathrm{C}$ steigern. Die bei der Ablage des Eies vorhandene milchig weiße Färbung geht mit dem Reiferwerden in eine gelbliche über. Solche schon reifenden Eier wurden im Wärmeschrank naturgemäß recht schnell ${ }_{n}$ ausgebrütet". Es zeigte sich bald, daß sich die Entwicklung durch Steigerung der Temperatur von 30 auf 35 Grad $\mathrm{C}$ ohne weiteres beschleunigen und umgekehrt durch Herabsetzung hemmen ließ. Es war leieht, auf solche Art eine ganze Reihe von Larven zum vorzeitigen Ausschlüpfen zu bringen. Der Vorgang selber und vor allem die Bewegungen des Embryos innerhalb der Eihülle wurden fortlaufend durch die Lupe beobachtet. Als erstes schimmerten die zuerst gelblichen später bräunlichen Mandibeln durch die Eimembran hindurch. Danach wurden die Augenflecke und die Tibien der Gliedmaßen erkennbar.

Besondere Erwähnung verdient die Lage des Embryos. Auch hier tritt uns die gleiche strenge Gesetzmäßigkeit entgegen wie bei der Ausrichtung der Eier (vergl. S. 58). Wie in der Abb. 37 schematisch angedeutet, ist der Kopf des Embryos stets nach unten mit dem Gesicht und der Bauchseite zur Wohnröhre des Geschlechtstieres gewendet. Der

1) Leider ist mir diese Arbeit erst jetzt, 2 Jahre nach meiner Geländearbeit, bekannt geworden. 
Rücken zeigt immer auf die hintere Wand der Eikammer. Die letzten Glieder des Hinterleibes sind zur ventralen Seite eingebogen. 'Sie werden von den drei Beinpaaren umklammert. Mit zunehmender Reife werden die Bewegungen des Embryos häufiger. Die

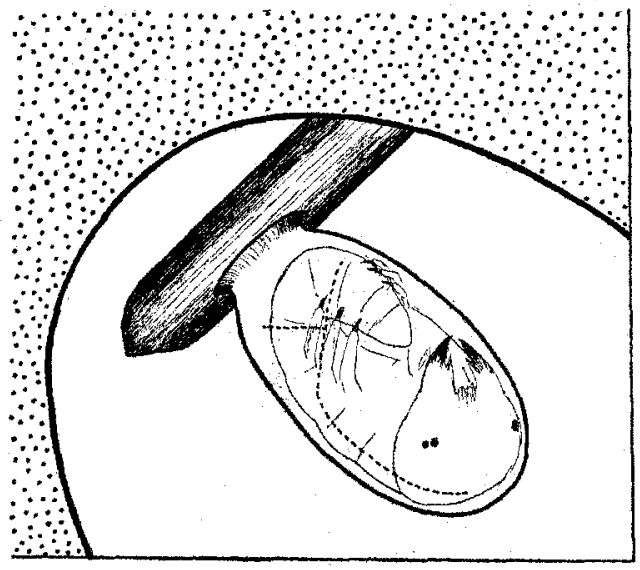

Abb. 37. Ei-Kammer von Bledius spectabilis, (schematisch). Darstellung der oberen Hälfte einer belegten EiKammer. Der Ei-Träger ist stets mit dem einen Ende am Dach der Kammer festgeklebt, Weist stets in den freien Kammerraum hinein und trägt anf zweidrittel Länge an der der Ausgangsöffnung zugewendeten Seite das Ei. Dieses ist mit einer schwach verbreiterten Platte dem Ei-Träger angeheftet.

Die Lage des Embryos im Ei ist stets dieselbe. Die Bauchseite und der mit kräftigen Kiefern versehene Kopf zeigen nach der Hauptröhre, die Rückenseite auf die hintere und untere Wandung der Kammer.

Mandibeln und auch das eingebogene Hinterleibsende bewegen sich in Abständen, bis schließlich etwas oberhalb der Basis des Eies ein feucht glitzernder Riß zu beobachten. ist. Die kräftigen Bewegungen sprengen endlich die Eihülle und im nächsten Augenblick macht der zur Larve gewordene Embryo die ersten freien, aber noch unbeholfenen Bewegungen auf dem Boden der Eikammer.

d) Die Larve.

Wie lange sich die Larve in der Eikammer aufhält, entzieht sich meiner Kenntnis. Ich habe nur feststellen können, daß die Wohnröhre der Imago sehr bald auch zum Wohngebiet der kleinen Larven wird. So kommt es, daß man sie in grober Zahl mit in der Röhre des Geschlechtstieres antrifft. Mit dem Größerwerden der Larven tritt jedoch eine Verschiebung in dem zahlenmäßigen Verhältnis ein. Immer seltener trifft man die größeren Larven in den Muttergängen an. Sie bauen jetzt ihre eigenen Röhren ganz ähnlich wie die der Muttertiere in der engeren Umgebung der Mutterröhre. Für das Wachstum der Larven scheinen eine gute Durchfeuchtung und hohe Temperaturen sehr förderlich zu sein. Abb. 38 zeigt eine 6 Tage alte Larve aus dem Brutofen. Sie ist infolge der schlechten

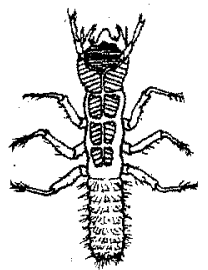

Abb. 38

6 Tage alte, im Brutschrank geschlüpfte Larye.

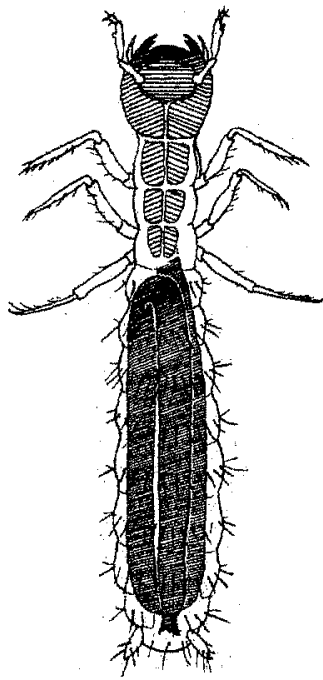

Abb. 39 .

Voll entwickelte Larve. Der Darm nimmt den ganzen Hinterleib ein und ist prall mit feinem Sediment gefüllt.

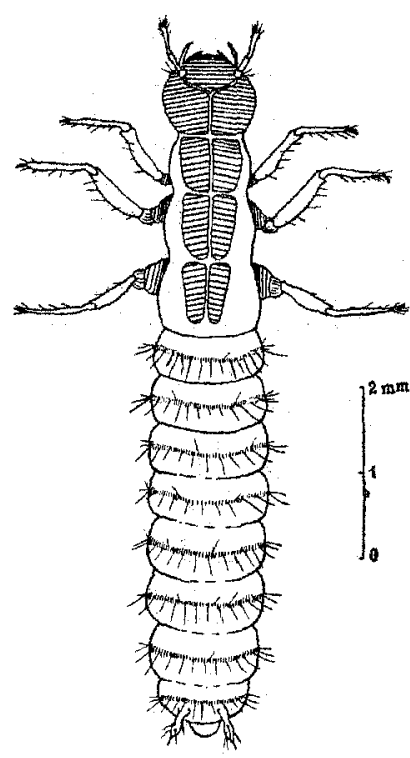

Abb. 40 ,

Die bereits starre, in derVerwandlung begriffene Larve. 
Ernährungsverhältnisse in der feuchten Kammer weit hinter den Larven des freien Standortes zurückgeblieben. Diese sind kräftiger und größer. Abb. 39 zeigt eine ältere Larve vom Lagunenwatt. In diesem Zustand entfaltet sie die größte Aktivität im Röhrenbau. Sie ist zwar nicht in so vollkommener Weise mit Hilfsorganen für die Grabetätigkeit ausgerüstet wie das Geschlechtstier, besitzt aber doch außer einem Paar kräftiger Oberkiefer (Abb. 42), Beingliedmafen, deren Tibien mit starken, zum Graben und Stützen geeigneten Dornen besetzt sind. Wie aus Abb. 43 hervorgeht, ist die Organisation des Fußes viel einfacher als beim Geschlechtstier. Die Tibie endet in einen starken Hauptdorn, um den herum in größeren Abständen etwa 6 Nebendornen angeordnet sind. Etwa in der Mitte des Hauptgliedes befindet sich eine längere Borste.

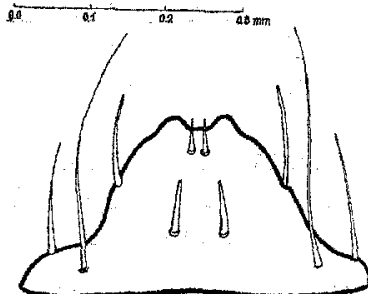

Abb. 41.

Der Clipeus der Larve.

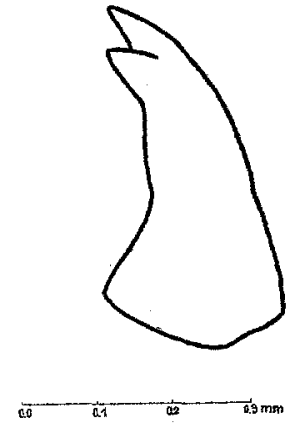

Abb. 42.

Die Mandibel der Larve.

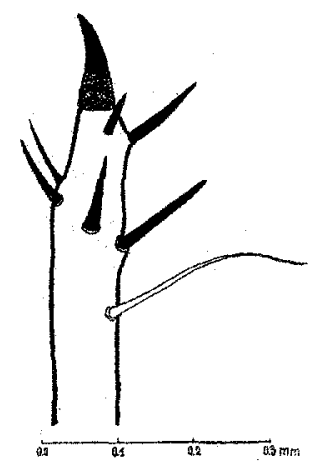

Abb. 43 .

Die mit Grabdornen bewaffnete Tibie (1. Beinpaar).

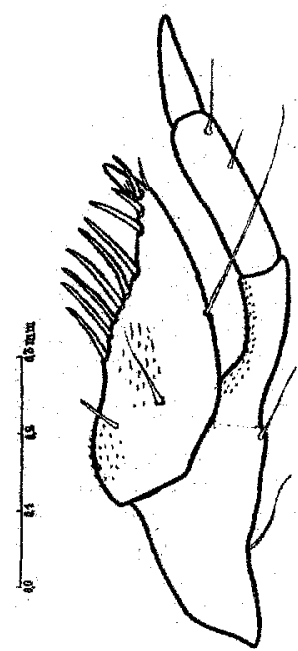

Abb. 44.

Die rechte Maxille der Larve

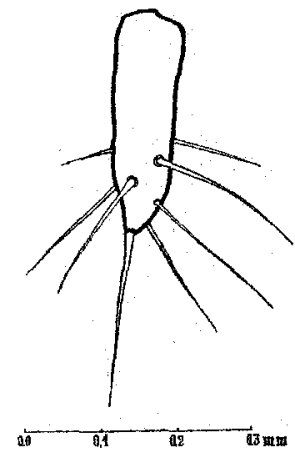

Abb. 45.

Der linke Cercus der Larve.

Der ganze Hinterleib der Larve ist durchsichtig. Er ist nur schwach chitinisiert aber dicht behaart oder, richtiger, mit feinen Borsten bedeckt. Der Darm, der meistens prall mit Schlick gefüllt ist, füllt den Hinterleib aus. Er macht eine einfache Schlaufe. Vom Oesophagus ausgehend, verläuft er an der ventralen Seite des Hinterleibes nach hinten, macht hier - von oben gesehen - eine Wendung nach links und erstreckt sich wieder nach vorn bis zur Brust, um schließlich nach abermaliger Wendung (rechts) auf der dorsalen Seite des Hinterleibes zum ventral gelegenen After zu führen (Abb. 39).

Zur Kenntnis der Systematik der Larve gebe ich in Anlehnung an die von SchöDte (66) und KROGERUS (39) beschriebenen Larven von Bledius-Arten anderer Standorte (Dänemark und Finnland) nebenstehend einige mit dem Zeichenapparat gemachte Zeichnungen 
bestimmter Organe wieder (Abb. 41 bis 45 ). Am meisten Aehnlichkeit hat die Larve von Bled. spectabilis mit der Larve von Bled. tricornis. Der Cercus ist bei Bled. spectabilis eher zylindrisch (Abb. 45) als keulenförmig (bei tricornis) gebaut. Besonderen diagnostischen Wert scheint die Maxille zu haben (Abb. 44). Sie weicht von allen anderen Formen ab. Der Maxillarpalpus ist sehr groß, sein zweites Glied hat zwei Borsten. Der Maxillarlappen verjüngt sich gegen die Spitze. An der äußeren Kante trägt er eine lange Borste und an der inneren Kante 6 Kammzähne. Der in die Spitze auslaufende Teil besteht aus einem sehr kräftigen, massiven Kammzahn (die Spitze selbst) und 4 kleineren Kammzähnen. Gebogene Kammborsten wie bei den Larven von Bled, arenarias, $B l$, talpa, $B l$. subterraneus, Bl. fluscipes und $B l$. opacus (nach KRoGERUS 39 , Abb. 16-20) trägt der Maxillarlappen von Bl. spectabilis nicht.

Die anfangs mit dem Muttertier zusammen, später aber für sich lebende Larve baut, wie schon erwähnt, eine eigene Röhre. Wie in der Abb. 46 angedeutet, hat sie eine ähnliche Form wie die Röhre des Muttertieres. Meistens geht sie nicht so tief hinab. Die Verjüngung an der Mündung ist ebenfalls vorhanden.

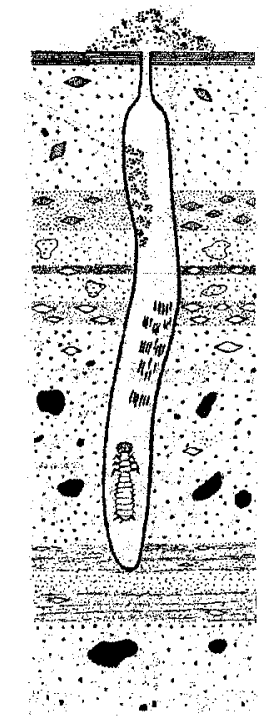

Abb. 46. Die Wohnröhre der Larve von Bledius spectabilis (sehematisch), Die wie beim Geschlechtstier unverzweigte Röhre der Larve ist etwas kürzer and enger. Die Verjlingung am oberen Ende ist vorhanden jedoch oft nicht so ausgeprägt.

(Vergl. Erläiuterungen im Text.)

Die von der Larve an die Oberfläche getragenen Krümelhäufchen unterscheiden sich in Form und Struktur nicht von denen des Geschlechtstieres.

Beobachtet man die Larve bei der Arbeit, so fällt sogleich ihre Schwerfälligkeit gegenüber dem Geschlechtstier auf. Sie scheint innerhalb der Röhre eine gute Orientierung zu haben. Ich sah sie schnell vorwärts und rückwärts laufen, doch konnte ich ein gelegentliches Umwenden im Röhrengang nicht beobachten. Recht bezeichnend für die Ungelenkigkeit des Hinterleibes ist die Art der Verteilung der ausgeschiedenen Kotwalzen. Sie werden nicht wie bei der Imago an einem streng begrenzten Platz der Röhre abgelegt (Abb. 31), sondern verteilen sich über die ganze innere Röhrenwand. Hier sind sie alle parallel zueinander ausgerichtet (Abb. 46). Thre Längsachse läuft mit der Röhre parallel. Struktur und Zusammensetzung der Kotwalzen sind dieselben wie beim Geschlechtstier. Bei groben Larven ist die Röhrenwand von den grauen Stäbchen dicht bedeckt.

Die erwähnte Schwerfälligkeit scheint der Grabfähigkeit jedoch keinen Abbruch zu tun. Schon im Juni waren im Königshafen von den Larven solche Standorte neu besiedelt worden, die vorher keinen Bestand an Gesehlechtstieren aufwiesen. Wegen ihrer Beziehung zur weiteren Entwicklung der Larve bedarf eine Besonderheit der Larvenröhre der Erwähnung. Im oberen Drittel der Röhre fand ich (Abb. 46) sehr häufig Sand von der mehrfach erwähnten Krümelstruktur seitlich angehäuft. Eine mit diesem Sand angesetzte Kultur ergab in wenigen Tagen einen üppigen Flor von Cyanophyceen und Diatomeen, den nämlichen Arten der Oberfläche. Ich glaubte zunächst, in diesem Sand einen Futtervorrat der Larve sehen zu müssen. Doch hierfür lief sich kein Nachweis beibringen, bis ich schlieflich in einer halb verfallenen und zum Teil mit diesem loekeren Sand angefüllten Röhre aus der Wand eine wagerechte schornsteinähnliche Billdung herausragen sah. Wie aus der photographischen $\mathrm{Abb} .47$ hervorgeht, ist sie von einem vertieften, ringförmigen Hof umgeben. Durch die runde Deffnung hindurch waren keine weiteren Einzelheiten zu erkennen.

\section{ह) Díe Verpappung.}

Als ich das auf Abb. 47 abgebildete Stück Sediment vorsichtig in kleinere Teile zerbrach, fiel mir eine große dottergelbe Larve entgegen. Sie war starr und unbeweglich. Vom Darm war nichts mehr zu erkennen. Stattdessen erschien die Chitinhülle prall mit 
einer milchig-gelben Masse angefüllt. Offenbar war das Tier gerade in der Umwandlung begriffen.

Um über die Bedeutung der schornsteinähnlichen Bildung Klarheit zu bekommen, machte ich eine Reihe von Brüchen durch das Sediment. Da es sehr leicht auseinanderfällt, sobald es aus dem natürlichen, geschichteten Verband herausgenommen wird, mußte ich sehr vorsichtig vorgehen. Als die röhrenförmige Mündung (Abb. 47) freigelegt war, kam eine zweite von derselben Form zum Vorschein und schließlich noch eine dritte gleiche, die endlich den Ausführungsgang aus einer größeren länglich-ovalen Kammer darstellte. In diesen Kammern fand ich je nach ihrem Alter eine kurz vor der Verpuppung befindliche, sich noch schwach bewegende oder eine bereits in der Umwandlung begriffene, starre Larve oder auch das schwach chitinisierte und pigmentierte junge Geschlechtstier.

Die photographischen Abbildungen 48 und 49 zeigen deutlich den schornsteinähnlichen Ausgang (Mündung III) der Verpuppungskammer. Die beiden oberhalb davon befindlichen Oeffnungen (I und II) lagen während der Aufnahme noch im Sediment. Abb. 48 zeigt die Haltung der dottergelben Larve, die regungslos in dieser Stellung bis zum Puppenstadium verharrt. Ganz ähnlich ist die Stellung der Puppe in der Kammer (Abb. 49).

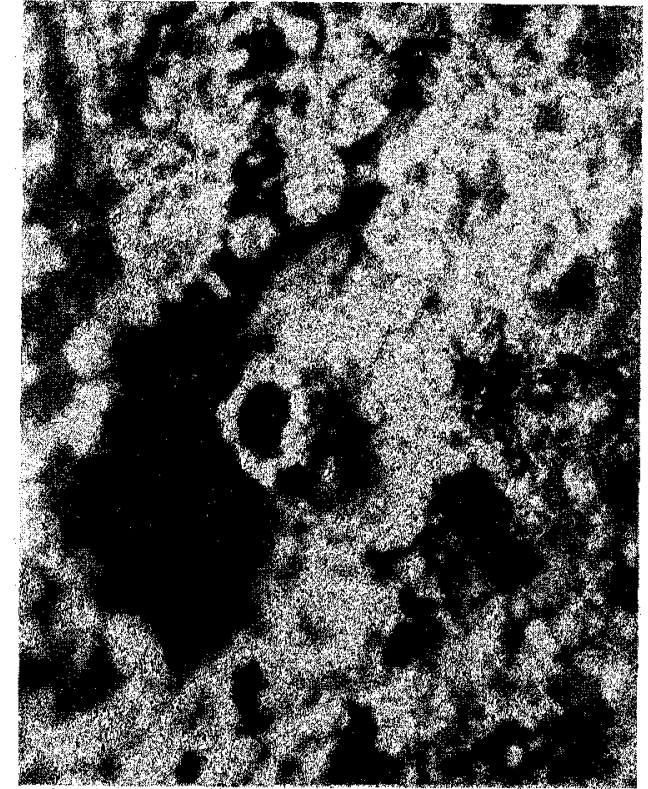

Abb. 47. Die obere der drei reusenartigenöffnungen der Verpuppungskammer ragt - umgeben von einer grabenförmigen Vertiefung schornsteinähnlich in die ehemalige Wohnröhre der Larve hinein. Vergr. 7-fach.

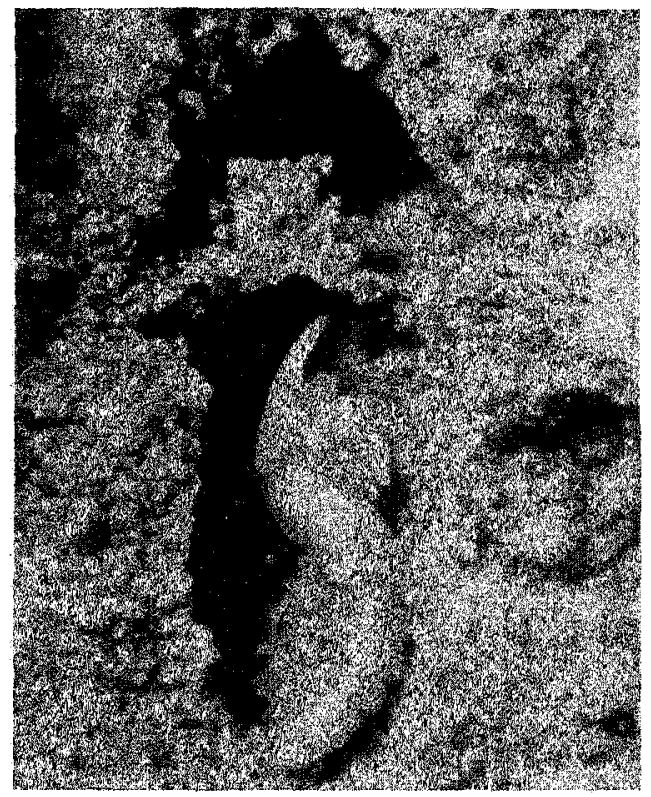

Abb. 49. Die charakteristische Haltung der Puppe in der Verpuppungskammer. Das in der Kammer noch unbeweglich ruhende Männchen ist erst sehr schwach chitinisiert und farblos. Vergr. 7-fach. 
In der halbschematischen Abb. 50 habe ich den sinnreichen Bau der Verpuppungskammer mit dem darin befindlichen Endstadium der Verwandlungsvorgänge dargestellt. Es wird nunmehr auch der problematische krümelige Sand, den ich oben bei der Beschreibung der Larvenröhre erwähnte, seiner, Herkunft nach verständlich. Wahrscheinlich handelt es sich dabei um den Sand, der für die Anlage der Verpuppungskammer fortgeräumt werden mußte.

Richten wir zum Sehluß unsere Gedanken auf Sinn und Zweck der: stets in dieser Weise gebauten Verpuppungskammer, so glaube ich in der reusenartig gesicherten Einrichtung eine Sicherheitsmaßnahme des sich der Verwandlungsruhe hingebenden Tieres sehen zu müssen, Es wird sich in erster Linie um eine Sicherung gegen

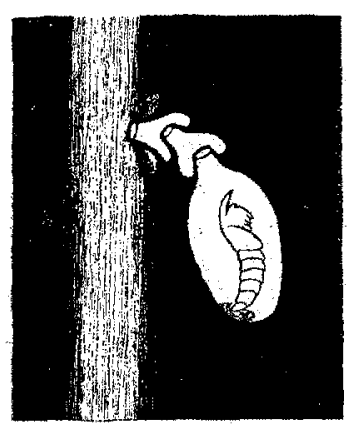

Abb. 50, Verpuppungskammer von Bledius spectabilis. Schematische Darstellung der durch dreifache Reusensicherung mit der ÂBenwelt verbundenen Verpuppungskammer. Die abgestreifte Larvenhaut ist am Boden der Kammer angedeutet. (Vergl. Text S. 65: and Abb. 47-49).

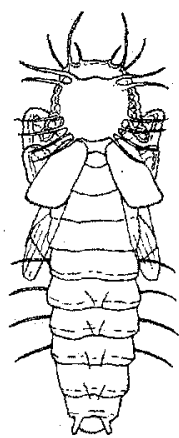

Abb. 51 . Die Puppe.

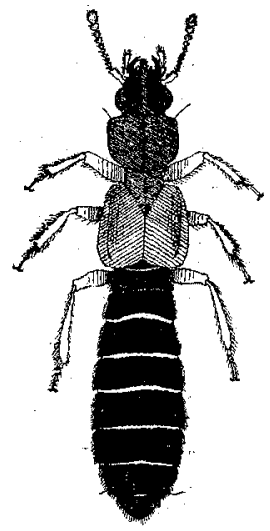

Abb. 52.

Das fertige Geschlechstier $\left(0^{7}\right)$. Vergr, etwa 7 -fach

eindringendes Wasser handeln. Die reusenartige Hintereinanderschaltung der drei Âusführungsgänge könnte auf den ersten Blick die Vermutung nahelegen, daß es sich um eine Sicherung gegen räuberische Käfer handele. Allein die in Frage kommenden Raubkäfer sind selber alle ausgezeichnete Graber und treiben ihre Gänge quer durch das Sediment zu ihrer Beute hin.

Meine, zuerst ausgesprochene Vermutung gewinnt an Wahrscheinlichkeit, wenn ich mich an den für die Verpuppungsvorgänge recht ungünstigen Juli des Jahres 1933 erinnere. Die Standorte wurden zu jener Zeit recht häufig und lange überflutet. Gleichzeitig war der Himmel längere Zeit bewölkt und die Temperaturen niedrig. Die Verpuppungskammern waren damals wohl besetzt, aber die Tiere darin waren tot und von Schimmelpilzen bedeckt. Hohe Bodenfeuchtigkeit und gleichzeitig niedrige Temperaturen scheinen den Ablauf der Verwandlungsvorgänge in der Verpuppungskammer zu hemmen, vergl. S. 61. Zur endgültigen Klärung dieser sehr wichtigen ökologischen Fragen müßte jedoch das Mikroklima innerhalb des Wohnsedimentes der Tiere noch eingehender, als ich es tun konnte, untersucht werden.

\section{Die staffelförmigen Strandhaken und -buchten am Ellenbogenstrand.}

Untèrhalb des Ellenbogen-Dünenkliffs, etwa auf der Höhe des Westfeuers, befinden sich im Sommer an der Hochwasserlinie Sandbildungen, die hakenförmig vom Strand auf die daran angrenzenden Wattflächen abzweigen. Schon nach wenigen Metern biegen sie aus der Nord-Südrichtung um in die Ostrichtung und laufen 10 bis $20 \mathrm{~m}$ parallel mit dem Strand. Die sich ostwärts erstreckenden Haken lassen zwischen sich und der Strandlinie eine flache Bucht entstehen. Das ebene Gelände dieser Bucht liegt wenige Zentimeter unter der Oberfläche der Sandhaken, so daß bei Hochwasser die Bucht eher und länger überflutet wird als der Haken. Diese Haken und Buchten ordnen sich am Ellenbogenstrand zwischen dem Gröning und dem aus der Westfeuer-Niederung austretenden Priel kulissenförmig hintereinander an (Abb. 53). 
Wesentlich anders sieht es im Winter an dieser Stelle des Ellenbogenstrandes aus. Die durch die Stürme hervorgerufene stärkere Wasserbewegung hat die Sandhaken fortgeräumt, so daß nur noch die im Sommer von ihnen umschlossenen Buchten festzustellen sind.

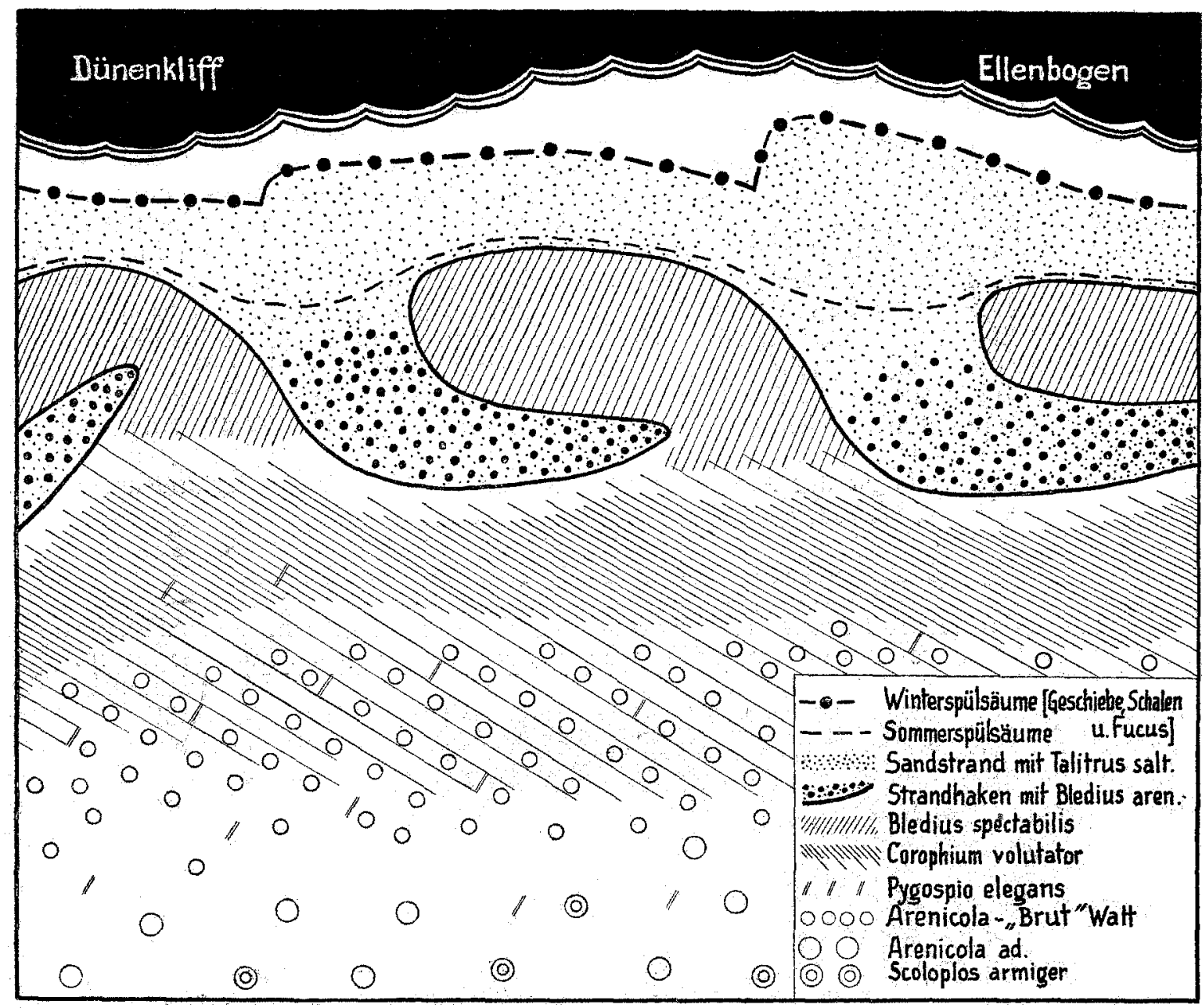

Abb. 53. Die staffelförmigen Strandhaken am Ellenbogenstrand und ihre Besiedelung.

\section{a) Das Sediment der Haken.}

Die Haken werden von einem hellen, locker gelagerten Sand aufgebaut. Ihre Oberfläche trägt manchmal Rippelmarken und ist fast immer mit kleinen Sandauswürfen von unbestimmter Form bedeckt. Die Korngrößenzusammensetzung ist aus dem nebenstehenden Blockdiagramm 12, Abb. 54, ersichtlich. Es ist ein ziemlich grober Sand, der sich zur Hauptsache aus den beiden Gruppen zwischen 1,00 und $0,25 \mathrm{~mm}$ zusammensetzt. Die Proben von verschiedenen Haken stimmten im sehr geringen Wassergehalt $(8-9 \%)$ gut überein. Schlickige Beimengungen fehlten vollkommen. Die Körner über $1,00 \mathrm{~mm}$ dürften auf die unmittelbare Nähe des ansteigenden Sandstrandes zurückzuführen sein, denn die Siebanalyse vom Sandstrand ergab, daß die Hälfte aus Körnern über 1,00 mm bestand.

Bei der lockeren Beschaffenheit des Sedimentes der Haken muß man sich über ihre jedenfalls für den Sommer nachweisbare, beständige Lage wundern. Die Untersuchung

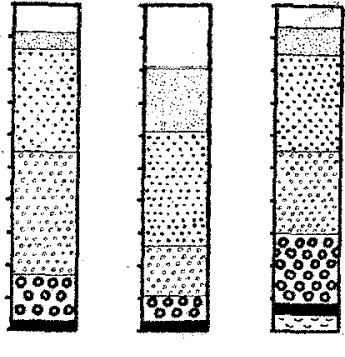

Abb. 54: Diagramm 12, 13 und 14 
ergab, daß auf allen Haken nahe unter ihrer Oberfläche ein lockeres Cyanophyceen-Geflecht vorhanden war. Erst wenn man die obersten $2-3 \mathrm{~mm}$ Sand entfernte, leuchtete das Grün der Algen, Microcolens chthonoplastes, durch.

\section{b) Das Sediment der Buchten.}

In den von den Sandhaken umschlossenen Buchten ist die Oberfläche des Sedimentes dunkel graugrün und der das Sediment dicht absehliebende CyanophyceenRasen nach der Ueberflutung schlüpfrig. Die Ablagerungen sind deutlich geschichtet und teilen weitere Merkmale mit dem Lagunen-Watt am Kersten Rimling (vergl. S. 52). Das umseitig stehende Bloekdiagramm, Diagr, 13 in Abb. 54, zeigt auch eine ähnliche KorngröBenzusammensetzung (vergl. außerdem Abb. 26). Stellt man das Blockdiagramm des Bucht-Sedimentes dem der Haken gegenüber, so lassen die großen Untersehiede auf zwei von einander verschiedene Sedimentationsvorgänge schließen. Das BuchtSediment ist tonig gebunden und der absolute Wassergehalt beträgt $110 \%$ von dem des Haken-Sedimentes. Der die Oberfläche bedeckende einbeitliche Algenfilz erhöht zusammen mit den tonigen Beimengungen die Widerstandsfähigkeit der Buchten gegen das Wasser. Im Winter spült das Wasser die lockeren Sandhaken fort und die widerstandsfähigeren Buchten bleiben stehen, so daf sie das umgebende Watt alsdann etwas überragen.

Das Sommerbild ist der Ausgangspunkt fur unsere biologisehe Bestandsaufnahme.

c) Die Besiedelung der Haken und Buchten.

Das unmittelbare Nebeneinandervorkommen der beiden so sehr verschiedenartigen Sedimente läßt von vornherein einen Unterschied auch in der Besiedelung erwarten.

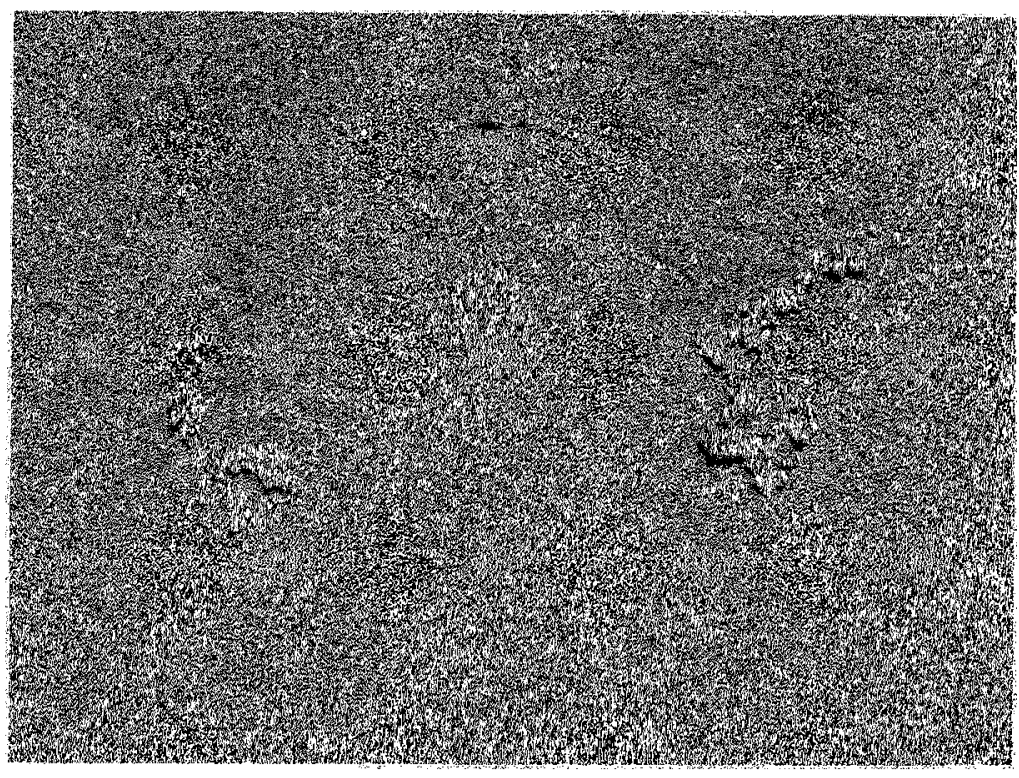

Abb 55 . Nahaufnahme ron der Oherfltiehe der von Bledius arenarius var subniger besiedelten Sandhaken am Ellenbogenstrand (vergl. Abb. 56). Die Wornen der an die Oberfidhe geturderten Sandmengen sind stets nnegelmabig linienförmig, niemals haufenformig. Die Anftragstormen entsprechen jeweils den von den Käfern beim Nahrungserwerb in den oberen 2 Millineten des Standortes binterlassenen Grabsponen Aufuhme kurz nach dem Aliaufen des Wassers.

die große Anzahl von Dipteren-Puppen. Die letzten gehören der Familie der Ephydrininae (vielleicht Hydrellia spec., nach frdl. Angaben von Herrn KRöBER, Hamburg) an. Eine sichere Bestimmung war wegen des nicht guten Erhaltungszustandes nicht möglieh.

belle 16 , bestätigt die Ver mutung and zeigt, daß trotz engster Nachbarschaft eine unbedingt sichere Grenzziehung möglich ist.

Schon die obertlächlich erkennbaren Spuren beider Standorte sind sehr versehieden. Aufderdunklen und glatten Oberflache der B uehten treten die beim Lagunenwatt näher beschriebenen Krüinel häufchen in Threr charakteristischen Ausbildung auf: Die Bestandsliste gibt für 1/g qm mit 23 Tieren eine sehr dichte Besiedelung von Bled, spectabilis und dem typisehen Nitbewohner Heterocerus flexuosus an. Neu für den Spectabilis-Standort (vgl. Lagunenwatt, S. 54) sind das gleichzeitige Vorkommen von Talitrus saltator und won 2 Bled areharius var. subniger sowie 
Die Spuren der Hakensände ließen auf eine dichte Besiedelung mit grabenden Käfern schlieBen. Der an die Oberfläche gebrachte Sand hatte jedoch eine ganz andere Form und Struktur als die von Bled. spectabilis geförderten Häufchen. Häufchen waren uiberhaupt nicht vorhanden. Wie aus den Abb. 55 und 56 hervorgeht, sind es linienförmige Ablagerungen, deren unregelmäßige Form am besten bald nach dem Ablaufen des Wassers beobachtet werden konnte. Es handelt sich um die Grab- und Freßspuren des Kurzflüglers Bledius arenarius var. subniger.

Die Bestandsliste Tab. 16 zeigt, in welch ungeheurer Menge Bled. arenarius auf diesen Sandhaken auftritt. Es waren durchweg 1200 Individuen auf einem Quadratmeter. Dabei handelt es sich um Mindestwerte, da manche Larve durch die Maschen meines Siebes hindurchgegangen sein dürfte. Als ständiger Begleiter ist der Raubkäfer Dyschirius angustatus zu nennen. Er wurde im benachbarten Bledius spectabilis-Standort ebensowenig angetroffen wie Heterocerus flexuosus auf einem Bledius arenarius-Standort im Königshafen beobachtet werden konnte. Zieht man aber die übrige Literatur heran, so ist das Besiedelungsverhältnis zwischen Raubkäfer einerseits und Bledius-Arten andererseits beim Vergleich verschiedener Gegenden nicht immer so beständig.

So kommt z. B. nach SCHNEIDER (67) auf der Insel Borkum Bled. arenarius zusammen mit Dyschirius thoracicus vor und ferner nach JoHNSON (zitiert nach SAINTE-DEvILLE (65) mit Dysch. impunctipennis. SAINTE-DEVILLE (65) berichten, daß Bled. arenarius mit Dysch. arenosus und Dysch. obscurtus, dagegen Dysch. angustatus, Dysch. politus mit den beiden Kurzflïglern Bled. opacus und Bled. nanus vergesellschaftet sind. KROGERUS (38) endlich findet Bled. arenarius im Rigaischen Meerbusen zusammen mit Dysch. impunctipennis und Dysch. obscurus.

Tabelle 16.

Besiedelung der Hakensände und Buchten.

Probe Nr. 1 bis 4: am 7. Vil. 1933 Hakensand $1 / 20$ qm

$\begin{array}{ll}\text { " } & \text { 6: am 5. VIII. } 1933 \text { 5. VIII. } 1933 \text { Bucht } 1 / 20 \text { qm }\end{array}$

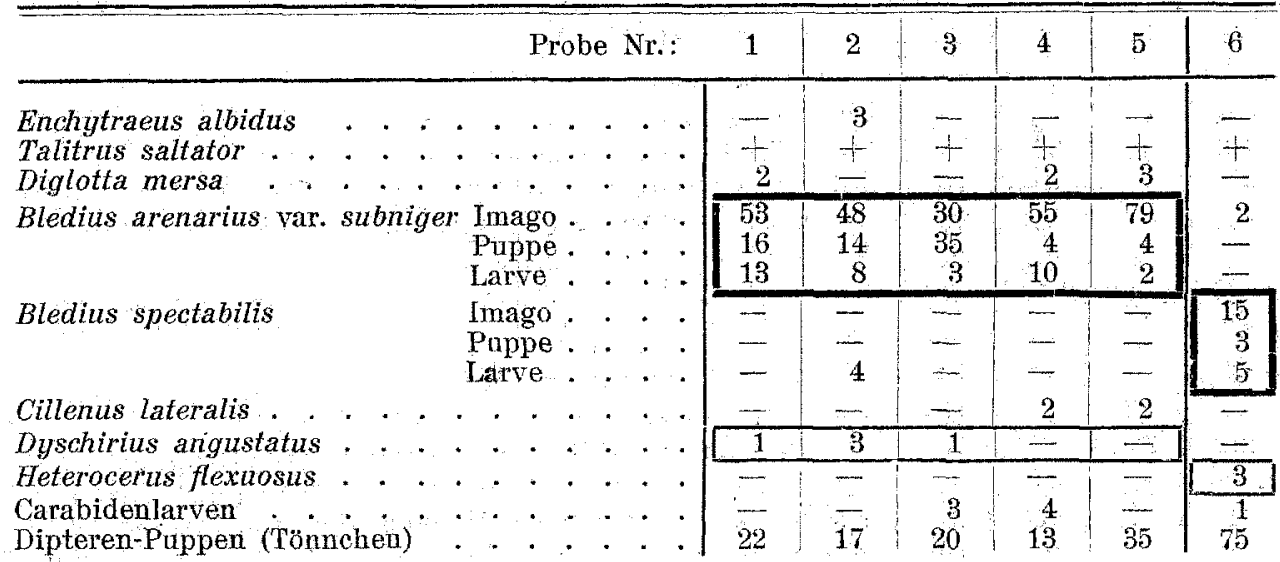

(Die umrahmten Zahlen kennzeichnen besonders die verschiedenartige Besiedelung der Haken und Buchten durch Bledias arenarius bezw, Bledius spectabilis einerseits und durch Dyschirius angustatus bezw. Heterocerus flexuosus andererseits).

Ob die wenigen Diglotta mersa ihre ganze Entwicklung auf den Sandhaken durchgemacht haben, kann ich nicht sagen. Larven habe ich lediglich auf dem Stromsand $\mathrm{C}$ (vergl. S. $72, \mathrm{Abb}$. 58) gefunden.

Schon bei WesEnBERG-LUND (86, S. 38) sind die Auswürfe der Bledias arenarius-Zone abgebildet. Sie stammen von den Hochsandebenen vor Röm (Lakolk), die seltener als unser Standort überflutet werden. Die Spuren werden nach dem Trocknen leicht durch den Wind verwischt, so daßs die ursprüngliche Form bald nicht mehr zu erkennen ist. Die auf den Abb. 55 und 56 sichtbaren Spuren sind gleich nach dem Ablaufen des Wassers enstanden, als die Oberfläche noch feucht und glatt war.

Mit der Spur hat es folgende Bewandnis. Es handelt sich nicht immer wie bei Bled. spectabilis um Sand, der aus der Tiefe des Sedimentes an die Oberfläche geschafft worden ist, sondern um Sand der Oberfläche selber. In dem 1 bis 2 Millimeter unter der 


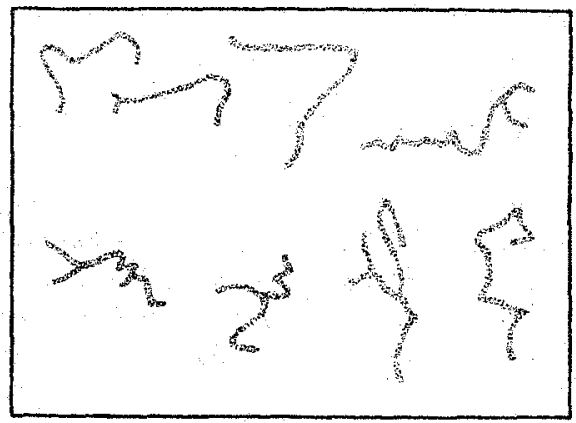

Abb. 56

Oberflächen-FreB-Spuren von Bledius arenarius var. subniger.

Oberfläche liegenden Cyanophyceengeflecht konnte ich Bled. arenarius beim Graben in wagerechter Richtung beobachten. Bläst man die sichtbaren Spuren fort, so wird der unregelmäbig gewundene Gang des Käfers frei. Abb. 56 gibt einige Typen dieser Frefspuren wieder. Sie werden als Frefspuren aufgrund der Beobachtungen und der Kotuntersuchungen bezeichnet. Der sogenannte "grüne Sand" bildet ja zusammen mit den darin lebenden Mirkroorganismen und Nematoden (WESENBERG-Lund, 86, MorteNSEN, 49 und Krogerus, 41) die Grundlage für die Ernährung von Bledius arenarius.

Die im Hakensand gefundenen Wohnröhren und Kammern von B. arenaris var. subniger sind nicht näher von mir untersucht worden. Auch entzieht sich meiner Kenntnis, ob der gegebenenfalls für den Bau dieser Hohlräume fortzuräumende Sand wie bei Bledius spectabilis nach oben getragen wird, oder ob die Hohlräume in dem locker gelagerten Sediment bereits durch einfaches Umpacken des Sandes gebaut werden.

Zur Hauptsache ist $B$. arenarius var. subniger im Königshafen auf diese Hakensände beschränkt. Er kommt außerdem auf der Strandebene vor der Oeffnung der Westfeuer-Niederung vor und schlieBlich am Fuße des Möwenberges, wo das Sediment allerdings bedeutend grobkörniger ist.

Die Korngrößenverteilung ist aus dem auf S. 67 befindlichen Blockdiagramm 14 ersichtlich. Der Standort war sehr trocken (vgl. Wassergehalt).

Interessant ist ein Vergleich der Bledius arenarius-Standorte des Königshafens mit den besiedelten Strandbildungen anderer, Gegenden. Das Kurvenbild, $\mathrm{Abb} .57$, zeigt deutlich, daß die Königshafen-Standorte wesentlich anders zusammengesetzt sind als die von den Inseln Trischen, Röm und der Halbinsel Skallingen. Die Kurvenwerte der letzten drei Standorte überdecken sich fast und lassen gut ihren einheitlichen Charakter als Flugsandebene erkennen.

Der Fläche nach gesehen sind die Bledius arenarius-Standorte im Königshafen ganz unbedeutend. Die meilenweiten Siedlungen an der übrigen deutschen und dänisehen Küste sind mir zwar bekannt, aber ich

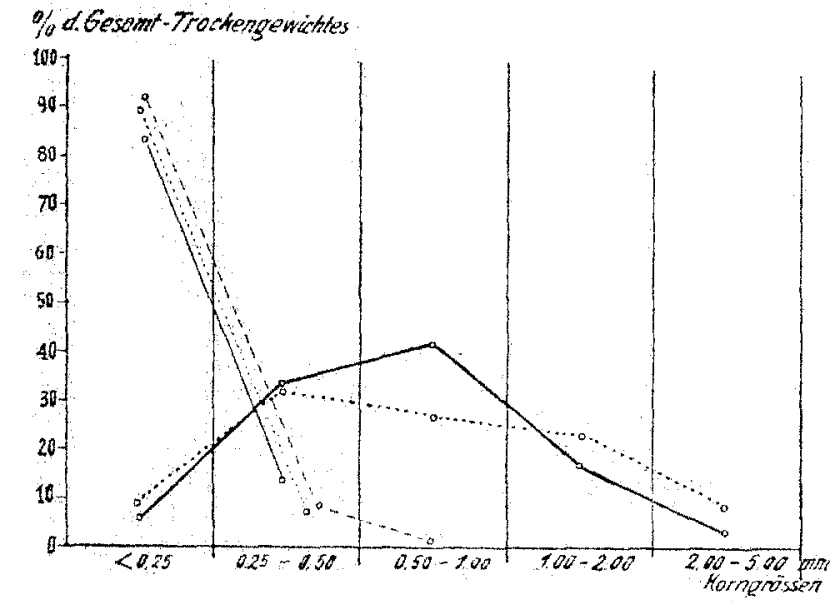

Königshafen, Sylt, Hakensände (Text S. 67)
$\ldots \ldots \ldots \ldots$ Insel Trischen, Holstein, Flugsandebene (Text)
Röm, Dänemark,
$\begin{array}{lll}\text { Halbinsel Skallingen, Dänemk. " } & \text { b. Lakolk }\end{array}$

Abb.57. Die von Bledius arenarius besiedelten Sedimente der Westküste Schleswig-Holsteins und Jütlands. (Insel Trischen, Sylt, Röm und Halbinsel Skallingen.) muß sagen, daß jene Standorte in der

Einförmigkeit hinsichlich Struktur und Besiedelung nicht zu überbieten sind. Das ökologisch Eindrucksvolle der Standorte im Königshafen aber liegt auf einer anderen Ebene. Hier sind es besonders die klar erkennbaren Gesetzmäbigkeiten in der Strandbildung und -zerstörung, also in der Geschichte des Biotops einerseits und die verschiedenartige Besiedelung eng benachbarter Standorte von grundsätzlich anderem Aufbau andrerseits. Die Käfer verlassen nicht allein ihren Standort beim Wechsel der Jahreszeiten, sondern dieser selbst verschwindet im Herbst unter dem zwangsläufigen Geschehen der landschaftsformenden Kräfte, um unter ihnen im Frühjahr wieder zu erstehen. In der alsdann folgenden Neubesiedelung mit einer bestimmten Gruppe von Tieren kommt das von keinem fremden Faktor gestörte Zusammenspiel reiner natürlicher Kräfte, das für die Vertiefung der ökologischen Forschung so wertvoll ist, in seltener Weise zum Ausdruck. 
7. Der Priel und seine Ufer.

a) Das Prielbett.

Ich erinnere an die bei der Besprechung der allgemeinen morphologischen und hydrographischen Verhältnisse (S. 4) vorgenommene Einteilung des Hauptpriels. Breit und flach und dennoch sehr schwer zugänglich liegt das Prielbecken unter dem Gröning. Dann folgt ostwärts das in 4 Abschnitte unterteilte Prielbett (Abb. 1). Schon am Ausgang des Beckens wird der Grund fester und sandiger. Er trägt gut. In dem dauernd überfluteten, noch flachen Bett findet man eine ziemlich gleichförmige Besiedelung von Arenicola marina. Einzelne Miesmuschelklumpen mit dunklen Fucus-Büscheln wechseln mit ebenfalls recht locker verteilten Zostera marina-Horsten ab.

Der Prielabschnitt I vertieft sich nach Osten immer mehr, sodaß man bei Niedrigwasser nicht mehr hindurchwaten kann. Vom Knie (Abschnitt $I$ und $I I$ ) ab nimmt das Prielbett kerbtalartige Formen an, die es bis zur Mündung unterhalb der äuBeren Miesmuschelbank behält.

Im Abschnitt I fand ich im Sommer 1932 am südlichen Ufer größere Bestände von Zostera marina mit eingestreuten Fucus-Inseln. Der mit Seegras bestandene Boden war außerdem von Lanice conchilega besiedelt (etwa 25 auf $1 / 20 \mathrm{qm}$, vergl. WohlenBERG, 90, Abb. 5). Der Boden bestand hier aus festem, feinem Sand, der sehr tragfähig war. Die unmittelbar benachbarten Fucus-Inseln dagegen bauten sich aus wasserhaltigem Feinsand mit schlickigen Beimengungen auf, worin man beim Hinübergehen tief einsank.

Noch ausgeprägter ist die Besiedelung mit Zostera marina im Prielabschnitt II. Hier läuft am südwestlichen Ufer eine etwa $2-10 \mathrm{~m}$ breite und $50 \mathrm{~m}$ lange Bank entlang. Sie war (1932) dieht mit dem gewëhnlichen Seegras bestanden und wies außerdem eine dichte Besiedelung von Lanice conchilega auf. Mit 65,71 und 72 besetzten Lanice-Röhren auf $1 / 20$ qm ist diese Bank der am stärksten mit Lanice besiedelte Standort des Königshafens. Die Fransen der Röhrenmündungen berührten sich fast. Der starke Wasserwechsel an dieser Bank dürfte für eine mehr als ausreichende Ernährung dieser Bestände sorgen.

Oberhalb der Bank steigt das Ufer nach Westen allmählich an. Es ist Sandwatt mit regelmäßiger Arenicola-Besiedelung. Weiter westwärts beginnt auf dem höher gelegenen Rücken zwischen den Prielabschnitten II und 1 das mit Mytilus und Fucus besiedelte Gebiet. Das Ostufer des Prielabschnittes II trägt am Nordende eine kleine Mytilus-Bank und steigt weiter ostwärts zum Ostfeuerwatt an, das im westlichen und südlichen Teil ein sehr unbeständiges Sandwatt darstellt. Das Gebiet am Prielabsehnitt III wird täglich umgelagert. In West-Ost-Erstreckung liegen hier (zwischen II und III) langgestreckte Strömungsbänke, auf deren schwach gewölbten Rücken Arenicola selten vorkommt. Dagegen sind die zwischen den Rücken liegenden Täler, deren Sediment im Gegensatz zu dem der Rücken stets wasserübersättigt ist, gut von Arenicola besiedelt. Weisen schon die Strömungsbänke auf die starke Ueberströmung dieser Wattflächen hin, so erst recht das "den Abschnitt III unmittelbar begrenzende Gebiet. Hier fehlen die Arenicola-Häufchen vollkommen. Der Sand in diesem Gebiet ist wasseruntersättigt, hell gewaschen (ohne $\mathrm{FeS}_{2}$ ), locker gelagert und im Augenblick der Ueberflutung triebsandähnlich. Schlieflich ist der sich ostwärts anschließende Sandhaken als Merkmal für die hier vorhandenen starken Umlagerungen zu nennen.

\section{b) Der Ophelia-Stromsand.}

Mit der Erörterung des Ophelia-Sandes wende ich mich dem Prielabschnitt Iff zu, einem Gebiet, das zu den interessantesten des Königshafens gehört, und zwar nicht nur in biologischer, sondern auch in morphologischer und geologischer Beziehung.

Erst ganz im Osten dieses Abschnittes tritt die Vegetation der inneren Miesmuschelbank an den Priel heran, der übrige Teil ist nacktes Sandwatt. Auf der Skizze, Abb. 58, habe ich den am nördlichen Ufer am Prielknie gelegenen Ophelia-Sand mit A bezeichnet. In steiler Wölbung tritt das Sandwatt aus dem hier bereits sehr tiefen Prielbett heraus. Infolge seiner Höhe drängt es sogar einen Teil des zuletzt vom nördlich gelegenen Ostfeuerwatt abfließenden Wassers nach Osten in Richtung des Hakens (Rechts von A) ab. Mit diesem Vorgang hängt auch die Hakenbildung zusammen.

Nach diesen Mitteilungen wundert man sich nicht, wenn die Korngrößenbestimmung einen nach oben wie unten eng begrenzten Bereich aufweist. Ein $10 \mathrm{~cm}$ langer Kern 
bestand fast nur aus den beiden Gruppen zwischen 1,00 und 0,50 und 0,50 und $0,25 \mathrm{~mm}$. Feineres und gröberes Material waren nur in kleinen Mengen vorhanden. Diese Art der Sedimentzusammensetzung und das lockere Gefüge bestätigten das Vorhandensein von unaufhörlich auslesenden und ordnenden Faktoren. (Vergl. auch die KorngröBenanlysen von Strombänken des Elbwatts; DitTMER, 13b, S. 41). Wie so leicht kein zweiter im Königshafen, unterliegt dieser Standort täglich dem lange wirkenden Wellenschlag und einer ausgerichteten Strömung. Das Sediment ist gewissermassen „gewaschener" Sand. Erst unterhalb der MNW-Linie findet sich blauschwarzes Pigment. Angesichts dieser

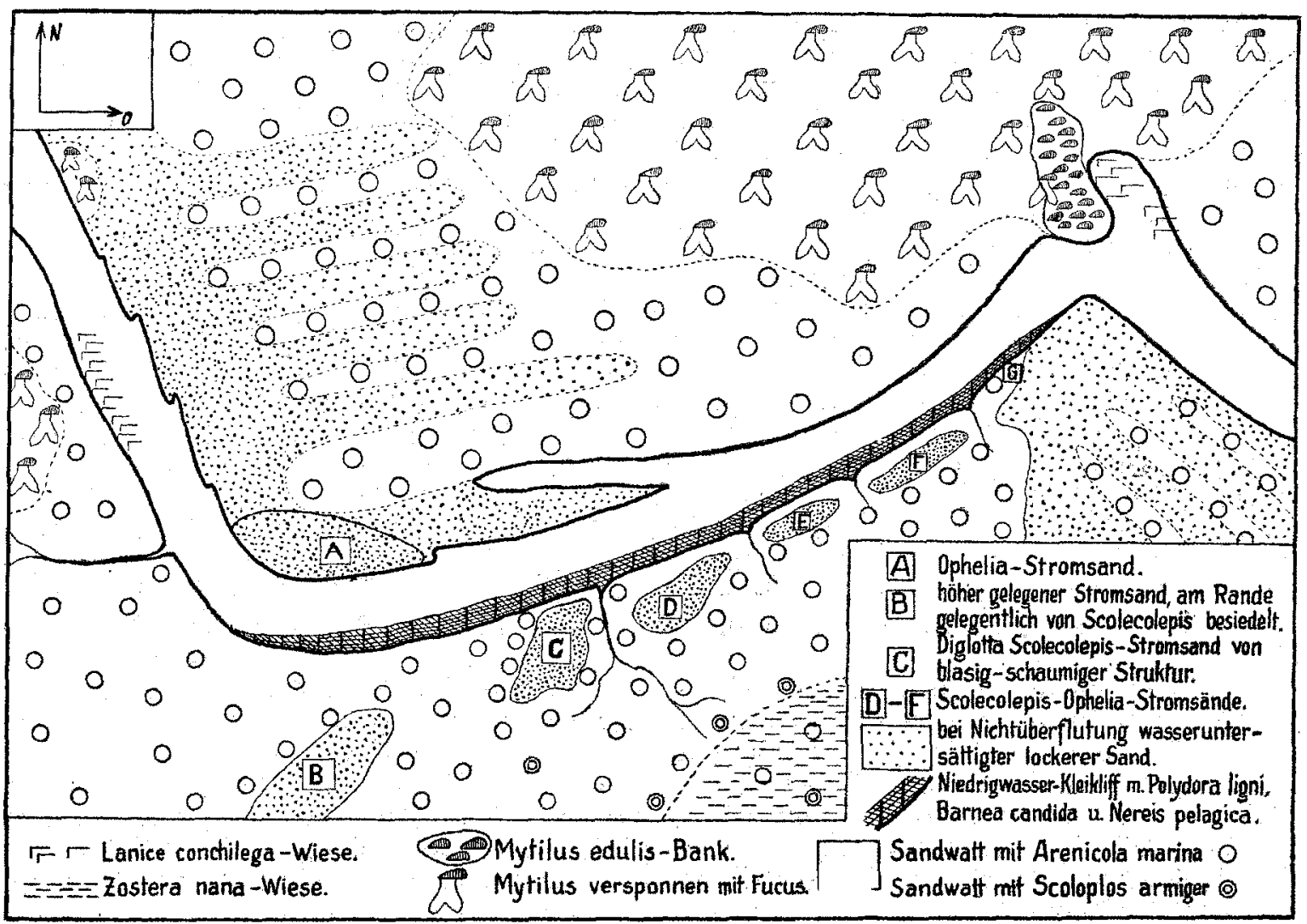

Abb. 58. Die Diglotta-Ophelia-Scolecolepis $=$ Stromsände an den Rändern des Hauptpriels.

hervorstechenden dynamischen und bodenphysikalischen Eigenschaften müßte man nach den biocoenotischen Gesetzen über spezialisierte Biotype eine zwangsläufig damit einhergehende Einseitigkeit in der Besiedelung erwarten, was dureh das hier folgende Besiedelungsbild bestätigt wird.

Tabelle 17.

Bestandsaufnahme: Stromsand A (Abb. 58.)

\begin{tabular}{|c|c|c|}
\hline Station: & $A_{1}$ & $A_{2}$ \\
\hline $\begin{array}{l}\text { Ophelia cluthensis }) \\
\text { Scolecolepis squamata }\end{array}$ & $\begin{array}{l}76 \\
24\end{array}$ & 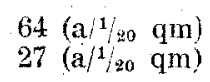 \\
\hline
\end{tabular}

Außer diesen beiden Würmern waren keine mit bloßem Auge sichtbaren Tiere zu finden.

1) Die Bestimmung der noch jungen Ophelia erfolgte nach FAUvel zuerst als O. limacina, obwohl die Artbeschreibung einige Lïcken hatte. Ende 1935 machte mich Herr A. C. STEPHEN vom Kgl. Schottischen Museum in Edinburgh auf eine neve, in der schottländischen Gezeitenzone gefundene Form aufmerksam. Nach MCGUIRE (46) handelt es sich um eine besonders durch die Zahl der Kiemen und Segmente von $O$. limacina unterschiedene Form, die als $O$. cluthensis neu beschrieben wurde. Nach frdl. Nachbestimmung meiner Sylter Ophelia-Stücke ordnet STEPHEN sie ebenfalls der neubeschriebenen Art $O$. cluthensis zu. 
Scolecolepis ist ein typischer Bewohner von unruhigen Außenzonen (vergl. auch Mortensen, 49), und Ophelia besiedelt nach HAGMEIER (21) vorwiegend reinen und groben Sand.

Die ausschließliche Besiedelung des besprochenen Sandes durch Ophelia und Scolecolepis führt uns auf zwei Begriffe der biocönotischen Forschung: Auf die Artenarmut und auf den Individuenreichtum, und es ist hier an den 1918 von THIENEMANN (81) ausgesprochenen Satz "Je mehr sich die Lebensbedingungen eines Biotops vom normalen und für die meisten Organismen Optimalen entfernen, umso artenärmer wird die Biocönose, um so gleichförmiger und um so charakteristischer wird sie, in um so größerem Individuenreichtum treten die einzelnen Arten auf" zu erinnern. Was dieser Autor und später andere (Hesse (28), Friederichs (18a)) von der Spezialisierung eines Biotops und deren Wirkung auf seine Besiedelung sagen, das trifft für den Ophelia-Sand voll und ganz zu.

Dieser Stromsand A, der an sich allen Wattieren zugänglich und für die Besiedelung offen ist, der täglich mit sauerstoffhaltigem und gewiß nicht nährstoffarmem Wasser umspült und überflutet wird, der in den lebenswichtigen oberen Schichten kein giftiges Schwefeleisen enthält, ist in der Tat verarmt. Die Lagerungsunbeständigkeit der oberen Schichten ist der stärkere Faktor, dem sich die anderen unterordnen müssen. Selbstverständlich tragen die ,anorganische Reinheit“ und vor allem die bei Nichtüberflutung vorhandene Wasseruntersättigung ihren Teil zur Verarmung bei, aber die Faktoren der Struktur und der Beweglichkeit spielen die größere Rolle.

Ophelia und Scolecolepis sind offenbar als einzige Vertreter der Königshafen-Fauna dieser Entfernung vom "Normalen" gewachsen, ja, nicht allein gewachsen, sondern besiedeln den Standort in größerer Zahl. (Ueber die Ernährungsweise von Scolecolepis vergl. S. 81).

\section{c) Die Miesmuschelbänke am Nordufer des Priels*}

aa) Lage und Aufbau.

Vom Ophelia-Stromsand weiter am Prielufer entlang nach Osten wandernd, findet man die Eintönigkeit des den Priel begleitenden Arenicola-Sandwatts durch die beiden Muschelbänke unterbrochen. Die erste, innere, liegt am Knie vom III. zum IV. Prielabschnitt, die zweite, äußere, liegt an der Mündung des Priels. Eine gedachte Verbindungslinie zwischen dieser äußeren Mytilus-Bank und der Ortschaft List deckt sich ungefähr mit der äußersten östlichen Grenze des Königshafenwatts. Beide Bänke haben sehr viel Gemeinsames. Sie liegen mit steilem Abfall unmittelbar am Priel und zwar beide an stark umströmten Stellen, die bei nittlerer Ebbetide selbst im kleinen Ruderboot ein tüchtiges In-die-Riemen-legen notwendig machen, wenn man ein paar Meter gegen den Strom gewinnen will. Ich erwähne das nur, um den ungewöhnlichen Standort mit wenigen Worten zu charakterisieren. Die Größe der Bänke ist ungefähr gleich. Die äußere liegt in S-förmiger Kurve mit der Längsachse senkrecht zum Priel und ist auch bei Niedrigwasser, wo sie 60 bis $70 \mathrm{~cm}$ über den Wasserspiegel emporragt (so auch die innere Bank), allseitig von Wasser umgeben, während die innere Bank nordwärts auf das stets trockenfallende Watt ausläuft. Schon aus diesem Grunde hat die äußere Bank eher bankartigen Charakter als die innere. Des Raumes wegen beziehen sich die folgenden Angaben über Besiedelüng usw. allein auf die äußere Bank. Das zuerst auffallende Gemeinsame ist der dunkel-olive Saum von Fucus, der diə Bank bis in größere Wassertiefen umkleidet. Bei beịden Bänken läßt der Tang die höhergelegenen tischförmigen Flächen unbesiedelt. Kraß wirkt der Farbunterschied. Die mittleren Flächen erscheinen nicht mehr blau durch die Miesmuschel sondern grau und weiß durch den überaus dichten Balanus-Bewuchs. Im Gegensatz zu dem im inneren Königshafen vorkommenden Fucus, der in gleicher Weise mit den Muscheln verankert aber hellbraun und brüchig ist, ist dieser dunkel und sehr elastisch. Von dem darunter liegenden dichten Muschelpelz ist nichts za sehen. Nimmt man die Algen beiseite, so bedecken die Muscheln, dicht aneinander gepackt, mit sehr weichem, schwarzblauem, halbflüssigem Schlick (Mudd) in den Lücken den Abhang der Bank. Im Fucus-Bereich feblen die Seepocken gänzlich.

Besonders nach Stürmen und höheren Wasserständen, wenn die Strömung vor den Bänken sehr stark ist, drängt sich die Frage auf, vermag sich die Bank nur durch ihren dichten Muschelbesatz hier draußen am harten Strom der Prielmündung zu halten oder hat sie darüber hinaus unter sich einen standbaften Kern. Hierüber wird nur eine Bohrung entscheiden können. Unter der etwa $10 \mathrm{~cm}$ starken lebenden Muschelschicht lag eine 3 bis 5 em dicke Schicht aus tief blauschwarzem, muddigem Schlick. Er enthielt viele 
Schalenbruchstücke der Miesmuschel. Darunter folgten bis zu einer Tiefe von $50 \mathrm{~cm}$ abwechselnd Schichten von grobem und ebenfalls dunkel pigmentiertem Sand mit Schill aus Mytilus und Litorina iitorea. Schlieflich folgten noch gröbere braune Sande mit zahlreichen 4 bis 6 -cm großen Geschieben. Angesichts der zahlreich vorhandenen größeren Steine kann man nicht mehr von einem regelrechten Wattsediment sprechen.

\section{bb) Die Epifauna der Muschelbänke.}

Ich habe bereits auf den sehr starken Bewuchs der mittleren, höchstgelegenen Teile durch Balanus und auf das voliständige Fehlen des Bewuchses innerhalb der mit Fucus dicht bedeckten Randgebiete hingewiesen. Bevor ich auf den Miesmuschelbestand selbst eingehe, führe ich die auf einer Fläche von $1 / 20 \mathrm{qm}$ gesammelten Tiere an.

Aeußere Miesmuschelbank (ohne Fucus).

Aufer Mytilus mit Balanus (vergl. unten) wurden gefunden:

$\begin{array}{lr}\text { Litorina litorea } & 13 \\ \quad \text { obtusata } & 8 \\ \text { Iaera marina } & 1 \\ \text { Gammarus zaddachi } & 12 \\ \text { Chiton marginatus } & 1 \\ \text { Gattyana cirrosa } & 1 \\ \text { (nach Stürmen: Eupagurus, Buccinum). }\end{array}$

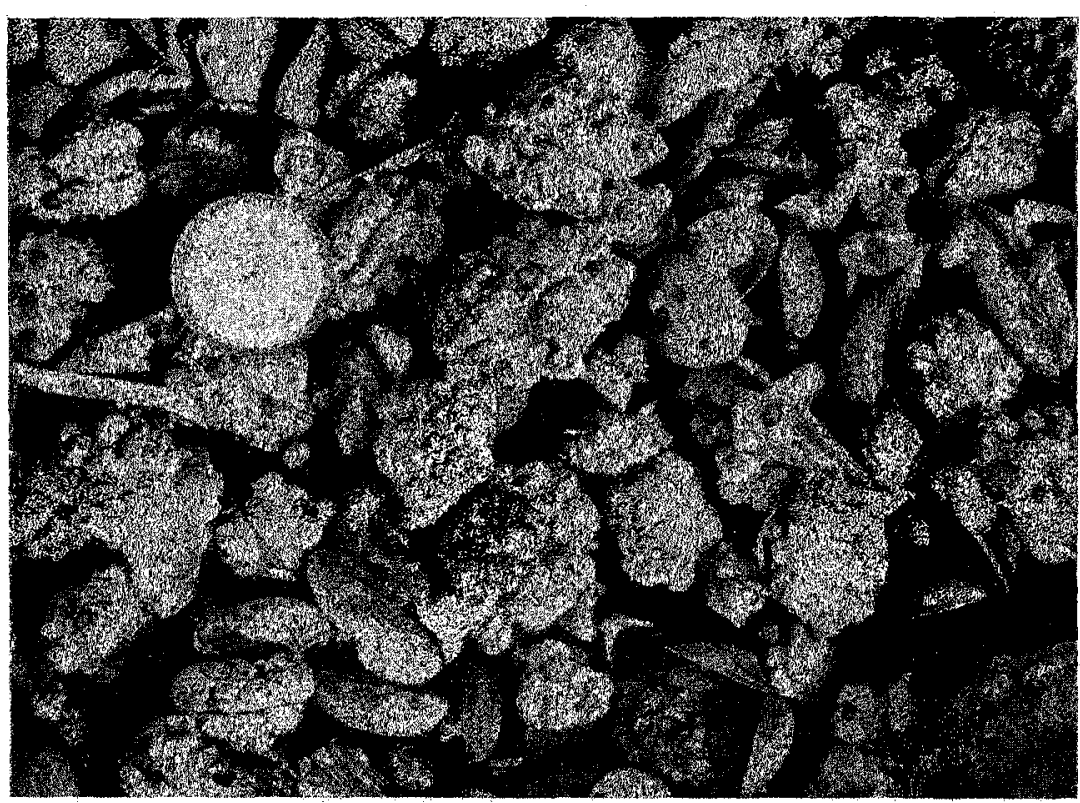

Abb. 59. Nur die nicht mit Fucus bewachsenen Teile der Bank sind außerordentlich dicht mit Balarus balanoides bewachsen. Man sieht auferdem Geschiebe und viele leere Schalen und Klappen.
Diese Art der Zusammensetzung der Epifauna spricht im Grunde eher für den Charakter eines dauernd überfluteten als für den eines regelmäßig trockenfallenden Standortes. Aber die angeführten Tiere halten sich während der

Nichtüberflutung in Nischen und Verstecken des dichten Muschelgespinstes auf, die ihnen das Abwarten der erneuten Uẻberflutung ohne Gefahr ermöglichen.

Abb. 59 zeigt außer der dichten $B a$ lanus-Besiedelung die Lagerung der großen Muscheln." Die Regellosigkeit täuscht mehr Steine und Klappen als lebende Muscheln vor. Die Bestandsaufnahme sagt darüber anders aus.

\section{IX. 1932}

Tabelle 18.

Besiedelung der äußeren Bank, Stat. 1 bis 4 je $1 / 20 \mathrm{qm}, 20 \mathrm{~cm}$ tief.

Stat. Nr. 1 und 2 a. d. mit Fucus bedeckten Randzone

Stat. Nr. 3 und 4 a. d. Fucus-freien, mit Balanus bewachsenen höheren Teil d. Bank.

\begin{tabular}{lrrrr}
\hline \hline Station: & 1 & 2 & 3 & 4 \\
\hline Anzahl Mytilus & 98 & 210 & 160 & 212 \\
Gewicht Mytilus & $1.337 \mathrm{~g}$ & $1.583 \mathrm{~g}$ & $1.585 \mathrm{~g}$ & $2.940 \mathrm{~g}$
\end{tabular}

Mit Ausnahme von Station 4 weicht das Gesamtgewicht (außer Klappen, Schalen, Steinen und Litorinen) trotz ungleicher Besiedelungsdichte nicht sehr voneinander ab. 
Station 4 weicht von den andern sowohl im Gesamtgewieht als auch in der Gröbenzusammensetzung ab. Es sind durchweg große Muscheln von 40 bis $60 \mathrm{~mm}$ Länge und über $25 \mathrm{~mm}$ Dicke. Hierzu kommt ein sehr dichter Balanus-Bewuchs, der an dieser Station bis zu $45 \%$ des Muschelgewichtes betrug. Beim Betrachten des Muschelpelzes im Querschnitt ergab - sich regelmäßig eine Schichtung derart, daß an der Oberfläche die großen Muscheln, die Klappen und Schalen einschließlich Litorinen vorhanden waren und die mittleren und unteren Schichten von kleineren Individuen eingenommen wurłen. Eine gute Vorstellung von dem dichten Muschelbesatz ergab das Nebeneinanderlegen . sämtlicher Muscheln. Sie bedeckten nicht weniger als $2750 \mathrm{qcm}$, mithin das Fünfeinhalbfache der ihnen am natürlichen Standort zur Verfügung stehenden Fläche $(1 / 20 \mathrm{qm})$. Diese starke Besiedelung ist nur bei außerordentlich günstigen Ernährungsbedingungen denkbar, die durch die unmittelbare Lage der Bank am Hauptpriel gegeben sind.

cc) Die Endofauna der äußeren Bank.

Das am freien Standort durchgeführte Aussieben hatte keinen Erfolg. Entweder waren die Tiere wegen des großen Siebrestes an Schill überhaupt nicht zu finden oder sie wurden beim Sieben durch den scharfen Schill zerstört. Es wurden daher mit dem weichen schwarzblauen Schlick in großen Glasbehältern Kulturen angesetzt. Es dauerte länger als einen Tag, bevor sich das überaus feine Sediment gesetzt hatte. Mit der Ablagerung einher ging die Ausscheidung elementaren Schwefels, wodurch das Sediment hinreichend gekennzeichnet sein dürfte. Der Versuch lohnte die aufgewandte Mühe. Auf $1 / 20$ qm Ausgangsfläche wurden nach 3 Tagen Sedimentationsrube gezählt:

\section{Colobranchus ciliatus 2 \\ Peloscolex benedeni 18 ,}

also Arten, die uns aus der Fucus-Mytilus-Wattzone vor dem Gröning bereits bekannt sind. In anderen Proben war Capitella capitata regelmäßig vorhanden (Abb. 60), Capitella gehört ja auch im sauerstoffarmen Schlamm des Schwarzen Meeres zu den Tieren, die den größten Gehalt an $\mathrm{H}_{2} \mathrm{~S}$ (bis $20,4 \mathrm{~cm}^{3} \mathrm{H}_{2} \mathrm{~S} / \mathrm{l}$ ) ertragen können (JACUBOWA und MALM, 30). Die charakteristische Zusammensetzung der Epi- und Endofauna weist somit auf die unmittelbare Nachbarschaft eines sauerstoffreichen und eines sauerstoffarmen Lebensraumes hin.

Der Abhang zum Priel ist bei beiden Bänken sehr steil und vollștändig mit Schalen, Schill und Steinen be deckt. Das Prielbett hat hier mit über $2,00 \mathrm{~m}$ unter MNW seine größten Tiefen. Im Bett selbst wachsen zwischen der inneren und äußeren Bank ziemlich dichte Bestände von über $3 \mathrm{~m}$ langen Chorda Filum, die an Mitilus - und Austernschalen verankert sind und an der Sprobspitze fast immer einen Polysiphonia-Büschel tragen. Ein paar hundert Meter unterhalb der äußeren Bank liegt eine Barre vor dem Priel, so daß man hier bei außergewöhnlich niedrigen Wasserständen (Sturm aus Ost, am 12. IV. 1934) zum Ellenbogenstrand waten kann.

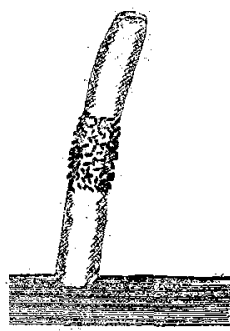

Abb, 60 .

Wohnröhre von Capitefla capitata aus feinstem Mudd, Schleim ind Kotperlen. Das obere Ende der Röhre ragt frei in das Wasser. (Juli 1933 in einer Kultur mit Mudd vom natïrlichen Standort).

\section{d) Das Südufer der Prielabschnitte III und IV.}

Beide Abschnitte unterscheiden sich am südlichen Prielufer auf den ersten Blick einerseits durch ihr Gefälle zum Priel und andrerseits durch die Oberflächenformen der den Priel begleitenden Wattflächen.

Vom Prielbett IV an ostwärts deutet die Wattoberfläche in ihrer ganzen Breite bis an die Insel Uthörn heran auf starke, täglich erfolgende Umlagerungen hin. Reines Sandwatt mit ausgesprochenen Rip eln; Trögen und Strömungsbänken begrenzt mit kaum wahr* nehmbarem Gefälle den letzten Prielabschnitt. Es ist die Tellina tenuis-Zone. Ganz anders ist dagegen die Uferzone des dritten Prielabschnittes. Ein gut besiedeltes; stets gut durchfeuchtetes Arenicola-Scoloplos-Watt tritt mit deutlichem Gefälle an das Prielbett heran. Ein pàar Meter von der Niedrigwassergrenze entfernt wird das Arenicola-Watt durch hellfarbige, schwach gewölbte Flächen unterbrochen. Es sind Stromsä nde, dỉe in reìhenförmiger Anordnung den ganzen Prielabschnitt III begleiten (vergl. Abb.58,B-F). Eine weitere 
Eigentümlichkeit des III. Abschnittes ist das Niedrigwassen-Ufer selber. Allerdings tritt sie beim gewöhnlichen Niedrigwasser nicht in Erscheinung. Beim Baden warde ich zum erstén Mal darauf aufmerksam, später dienten die Ostwindwetterlagen mit ihren ungewöhnlichen Wasserständen zur näheren Untersuchung. Es zeigte sich, daß das Ufer des III. Abschnittes in seiner ganzen Länge von einem steilen, $50-70 \mathrm{~cm}$ unter dem gewöhnlichen Niedrigwasserspiegel ansetzenden und wandartig abfallenden Kliff, das oben auf S. 6 beschrieben wurde, gebildet wird. Diesem und der vorher beschriebenen Kette von Stromsänden will ich mich nummehr zuwenden.

\section{aa) Die Stromsände.}

Die lănglich ovale Form und die schwache Wölbung treten am besten im Augenblick der Ueberflutung in Erscheinung und die Beschaffenheit ihres Sedimentes am besten beim Hinüberschreiten. Abb. 61 läßt Form und Oberfläche des Stromsandes C (vergl. auch Abb. 58) gut erkennen. Der Apparat steht südlich vom Stromsand auf dem Arenicola-ScoloplosWatt in ganz flachem Wasser. Wenige Minuten nach der Aufnahme wurde der Sand überflutet. Die Umgebung der Sände ist dunkel, fest und mehr oder weniger dicht mit den Kotringeln des Sandwurms bedeckt. Die Sände dagegen sind hell und die oberen Schichten locker gelagert. In der Umgebung tritt das schwarzblaue Pigment bereits $1 \mathrm{~cm}$ unterhalb der Oberfläche auf, auf den Sänden dagegen erst bei einer Tiefe von 6 bis $12 \mathrm{~cm}$. Eine

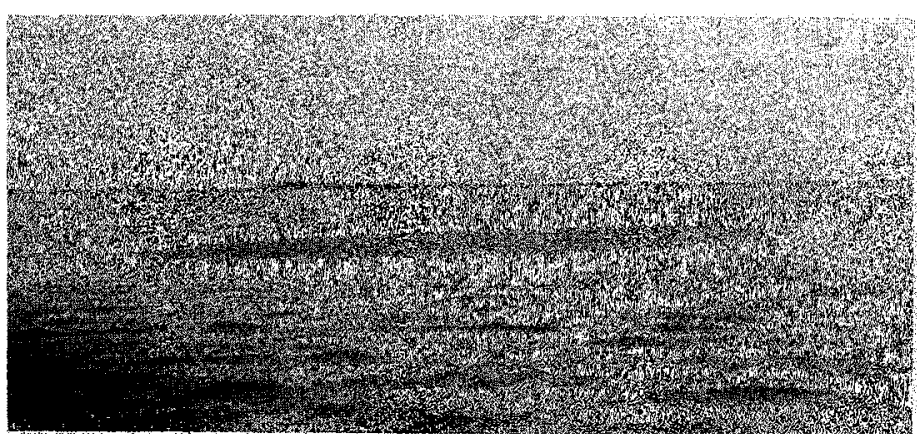

Abb. 61. Wer Ofglotta-Scoleoolepls-ophelta-Stromsand an großen Phel kurz vor der Ueberflating. In Hintergrund die Ellenbogen-Dinen mit dem Leucliturm ostfener. weitere Eigenart der Stromsände am III. Prielabschnitt liegt in der Struktur ihrer Sedimente. Es handelt sich nämlich nicht um locker gelagerten Sand schlechthin, sondern um lufterfüllte Schichten, die in weehselnder Stärke zwisehengelagert sind und in Stromsand $\mathrm{C}(\mathrm{Abb}$. 58 und 61 regelrecht als Porenluft ho rizont ausgebildet sind. In den meisten Fällen setzt diese Schicht 2 bis $3 \mathrm{~cm}$ unter der dichter gelagerten Oberfläche ein und kann bis zu $8 \mathrm{~cm}$ Mäehtigkèit erlangen. Diese vom uingebenden ArenicolaSediment sehr abweichenden Verhältnisse machen sieh auch in der Besiedelung bemerkbar. Während das allmälich zum Ptiel abfallende Watt vorwiegend von Arenicola und SeOloplos armiger und ferner von Cardium edule, Nereis diversicolor und Nephthys Hombergï besiedelt ist, beschränken sich die Stromsände (Abb. 58, Sand B, D, E u. F) umso mehr auf Scolecolepis und Ophelia clathensis je unbeständiger und ausgewaschener, d. h. Je freier von Faulnisstoffen ihr Sediment ist. Das unbeständigste Gebiet liegt bei G. Es ist ein höherer Sandrücken, der von starken Flutströmen nach Westen gedrückt wird. Hier fand ieh genau wie in Ophelia-Sand (Abb. 58, A. vergl. S. 71) nur Scolecolepis und Ophelia. Eine Ausnahme macht der Stromsand C.

\section{bb) Der Diglotta-Scolecolepis-Ophelia Stromsand.}

$$
\text { a) Das Sediment. }
$$

Dieser Sand (Abb. 58, C.) liegt ebenso wie die andern, soeben besprochenen Sände auf dem Arenicola-Scoloplos Watt einige Meter von der Prielkante entfernt. Seine meistens glatte oder von Rippelmarken gefurchte Oberfläche ist heller und liegt etwas höher als die der östlich gelegenen Sände $\mathrm{D}-\mathrm{F}$ und etwas tiefer als der westlich gelegene B. Wie zwischen den anderen Sänden, läuft auch zwisehen $\mathrm{C}$ und D eine kleine Rinne zum Priel hinunter. Manchmal erscheint an der Oberfläche ein Kothäufehen von Arenicola. Es handelt sich offenbar um verschlagene Tiere, die am Tage darauf meistens schon nicht mehr feststellbar sind. Schreitet man über C hinweg, sobald der Sand eben überflutet ist, so bricht viel Luft von unten durch, Sie entströmt dem beim Hinüberschreiten in seiner Lagerung gestörten Sand. 
Der Anteil der Koingrößengruppen beschränkt sich nach den beiden untenstehenden Biockdiagrammen (Diagr. 15 u. 16, Abb. 63) zur Hauptsache auf zwei Gruppen, nämlich whisehen 1,00 und $0,25 \mathrm{~mm}$ Durchmesser. Vom Gröberen (bis $2,00 \mathrm{~mm}$ ) und vom Feineren (bis $0,10 \mathrm{~mm}$ ) war nur wenig vorhanden. Aehnlich wie bei A (vergl. S. 71) liegt also wohl infolge der am Standort herrschenden Wasserbewegung eine weitgehendeVerarmung an verschiedenen Korngrößen und damit also eine typische Strombank vor. Der mit Diagr. 15 dargestellte Sedimentkern wurde bei Niedrigwasser, etwa 2 Stunden nach Trockenfallen entnommen, Diagr. 16 dagegen sogleich nach dem Troekenfallen des Sandes. Der Vergleich des Wassergehaltes beider Proben läßt erkennen, dab die oberen untersuchten $10 \mathrm{~cm}$ des Sediments mehr als $40 \%$ ihres Wassers während der Ebbe, bezw. der Zeit der Nichtüberflutung, verloren haben. Die Frage nach dem schnellen Verbleib des Wassers ist durch die Lage der Bank (Gefälle nach allen Seiten) und durch die Grobkörnigkeit des ausgewaschenen Sandes, der das Wasser schnell abwärts führen kann, leicht geklärt. Ein geringer Teil mag auch durch Verdunstung verloren gehen. AufjedenFallist das

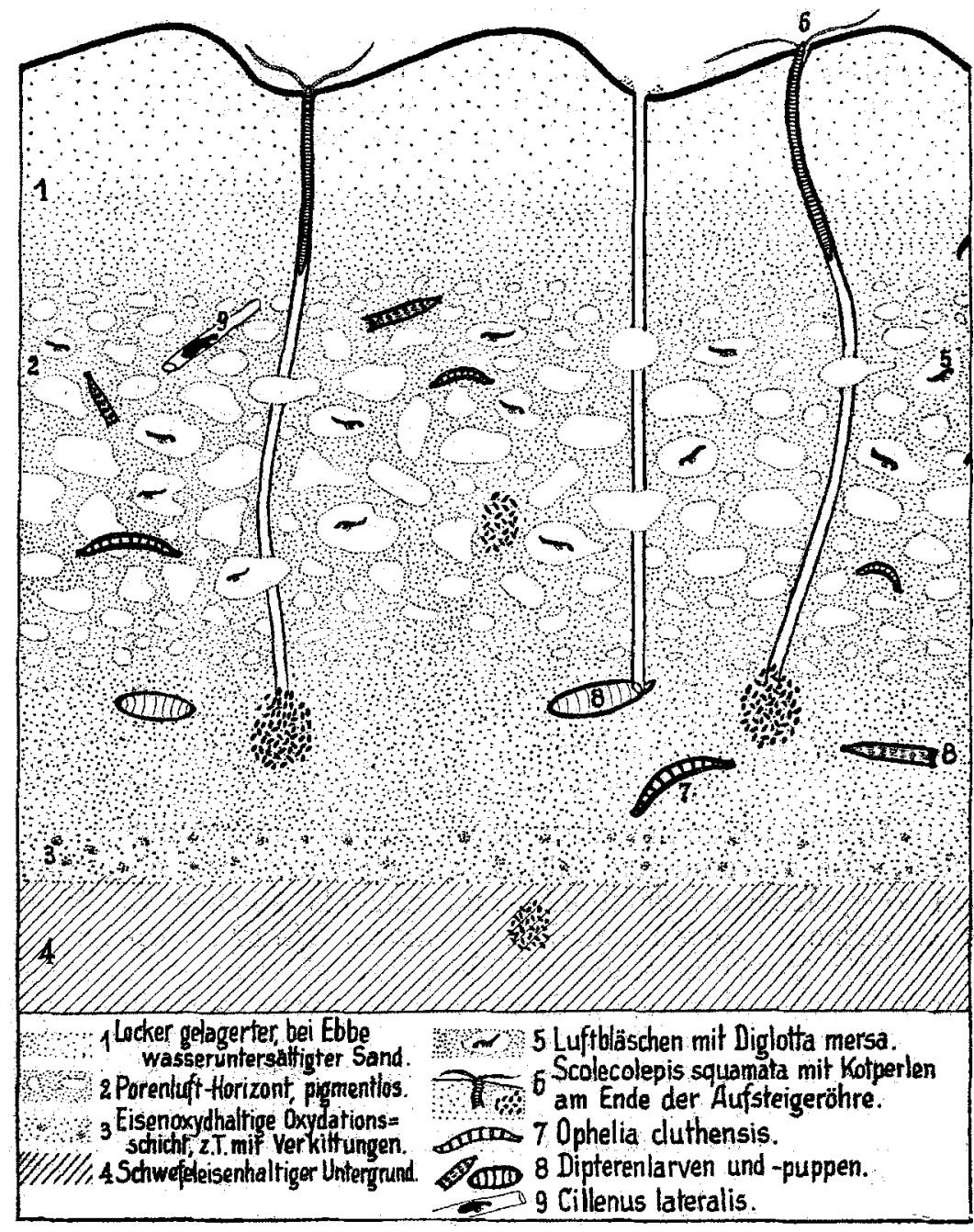

Abb. 62

Gefüge und Besiedelung des Diglotta-Scolecolepis-Ophelia-Stromsandes. Sediment gerade bezüg-

lich der Wassersättigung durch große Gegensätze ausgezeichnet, was für die ökologische Bewertung des Standortes hervorzuheben ist.

Der Porenluft-Horizont, wie ich diese Schicht hellen lockeren Sandes von blasig-schaumiger Struktur genannt habe, ist auf der C-Bank mit $8 \mathrm{~cm}$ Mächtigkeit umfangreicher als auf allen andern benachbarten Strombänken. Am gebrochenen Sediment sind die einzelnen Luftkämmerchen gut zu erkennen (Abb. 62). Sie haben meistens runde oder ovale Form und erreichen vereinzelt Durchmesser bis zu 6 und $7 \mathrm{~mm}$ in der Wagerechten. Unter diesem Porenlufthorizont folgt eine dichter gelagerte Schicht von grauem, grobem Sand, die nach unten von einer dünnen braunen Oxydationssehicht und schlieflich von blaugrauem Sand $\left(\mathrm{FeS}_{2}\right)$ begrenzt wird. Da der Stromsand $\mathrm{C}$ eine von allen andern ähnlichen Standorten abweichende

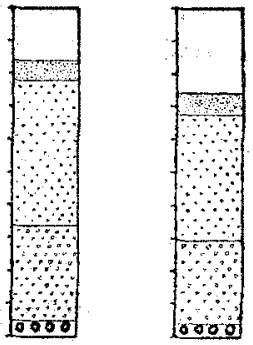

Abb. 63.

Diagramm 15 und 16 Diglotta-ScolecolepisStromsand

15: Stromsand $\mathrm{C}$ bei $\mathrm{NW}$

16: Stromsand $\mathrm{C}$ sogleich nach dem Trockenfallen. 
Besiedelung aufwies, versuchte ich, die Porenluft quantitativ zu bestimmen. Mein Arbeitsprogramm ließ es nicht zu, für die genauere Analyse einen Hilfsapparat ${ }^{1}$ ) anzufertigen. Ich ging daher in der einfachsten Weise vor. Ein beiderseits offener, mit einer Einteilung versehener Zylinder (gewöhnlicher Lampenzylinder) wurde jedesmal so tief in das Sediment hinabgedrückt, bis die $30 \mathrm{ccm}$-Strichmarke erreicht war. Am unteren Ende verschlossen, wurde die ganze Probe mit Wasser angefüllt und geschüttelt. Nachdem sich der Sand gesetzt hatte, wurde ein paar Mal hart gestoßen und der neue Stand im Zylinder mit dem ersten verglichen. War Luft im Sediment vorhanden gewesen, so mußte das neue Volumen - nach Verdrängung der Luft durch das Wasser - um so viel weniger betragen, als vorher Luft im Sediment vorhanden gewesen war. Auf diese Weise wurde das Sediment des Stromsandes C mit dem des benachbarten Arenicola-Watts verglichen. Die gemessenen Werte sind in der folgenden Tabelle einander gegenübergestellt.

Tabelle 19.

\begin{tabular}{|c|c|c|c|c|}
\hline \multirow{2}{*}{ Probe: } & \multicolumn{2}{|c|}{ Stromsand C } & \multicolumn{2}{|c|}{ Arenicola-Watt } \\
\hline & natürlich : & sedimentiert: & natürlich: & sedimentiert: \\
\hline 1 & $30 \mathrm{cem}$ & $27 \quad \mathrm{ecm}$ & $30 \mathrm{ccm}$ & $29,0 \mathrm{ccm}$ \\
\hline 2 & $30 "$ & $25,0 \quad \%$ & $30 \quad$ & $29,5 \Rightarrow$ \\
\hline 3 & 30 & 27,0 & 30 & 28,5 \\
\hline 4 & 30 & 24,5 & 30 & 29,0 \\
\hline 5 & 30 & 28,0 & 30 & 30,0 \\
\hline 6 & 30 & 27,0 & 30 & 29,5 \\
\hline 7 & 30 & 26,0 & 30 & 30,0 \\
\hline 8 & 30 & 26,5 & 30 & 29,0 \\
\hline 9 & 30 & 27,0 & 30 & 30,0 \\
\hline 10 & 30 & $25,5 \quad$ & 30 & 30,0 \\
\hline $1-10$ & $300 \mathrm{cem}$ & $263,5 \mathrm{ccm}$ & $300 \mathrm{ccm}$ & $294,5 \mathrm{ccm}$ \\
\hline & Schwand & $2,2 \%$ & Schwund & \\
\hline
\end{tabular}

Der Unvollkommenheit dieser rohen und schnellen Feldmethode bin ich mir wohl bewußt. Die gewonnenen Zahlen sollen auch keinen absoluten Meßwert sondern lediglich einen Vergleichswert darstellen und nur als solcher zur Kennzeichnung des Sedimentes des Stromsandes gegenüber dem normalen Wattsand dienen.

Wie in vielen anderen Fällen, kommt es auch in diesem nicht darauf an $\mathrm{zu}$ wissen, ob etwa $11,5 \%$ oder $13,0 \%$ Luft im Sand vorhanden sind, sondern es geht m. E, darum, aus der Gruppe von Faktoren, durch die jeder Standort ausgezeichnet zu sein pflegt, de njenige $\mathrm{n} z u$ ermitteln, der vor allen andern dem Standort sein besonderes, einmaliges Gepräge gibt. Das glaube ich, mit der Gegenüberstellung getan und damit das umgebende Arenicola-Watt als praktisch luftleer und den Diglotta-Sand als luftgefüllt dargelegt zu haben.

$$
\text { 3) Die Besiedelung. }
$$

Als ich am 25. Juni 1933 die Kette der Stromsände entdeckte, fielen mir auf dem Sand $C$ winzige Krümelhäufchen auf. Beim Betrachten der Wattoberfläche aus der Nähe bemerkte ich Cillenus lateralis und außerdem eine Anzahl winziger schwarzer Käfer. Die letztgenannten waren Diglotta mersa Halid. Das Aussieben hatte folgende Ergebnisse:

Tabelle 20.

29. Juni 1983. 1/20 qm.

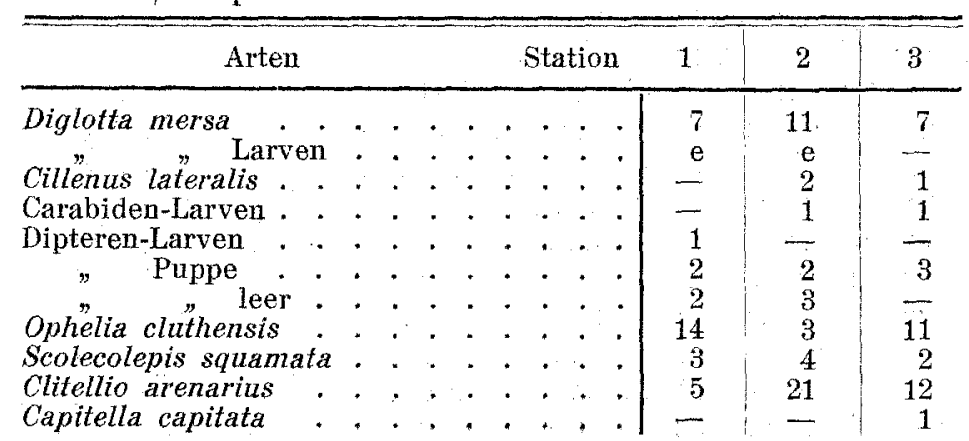

1) Leider war mir der von SIEGRIST (70) beschriebene Apparat zur Bestimmung der Luft- und Wasserkapazität noch nicht bekannt. 
Das ist auf den ersten Blick eine überraschende Zusammensetzung, wenn man Mutrogen die Besiedelung des unmittelbar benachbarten Watts betrachtet (vergl, unten能(thende Tabelle 21).

In der Skizze, Seite 77 Abb 62 , habe ich die eigenartige Struktur des Sedimentes und die Gruppierung einiger Organismen schematisch angedeutet. Besonders auffallend Find de senkrechten, leicht zusammenfallenden Röhrén, die auf die aus der Puppenhülle sehlupfende Fliege zurückgehen. An der Oberfläche ist kurz nach dem Ausschlüpfen ein wenig Sand um das Loch herum aufgeworfen, und am Ende der Röhre befindet sich die levere Hülle mit geöffnetem Deckel (in der Mitte bei 8 ).

Ferner durchlaufen die Aufsteigeröhren von Scolecolepis squamata; meistens aus den tieferen Schichten des Standortes kommend, in leichten Krümmungen das Sediment bis zur Oberfläche. - In dem sonst reingewaschenen Sand fielen hier und da dunkle Zonen auf. Es waren die Kotperlen von Scolecolepis, die am unteren Ende der Aufsteigeröhre abgelegt werden.

Tabelle 21.

Bestandsliste von dem den Diglotta-Stromsand unmittelbar umgebenden Watt, 29. Juni 1933 .

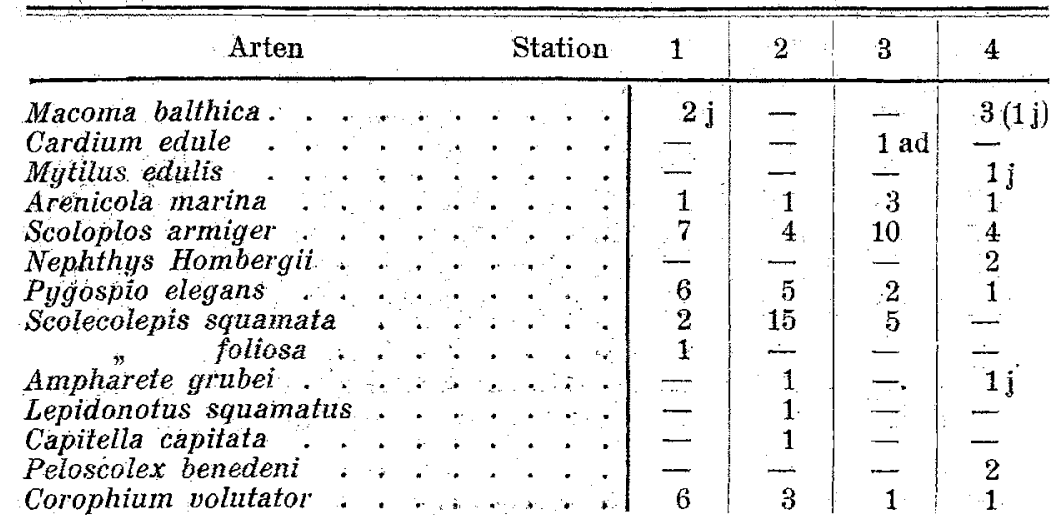

binterlassen.

Cillenus wurde beim Bau seiner Gänge angetroffen. Krümelhäufchen wurden seltener gefunden.

Beim vorsichtigen Auseinanderbrechen des lockeren Sandes konnte Diglotta mersa in den kleinen (allseitig ?) geschlossenen Hohlräumen des beschriebenen Porenlnfthorizontes nachgewiesen werden, und zwar nur dort. Da der Sand auseinanderfiel, waren feinere Einzelheiten schlecht zu beobachten. Ob zwischen den Hohlräumen Verbindungsgänge bestehen, habe ich nicht mit Sicherheit nachweisen können. Bemerkenswert scheint mir ein leichter Glanz zu sein, durch den sich die Wände der Bläschen auszeichnen. Diglotta versteht es, die Sandkörnchen geschickt mit den Mandibeln zu packen und fortzuschaffen, womit jedoch nichts über die Entstehung der Luftkämmerchen gesagt sein soll. Ich vermute, daf deren Entstehung anderen Ursachen zuzuschreiben ist, wenngleich Diglotta an ihrer Standhaftmachung beteiligt sein dürfte.

Am Westrand von Sylt und auf der Helogländer Düne bin ich diesen Frágen der Porenluft-Bildung nachgegangen. Auf Helgoland konnte ich dieselben Porenluftschichten im Brandungssand nachweisen. Die aus dem Brandungssand nach dem Zurücklaufen der Welle aufsteigenden Luftbläschen sind ja allgemein bekannt. Sie gelangen aber nur dann an die Oberfläche und zerplatzen, wenn ihr Auftrieb stark genug ist, den über ihnen ruhenden, dichter gelagerten Sand, die "hangende" Schicht, zu durchbrechen. Da diese Bedingung meistens nur für einen Teil der Bläschen erfiillt ist, bleibt der Rest unten. Im Helgoländer Hafengelände konnte ich zwei solcher Schichten übereinander feststellen. Ist ein solcher Porenluft-Horizont erst einmal stabil geworden, so vermag er sich lange zu halten. Tch möchte daher die Beständigkeit des Porenluft-Horizontes im Stromsand mit der Art der Wasserbewegung innerhalb des Sedimentes in $\mathrm{Zu}$ sammenhang bringen. Infolge des gut ausgeprägten. Gefälles wird das Wasser der 
oberen Schichten während der Ebbe nach und nach auf kapillarem. Weg nach unten fließen, wobei die kapilláren Bahnen die Bläschen umgehen, so daß diese erhalten bleiben.

Wovon sich Diglotta an diesem sandigen Standort ernährt, entzieht sich meiner Kenntnis, da ich keine Darmuntersuchungen gemacht habe. Nach KEMNER (35) frift die Larve pflanzlichen Detritus und Diatomeen. Wenn auch die Diatomeen sogar in dem reinen Sand vorhanden sind, so dürfte im Stromsand der Detritus keine Rolle spielen. Da unser Diglotta-Standort tief im Königshafen liegt und täglich insgesamt 8 bis 10 Stunden überflutet wird, führe ich einige abweichende Angaben tiber Standort und Verbreitung aus der Literatur an.

KENANER (35) sieht in der reichen Beborstung und in den starken Klauen sowie in dem mit zwei Haken versehenen Hinterleibsende der Larve eine Anpassung ,an die gelegentlich (!) ${ }^{1}$ ) submerse Lebensweise". Das thm vorliegende Exemplar stammte aus der Strandzone bei Esbjerg. Auch JoHANSEN (32, S. 284) gibt als Fundort für Diglotta „unter Steinen und Tang am Strand von Esbjerg“" an. Nach von LENGERken (43, S. 85) findet man Käfer und Larven „am Meeresstrand, auf Borkum auf dem etwas begrünten Watt. Unter Steinen, erheblich seewärts der Hochwassermarke. - Bei jeder Flut unter Wasser. Gelegentlich unter feuchtem Tang an der Flutmarke (BENICK)".

Unter diesen Zitaten ist keines, das einen Standort beschreibt, der meinem im Königshafen ähnlich ist, so daß man nicht recht weiß, ob es sich bei den zitierten Funden um ausgesprochene Diglotta-Biotope oder nur um gelegentliche Funde handelt.

Auch über die Lebensweise von Diglotta sind die Angaben in der Literatur überaus dürftig. Nur bei BENICK (3) finden sich einige Angaben über das pünktliche Eingraben der Käfer, so bald die Flut "noch 1 bis $1 \% \mathrm{~m}$ entfernt ist".

Meine Feststellungen bei verschiedenen Wetterlagen gehen dahin, daß Diglotta längst unter der Sandoberfläche in Sicherheit war, wenn das heraufkommende Wasser den Stromsand C (vergl. Abb. 61) umgab. Bis zur Ueberflutung verstrich dann meistens noch über $1 / 2$ Stunde. Ich habe versucht, durch Messung der Temperatur- und Wasserstandsschwankungen im Sediment Faktoren zu finden, die den Käfer gegebenenfalls zum rechtzeitigen Eingraben bewegen könnten.

Zunächst führe jeh einige Beobachtungsergebnisse über die Wasserstandsveränderung im Sediment kurz vor und im Augenblick der Ueberflutung an.

\section{Tabelle 22 .}

31. VII. 1933. Diglotta-Stromsand C.

Veränderungen des Grundwasserstandes während der Ueberflutung.

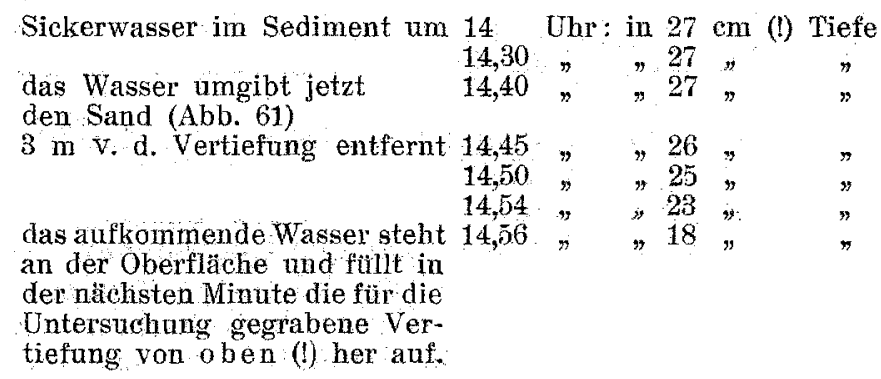

Die Beobachtungsreihe zeigt also, daß der Stromsand so schnell überflutet wird, daf das Wasser keine Zeit findet, von den Seiten her allmählich in das Sediment einzudringen, um von unten nach oben aufzusteigen, sondern im Augenblick des vollständigen Untertauchens besteht noch ein Gefälle von der Oberfläche des Sedimentes nach den tieferen Lagen. Es hat also den Anschein, als bestehe im Bereich der blasigen Schichten bei Ebbe wie bei Flut stets aur eine Strömungsrichtung in den kapillaren Bahnen, nämlich eine von oben nach unten gerichtete. Durch diese Art der Bestauung, der Sättigung und der Untersättigung (Ebbe) der Stromsandsedimente wird auch die Beständigkeit des Porenluft-Horizontes verständlich.

Danach ist also nicht anzunehmen, daß die an der Oberfläche herumlaufenden Käfer durch die möglicherweise vor der Ueberflutung bereits einsetzende, von unten aufsteigende Standortsfeuchtigkeit zum rechtzeitigen Eingraben ermahnt werden, denn das Sickerwasser im Sediment vermag ja in keiner Weise mit dem Bestaungswasser Schritt zu halten.

1) Vom Verfasser ausgezeichnet. 
Aufschlußreicher für die Klärung dieser Frage scheint mir das Studium der fomperaturkurven während der Ueberflutung des Stromsandes zu sein.

Ich maß die Temperaturen

a) der Luft, $10 \mathrm{~cm}$ über dem Stromsand

b) des Sedimentes, $6 \mathrm{~cm}$ tief im Sand

c) des Wassers, beim Ueberfluten des Stromsandes.

Die Meßergebnisse sind in dem nebenstehenden Kurvenbild (Abb. 64) wiederyegeben. Beim Beginn der Messungen (10 h $15 \mathrm{Min}$.) umgab das Wasser gerade den Stromsand (etwa wie in Abb. 61). Um 10 Uhr 42 wurde der Sand überflutet. Vom Beginn der Messungen an fällt die Luft-Temperatur leicht $a b$, un im Augenblick der Ueberflutung einen tiefen Sprung zu machen.

Die im Sediment gemessenen Werte sind bis zum Augenblick der Ueberflutung auffallend stabil. Erst beim Unterlaufen schnellen sie um einen Grad höher, jedoch nur für einen Augenblick, und nehmen nach 14 Minuten ihren alten Wert wieder ein.

Der erste den Standort überflutende Wassersaum hat beim Ueberfließen der erwärmten Wattflächen viel Wärme gespeichert (25 Grad). Das nachrückende Wasser aber fällt im Laufe einer halben Stunde um 4 Grad, also auf 21 Grad.

Wenn auch diese Werte noch nichts über die direkte Wirkung der mit der Ueberflutung $\mathrm{zu}-$ sammenhängenden Temperaturen aussagen, so bestärken sie doch in der Vermutung, daß, sobald der Königshafen mit neuem Wasser aus der offenen

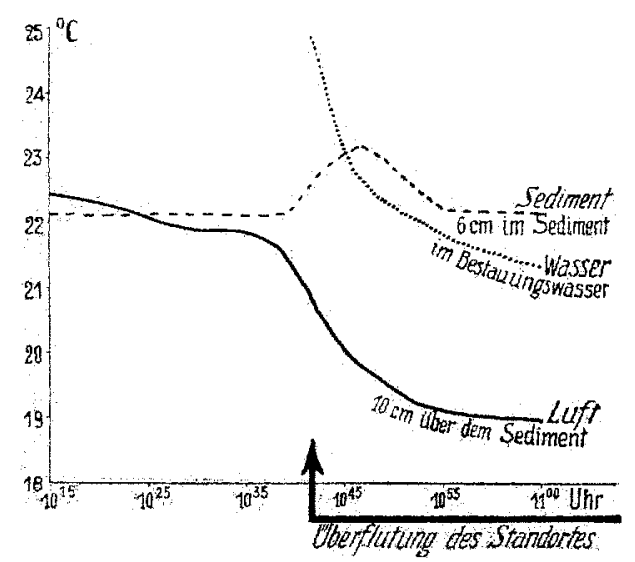

Abb. 64. Diglotta-Stromsand 6. VII. 1933. Temperaturverlauf während der Ueberflutung. See aufgefüllt wird, die Luft-Temperaturen im Gebiet ganz allgemein sinken. Es wäre denkbar, daß solche Veränderungen von den Stromsandbewohnern (Cillentus und Diglotta) wahrgenommen werden und sie alsdann die Tiefe aufsuchen lassen. Vielleicht aber wohnt den Tieren ein Tiderhythmus inne, denn auch des Nachts sah ich Diglotta und Cillenus auf der Oberfläche des Stromsandes umherlaufen. Wie sollten nämlich die Tiere nachts oder in den frühen Morgenstunden, wenn sich die Wasser- und Lufttemperaturen gelegentlich überdecken, also keine Unterschiede wahrzunehmen sind, durch äußere Einflüsse zum Eingraben veranlaßt werden?

Zum dauernden Bewohner des Stromsandes gehört neben Diglotta Cillenus lateralis. Auch die Larven sind ständig vertreten. Ebenso wie die Larven von Diglotta habe ich die Carabidenlarven nur im Sediment, nie an der Oberfläche, feststellen können. Cillenas hält den Diglotta-Bestand recht kurz. Beim Ueberqueren der Standortsoberffäche verzehrt Cillenus im Handumdrehen eine ganze Anzahl Diglotta kurz hintereinander.

Im Dezember fand ich keine Diglotta mehr auf dem Stromsand. Die ersten wurden am 7. April wiedergefunden bei einer Luft-Temperatur über dem Sediment von 10,750 und von $10^{\circ}$ in $7 \mathrm{~cm}$ Tiefe. Die Käfer waren trotz dieser Temperaturen in ständiger Bewegung. caesia Meig.

Bei den mit im Stromsand lebenden Dipteren-Larven handelt es sich um Lispa

Ueber die Ernährungsweise von Scolecolepis squamata, die mit zu den Bewohnern des Stromsandes gehören, gibt folgende Beobachtung Auskunft. Das erste, den Standort überflutende Wasser schob im Sommer einen breiten Saum von jungen Litorinen von etwa $0,7 \mathrm{~mm}$ Größe vor sich her. Beim Ueberfluten konnte ich beobachten, daß Scolecolepis in dem Augenblick, als das Wasser den Sand eben bedeckte, in ihrer Aufsteigeröhre an die Oberfläche kamen und ihre langen Tentakel fischend hin- und herpendeln ließen (Abb. 62). Im Darm der Würmer konnte ich nachher 6,8 ja bis zu 10 Litorina litorea aneinander gereiht nachweisen.

ce) Das Klei-Kliff im Prielabschnitt III.

Auf die Bedeutung der gefundenen tonigen Ablagerungen für die Geschichte des Königshafens habe ich auf S. 6 hingewiesen. Hier geht uns dieser Klei nur als Biotop an. 
a) Das Sediment.

Nach den bisherigen Feststellungen erstreckt sich das Klei-Kiff über das ganze südliche Ufer vom Abschnitt III. Auf Abb. 58 ist es als AuBenkurve kenntlich gemacht. Begreiflicherweise findet der Strom im Ton ein sehr beharrliches Widerlager.

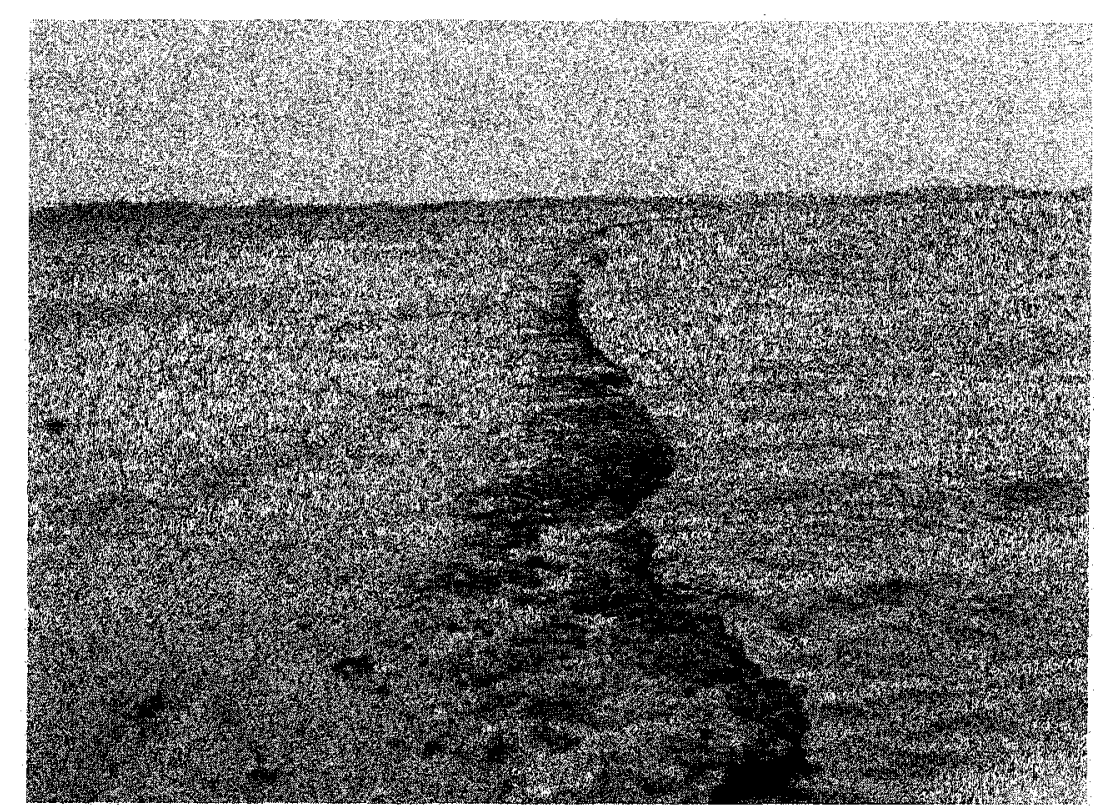

Abb. 65. Das Niedrigwasserkliff des Königshafenpriels wird nur bei außergewöhnlich niedrigen Wasserständen (Sturm aus Ost) sichtbar Eine fette Kleikante fällt $1 \mathrm{~m}$ steil, dann in Terrassen zum Prielbett ab und bildet in diesem II. Abschnitt des Priels ein tabes Widerlager gegen die in der Außenkurve vorhandene Strömung Im Hintergrund die hohen Dünen von List-Land. (Besiedelung des Kliffs siehe unten).

Die photographische Abbildung 65 hält den selten vorkommenden Fall des Trockenfallens fest. Bei einein kurzen Aufenthalt in List, am 12. April 1984, gelang es mir, während eines Ost-Sturms das Kliff in seiner ganzen horizontalen Ausdehnung zu photographieren. Bei gewöhnlichen Wasserständen liegt die obere Kante etwa $50-70 \mathrm{~cm}$ unter MNW ; sie ist also gewöhnlich unsichtbar. Morgens am 12. April lag sie beim tiefsten Wasserstand $40 \mathrm{~cm}$ darüber! Zwischen dem Priel (rechts) und dem Watt (links) ist das Kliff deutlich erkennbar. Die auf S. 72 besprochene Kette von Stromsänden ist auf dem allmählich zum Priel abfallenden Watt schwach zu erkennen. Fast in seiner ganzen Längserstreckung fällt das Kliff mindestens einen Meter mauerartig steil zum Prielbett ab. Gegenüber der inneren Muschelbank sogar bis zu $2 \mathrm{~m}$.

Die im Claussenschen Schlämmapparat aufgearbeitete Probe ergab nichts Siebbares, so daß eine tatsächliche Trennung dieser feinen Ablagerungen mit meinen einfachen Hilfsmitteln nicht möglich war. (Eine genaue Korngrößenbestimmung findet sich auf S. 17, Tab. 7.) Nur um diese Ablagerung den anderen Sedimenten des Gebietes gegenüberstellen zu können, habe ich das Blockdiagramm gewählt (Abb. 66). Der absolute Wassergehalt betrug annähernd $50 \%$ Dabei machte der Ton einen festen und abgelagerten, geradezu wasserarmen Eindruck.

Vergegenwärtigen wir uns anhand der Abb. 58 auf S. 72 die Blockdiagramme 15 und $16(\mathrm{Abb}, 63)$ und das Diagramm vom Kliff (Abb. 66), was etwa einem Schnitt rom Stromsand A nach $C$ gleichkäme, so findet man innerhalb dieses kleinen Bezirkes Standorte mit sehr voneinander abweichenden Eigenschaften. Wie die Besiedelung des Klei-Kliffs zeigt, kommt die durch die Sedimentanalyse nachgewiesene Ausnahmestellung in derselben Weise auch durch die biologische Bestandsaufnahme zum Ausdruck.

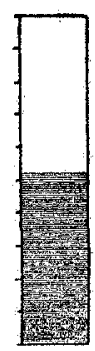

Abb. 66

Kleikliff am Prielabschnitt 111

b) Die Besiedelung.

Für die Bestandsaufnahme wurde der schwer aufschwemmbare Ton vorsichtig aufgeschlämmt und die vorhandenen Tiere dann ausgesiebt. Es wurden nachgewiesen:

$$
\begin{aligned}
& \text { Barnea candida } \\
& \text { Polydora ligni } \\
& \text { Microspio wireni } \\
& \text { Nereis pelagica } \\
& \text { Corophium volutator. }
\end{aligned}
$$


Mit Ausnahme von Corophium kommen die Bewohner des Kliffs an keinem andern stutudort des Königshafens vor. Polydora ligni und Microspio wireni wurden zum ersten Mal tür das Wattenmeer und die weitere Deutsche Bucht nachgewiesen. Nach SöDERström's Angaben über die Lebensgewohnheiten von Polydora ligni entspricht der Ton am Priel Swotry gut den Ansprüchen dieses Wurms (71). Die Wohndichte von Polydora war außerordentlich groß. Ich zählte durchweg 4 Polydora und 1 Corophium auf einem qem Grundthiche. Die übrigen Mitbewohner waren seltener vertreten.

Hinsichtlich Art und Dichte erinnert die Besiedelung an die von den Helgoländer Kreideklippen bekannte Siedlungweise von Polydora cillata.

An Einschlüssen barg der Ton viele Austern-Klappen, Bruckstücke von Seegrasblättern und Cardium- und Mytilus-Schalen. Die Austern waren am stärksten vertreten.

Das Besiedelungsbild spricht dafür, daß mit dem Klei-Kliff im Prielabschnitt III abermals ein stark spezialisierter Biotop vorliegt. Neben den beteiligten Korngrößengruppen und der Lage zum Tidebereich dürfte vor allem der physikalische Zustand, åzmlich die gleichmäßig feste und doch plastische Struktur dieses Sedimentes die Ursache caftir sein, daß bohrende Tiere wie Barnea und Polydora hier leben können. Ob und welche Beziehungen Nereis pelagica, die ich auf dem Watt nie gefunden habe, zu den besonderen Eigenschaften des Kliffs unterhält, kann ich nicht sagen. Vielleicht ist es zur Hauptsache die ständige Wasserbedeckung, denn nach HaGMEIER (21, S. 17), dessen Untersuchuchungsgebiete zur Hauptsache unter der MNW-Linie liegen, ist $N$. pelagica die "häufigste Art der Gattung Nereis im Wattenmeer".

Wenden wir nunmehr unsern Blick zurück auf den Prielabschnitt III als Ganzes, so durfte er durch die vorangegangenen Betrachtungen biologischer und sedimentanalytischer Art als ein recht aufschlußreiches ökologisches Untersuchungsgebiet gekennzeichnet sein. Der Ophelia-Sand auf dem Nordufer (vergl. Abb. 58) und der Diglotta-Sand sowie das Polydora-Barnea-Kliff gegenüber auf dem Südufer des Prieles sind Biotope, deren Sedimente und Morphologie, deren Besiedelung und Geschichte uns auf verschiedene Grundbegriffe der Lebensgemeinschaftslehre führen mußten. Vor allem wird sich der historische Faktor nicht so leicht wieder mit solcher Notwendigkeit und Berechtigung in den Kreis der ökologischen Fragestellungen vordrängen. Unter den übrigen sogenannten abiotischen Faktoren tritt das Gefüge der Sedimente in den Vordergrund. Es bestimmt die ausgesprochene Eigenart der einander eng benachbarten und doch voneinander grundverschiedenen Biotope.

\section{F. Schlußwort.}

Mit der Besiedelung des Kleikliffs beschließe ich meine Darlegungen über die Oekologie des Königshafens.

Ich sagte bereits in der Einleitung, daß hiermit erst der Anfang in der biocönotischen Erforschung der eigentlichen Watten der deutschen Nordseeküste gemacht sei. Gerade im Tidebereich unserer Küste, wo die zahlreichen Faktoren der kleinen Standorte von dem einen gewaltigen Faktor der Flut und Ebbe bestimmt werden, harrt noch manches biologische Problem der Lösung. Es ist merkwürdig, daß die Erforschung der Meere nicht ihren Ausgang vom Wattenmeer, wie es naheliegend gewesen wäre, genommen hat. Zwar kann die Wattenmeerforschung diesen historischen Vorsprung nicht wieder einholen, aber in einem grundsätzlichen Punkt wird sie der rein marinen Forschung überlegen bleiben, daß es ihr nämlich vergönnt ist, den zu erforschenden Standort direkt zu beobachten, wenn das Meer ihn im Wechsel der Tide für einige Stunden am Tage freigibt. Die Arbeiten - Analyse und Beobachtung - im Gezeitenbereich sind nicht leicht, aber bei zielbewuBtem Ausbau der Geländeforschung werden die Ergebnisse der Untersuchungen die aufgewendete Mühe belohnen.

Obwohl die Standortsforschung im Wattenmeer als jüngstes Teilgebiet der Meeres" forschung noch am Anfang steht, hat sie sich bereits in den Dienst großer Aufgaben mit praktischen Zielen stellen können. Auf Grund der Erkenntnis, daß alle Lebewesen des Wattenmeeres mit wenigen Ausnahmen irgendwie ihren arteigenen Anspruch an das von ihnen bewohnte Sediment stellen, steht uns der andere Weg offen, von der Art der Besiedelung auf die "Boden"-Eigenschaften der von den Organismen besiedelten Gebiete direkte Schlüsse zu ziehen.

Im Forschungsprogramm für die Landgewinnung an der Westküste SchleswigHolsteins gehört daher die biologische Bestandsaufnahme bereits zu den natürlichen Hilfsmitteln, den Stand und den Wert der Wattflächen auf ein vergleichbares Maßs zu bringen. 


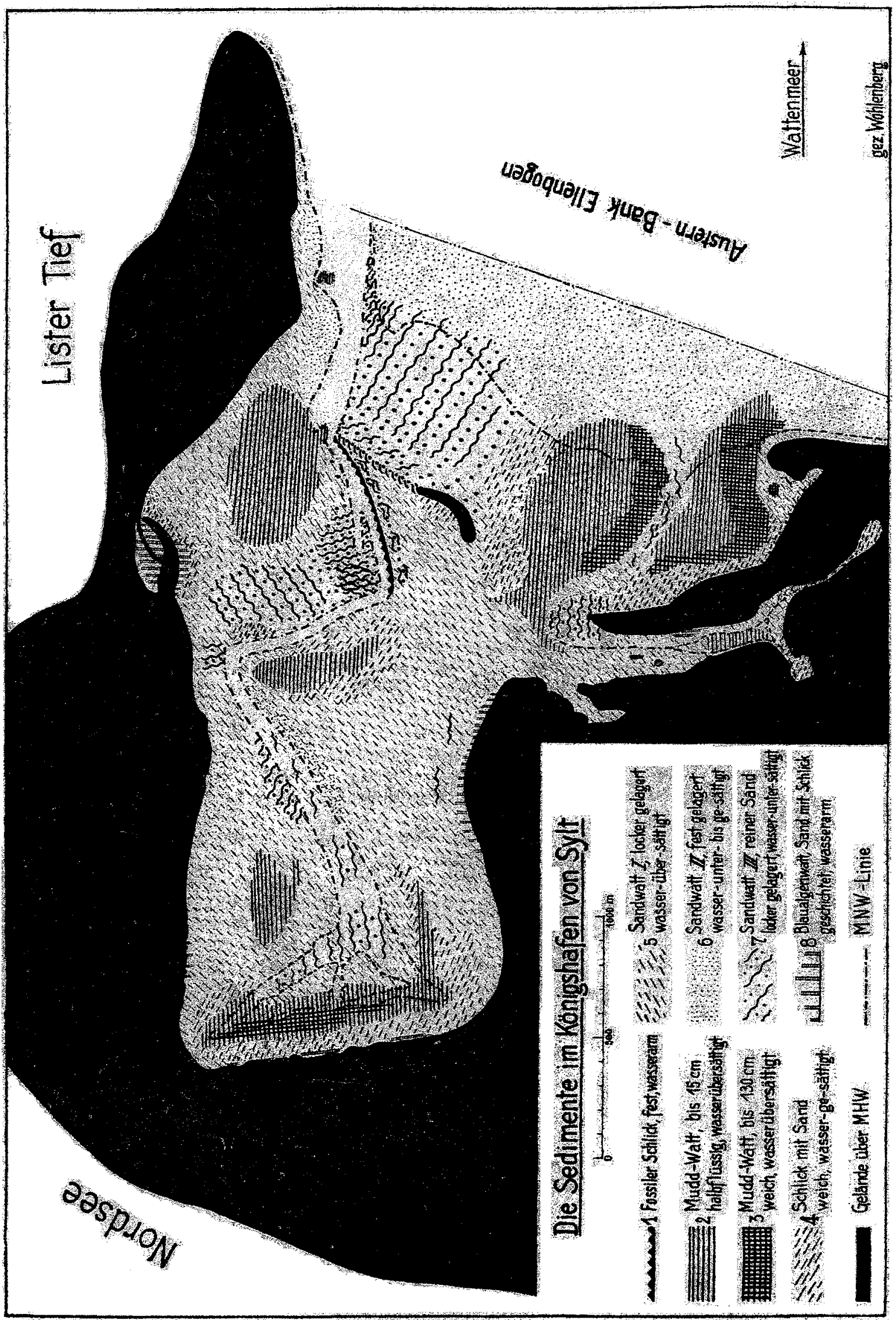

Abb. $6 \%$ 
Die Organismen antworten auf die Vielheit der Faktoren in ihrer geschlossenen Gesamtheit. Die Art ihrer Besiedelung ist, im weitesten Sinne gesprochen, der lebendige Ausdruck für die Summe und Verknüpfuug der Faktoren ${ }^{1}$ ). Darin liegt die Ueberlegenheit der biologischen gegenüber den rein mechanisch gerichteten Analysen begründet. Darüber hinaus ist die Kenntnis der Organismen und ihrer Lebensweise die Grundlage dafür, ihre Leistung für den Gesamthaushalt der Watten einzuschätzen. Sie gibt uns Richtlinien, die Anreicherung der Wattsedimente mit organischen Stoffen zu lenken und zu fördern (WOHLENBERG, 89), wodurch die Ablagerungen vor unseren Küsten - nationalwirtschaftlich gesehen - erst den Charakter wertvoller und für lange Zeiten ergiebiger Böden erhalten.

\section{G. Erläuterungen \\ zur Karte ïber die Sedimente und ihre Besiedelung.}

In den vorangegangenen Abschnitten über die einzelnen Biotope sind die engen Beziehungen zwischen den Standorten und ihrer Besiedelung aufgezeigt worden. Mit der nebenstehenden Uebersichtskarte (Abb.67) will ich - soweit der Mabstab eine hinreichende Aufteilung zuläßt - versuchen, ein Gesamtbild von der Verteilung der so sehr voneinander verschiedenen Sedimente festzuhalten.

Da die quantitativen Bestandsaufnahmen in den Jahren 1932/3 eindeutig ergeben haben, daß die Bindungen zwischen Tier und Sediment im Wattengebiet des Könighafens von Sylt derart beständig und charakteristisch sind, daß durchweg die Ausdehnung einer bestimmten Besiedelungsgruppe jeweils mit einer gut umrissenen Sedimentart zur Deckung zu bringen ist, würde sich das Verteilungsbild der Tiere von dem der Sedimente in keinem wesentlichen Punkt unterscheiden. Ich begnüge mich daher mit der überschläglichen Darstellung der Sedimente allein, verweise im folgenden Text auf den Charakter der Besiedelungsgruppe und setze im übrigen die Einzeldarstellungen im Hauptabschnitt dieser Arbeit als gelesen voraus.

Der Charakter der Besiedelungsgruppen ist nach den Eigenschaften ihres Wohnsedimentes festgelegt, d. h. es erfolgte keine Unterscheidung nach Gesichtpunkten der Ernährung, Nahrungsaufnahme u. a., sondern in erster Linie nach den physikalischen Eigenschaften (Aufbau, Gefüge, Wassergehalt u. a.) ihrer Standorte, wobei das jeweilige Charaktertier der Namensträger der Gruppe wurde. Selbstverständlich sind Uebergänge sowohl in der Zusammensetzung der Bewohner, als auch im Aufbau der Sedimente vorhanden. Diese Feînheiten vermag die Uebersichtskarte nicht wiederzugeben, wie man ja überhaupt bei jeder kartenmäßigen Darstellung eine gewisse Sehematisierung mit in Kauf nehmen muß.

Das Verteilungsbild der Sedimente bestärkt die im Anfang der Arbeit gemachte Aussage, daß der Königshafen ein Wattgeblet ganz besonderer Prägung darstelle. Auf kleinem Raum liegt hier eine jeden mit den Wattverhältnissen unserer. Küste Vertrauten überraschende Mannigfaltigkeit vor. Aus Gründen der Uebersichtlichkeit beschränke ich mich auf die Herausstellung von sieben Watt-Typen und ordne ihnen ebenfalls sieben Besiedelungsgruppen $\mathrm{zu}$.

Eine rein topographisch gesehene Zweiteilung des Untersuchungsgebietes in den „inneren" und äußeren". Hafen, wie NIENBURG (53) sie s. Zt. vornahm. ist weder durch die Verteilung der Sedimente noch der Organismen gegeben.

\section{A. Fossiler Sehlick (Sign. 1).}

Nur im vorletzten Prielabschnitt steht dieses Sediment etwas unter der MNW-Linie an. Auf der ganzen Strecke bildet es die Aufenkurve des Priels und ist infolgedessen in der Abtragung begriffen. Dem Gefüge und Aufbau nach besitzt diese ältere Ablagerung tonigen Charakter und beherbergt vorwiegend bohrende Tiere.

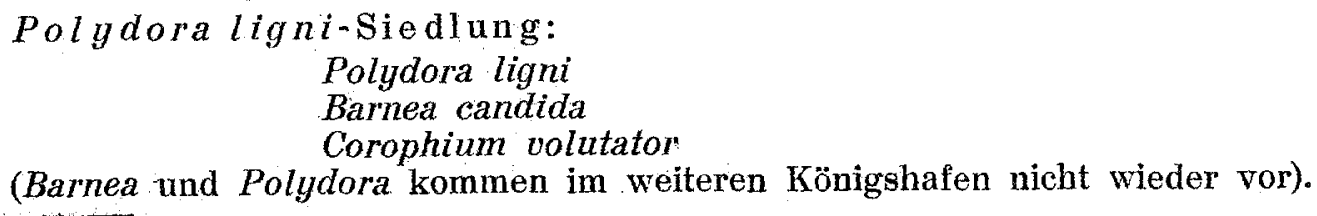

(Barnea und Polydora kommen im weiteren Königshafen nicht wieder vor). 


\section{B. Mudd-Watt (Sign. 2 und 3).}

Das Mudd-Watt ist überall dort anzutreffen, wo Fucus Mytili und Zostera angustifolia und $Z$. stenophylla bestandbildend auftreten. Außerdem vor dem Gröning und auf dem Odde-Watt. Die Mächtigkeit dieser stark organogenen Ablagerungen erreicht vor dem Lister Haken (hier ohne lebenden Bewuchs) mit $130 \mathrm{~cm}$ den Höchstwert (Sign. 3). Bewohnt wird dieses erst im Entstehen begriffene Sediment durch die

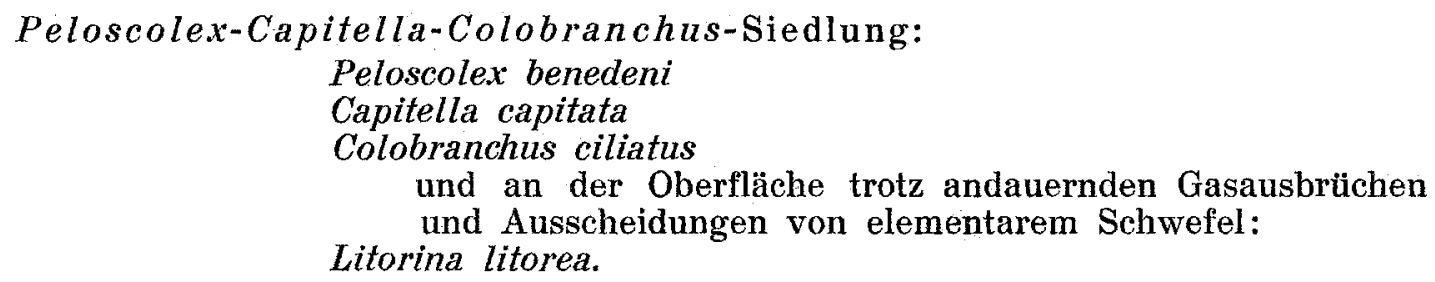

C. Schlick-Watt (Schlick mit Sand, Sign. 4).

Der Königshafenschlick ist kein Schlick, wie wir ihn vom übrigen Wattenmeer der Westküste Schleswig-Holsteins und der ostfriesischen Küste kennen, Das Nebeneinander größter Gegensätze in den Korngrößen ist bezeichnend. Größere Zonen dieser weichen, gut gebundenen Ablagerung finden sich vor dem Gröning, vor der Odde und im Kleinen Hafen. Diese Zonen enthalten die

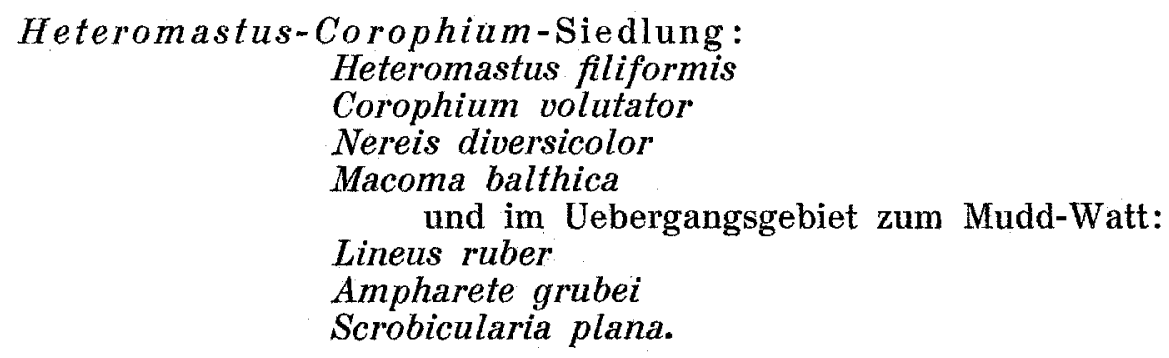

D. Sand-Watt (Sign. 5 bis 7).

Die Sand-Watten nehmen die größte Fläche des Untersuchungsgebietes ein. Sie werden dreifach unterteilt. Allerdings unterscheiden sie sich nicht so sehr in der Korngrößenzusammensetzung als vor allem

1. im Gefüge (Festigkeit, Wassersättigung, Luftgehalt)

2. im Gehalt an reduzierenden Verbindungen $\left(\mathrm{H}_{2} \mathrm{~S}\right.$ und $\left.\mathrm{FeS}_{2}\right)$.

Das Sand-Watt I wird unterteilt

a) in ein zonenartig, bis $25 \mathrm{~cm}$ (max. $50 \mathrm{~cm}$ ) unterhalb der Hochwassergrenze reichendes, festgelagertes Watt von geringerem Wassergehalt (auf der Karte nicht besonders hervorgehoben, vergl. S. 45) und

b) in ein nach unten daran anschließendes, stets wasserübersättigtes Watt von lockerem Aufbau und blauschwarzem bis blaugrauem Pigment $\left(\mathrm{FeS}_{2}\right)$ und allgemeinerer Verbreitung bis unter die MNW-Linie (Sign. 5).

Sie werden in kennzeichnender Weise besiedelt von

a) Arenicola marina (Junggut) -Clitellio-Siedlung:

Arenicola marina (jung)

Clitellio arenarius

Pygospio elegans.

b) Arenicola marina (alt) - Scoloplos-Siedlung:

Arenicola marina (alt)

Scoloplos armiger

(an der Oberfläche oft Rasen von Zosterea nana)

Nephtys Hombergii

Cardium edule

Tellina tenuis (in reinem Sand ohne $\mathrm{FeS}_{2}$, Außenbezirke, nahe der NW-Grenze). 
Das Sand-W att II (Sign. 6)

Nindet sich zur Hauptsache an der Ostgrenze des Gebietes. Es ist ein festgelagertes, wassergesättigtes, an und vorwiegend u ter der MNW-Linie sehr gleichmäßig und feinkörnig ausgebildetes Sediment. Es trägt meistens geschlossene Bestände von Zostera murina und beherbergt die

Mya truncata-Amphitrite-Lanice-Siedlung:

Mya truncata

Amphritite johnstoni

Lanice conchilega

\section{Nassa reticulata \\ Psammechinus miliaris.}

Das Sand-Watt III (Sign. 7)

kommt in erster Linie zu beiden Seiten des III. Prielabschnittes vor. Infolge Einwirkungen von beständiger Strömung und Wellenschlag ist es wenig formbeständig und verarmt an organischen Bestandteilen. Das Gefüge ist ausgesprochen porös und die Ablagerungen bei Nichtüberflutung bis zu einer Tiefe von $27 \mathrm{~cm}$ wasseruntersättigt. Es handelt sich um Strömungssände und Brandungsgürtel. Die kennzeichnenden Tiergruppen enthält die

Ophelia cluthensis-Scolecolepis-Siedlung:

Ophelia cluthensis

Scolecolepis squamata

Clitellio arenarius

Dipteren-Larven

Diglotta mersa
Cillenus lateralis wenn ein Por enlufthorizont ausgebildet ist.

\section{E. Blaualgen-Watt (Sign. 8).}

Es tritt innerhalb und vor der Nehrung am Kersten-Rimling, innerhalb der staffelförmig am Ellenbogenstrand angeordneten Sandhaken, vor dem Gröning, dem Mövenberg sowie am Kleinen Hafen in tischeben en Flächen auf.

Alle Ablagerungen sind geschichtet. Sandlagen mit eingestreuten Kieseln wechseln $\mathrm{ab}$ mit dünneren und bindigen Schlick schichten, die viele Diatomeen und Cyanophyceen enthalten. Stets wird die Oberfläche von einer lederartigen Cyanophyceenhaut gebildet. Das Sediment ist immer - aueh unmittelbar nach dem Zurückfließen des Wassers - wasserarm. Es beherbergt die

Bledius spectabilis-Enchyträus albidus-Siedlung:

Bledius spectabilis

Heterocerus flexuosus

Cillenus làtèralis

Enchyträıs albidus. 1 )

\section{H. Zusammenfassung.}

Nach Erörterungen über die Lage des Untersuchungsgebietes zum Meer und über die Morphologie der Priele und Wattflächen werden aus der Literatur über den Königshafen zwei Fragen herausgestellt, und zwar die nach den früheren Tiefenverhältnissen und die nach der Versandung. Durch die Feststellung mächtiger und tiefliegender $\mathrm{Ab}$ lagerungen im Prielabschnitt III (Abb. 58) wird erstmalig der Nachweis geführt, daß der Königshafen entgegen den bisherigen Ansichten nicht immer so flach wie heute gewesen ist.

1) Die sandigen Standorte mit der Bledius a renarius-Hydrellia-Siedlung (vgl. Text S. 68) sind in der vorstehenden Zusammenfassung und auf der Uebersiehts-Karte nicht besonders angeführt worden. Zum Unterschied vom touigen. Blaualgenwatt mit der Bledius spectabilis-Enchyträus-Siedlung kann ihr Wohnbezirk kaum noch als Wa $t \mathrm{t}$ formation angesprochen werden. Es ist vielmehr ein Grenzbiotop, der eher den Strand- als den Wattlebensräumen zuzuordnen ist. 
Die heute vegetationslose Sandinsel Uthörn wird auf eine ehemals in den Königshafen hineingewanderte Düne oder weit vorgerückte Odde-Bildung zurückgeführt und die Sandwatten durch das Hineinwandern bezw. durch den vom Wasser bewirkten späteren Abbau der Düne erklärt.

Die Länge der Insel Uthörn hat nach dem Einheitsblatt des Deutschen Reiches $(1: 100000)$ und nach des Karte bei Nienberg (53) bis heute etwa $500 \mathrm{~m}$ ihrer Länge eingebüßt.

Das Wasser im Königshafen.

Der Wasserhaushalt des Königshafens wird an festgelegten Stationen untersucht. Im Lister Tief, im Hauptpriel und auf den Wattflächen werden folgende Bestimmungen durchgeführt:

Temperatur, Wasserstoffzahl $(\mathrm{pH})$,

Sauerstoff, Salzgehalt, Schwefelwasserstort.

Alle Untersuchungen werden gleichzeitig und während der Dauer einer vollständigen Flut- oder Ebbeperiode, also 6 Std. lang in 1 stündigen Abständen vom verankerten Boot aus gemacht. Das Wasser des Hauptprieles zeigt deutlich den Einfluß der benachbarten Wattflächen. Das über den Wattflächen befindliche Wasser ist großen Schwankungen ausgesetzt. Mit zunehmender Assimilationstätigkeit der Pflanzen steigt die Sauerstoffsättigung auf $238 \%$, die $\mathrm{pH}-\mathrm{Zahl}$ auf 9,10 und die Temperaturwerte am Nachmittag auf über $26^{\circ} \mathrm{C}$. Nachts fällt die $\mathrm{O}_{2}$-Sättigung auf $43 \%$ die pH-Zahl auf 7,9 und die Temperatur auf $13^{\circ} \mathrm{C}$. Bei vorsichtiger Entnahme ist $\mathrm{H}_{2} \mathrm{~S}$ nicht, oder nur in Spuren nachweisbar. Auch während der Nichtüberflutung bleibt auf den mit Pflanzen bewachsenen Flächen stets Wasser zurück.

Die Sedimente im Königshafen.

Nach der Besprechung der Untersuchungsmethoden werden die sandigen und schlickigen Ablagerungen und ihre Verteilung über die verschiedenen Wattgebiete zusammen mit morphologischen und biologischen Erscheinungen beschrieben. Die Königshafensedimente weichen im starken Maße von den vom Wattenmeer bekannten ab. Für die faulschlammähnlichen Ablagerungen, die uberaus reieh an Wasser, an organischer Substanz und, als Ort des Abbaus, ebenfalls reich an $\mathrm{H}_{2} \mathrm{~S}$ sind, wird der Begriff Mudd-Watt geprägt. Anhand von Korngrößenverteilungskurven wird die Zusammensetzung der auf dem Odde-Watt längs einem Sehnitt von der HW-bis zur NW-Linie vorhandenen Sedimente dargestellt. Der feinkörnige Anteil nimmt in diesem Gebiete nach der Tiefe bin zat.

Die in Königshafen festgestellten tonigen Ablagerungen (Prielabschnitt III) sind sehr reich an eingebetteten Foraminiferen.

Die Sedimente der Hochwassergrenzgebiete zeichnen sich durch den einheitlichèn Cyanophyceen-Rasen, ihren geschichteten Aufbau und ihre für 5 Standorte gleichbleibende Besiedlung mit Bledius spectabilis aus.

Die vegetationslosen Wattgebiete werden aufgeteilt in solche mit formbeständiger und solche mit durch die tägliche Ueberflutung gestörter Oberfläche.

Die fossilen Sedimente werden den heute entstehenden gegenübergestellt:

Das im Sediment enthaltene Wasser, das Zwischenraumwasser, wird auf Temperatur, Salzgehalt, Wasserstoffzahl, Sauerstoff und Sehwefelwasserstoff untersucht.

(Tabelle 8, 9, 13, 14.)

Der kleine Hafen.

Der sogenannte kleine Hafen wird auf Grund von hydrographischen Untersuchungen (Tabelle 10 und 11) als Nebengebiet mit Süßwasserzufluß (Entwässerungssiel) beschrieben.

Die Lebensgemeinschaften.

Die biologische quantitative Untersuchungsmethode wird erörtert.

Die Niedrigwasserlinie im Osten wird als biologische Grenze gekennzeichnet.

Anhand der quantitativen Bestandsaufnahme vom Watt der Tonnenlegerbucht wird das Verhalten der Wohndichte zwischen den beiden Polychaeten Arenicola marina und Nereis diversicolor eingehend besprochen.

Das auffallende Aussetzen in der sonst gleichmäBigen Arenicola-Besiedlung kann auf flach gelagerte, in Fäulnis begriffene Seegrasschichten zurückgeführt werden. 
Die zahlreichen Capitelliden kennzeichen den Standort als sauerstoffarmes Gebiet. Das Zwischenraumwasser enthält über $8 \mathrm{mg} \mathrm{H}_{2} \mathrm{~S}$ im Liter. Die Wasserstoffzahl fällt mit zunehmender Tiefe.

Für das sprunghafte Ausbleiben von Arenicola auf dem Mövenberg-Watt wird die Wasseruntersättigung der oberen Schichten verantwortlich gemacht.

Auf dem Uthörner Außenwatt kann die 1932 vorgefundene Besiedelung mit der von 1934 verglichen werden. Der Cardium-Brutfall 1934 mit fast 40000 Muscheln auf den Quadratmeter kann als Null-Gruppe 1934 bis Mai 1936 gewichts- und meBanalytisch verfolgt werden.

Die zonenartige Besiedelung des Gröning-Watts 1932 wird der 1934 gefundenen gegenübergestellt. Die Bestandsdichten von Macoma, Scrobicularia und Corophium sind großen Schwankungen unterworfen.

Der von NiENBuRg beschriebene Fucus-Gürtel war 1934 aufgelöst. Die Miesmuscheln lagen in Klumpen versponnen ohne Fucus auf dem weichen und schwer zugänglichen Mudd-Watt. Das auf dem Ostfeuer-Watt in großer Ausdehnung festgestellte Gebiet mit Fucus Mytili muß nach der 10 Jahre zurückliegenden Vegetationskarte von NIENBurg (53) als neue Bildung angesehen werden.

Das Lagunen-Watt unterm Kersten Rimling wird als Ergebnis der gesetzmäßigen Strandentwicklung des Ellenbogens geschildert und damit der historische Faktor als Standortskriterium in die ökologische Betrachtung einbezogen. Das Sediment der Lagune ist keine normale Watt-Ablagerung. Wind und Wasser bewirken abwechselnd verschiedenartige Zufuhren von Ablagerungsstoffen, die von dem Cyanophyceen-Rasen schichtartig gebunden und dem Standort einverleibt werden.

Der diagnostische Wert der mechanischen Bodenanalyse (Korngrößenbestimmung) muß durch qualitativ bestimmbare Bodenmerkmale erheblich herabgesetzt werden.

Mit der Besiedelung des Lagunenbodens ist die Biologie des Kurzflüglers Bledius spectabilis unter Berücksichtigung der besonderen Standortsverhältnisse Gegenstand eingehender Erörterungen. Bled. spect. ist bezüglich der mit ihm vergesellschafteten Tiere nư im Königshafen stenotop. - Die Auftragskrümelhäufchen und die Wohnröhre werden beschrieben und ihre Entstehung aufgrund von Beobachtungen erklärt. Sie werden der Korngrößenbestimmung unterworfen. Es werden alle Größen nach oben befördert, die gröberen Bestandteile des Sediments überwiegen jedoch. - Das Schwärmen konnte im Juni über dem Standort beobachtet werden. - - Die gesamte Brutpflege wird eingehend behandelt. Die stockwerkartige Anlage der einzelnen Eikammern, das am Dach der Eikammer befestigte Ei, die Lage und Entwicklung des Embryos u. a. wird neben zusammenhängenden Temperaturmessungen am Standort beschrieben. Die Weiterentwicklung und Lebensweise der Larve wird am freien Standort verfolgt, für die Bestimmung wichtige Organe gezeichnet. Die Verpuppungskammer ist mit der Außenwelt durch 3 reusenartig hintereinander angeordnete Ausführungsgänge verbunden. In dieser Kammer verwandelt sich eine einzelne Larve zum Geschlechtstier.

Am Ellenbogenstrand staffelförmig angeordnete Strandhaken und -buchten werden als jahreszeitlich bedingte Biotope nachgewiesen. Mit ihrer ausgeprägten morphologischen Gliederung gehen scharf getrennte Besiedelungsbilder der Bledias arenarius- sowie der Bledius spectabilis-Gemeinschaften einher.

Die Korngrößenzusammensetzung der Bledius arenarius-Standorte wird mit der der Insel Trischen, der Insel Röm und der jütischen Halbinsel Skallingen verglichen. Die Oberflächenspuren von Bledius arenarius var. subniger sind anders als die von Bledius spectabilis.

Durch ihre Lage zum Hauptpriel zeichnen sich die Prielufer durch stark spezialisierte Biotope auş. Damit parallel geht ihre ebenfalls spezialisierte Besiedelung. Ständig in der Umlagerung begriffene Biotope sind ganz stabilen eng benachbart.

Der Ophelia-Stromsand baut sich zur Hauptsache aus 2 Korngrößengruppen auf und beherbergt nur 2 Tierarten: Ophelia clathensis und Scolecolepis squamata. Der Standort hat während der Ueberflutung triebsandähnlichen Charakter. Die Standortsoberfläche ist bei Nichtüberflutung bis zu $27 \mathrm{~cm}$ Tiefe wasseruntersättigt.

Der Stromsand C am südlichen Prielufer nimmt eine Sonderstellung ein. Der unter der Oberfläche befindliche Porenlufthorizont wird vom Kurzflügler Diglotta mersa bewohnt. Nicht direkt an diesen Horizont gebunden sind Ophelia, Scolecolepis und Dipterenlarven. - Das Porenvolumen wird gemessen und über die Lebensweise von Diglotta anhand von Beobachtungen und Messungen am freien Standort Mitteilung gemacht. 
Die beiden Miesmuschelbänke am Nordufer des Priels, ihre Epi- und Endofauna werden quantitativ untersucht.

Von Capitella capitata wird die Wohnröhre und von Scolecolepis die Ernährungsweise auf dem Diglotta-Sand beschrieben.

Der Prielabschnitt III wird als der ökologisch aufschluBreichste Abschnitt des Untersuchungsgebietes angesehen. Junge und fossile Sedimente sind einander unmittelbar benachbart.

Es wurde durch Untersuchung verschiedenartigster Biotope nachgewiesen, daB die im Watt lebenden Organismen gut an die mit der Tide zwangsläufig verbundenen Schwankungen bezüglich der Temperatur und der chemischen Eigenschaften angepaßt sind. Dagegen wirken die bodenphysikalischen Faktoren, worunter besonders das Sedimentgefüge (Luftgehalt, Wassergehalt, Ueber- bezw. Untersättigung, Festigkeit, Einlagerungen) verstanden werden soll, in erster linie auslesend und begrenzend. Sie sind der Korngrößenzusammensetzung als Standortskriterium weit überlegen.

Für die deutsche Bucht konnten folgende Tiere zum ersten Mal nachgewiesen werden:

$$
\begin{aligned}
& \text { Polydora ligni } \\
& \text { Colobranchus ciliatus } \\
& \text { Microspio wireni } \\
& \text { Heteromastus filiformis } \\
& \text { Ophelia cluthensis } \\
& \text { Archisotoma besselsi. }
\end{aligned}
$$

Im Schlußwort wird auf die grundsätzliche theoretische und praktische Bedeutung der Wattenmeerforschung hingewiesen.

\section{Schriftenverzeichnis.}

1 ALLen, E. I. On the Fauna and Bottom Deposits near the Thirty-Fathom Line from Eddystone Grounds to Star Point. Journ. Mar, Biol. Ass. N. S. 5. 1899.

2 Astworth, J. H. Arenicola. Liverpool Mar. Biol. Comm. Memoirs. 11. 1904.

3 BENICK, L. Ueber das Sammeln von Norddeutsehen Sand- und Küstenkäfern Koleopt. Rundschau 14. $2,3.1928$.

4 BLEGVAD, K. Food and Conditions of Nourishment among the communities of invertebrate animals found on or in the sea bottom in Danish waters.. Rep. Dan. Biol. Stat. 22. 1914

5 BORDEN, M. A. A study of the respiration and the function of Haemoglobin in Planorbis corneus and Arenicola marina. Journ. Mar. Biol. Ass. N. S. 17. 1981.

6 Bkenm, V. und RotTNeR, F. Die Biocönosen der Lunzer Gewässer. Int. Rev, d. ges. Hydrobiol, 16. 1926

7 BRoEkherysen jri, G. J. The Extremes on Percentages of Dissolved Oxygen to which the Fauna of a Zostera Field in the Tide Zone at Nieuwediep can be exposed. Areh. Neerlandaises de Zoologie 3. 1935.

Brown, J. M. On a new Shoredwelling Collembolan with Remarks on the British Littoral Species of Collembola. Ann. Mag. Nat. Hist.. Ser. 9. 16. 1925. 9 Bkoce, J. RoN. Seasonal and Tidal pH-Variations in the Water of Port Erin Bay. Trans. Liverpool Biol.
Soc. 39. 1925.

10 - Physical Faktors on the Sandy Beach. Part I: Tidal, Climatic and Edaphic. Part II: Chemical Changes Carbon Dioxide Concentration and Sulphides. Journ. Mar. Biol. Ass. N. S. 15. 1928.

11 BuDdENBRock, W. v. Ueber die Statocysten im Sande grabender Meerestiere. I. Biol. Zentralbl. 32.1912

12 Colman, J, The Nature of the Intertidal Zonation of Plants and Animals. Journ. Mar. Biol. Ass. N. S. 18. 1933.

13a DAvis, F. M. Quantitative Studies on the Fauna of the Sea Bottom. Fish. Investig. Ser. 2, 6. 1923. 8. 1925.

$13 \mathrm{~b}$ Ditrmer, E. Vorland und Watten zwischen Steinloch und Dwarsloch. A. d. Archiv d. Deutschen Seewarte: 55, 6. 1936.

14 DRucker, G. ZurMethodik der Schwefelwasserstoffbestimmung im Meerwasser. Int. Rev. Hydrobiol. 16. 1936.

15 Fauver, P. Polychètes errantes. Faune de France. 5. Paris 1923.

16 - Polychètes sédentaires. Faune de France. 16. Paris 1927.

17 Fraeser, J. H. Observations on the Fauna and Constituents of an Estuarine Mud in a Pollnted Area Journ. Mar. Biol. Ass. N. S. 18, 1. 1982.

18 a FneperchS, K. Die Grundlagen und GesetzmäBigkeiten der land-und forstwirtschaftlichen Zoologie 1. Berlin 1930.

$18 \mathrm{~b} \mathrm{FUGE,} \mathrm{B.} \mathrm{Einwanderung} \mathrm{von} \mathrm{Insekten} \mathrm{auf} \mathrm{einer} \mathrm{entstehenden} \mathrm{Insel} \mathrm{unter} \mathrm{Berüeksichtigung} \mathrm{der} \mathrm{gesammelten}$ Coleopteren. Zeits. wiss. Ins. Biol. 14. $1918 / 19$.

19 Gessner, F. Die Schltimmanalyse. Leipzig. 1981.

20 HAGMEIER, A. Vorläufiger Bericht über die vorbereitenden Untersuchrongen der Bodenfauna der Deutschen Bucht etc. Ber. d. Deutschen Wiss. Kommission für Meeresforschung N. F. 1. 1925.

21 - und KÄNDLER, R, Neue Untersuchungen im nordfriesischen Wattenmeer und auf den fiskalischen Austernbänken. Wiss. Meeresunters. Abt. Helgoland, 16, 6. 1927.

22 - Die Besiedelung des Felsstrandes und der Klippen von Helooland, Teil I. Der Lebensraum. Wiss. Meeresunters. Abt: Helgoland 15, 18a. 1930.

22 - Eine Fluktuation von Mactra (Spisula) subtruncata da Costa an der ostfriesischen Meeresküste. - Ber. d. Deutschen wiss: Komm. f. Meeresforseh. N. F. 5. 1930.

23 - und Hinnicms, J. Bemerkungen über die Oekologie von Branchiostoma lanceolatum (Pallas) und das Sediment seines Wohnorts. Senckenbergiana. 13. 1981. 
24. HANSEN, C. P. Das Schleswig'sche Wattenmeer. Glogau, 1865.

25 HECHT, F. Der chemische Einfluß organischer Zersetzungsstoffe auf das Benthos ete. Senckenbergiana. 14. 1932.

26 - Der Verbleib der organischen Substanz der Tiere bei meerischer Einbettung. Senckenbergiana. 15. 1933.

97 - und MATERN, H. Zur Oekologie von Cardium edule L. Senckenbergiana. 5. 12.1930.

20 HESSE, R. Tiergeographie auf ökologischer Grundlage. Jena, 1924.

29 IBANEZ, O. Gomez. On the Colorimetric of $\mathrm{pH}$ in Sea Water. Journ. Mar. Biol. Ass. N. S. 15, 2. 1931.

30 Jacubowa, LYDIA und MaLM, EUG. Die Beziehungen einiger Benthos-Formen des Schwarzen Meeres zum Medium. Biol. Zentralbl. 51. 1931.

31 JENSEN-HAARUP, A. C. Biller, der lever i havet. Naturen, 3. 1902.

32 JohanseN, J. P. Danmarks Rovbiller. Kopenhagen, 1914.

33 Johnstone, J. Cardiam, Liverpool Mar. Comm. Mem. 2. 1899.

34 KANDLER, R. Verbreitung und Wachstum der Austermbrut im Wattenmeer. Wiss. Meeresunters., Abt. Helgoland. 17. 1928.

- siehe auch unter HAqMEIER (21).

35 KeMver, N. A. Zur Kenntnis der Staphyliniden-Larven. Entomol. Tidskrift 46, 1.1925.

36 Kolumbe, E. Der Königshafen bei List auf Sylt. Die Heimat. Jahrg. 39, 9. 1929.

37 - Ein Beitrag zur Kenntnis der Entwicklungsgeschichte des Königshafens bei List auf Sylt. Wiss. Meeresninters. N. F. Abt. Kiel. 21, 2. 1933

37 a KRejci-Graf. Grundlagen der Erdölgeologie. Schr. a. d. Geb. d. Brennstoffgeologie. Stuttgart 1930, H. 4.

38. KRogerus, R. Weitere Beitrige zur Kenntnis der Biologie und Verbreitung einiger Bledius- und Dyschirius-Arten. Notul. Ent. 5. 1925.

39 - Studien über Lebensweise und Entwicklung einiger Bledius-Arten. Acta Soc. Fauna et Flora Fenn. 56. 1925 .

40 - Beobachtungen über Bledius- und Dyschirius-Arten auf Degersand (AI, Eckerö). Mem. Soc. F. F1. Fenn. 5. 1929.

41. Ueber die Oekologie und Verbreitung der Arthropoden der Triebsandgebiete an den Kïsten Finnlands. Acta Zoologica Fennica 12. 1932.

42 Lengerken, H. v. Coleoptera III in: P. Schulze, Biologie der Tiere Deutschlauds. 16, 40. Berlin 1925.

43 - Die Salzkäfer der Nord- und Ostseeküste. Leipzig, 1929.

44 LUNDBEcK, J. Beobachtungen über die Tierwelt austrocknender Salzwiesen-Tümpel an der Holsteiner Ostseekiiste. Arch. Hydr. Plankt. 24. 1932.

45 Mager, Friedr. Der Abbruch der Ir sel Sylt durch die Nordsee. Eine historisch-geographische Untersuchung. Veröff. d. Schl.-Holst. Universit. Ges. No.8. Schriften d. Baltisehen. Komm. z. Kiel. 5..1927.

- MaterN, $\mathrm{H}$, siehe unter No. 27 (HEChT und MaterN).

46 Mc GuIRe, Isab. P. Note on a New Species of Polychaete (Ophelia cluthensis). The Seottish Naturalist 1935.

47 Meyn, L. Geognostische Beschreibung der Insel Sylt und ihrer Omgebung. Abhdig. z. Gèolog. Spezialkarte v. Preußen u. d. Thür. Staaten. 1, 4. Berlin 1876.

48 Moore, Hilary B. The Muds of the Clyde Sea Area 1II. Chemical and Physical Conditions; Rate and Nature of Sedimentation and Fauna. Journ. Mar. Biol. Ass. N. S. 17, 2. 1931.

49 Mortensen, TH. Biologiske Studier over Sandstrandsfaunen, saerling ved de danske Kyster. Vidensk. Medd. fra Dansk naturh. Foren. 74. 1922.

50 Neresmetmer und WAGNER. Coleopterenfauna der Mark Brandenburg VII. Entomol. Mitt. 7.1918.

51 Nicol, EDITH A. T. The Ecology of a Salt-Marsh. Journ. Mar. Biol. Ass. N. S. "20, 2.1935.

52 Ninnburg, W. Eine eigenartige Lebensgemeinschaft zwischen Fucus und Mytilus. Ber. d. Deutschen Bot. Ges., Jahrg. 1925. 43, 6. 1925.

53 - Zur Oekologie der Flora des Wattenmeeres. Wiss. Meeresunters. Abt. Kiel. 20.1927.

54 - Fucus Mytili spec. nov. Ber. d. Dt. Bot. Ges., 50a. 1932.

55 OrToN. J. H. Rate of Growth of Cardium edule. Journ. Mar. Biol. Ass. N. S. 14. 1926.

56 Petersen, C. G. J. und BoYsen-JEnsen, P. Valuation of the Sea I. Animal Life on the Seabottom, its food and quantity. Rep. Dan. Biol. Stat. 20. 1911.

57 Pterre, M. J., Bruce, J. R. and H. B. MoOrE. A Quantitive Studie of the Fauna of the Sandy Beach of Port Erin. Jounn. Mar. Biol Ass., N. S. 18. 1932

57 a RED, D. N. On some Factors limiting the Habitat of Arenicola marina. Journ. Mar. Biol. Ass. N. S. 16. 1929.

58 Pratse, O. Die Sedimente der Deutschen Bucht. Wiss. Meeresunters. Abt. Helgoland 17. Nr. 6.1931.

59 Rernke, J. Die Entwieklungsgeschichte der Dünen an der Westküste Schleswig-Holsteins. Sitz.-Ber. d. Kgl. Akad. d. Wissensch. Berlin. 1903.

60 - Botanisch-geologische Streifzüge an den Küsten des Herzogtums Schleswig. Wiss. Meeresunters. Abt. Kiel. 8. Ergänzungsheft. 1903.

60a ReITter, E. Fauna Germanica. Die Käfer d. Dt. Reiches. I-V. Stuttgart, $1908-16$.

61 ReMANE, A. Verteilung und Organisation der benthonischen Mikrofauna der Kieler Bucht. Wiss. Meeresunters. Abt. Kiel. 21, 2. 1938.

62 RichteR, R. Flachseebeobachtungen zur Paläontologie und Geologie, Senckenbergiana. VII. 6. 1924.

63 - Eine geologische Exkursion in das Wattenmeer. Natur a. Mus. 56. 1926.

64 - Gründung und Anfgaben der Forschungsstelle für Meeresgeologie Senchenberg in Willielmshaven. Natur und Museum. 59. 1929.

65 SatnTe, J., Devile, Clame. Kleinere Mitteilung über die Dyschirius-Arten Europas. Koleopt. Rundschau 11. 1924.

66 Schiöntk, J. C. De tunnelgravende Biller Bledius, Heterocerus, Dyschirius og deres danske Arter. Naturhistor. Tiddskrift 3, IV. 1866.

67 SChneIDER, O. Die Tierwelt der Nordsee-Insel Borkum. Abhdl. Naturw. Ver. Bremen, 16.1900.

68 Schulz, B. Hydrographische Beobachtungen etc. Aus dem Archiv d. Deatschen Seewarte. 11. Jahrg., 1922.

69 SchumACHER, A. Die Gezeiten der Sylter Gewässer nach den Beobachtungen im August 1921 . I. Die Gezeitenströmungen. ebenda, 41. Jahrg., 1923. 
70 StEGRIST, R. Zur Praxis der physikalisehen Bodenanalyse. Vierteljahrssehr. d. Naturforsch. Ges. Zürich. 76. 1931 .

71 SöDerströ, A. Studien über die Polychaetenfamilie Spionidae. Uppsala 1920.

72 STrephen, A. C. Notes on the Quantitive Distribution of Moluses and Polychaetes in Certain Intertidal Areas on the Scottish Coast. Proc. R. Phys. Soc. 21. 1928

73 - Studies on the Scottish marine Fauna: The Fauna of the Sandy and Muddy Areas of the Tidal Zone. Trans. R. Soc. Edinb., 56. Part II. 1929.

74 - Studies on the Scottish Marine Fauna. Additional Observations on the Fauna of the sandy and muddy Areas of the Tidal Zone. Trans. R. Soc. Edinb. 56. 1930.

75 - Notes on the Biology of certaiu Lamellibranchs on the Scottish Coast. Journ. Mar. Biol. Ass. N. S. 17. 1981 .

76 - Notes on the Biology of some Lamellibranchs in the Clyde Area. ebenda. 18. 1932.

77 STockan, 0. Beiträge zum: Halophytenproblem II. Standort und Transpiration der Nordsee-Halophyten. Zeitschr. f. Botantk 17. 1925.

78 ThaMoRUP, E. Untersuchungen über die Grundwasserverhaltnịse auf Skalling. Geografisk Tiddslkrift $38,3-4.1935$.

79 ThambrUP, H. M. Beiträge zur Okologie der Wattentauna auf experimenteller Grundlage. Medd. fra Korm. t. Danmarks Fiskeri- og Havundersogelser, Serie: Fiskeri. 10, 2. 1935.

80 Trmenemand, A. Lebensgeneinschatt und Lebensraum. Naturwiss. Wochenschrift N. F. 17, 20+21. 1918.

81 - Grundsütze f. d. faunistische Erforsehung d. Heimat. Nordelbingen. 4. 1925.

82. THokAdE, H. Die Gezeiten der Sylter Gewässer nach den Beobachtungen im August 1921. II. Schwankungen des Wasserspiegels. A. d. Archiv d. Deutschen Seewarte, 41. Jahrg., 1928.

83 Truswern, F. Sternformige Fähren von Corophium. Senckenbergiana 12. 5. 556. Frankfurt a./M. 1930.

84 Wazsh, GEo. B. The origin and distribution of the Coast Coleoptera of the British Isles. Entomot, Month. Magaz. 62. 1926.

85 WeIcklT, G. Die nordfriesisohen Inseln vormals und jetzt. Hamburg 1858.

86 Whiseiberg-Lund, C. In Eug. WArnuna: Bidrag til Vadernes, Sandenes og Marskens Naturhistonie. Kg. Danske Vid. Selsk. Skrifter, 7. Rk. Naturvidensk. og Mat. Afd. 2, 1. 1904.

87 Werzei, W. Zur Sedimentpetrographie des Nordseebodens, insbesondere des schleswig-holsteinisehen Wattenmeeres. Wiss. Meeresunters. Abt. Kiel. 21, 1. 1931

88 WomLanbera, E. Die Getine Insel in der Eideruündung. Aus dem Archiv d. Deutschen Seewarte, 50, 2. 1931 .

89 - ders. Biologische Landgewinnungarbeiten im Wattenmeer. Der Biologe, Jahrg. 3, 7. 1934.

90 - ders. Beobachtungen uiber das Seogras, Zostera marina L, und seine Erkrankung im nordfriesisehem Wattenmeer. Nordelbingen, Beitrige zur Heimatforschung in Schleswig-Holstein, Hamburg und Lübenk. 11. 1985.

91 WohfF, Whurim. Die Entstehung der Insel Sylt. 2. Aufl., Hamburg 1920.

92 Wuxp, $A$. Die chemischen und physikalischen Eigenschatten des Meerwassers, - Tabulae Biologitae. 4. 1927 . 